\title{
Heat-processed fats : analysis of genotoxicity
}

Citation for published version (APA):

Hageman, G. J. (1990). Heat-processed fats : analysis of genotoxicity. [Doctoral Thesis, Maastricht University]. Rijksuniversiteit Limburg. https://doi.org/10.26481/dis.19900622gh

Document status and date:

Published: 01/01/1990

DOI:

10.26481/dis.19900622gh

Document Version:

Publisher's PDF, also known as Version of record

\section{Please check the document version of this publication:}

- A submitted manuscript is the version of the article upon submission and before peer-review. There can be important differences between the submitted version and the official published version of record.

People interested in the research are advised to contact the author for the final version of the publication, or visit the DOI to the publisher's website.

- The final author version and the galley proof are versions of the publication after peer review.

- The final published version features the final layout of the paper including the volume, issue and page numbers.

Link to publication

\footnotetext{
General rights rights.

- You may freely distribute the URL identifying the publication in the public portal. please follow below link for the End User Agreement:

www.umlib.nl/taverne-license

Take down policy

If you believe that this document breaches copyright please contact us at:

repository@maastrichtuniversity.nl

providing details and we will investigate your claim.
}

Copyright and moral rights for the publications made accessible in the public portal are retained by the authors and/or other copyright owners and it is a condition of accessing publications that users recognise and abide by the legal requirements associated with these

- Users may download and print one copy of any publication from the public portal for the purpose of private study or research.

- You may not further distribute the material or use it for any profit-making activity or commercial gain

If the publication is distributed under the terms of Article $25 \mathrm{fa}$ of the Dutch Copyright Act, indicated by the "Taverne" license above, 


\title{
HEAT-PROCESSED FATS: ANALYSIS OF GENOTOXICITY
}

\author{
PROEFSCHRIFT
}

ter verkrijging van de graad van doctor

aan de Rijksuniversiteit Limburg te Maastricht, op gezag van de Rector Magnificus, Prof. Dr. F.I.M. Bonke, volgens het besluit van het College van Dekanen,

in het openbaar te verdedigen op vrijdag, 22 juni 1990 om 16.00 uur

door

Gerrigje Johanna Hageman

geboren te Zwollerkerspel op 10 juni 1960 
Promotores:

Co-promotor:

Beoordelingscommissie:
Prof. Dr. F. ten Hoor

Prof. Dr. P.Th. Henderson

Dr. J.C.S. Kleinjans

Prof. Dr. F.T. Bosman, voorzitter

Prof. Dr. P.J. Brombacher

Prof. Dr. V.J. Feron

Prot. Dr. J.P.M. Geraedts

Prof. Dr. A.J. Vergroesen

CIP-GEGEVENS KONINKLIIKE BIBLIOTHEEK, DEN HAAG

Hageman, Gerrigje Johanna

Heat-processed fats: Analysis of genoloxicity/

Gerrigje Johanna Hageman - [S.I.:s.n.] - III

Thesis Maastricht. - With ref. -With summary in Dutch.

ISBN 90-9003487-0

SISO 676.1 UDC 615.9:641.522

Subject headings: heated fats / genoloxicity / lipid oxidation

Omslag: Janneke Dogger

Druk: Drukkeri] Aiberts/Druko, Gulpen

Het verschijnen van dit proefschrift werd mede mogelijk gemaakt door steun van de Stichting Dr. Ir. J.H.J. van de Laar

van de Stichting Het Scholten-Cordes Fonds

en van Smilfood bv 


\section{Contents}

\section{Chapter 1}

Heat-processing of food: Passible role of heat-processed lipids in colon tumorigenesis

1. Heat-processing of food

2. Toxicological aspects of heat degradation products

2.1 Carcinagenesis and genotoxicity

2.2. Toxicological risk assessment of carcinogens

2.3. Polycyclic aromatic hydrocarbons

2.4. Caramelization products

2.5. Maillard reaction products and amino acid pyrolyzates

2.6. Lipid oxidation products

3. Heat degradation products and human health risk

3.1. Current status of toxicological risk estimation of amino acid pyrolyzates

3.2. Heat-processed fats and colon cancer risk

3.3. Deep-frying fats as a source of oxidized lipids and mutagens

4. Aim of the thesis

\section{Chapter 2}

Detection of 6-thioguanine-resistant human peripheral blood lymphocytes using 5-bromodeoxyuridine labeling in combination with immunocytochemical staining: Application for in vivo and in vitro mutagenicity testing

\section{Chapter 3}

Assessment of mutagenicity of repeatedly used deep-frying fats

\section{Chapter 4}

Linoleic acid hydroperoxide concentration in relation to mutagenicity of repeatedly used deep-frying fats 
Chapter 5

Page

Comparison of mutagenicity of repeatedly used deep-frying fats in the Salmonella/microsome assay with genotoxicity to human lymphocytes in witro

\section{Chapter 6}

Mutagenicity of deep-frying fat, and evaluation of urine mutagenicity in man after consumption of fried potatoes

\section{Chapter 7}

Analysis of faecal and urine mutagenicity in man after consumption of mutagenic deep-frying fat

\section{Chapter 8}

Effect of short-term feeding of mutagenic repeatedly used deep-frying oils on cell proliferation in the rat gastro-intestinal tract and the excretion of mutagens in urine and faeces of rats

\section{Chapter 9}

General discussion and concluding remarks

Summary

Samenvatting

Dankwoord

Curriculum vitae 


\section{Abbreviations}

\begin{tabular}{|c|c|}
\hline $\mathrm{BHA}$ & butylated hydroxyanisole \\
\hline BHT & butylated hydroxytoluene \\
\hline BrdU & 5-bromodeoxyuridine \\
\hline $\mathrm{CO}$ & coconut oil \\
\hline DCM & dichloromethane \\
\hline DMSO & dimethylsulphoxide \\
\hline DPTG & dimeric and polymeric triglycerides \\
\hline HGPRT & hypoxanthine guanine phosphoribosyll transferase \\
\hline HPLC & high-pertormance liquid chromatography \\
\hline ID & internal diameter \\
\hline i.p. & intraperitoneally \\
\hline LAHPO & linoleic acid hydroperoxides \\
\hline $\mathrm{LI}$ & labeling index \\
\hline $\mathrm{LI}_{\mathrm{C}}$ & labeling index of control lymphacyte cultures \\
\hline Me & methanol \\
\hline MDA & malondialdehyde \\
\hline $\min$ & minute(s) \\
\hline NPF & non-polar fraction \\
\hline PHA & phytohaemagglutinin \\
\hline PBS & phosphate-buffered saline \\
\hline PE & petroleum ether \\
\hline PF & polar fraction \\
\hline $\mathrm{P} / \mathrm{S}$ & $\begin{array}{l}\text { ratio of polyunsaturated fatty acids and saturated fatty } \\
\text { acids. }\end{array}$ \\
\hline $\mathrm{PO}$ & polyunsaturated fatty acid-rich frying oil \\
\hline PUFA & polyunsaturated fatty acids \\
\hline rev & revertants \\
\hline RP & reversed phase \\
\hline SCE & sister chromatid exchange \\
\hline $\mathrm{SD}$ & standard deviation \\
\hline SEM & standard error of mean \\
\hline TBA-RS & thiobarbituric acid-reactive substances \\
\hline $6-\mathrm{TG}$ & 6-thioguanine \\
\hline $\mathrm{TG}^{r}$ & 6-thioguanine-resistant \\
\hline THF & tetrahydrofuran \\
\hline Tpot & potential doubling time \\
\hline UV & ultra violet \\
\hline$V f$ & variant frequency \\
\hline
\end{tabular}




\section{Chapter 1}

\section{Heat-processing of food: \\ Possible role of heat-processed lipids in colon \\ tumorigenesis}

1. Heat-processing of food

2. Toxicological aspects of heat degradation products

2.1. Carcinogenesis and genotoxicity

2.2. Toxicological risk assessment of carcinogens

2.3. Polycyclic aromatic hydrocarbons 14

2.4. Caramelization products 15

2.5. Maillard reaction products and amino acid pyrolyzates 16

2.6. Lipid oxidation products 18

3. Heat degradation products and human health risk 20

3.1. Current status of toxicological risk estimation of amino acid pyrolyzates

3.2. Heat-processed fats and colon cancer risk

3.3. Deep-frying fats as a source of oxidized lipids and mutagens

4. Aim of the thesis

\section{Heat-processing of food}

The use and control of fire by early Human, some 14 million years ago, has had a tremendous impact on diet and availability of foods (Eaton et al., $1985 ;$ 1988). Heat processing of food, involving roasting, boiling, baking and frying, has been used ever since as a means of food preservation, and for improvement of taste and digestibility. Mild heat treatment of food has beneficial effects, since it prevents decomposition due to autolysis by endogenous lytic enzymes or putrefactive bacteria and fungi. Oxidizing enzymes in foods of animal and vegetable origin, which catalyze reactions leading to off-tastes, as well as flavors and colors, are also denatured by heat treatment. An additional benefit is the inactivation of antinutrients, such 
as protease inhibitors which are present in many legumes, cereals and other vegetables (Gurr, 1988, Mauron, 1989). Heat processing of food however may also cause loss of essential nutrients, in particular of water-soluble vitamins, which tend to be less stable than fat-soluble vitamins. Vitamin losses are highly determined by other physical factors as well, including $\mathrm{pH}_{\text {, }}$ water activity and availability of oxygen (Quattrucci, 1988).

In industrial countries, between 1850 and 1950, a steadily increasing proportion of tood has been prepared in factories, and after 1950, food industry has expanded rapidly (Mauron, 1989; Passmore and Eastwood, 1986). At present, industrially processed toods are estimated to provide approximately $75 \%$ of total daily energy consumed in The Netherlands and other developed countries (Gurr, 1988; Keuning and Beek, 1985). Concurrently with increasing consumption of processed foods in industrial countries, per capita consumption of dietary lipids has also increased. In The Netherlands, approximately $40 \%$ of daily energy intake is supplied by dietary fat (Anonymous, 1988b), while in less developed countries average per capita consumption of dietary fat is generally much lower (Rose et al., 1986). With most of our food being processed, constituents of food are likely to be heat-processed, and consequently may be subject to heat degradation.

Heat degradation products of dietary constituents receive increasing attention from the perspective of health risk assessment, since some of the compounds involved have been found to be mutagenic and carcinogenic (Larsen and Pauisen, 1987). Biological effects of heat degradation products of food have been extensively reviewed (Anonymous, 1983, 1985a; 1986; Frankel, 1984; Fretheim, 1983; Furihata and Matsushima, 1986; Gurr, 1988; Jägerstad et al. 1986; Larsen and Paulsen, 1987; O'Brien and Morrissey. 1989; Phillips, 1983; Powrie et al., 1986; Quattrucci, 1988; Smith and Johnsorn, 1989; Sugimura et al.,1986; Sugimura, 1985; Weisburger et al, 1986). In the following part, first the current hypotheses regarding the mechanisms of chemical carcinogenesis will be presented in a brief overview, as well as various test systems applied in genotoxicity and carcinogenicity evaluation of a chemical. Next, toxicological aspects of the most important classes of heat degradation products will be reviewed briefly. Since increased consumption of heat processed lipids is evident in Western societies, special attention will be paid to heat-degradation and oxidation products of lipids. This will be followed by a discussion dealing with evaluation of human health risk of some of the recently discovered heterocyclic amines, which are presently intensively evaluated, and which may serve as an illustrative case for other mutagens and carcinogens formed during processing of food. Finally, a possible rale of lipid axidation products in colon carcinogenesis will be postulated. 


\section{Toxicological aspects of heat degradation products}

\subsection{Carcinogenesis and genotoxicity}

The process of carcinogenesis is presently considered to be a complex multiple-step event (Weinberg, 1989). In experimental models, such as in mouse skin carcinogenesis, at least three steps have been distinguished: initiation, promotion and progression. The process of tumor-initiation has been considered to involve an irreversible; heritable change in the DNA of a cell (Pitot, 1990). This alteration in the DNA may be a gene mutation, or structural and numerical chromosomal changes, and possibly also translocations, gene amplifications, or other gene or DNA rearrangements (Arlett and Cole, 1988; Barrett et al., 1988; Farber, 1987). It should be emphasized that the interaction of a chemical with DNA alone is not sufficient to initiate carcinogenesis; both in vivo and in vitro it has been observed that a round of cell proliferation is required as well (Farber, 1987; Pitot, 1990). During the promotional phase clonal expansion of initiated cells takes place. The principal characteristic of the stage of promation in several model systems of multistage tumorigenesis has been reported to be its reversibilüty (Pitot, 1990). Agents which cause or enhance cellular proliferation are therefore considered to possess tumor-promoting potential. The stage of tumor progression has been defined as that stage of tumorigenesis exhibiting measurable and/or morphologically identifiable (karyotypic) changes in the structure of the cell genome (Pitot, 1990). Such changes are directly related to the increased growth rate, invasiveness, metastatic capability, and biochemical changes in the neoplastic cell. The stage of progression is considered to be irreversible owing to alterations in the cell genome which have been observed to occurr during tumorprogression in various multistage tumorigenesis models (Pitot, 1990).

Proto-oncogenes are genes that regulate and control cell growth and proliferation, and have been recognized as molecular targets of special relevance for the process of carcinogenesis (Farber, 1987; Stowers et al., 1987; Weinberg, 1989). Neoplastic development is thought to be the result, at least in part, of abnormal activation of these proto-oncogenes, which were originally discovered as the transduced genes of acute transforming retroviruses (Land et al., 1983). The conversion of proto-oncogenes to activated oncogenes may occur via mechanisms including point mutations, gene amplification, chromosomal rearrangements, and promotor insertion (Farber, 1987). In addition to the activation of proto-oncogenes, the inactivation of tumor suppressor genes which are involved in negative regulation of oncogenes, may also be a necessary but distinct step in neoplastic development (Sager, 1986; Stowers et al. , 1987; Weinberg. 1989). The activation of proto-oncogenes by genetic alterations results in changed levels of expression of the normal protein product, or in expression of an abnormal protein, consequently leading to abnormal cellular growth 
and/or differentiation.

In different human and rodent tumors specific chromosome delletions and rearrangements as well as point mutations in specific oncogenes have been demonstrated (Cerutti, 1988; Fox, 1988; Weinstein, 1989). Although at present it is not clear whether genetic alterations observed in tumor cells are causative in initiation or progression or both (Fox, 1988; Weinstein, 1989), and although non-genotoxic carcinogens appear to act through mechanisms not invoving genetic alterations, genetic change is part of many theoretical bases of the cause and nature of malignancy (Farber, 1987; Fox, 1988, Pitot, 1990). Therefore, detection of genetic alterations in short-term in vivo and in vitro assays is considered to indicate possible carcinogenic potential of a particular agent. Since at present the detection of changes at specific sites of the DNA (oncogenes or tumor suppressor genes) requires demanding procedures and is not yet available for routine testing, shortterm genotoxicity assays developed during the past two decades which are based on measurement of "surrogate" end points, may still be useful for identification of possible genotoxic carcinogens, as well as for elucidation of their mode of action (Williams, 1989).

\subsection{Toxicological risk assessment of carcinogens}

Since carcinogens are widely distributed in the human environment and may not always be eliminated or banned, toxicological assessment of risk to man posed by possible carcinogens will be necessary to make a proper judgement with respect to the cacinogenic threat of each compound (Kroes, 1987). This may specifically apply to the dietary compounds which are produced during processing and preparation of food, and some of which have been found to possess carcinogenic properties in laboratory animals (Sugimura et al., 1986). Although human data provide the only direct evidence that a chemical produces cancer in man, it is obvious that for most chemicals such data will be not or only limited available. Moreover, epidemiologic evaluation of carcinogenic risk alone is unreliable due to the difficulties of estimating exposure levels, long latency periods, and to the presence of confounding factors (Doll and Peto, 1981). Consequently, negative epidemiologic results cannot ensure complete absence of carcinogenic risk from a compound or process. Additional data are therefore obtained from various experimental studies, which include (i) long-term bioassays with animals measuring the incidence of neoplasms; (ii) shortterm in vitro and in vivo tests, designed to detect early effects of neoplasia, genetic alterations or cell transformation; and (iii) evaluation of biotransformation, pharmacokinetic properties and elucidation of the mechanism of chemical carcinogenesis. Over the past two decades various mutagenicity and carcinogenicity test systems with different biological end points have been developed (Table 1.1). 
Table 1.1. Test systems in mutagenesis and carcinogenesis.

\begin{tabular}{|c|c|c|c|}
\hline End point & Organism/cell & Test system & Target \\
\hline $\begin{array}{l}\text { 1. Gene mutations } \\
\text { - point mutation } \\
\text { within locus } \\
\text { - multilocus deletions }\end{array}$ & $\begin{array}{l}\text { prokaryotic microbes } \\
\text { (bacteria) } \\
\text { eukaryotic microbes } \\
\text { (yeasts/fungi) } \\
\text { insects } \\
\text { mammalian cells }\end{array}$ & $\begin{array}{l}\text { Escherichia coli } \\
\text { Salmonella typhimurium } \\
\text { Saccharomyces cerevisiae } \\
\text { Neurospora crassa } \\
\text { Aspergillus nidulans } \\
\text { Drosophila melanogaster } \\
\text { germ cells } \\
\text { somatic cells } \\
\text { cell lines } \\
\text { human fibroblasts } \\
\text { human lymphocytes }\end{array}$ & $\begin{array}{l}\text { DNA } \\
\text { strand } \\
\mid\end{array}$ \\
\hline $\begin{array}{l}\text { 2. Chromosomal mutations } \\
\text { - numerical } \\
\text { - structural aberrations } \\
\text { - translocations } \\
\text { - DNA damage/repair }\end{array}$ & $\begin{array}{l}\text { bacteria } \\
\text { yeasts/fungi } \\
\text { mammalian cells in vitro } \\
\text { in wivo systems } \\
\text { (mouse, hamster, rat) }\end{array}$ & $\begin{array}{l}\text { Bacillus subtilis } \\
\text { E. coli } \\
\text { S. cerevisiae } \\
\text { A. nidulans } \\
\text { various cells and cell lines } \\
\text { human lymphocytes } \\
\text { bone marrow cells } \\
\text { lymphocytes } \\
\text { tissues }\end{array}$ & $\mid$ \\
\hline $\begin{array}{l}\text { 3. Cell biology } \\
\text { - morphology } \\
\text { - transformation }\end{array}$ & mammalian cells in vitro & $\begin{array}{l}\text { various cells } \\
\text { cell lines } \\
\text { human fibroblasts }\end{array}$ & $\begin{array}{l}\text { Chromo- } \\
\text { some } \\
\mid\end{array}$ \\
\hline $\begin{array}{l}\text { 4. Organ neoplasia } \\
\text { - initiation-promotion-pro- } \\
\text { gression }\end{array}$ & in wivo systems & $\begin{array}{l}\text { skin, lungs, liver, } \\
\text { bladder, mammary } \\
\text { gland, gastro-intestinal } \\
\text { tract }\end{array}$ & $\begin{array}{l}\text { Cell } \\
\text { Organ }\end{array}$ \\
\hline
\end{tabular}

Modified from De la lglesia et al., 1980. 
Short-term in vitro and in vivo genotoxicity assays generally are designed to detect DNA damage or alterations, and these tests are associated primarily with the initiation phase of carcinogenesis (Williams, 1989). These tests do not detect agents that cause cancer by non-genotoxic mechanisms, and do not evaluate pharmacokinetic, metabolic and DNArepair factors that influence species and tissue-specific susceptibilities. Although these tests have initially been considered to be an alternative for in vivo carcinogenicity assays, their predictive value has been found to be disappointingly low, ranging from 60 to $80 \%$ (Douglas et al., 1988; Tennant et al., 1987; Williams, 1989; Zeiger, 1987). The carcinogenicity of a compound in animals is established when administration in adequately designed and conducted experiments results in an increase in the incidence of one or more types of malignant neoplasms in treated animal as compared to untreated animals maintained under identical conditions except for exposure to the test compound (Anonymous, 1984). However, various tumor end points may be expected depending on route of administration, and species, strain and sex of the animals. In addition to increased tumor incidence, occurrence of tumors at sites not or rarely seen in control animals, and decreased latency periods may also be relevant end points. However, at present it is not clear whether these various patterns of tumor development are of different significance with respect to human risk (Anonymous, 1984). Therefore, it has been advised that animal studies, whenever possible, should be supplemented with studies of mechanisms, metabolism and pharmacodynamics, to provide additional information for risk evaluation (Anonymous, 1984; 1988a). Since none of the above presented single methods is able to produce adequate data, it is evident that results of various tests should be integrated for a reliable estimate of a chemical's risk to man.

\subsection{Polycyclic aromatic hydrocarbons}

Pyrolysis products of organic matter, belonging to the class of polycyclic aromatic hydrocarbons (PAHs) have been studied for a long time. Benzo(a)pyrene and other PAHs were recognized as potent carcinogens as early as 55 years ago (Phillips, 1983). Production of PAHs occurs at temperatures higher than $400 \circ \mathrm{C}$; at lower temperatures minimal amounts of PAHs are formed. Grilling or roasting of meat and fish on an open fire leads to PAHs contamination in several ways. PAHs may be "endogenously" formed from food constituents when the surface of the food is exposed to high temperatures, and they may also be derived from the combustion fuel. Highest contamination with PAHs is derived from melted fat which drips from the meat on the heat source; PAHs are produced and subsequently spread into the atmosphere and deposited on the surface of the meat (Fretheim, 1983). Levels of PAHs in heat-processed food may be as high as $200 \mu \mathrm{g} / \mathrm{kg}$, depending on grilling or smoking conditions (Larsen and Paulsen, 1987). PAHs are present not only in broiled and smoked fish and meat and in 
roasted coffee, but levells in the $\mathrm{ppb}$ range have also been found in fresh meats, seafood, vegetables, oils, grains, fruits, whisikey etc. (Anonymous, 1983). It can be assumed that in the latter cases the PAHs contamination derives primarily from air and water pollution or from food or beverage containers.

PAHs are promutagens and procarcinogens; upon oxidation by the cytochrome $P_{450}$ system ultimate mutagens and carcinogens are produced. The active metabolite of benzo(a)pyrene, used as model PAH in many studies, has been demonstrated to be the diol-epoxide (Anonymous, 1983). Many PAHs are genotoxic after microsomal metabolism in various in vitro short-term assays, both prokaryotic and eukaryotic (Anonymous, 1983; Phillips, 1983). More than 20 PAHs have been identified in food, of which more than 10 have been shown to be carcinogenic to animals; oral carcinogenicity data however, have been considered inadequate (Anonymous, 1973; 1983; Larsen and Paulsen, 1987).

\subsection{Caramelization products}

When mono- and disaccharides are heat-treated, they undergo dehydration first, which is followed by complex reactions not yet understood, eventually leading to many brown-colored intermediates and end products. This process is known as caramelization. Caramelization products of carbohydrattes, treated in presence of ammonia, alkalis, sulphites and acids are widely used in food as colour additives (Quattrucci, 1988). In recent years, several doubts have arisen on their safety. In model browning systems, containing sugars and ammonia, mutagenic activity to Salmonella typhimurium has been observed to develop, which appeared to be related to the production of pyrazines. Subsequently, isolated pyrazines have been demonstrated to be mutagenic (Springarn and Garvie, 1979). A diversity of caramelization compounds with varying genotoxic activities in various shortterm assays including mammalian cells, has been identified (Nishi et al., 1989; O'Brien and Morrissey, 1989; Powrie, 1986). These include directacting as well as promutagenic compounds. Animal studies have shown dose-related growth retardation, caecal enlargement and haematological changes (decrease in white blood cell count) after long-term administration of carameis produced with addition of ammonia (Quattrucci, 1988). No carcinogenicity data are available. In contrast, antimutagenic properties of caramelized sucrose have been reported as well (Chan et al, 1982; Powrie, 1986). 


\subsection{Products of Maillard reaction and amino acid pyrolyzates}

The formation of brown pigments and flavor compounds from reducing sugars, heated in the presence of amines is called the Maillard reaction, which is dependent on temperature and waler content of food (Jägerstad et al., 1986). In dry food systems, the reaction may take place at temperatures below $100 \circ \mathrm{C}$, and the rate increases rapidly at temperatures above $1000 \mathrm{C}$ (O'Brien and Morrissey, 1989). Numerous Maillard reaction products can be isolated from either model browning systems or heated foods (Jägerstad ef all, 1986, O'Brien and Morrisey, 1989). Maillard reactions have been implicated in the formation of imidazoquinolines and imidazoquinoxalines, heterocyclic amines which were first isolated from fried and boiled proteinaceous foods (Sugimura et al., 1977; Jägerstad et al., 1986). These compounds were found to be potent mutagens in the Salmonella/microsome assay after hepatic microsomal metabolism (Sugimura et al., 1986).

Other pyrolyzates of amino acids have been isolated from beef extracts and heated proteins and include indoles, imidazoles, carbolines, carbazoles and pyridines (Dolara and Bianchini, 1988; Furihata and Matsushima, 1986; Sugimura et al., 1986). Most of these bacterial mutagens have been found to be carcinogenic to rodents (Table 1.2). Their isolation, as well as their mutagenic and carcinogenic properties have been extensively reviewed (Anonymous 1986; Furihata and Matsushima, 1986; Sugimura et al., 1986; O'Brien and Morrisey, 1989). Most recently isolated and identified mutagen from fried ground beef is 2-amino-1-methyl-6-phenylimidazo[4,5-6]pyridine (PhIP; Felton et al., 1984, 1986). Heterocyclic amines show genotoxic effects in various short-term assays applying mammalian cells; potencies vary depending on the test system used and compound tested (Anonymous, 1986; Dolara et al., 1985; Furihata and Matsushima, 1986; Wild et al., 1985).

2-Amino-3,8-dimethylimidazo-[4,5-f]quinoxaline (MelQx), 2-amino-3,4,8trimethylimidazo-[4,5-f]quinoxaline (4,8-DiMelQx) and PhIP have been found to be the major mutagens in fried beef, comprising approximately $75 \%$ of the total mutagenic activity, whereas 2-amino-3-methylimidazo-[4,5-f]quinoline (IQ) has only been found in trace amounts (Larsen and Paulsen, 1987). Concentrations of MelQx in fried beel and beef extracts are reported to reach levels of $300 \mu \mathrm{g} / \mathrm{kg}$ (Jägerstad et al, 1986). Few data are available on concentrations of heterocyclic amines in heat processsed meat products, due to complex analytical methods required (Hatch and Felton, 1986). 
Table 1.2. Mutagenicity and carcinogenicity of pyrolysis products of amino acids and proteins in coaked loods.

\begin{tabular}{|c|c|c|c|}
\hline \multirow[b]{2}{*}{ Compound } & \multicolumn{2}{|c|}{$\begin{array}{l}\text { Mutagenicily to } \\
\text { Salmonella tester strain }\end{array}$} & \multirow[t]{2}{*}{$\begin{array}{l}\text { Garcinogenicity to } \\
\text { rodents }\end{array}$} \\
\hline & 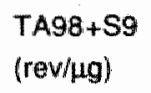 & $\begin{array}{l}\text { TA100+Sg } \\
(\text { rev/ } / \mu g)\end{array}$ & \\
\hline $\begin{array}{l}\text { 1. 2-Amino-9H-pyrido - } \\
\text { [2,3-b]-indole (A-alpha-C) }\end{array}$ & 300 & 20 & $+(800 \mathrm{mg} / \mathrm{kg}$ in diet $)$ \\
\hline $\begin{array}{l}\text { 2. 2-Amino-3-methyl-9H-pyrido } \\
{[2,3 \text {-b]-indole (MeA-alpha-C) }}\end{array}$ & 200 & 1.20 & $+(800 \mathrm{mg} / \mathrm{kg}$ in diet $)$ \\
\hline $\begin{array}{l}\text { 3. 2-Amino-6-mety\|-dipyrido- } \\
{\left[1,2-a: 3^{\prime}, 2^{\prime}-d\right] \text {-imidazole }(G / u-P-1)}\end{array}$ & 49000 & 3200 & $+(500 \mathrm{mg} / \mathrm{kg}$ in diel $)$ \\
\hline $\begin{array}{l}\left.\text { 4. 2-Aminodipyrido-[1,2-a: } 3^{\prime}, 2^{\prime \prime}-d\right]- \\
\text { imidazole (Glu-P-2) }\end{array}$ & 1900 & 1200 & $+(500 \mathrm{mg} / \mathrm{kg}$ in diet $)$ \\
\hline $\begin{array}{l}\text { 5. 3,4-Cyclopenteno-pyrido- } \\
\text { [3,2-a]-carbazole(Cys-P-1) }\end{array}$ & 98 & no data & no data available \\
\hline $\begin{array}{l}\text { 6. 2-Amino-3-methylimidazo- } \\
{[4,5-1] q u i n o l i n e ~(I Q)}\end{array}$ & 33000 & 7000 & * (300 mg/kg in diel) \\
\hline $\begin{array}{l}\text { 7. 2-Amino-3,4-dimethylimidazo- } \\
{[4,5 \text {-f]quinoline (MelQ) }}\end{array}$ & 611000 & 30000 & $\begin{array}{l}\text { * (100 and } 400 \\
\text { mg/kg in diet) }\end{array}$ \\
\hline $\begin{array}{l}\text { 8. 2-Amino-3,8-dimethylimidazo- } \\
{[4,5 \text {-f]quinoxaline (MelOx) }}\end{array}$ & 145000 & 14000 & $+(300 \mathrm{mg} / \mathrm{kg}$ in diet $)$ \\
\hline $\begin{array}{l}\text { 9. 2-Amino-3,7,8-trimetyllimidazo- } \\
{[4,5-1] \text { quinoxaline (7,8-DiMelQx) }}\end{array}$ & 163000 & 9900 & no data avallable \\
\hline $\begin{array}{l}\text { 10.2-Amino-3,4,8-trimetylimidazo- } \\
{[4,5 \text {-f]quinoxaline }(4,8 \text {-DiMelox })}\end{array}$ & 183000 & 8000 & no data avallable \\
\hline $\begin{array}{l}\text { 11.3-Amino-1,4-dimethyl-5H-pyrido- } \\
{[4,3,6] \text {-indole (Trp-P-1) }}\end{array}$ & 39000 & 1700 & $+(2 \mathrm{mg} / \mathrm{kg}$ in diet $)$ \\
\hline $\begin{array}{l}\text { 12.3-Amino-1-methyl-5H-pyrido- } \\
{[4,3,6] \text {-indole (Trp-P-2) }}\end{array}$ & 104000 & 1800 & $+(1-2 \mathrm{mg} / \mathrm{kg}$ in diet $)$ \\
\hline
\end{tabular}

After: Sugimura et al., 1986; Furihata and Matsushima, 1986; Felton et al. 1984. Mutagenicity is expressed as number of his ${ }^{+}$revertant colonies induced per $\mu g$ of compound. + carcinogenic in rodents, the dose included in the diet is shown between parentheses. 
Analysis of meals containing heated products and composed of regular products consumed in The Netherlands, has yielded estimates of 15-20 $\mu \mathrm{g} / \mathrm{kg}$ for IQ, DiMelQx, MelQx and PhIP (Alink et al, 1988). Mutagen formation in fried ground beef appears to be temperature dependent (Pariza et al. 1979); increased mutagenicity has been observed in beef fried at temperatures ranging from 191 to $210^{\circ} \mathrm{C}$. whereas beef fried at $143^{\circ} \mathrm{C}$ had low levels of mutagenicity. increasing the fat content of fried ground beef has been shown to enhance mutagen formation, which has been attributed to a more efficient heat transfer (Springarn et al., 1981; Knize et al., 1985; Nilsson et al., 1986). However, interactions of amino acids with lipids may have produced mutagenic compounds as well, since heated reaction mixtures of lipids and amino acids have been reported to induce increased mutagenic activity (Vithayathil et al., 1983; Yoshida and Okamoto 1980). In contrast, antimutagenic activity of browning reaction products of L-lysine and D-fructose have also been demonstrated (Chan et al, 1982).

\subsection{Lipid oxidation products}

Heat degradation of dietary lipids may involve oxidation as well as chemical processes which do not necessarily involve oxygen (Frankel, 1984;1987). Oxidative deterioration of lipids is enhanced at high temperatures, but may occur at ambient or even freezer temperatures. The process of lipid oxidation or autoxidation of polyunsatured fatty acids (PUFA) involves free radical mechanisms (Frankel, 1984;1987; Halliwell and Gutteridge, 1984). Lipid peroxidation proceeds in three stages: initiation, propagation and termination. Initiation takes place by loss of a hydrogen radical in presence of trace metals, light or heat. The resulting lipid free radicals (L.) react with oxygen to form peroxy radicals (LOO.). In the propagation process, $L O O$. react with more $\mathrm{LH}$ to form lipid hydroperoxides (LOOH), which are the primary products of autoxidation (Figure 1.1). Termination of lipid oxidation may follow several ways. Two lipid carbon radicals or peroxyradicals may combine and form dimeric and polymeric products. Alternatively, a peroxy radical can form a cycic peroxide, which as a free radical itself, can undergo cyclization to a cyclic endoperoxide, which on heating in the presence of axygen can split into a number of endproducts characteristic of lipid oxidation, including aldehydes, ketones, alcohols, hydrocarbons, esters, furans and lactones. Lipid hydroperoxides can react again with oxygen to form secondary products, which may be volatile, or condense into dimers and polymers, which can also break down and produce volatile materials (Frankel, 1984; 1987).

Peroxidation of lipids in food occurs easily, because the reaction is catalyzed by components of the foods. Important non-enzymic catalysts are 
iron and copper (Frankel, 1987; Gurr, 1988). Fresh plant and animal products contain the enzyme lipoxygenase which catalyzes the formation of hydroperoxides of PUFA (Halliwell and Gutteridge, 1985). Antioxidants such as naturally occurring alpha-tocopherol, beta-carotene, ascorbic acid, as well as the synthetic compounds butylated hydroxytoluene (BHT) and butylated hydroxyanisole (BHA) retard the process of lipid oxidation by scavenging free radicals (Frankel, 1984; 1989; Gurr, 1988). Cholesterol and related sterols are also subject to autoxidation during heating (Bascoul et al., 1986; Gurr, 1988). The lipid oxidation products malondialdehyde (MDA) or MDA-like substances have been detected in various foods, including oils, lipid containing vegetable products, and meat and fish (Shamberger et al, 1977; Siu and Draper, 1978); concentrations in heat-processed meats reached levels as high as $30-40 \mathrm{mg} / \mathrm{kg}$. Heat-treated triglycerides may form considerable amounts of lipid oxidiation products including cyclic monomers, peroxides, hydroperoxides, di- and polymeric triglycerides, as well as low molecular weight degradation products (Gurr, 1988; Sebedio et al., 1987; Stevenson, 1984; Thompson and Aust, 1983), which may involve 30 to $40 \%$ of the triglycerides. Oxidized lipids and aldehydes including MDA, are highly reactive compounds and are reported to bind covalently to proteins, amino acids and sugars (Esterbauer, 1982; Gurr 1988; Gutteridge, 1982; Halliwell and Gutteridge, 1984; Piche et al., 1988). MDA as well as other carbonyls have been observed to catalyze nitrosation reactions in the presence of free nitrite, which may result in the formation of potentially carcinogenic nitrosamines (Hartman, 1983; Kurechi et al., 1980).

Initiation:

$\mathbb{L H}$

Propagation:

$\mathrm{L*}+\mathrm{O}_{2}$

$\mathrm{LOO}+\mathrm{LH}$

Termination: trace metals, light

heat

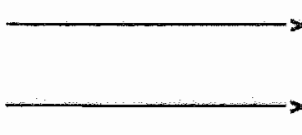

secondary monomers dimers and

polymers
100

$\mathrm{LOOH}+\mathrm{L}$.

volatile

breakdown

products

Figure 1.1. Process of lipid oxidation. 
The lipid oxidation products MDA, hydroperoxides of linoleic acid, various aldehydes and carbonyls, as well as oxidized sterols are mutagenic in the Salmonella mutagenicity assay (Basu and Marnett, 1983; MacGregor et al, 1985; Smith et al., 1986; Yamaguchi and Yamashita, 1979; 1980). Various fipid oxidation products, including oxidized sterols, hydroxy- and hydroperoxyeicosatetraenoic acids, alkenals, MDA and hydroperoxides of linoleic acid have been shown to be genotoxic to mammalian cells (Brambilla et al., 1986; Cajelli et al., 1987; Nakayama et al., 1986; Kelsey and Pienta,1979; Vaca et al., 1988; Weitberg and Corvese, 1989). Acute or short-term oral administration of oxidized oils or isolated fractions containing oxidation products, to laboratory animals has been reported to induce adverse biological effects (Alexander, 1981; Gurr, 1988). These include cellular damage and increased liver and kidney weights, cellular damage to epidymides and testes, increased lipid oxidation in hepatic and renal tissue, as well as teratogenic effects (Alexander 1981; Alexander et al., 1987; Cutler and Schneider, 1973; Izaki et al.,1984; Kanazawa et al.,1986). Consumption of cooked, stored meat, containing MDA or MDA-like substances has been shown to increase urine excretion of these lipid oxidation proucts in humans (Jacobsen et al., 1983). Urinary excretion of MDA is considered an indicator of dietary intake of lipid oxidation products as well as of endogenously occurring lipid oxidation (Draper et al., 1984). Chronic oral administration of MDA at doses ranging from 0.1 to $10 \mu \mathrm{g} / \mathrm{g}$ bodyweight, has been associated with increased neoplastic and hyperplastic changes in the liver of mice (Bird et al., 1982; Siu et al.,1983). In another study however, no increased tumor incidence was seen after chronic administration of MDA with drinking water containing concentrations of MDA up to $0.5 \%$ (Apaja, 1980). MDA is the only lipid oxidation product on which carcinogenicity data are available. In contrast, antimutagenic and antitumorigenic oxidative derivatives of linoleic acid, which contain a conjugated double-bound system and are reffered to as CLA, have also been isolated from fried ground beef ( $\mathrm{Ha}$ et al. ,1987; Pariza, 1988).

\section{Heat degradation products and human health risk}

At present, a small number of mutagens produced during heatprocessing of food has been evaluated for carcinogenicity in animal experiments. Several heterocyclic amines as well as PAHs and MDA have been shown to be carcinogenic in animals and may therefore pose a serious hazard to human health. Although PAHs are widely distributed in the human environment, limited data are available on carcinogenicity after oral administration (Anonymous, 1973; 1983). Tobacco smoke and urban air are considered to be the main sources of PAH-production (Anonymous, 1983). Since epidemiologic evidence has indicated that intake of food containing traces of PAHs does not contribute appreciably to human cancer risk 
(Anonymous, 1983), toxicological risk assessment of consumption of PAHs will not be discussed further. In addition, toxicological data avalable on caramelization products are too limited to allow a meaningful discussion of their toxicological risk. Since most data are available on the heterocyclic amines IQ, MelQ and MelQx, which thave been found in heat-processed meat and fish, in the following part the current status of risk evaluation of these compounds will be discussed. This part is ment to illustrate the special issues encountered and problems to be solved in risk estimation of constituents which are commonly present in heat-processed foods. This will be followed by a discussion of the possible risks posed by oxidation and heat degradation products of lipids.

\subsection{Current status of toxicological risk assessment of amino acid pyrolyzates}

Carcinogenicity in rodents of the most potent bacterial mutagens, the amino acid pyrolyzates 10 and $\mathrm{MeIQx}$, which are present in fried beef, has been observed at a single dose of $0.03 \%$ in diet for a single compound (Sugimura et al., 1986). Target organs have been reported to include liver, Zymbal gland, colon and small intestines (Anonymous, 1986; Kato et al., 1989). In contrast, chronic dietary administration of mutagen-containing charred fish meat at a level of $25 \%$ in diet, has not been reported to increase tumor incidence in rats (Fuji et al., 1987). However, in this latter study doses of heterocyclic amines consumed have not been determined. Recently, Alink et al. (1989) have reported increased incidences of epithelial tumors in male, but not in female rats fed a balanced human diet containing thermally processed foods, which resulted in an intake of mutagenic heterocyclic amines of $0.5-0.7 \mu \mathrm{g} / \mathrm{kg}$ body weight/day. No increased tumor incidences have been observed in this study at sites reported to be specific for carcinogenic heterocyclic amines. These data suggest that risk assessment of intake of carcinogenic heterocyclic amines with human diet of doses which are 5000-fold llower that TD $_{50}$ for rats (Alink et al., 1989; Felton et al., 1986), is hindered by the complexity of the human diet (Weisburger ell al., 1986), of which carcinogenicity inhibiting as well as enhancing effects are not suffiently known at present.

In short-term in vitro assays using mammalian cells, MelQx and IQ have been observed to induce only weak positive effects (Dolara et al. 1985; Howes et al.,1986; Hatch and Felton, 1986; Nakayasu et al., 1983). High doses of $I Q$ have been shown to be negative in inducing in vivo gene mutations or chromosome aberrations, and induced a borderline effect on frequencies of sister chromatid exchanges (SCE) (Minkler et al., 1984; Tucker et al, 1989; Wild et al, 1985). More recently, it has been shown that liver-microsomal metabolites of $1 \mathrm{Q}$ and MelQx are weak inducers of SCE in human lymphocytes at realistic exposure levels of 0.1 to $0.8 \mu \mathrm{g} / \mathrm{ml}$ (Aeschbacher and Ruch, 1989). In the same study, chromosome aberrations have not been detected in human. Iymphocytes at 100 -fold higher concentrations. IQ has been observed to be not capable either of increasing 
numbers of micronuclei or mutation frequencies at the hypoxanthine guanine phosphoribosyl transterase (hgprt) locus in human lymphocytes, using human-liver microsomal activation at realistic as well as high exposure levels of 1 to $10 \mathrm{mM}$ (McManus et all, 1988). The striking paradox between genotoxic potency in bacterial and mammalian assays may be due to differences in activities of acyltransferases; which have been shown to metabolize the mutagenic microsomal $\mathrm{N}$-hydroxy derivatives of $\mathrm{IQ}$ and MelOx, resulting in a 10 - to 30 -fold increase in mutagenic potency and DNAbinding capacity (Negishi et al, 1989; Snyderwine et al, 1988). In addition, specific DNA repair capacities of mammalian cells may make them less susceptible to genotoxic effects of MelQx and IQ, and it has been postulated that these cells may be more relevant than prokaryotic organisms for genotoxic risk evaluation of dietary components (Aeschbacher and Ruch, 1989).

Few epidemiologic studies are available, which have evaluated health effects of consumption of heat-processed foods (Archer, 1989). In a prospective Japanese cohort study, Kuratsone et al. (1986) have observed increased mortality of cancer and increased stomach cancer mortality with increased consumption of brolled fish, whereas in a group of Japanese Seventh-day Adventists stomach cancer mortality has been found to be significantly lower. Seventh-day Adventists are known to abstain from broiled and fried meats and fish, and not to use alcoholic drinks. Colon cancer mortality of has been reported to be lower in Seventh-Day Adventists than in populations consuming mixed western diets (Phillips et al., 1980). Furthermore, in a case-control study high consumption of processed lunchmeat and pan-fried foods has been associated with increased colon cancer risk (Young and Wolf, 1988). Another case-control study however, has not shown increased risk for colon cancer in persons with more frequent use of broiled and fried meats five years before diagnosis (Lyon and Mahoney, 1988). These data are too limited to draw any conclusions, but it should be noted that the positive associations observed between meat or animal protein intake and colon cancer mortality (Armstrong and Doll, 1975; Rose et al., 1986; Willet, 1989) may be additional evidence for a role of heatprocessed meat in human cancer, since most meats are heat-treated before consumption. In addition, increased faecal mutagenicity as well as the presence of metabolites of heterocyclic amines has been observed in 3 human volunteers after consumption of fried beef, indicating the colon may be a target for genotoxic effects of heterocyclic amines (Hayatsu et al., $1985)$.

The possible role of heterocyclic amines in colon cancer receives increasing attention (Bird and Bruce, 1984; Tudek et al., 1989). In animal carcinogenicity studies, increased tumor incidence has been observed in the colon of rats after chronic dietary administration $0.03 \%$ of $1 \mathrm{Q}$ and $\mathrm{MelQ}$ (Takayama et al., 1984; Kato et al., 1989; Sugimura, 1985). These heterocyclic amines have also been tested in vivo in animal models determining nuclear aberrations, SCE's or aberrant crypt foci in mucosal 
tissue of the colon after a single oral dose (Bird and Bruce, 1984; Couch et al., 1987; Tudek et al, 1989; Wargovich el all. 1983). Using these models, it has been observed that $\mathrm{QQ}$ and $\mathrm{Mel} \mathrm{Q}$ are inducers of nuclear aberrations in murine colon, with effective doses ranging from 10 to $200 \mathrm{mg} / \mathrm{kg}$ (Bird and Bruce, 1984). MelQ has been shown to be a weak inducer of SCE's in colonic tissue of mice at doses ranging from 50 to $200 \mathrm{mg} / \mathrm{kg}$ (Couch et al. 1987). At even higher doses of 200 to $400 \mathrm{mg} / \mathrm{kg}, \mathrm{IQ}$ and $\mathrm{MelQ}$ have been shown to be potent inducers of aberrant foci in the colon of rats, but not in mice (Tudek et al., 1989). In addition, dietary modulation of genotoxic effects of IQ has also been demonstrated using this model. Feeding of $20 \%$ corn oil has been shown to increase nuclear aberrations in colon of mice induced by $\| Q$, whereas cellulose was without effect and $20 \%$ olive oil reduced the nuclear damaging effect of IQ (Dolara et al., 1986). These data appear to support a role for specific heterocyclic amines in tumorigenesis of the colon, although the effective doses are extremely high and exceed realistic exposure levels at least a 1000-fold.

It will be clear from the above cited studies, that reliable risk estimation of mutagenic heterocyclic amines is not possible at present. Limited data are available, which do not allow for quantitative risk estimation. Mutagenic heterocyclic amines have been found in trace amounts ( $\mathrm{ppb}$ level) in heatprocessed food, while carcinogenicity in rodents, and genotoxicity in vitro in human cells, and in wivo in rodents has been observed at much higher than realistic exposure levels. Furthermore, fried foods have been found to contain mixtures of mutagens, whereas at present data are available of single compounds only. Therefore, in vivo and in vitro studies, which apply realistic doses, representative mixtures of mutagens and also involve modulating dietary factors, are needed to provide necessary additional information with respect to human carcinogenic risk evaluation.

\subsection{Heat-processed fats and colon cancer risk}

Epidemiologic and experimental data support an association between high dietary fat intake and cancer of breast, large bowel and prostate, although not all data are consistent with the association (Byers, 1988; Hill, 1987; Pariza, 1988; Reddy, 1987; Rogers and Longnecker, 1988, Willet, 1989). In contrast, per capita fat consumption has been found to be inversely related to stomach cancer mortality (Armstrong and Doll, 1975), whereas no other tumor sites have been reported to be associated with high fat intake. Some epidemiologic studies have evaluated specific effects of saturated and polyunsaturated fatty acids intake on cancer mortality or colon tumor incidence. Usually fat has been divided into two categories, animal or vegetable. These categories thowever, do not fully represent saturated and unsaturated fats, since some animal fats (e.g. chicken, pork and fish) may contain considerable amounts of polyunsaturated fatty acids (PUFA), whereas some vegetable fats (e.g. coconut oill) may contain minimal amounts of PUFA. Data obtained with these studies yileld conflicting results, 
with some pointing to a positive relation between animal or salurated fat consumption and colon cancer incidence, and others finding no association (Byers, 1988; Rogers and Longnecker, 1988; Willett, 1989). In contrast, some report an inverse relation between saturated fat intake and colon cancer incidence, whereas others have found an inverse relation between vegetable fat intake and colon cancer incidence (Stemmerman et al., 1984; Willet, 1989). One Dutch correlational study has shown a positive association between colon cancer montality and per capita consumption of total fat, saturated fat, monounsaturated fat and polyunsaturated fat 10 years previously (Anonymous, 1985b).

Various explanations may be imaginable for these conflicting results, including difficulties in estimation of dietary intake as well as confounding effects of other dietary and environmental factors. High intake of meat with animal fats may explain the positive relation between saturated or animal fat intake and colon cancer, whereas intake of fiber and the antioxidants and presumable anticarcinogens alpha-tocopherol and beta-carotene (Ames, 1983; Hayatsu, 1988) may be associated with consumption of vegetable fats, which may result in an inverse relationship between vegetable fat intake and colon cancer. However, another confounding factor may be heatprocessing of dietary lipids which has not yet been evaluated in epidemiologic studies. A specific effect of heat-processed lipids may be indicated by results of a case-control study recently reported by Peters et al. (1989). In this study high consumption of deep-fried foods has been onserved to be associated with increased colon cancer risk. Since the authors do not report adjustment for total fat intake, this finding does not give a definitive clue for the involvement of heat-processed lipids in colon tumorigenesis and will have to be confirmed in other studies.

Although the secondary oxidation product MDA has been shown to possess carcinogenic properties in mice (Bird et al., 1982; Siu et al., 1983), no data are available on analysis of carcinogenicity of other oxidized lipids. Oxidized lipids however, may possess tumor-initiating properties since some have been found to exert genotoxic effects in the Salmonella microsome assay as well as in mammalian cells. MDA, hydroperoxides of linoleic and linolenic acid, and various aldehydic products and carbonyls have been reported to be mutagenic to Salmonella typhimurium (Basu and Marnett, 1983; Mukai and Goldstein, 1976; Marnett et al., 1985; Yamaguchi and Yamashita, 1979; 1980). Methyl linoleate hydroperoxide has been shown to induce single strand breaks in DNA of human fibroblasts at doses ranging from 50 to $100 \mu \mathrm{M}$ (Nakayama et al., 1986), and the same effects have been reported for hydroperoxides and hydroxides of 6,8,11,14-eicosatetraenoic acid in human lymphocytes at doses ranging from 5 to $20 \mu \mathrm{M}$ (Weitberg and Corvese, 1989). Several aldehydic products, including 4-hydroxynonenal have been shown to induce DNA single strand and double strand breaks, and increase SCE frequencies in Chinese hamster ovary cells (Brambilla et al., 1986). In addition, 4-hydroxynonenal has induced a dose-related increase in mutations at the hgprt locus in V79 Chinese hamster cells at dose ranges from 10 to $50 \mu \mathrm{M}$ (Cajelli et al., 1987). These data indicate that 
oxidation products of fatty acids other than MDA may also be involved in tumor-initiation. Therefore, determination of possible tumor-initiating activity of heat degradation and oxidation products of lipids in experimental studies appears to be of relevance for evaluation of carcinogenic risk.

Whereas effects of heat-processsed lipids have not been evaluated in experimental carcinogenicity studies, the role of unheated dietary fat in colon carcinogenesis has been comprehesively investigated in two-stage animal models. Using this initiation-promotion model, high intake of unheated dietary fat has been shown to enhance chemically induced colon tumorigenesis, but the enhancing effect appears to be dependent on the type of fat as well (Reddy, 1987). In carefully controlled studies, high intake of dietary corn oil, beei-fat, safflower oil, and lard has been shown to enhance colon tumorigenesis, whereas diets high in olive oil, coconut ail, and fish oil are without enhancing effects (Carroll, 1987). The enhancing effect of high-fat diets with ad libitum feeding as has been applied in earlier studies, has been related to high energy intake; increased bodyweights in the high-fat groups appeared to explain increased tumor incidence (Pariza, 1988; Rogers and Longnecker, 1988). It has also been demonstrated that linoleic acid is essential for optimal tumor development, as it is for normal growth and development (Pariza, 1988; Sakaguchi et al., 1986).

High levels of dietary fats are postulated to exert tumor enhancing effects via increased bile excretion and high levels of faecal fatty acids, which have been shown to be irritating and toxic to the colonic epithelial cells (Bird, 1986). This may increase cancer risk by affecting promotion and possibly also initiation of colon carcinogenesis (Bruce, 1987; Nair, 1988; Pariza, 1988). High fat diets may also influence composition and metabolic activity of colonic microflora, either directly or indirectly via enhanced bile excretion (Goldin, 1986; Nair, 1988), thereby causing altered metabolism of possible carcinogenic or carcinogenicity enhancing compounds, such as neutral steroids. Suzuki et al. (1986) have isolated the sterols cholest-4-en-3-one and 5-alpha-cholestan-3-one from human faecal extracts, which have been observed to be active compounds in the colonic nuclear aberration assay. These oxidation products of cholesterol may either be produced by bacterial transformations in the large bowel or may be derived from oxidized sterols in food (Bruce, 1987; Suzuki et al., 1986). Furthermore, axidation products of linoleic and arachidonic acid have been reported to stimulate DNA synthesis and cell proliferation, and to induce ornithine decarboxylase (ODC) activity in rat colon after intrarectal administration (Bull ef al., 1984,1988), which effects are considered to be markers of tumor promotion (Hicks, 1983; Weinstein, 1988). Effects of oral administration of heat-processsed or oxidized lipids on cell proliferation, tumor initiation or promotion in the colon however, have not yet been evaluated. These biologically active lipid oxidation products can be derived from dietary fats, and therefore, investigation of tumor-enhancing effects of lipid oxidation products present in the diet appears to be indicated. 
Since the colon may be considered a possible target organ for possible carcinogenic lipid oxidation products present in heat-processed fats, the presence of these compounds in the colonic lumen will have to be demonstrated. Metabolic studies in rats, performed with ${ }^{14} \mathrm{C}$-llabeled linoleate hydroperoxides, low molecular weight secondary products and fractions rich in polymeric degradation products, have shown that radioacitivity is excreted in faeces, being 45 to $53 \%$ for the polymercontaining fraction, and 13 to $40 \%$ for linoleate hydroperoxides, while low molecular weight compounds have been reported to be almost completely absorbed and metabolized with only $3 \%$ excreted in faeces (Kanazawa et al., 1985, Oarada al., 1986; Bergan and Draper, 1971). Thermally oxidized fats, or isolated fractions containing oxidation products, have been reported to induce microsomal enzyme activities in the liver as well as in the colon after short term dietary administration. (Andia and Street, 1975; Perciballi and Pintauro, 1985). These data indicate that orally adiministered lipid oxidation products or their metabolites may actually reach the colon, either via the luminal contents or by the bloodstream.

The data presented above appear to provide some evidence for an involvement of thermal oxidation and degradation products of dietary lipids in colon tumorigenesis. However, no data are availble which indicate that tumor-initiating or promoting effects may be exerted in the colon after consumption of heat-processed lipids. Therefore, determination of genotoxic and other biological effects of heat-processed dietary lipids appears to be indicated, with special attention to possible effects exerted in the colon.

\subsection{Deep-frying fat as a source of oxidized lipids and mutagens}

Heat-processed dietary lipids are found in many food products, but dietary lipids whih are almost certainly subject to heat-treatment are considered to be deep-frying fats. Heated deep-frying ails are probably the most extreme example of heat-processed lipids, since these may be kept at high temperatures (160-200 $\left.{ }^{\circ} \mathrm{C}\right)$ for long periods of time, with oxygen introduced into the oll during frying of foods, which are conditions favouring oxidative deterioration of the frying oil (Chang et al., 1978; Stevenson et al, 1984). Deep-fat frying is a common cooking practice in The Netherlands, and is applied for preparation of potatoe chips, French fries, various meat products, nuts etc, during home cooking as well as industrial food processing. Based on consumption data, recently collected in The Netherlands in a dietary record survey with 5898 participants representative of the Duch population, mean daily intake of lipids from deep-fat fried foods is estimated to be at least $6.4 \mathrm{~g}$ per person (Anonymous, 1988b). Assuming that $20 \%$ of the fat of deep-fried foods is derived from the frying oil, mean daily intake of heat-processed fat is approximately $1.2 \mathrm{~g}$ per person. This is likely to be a minimum estimation of consumption of all possible heatprocessed lipids, since it does only include deep-frying fat and does not take into account consumption of heat-processed fats from pan-fried meats, 
confectioneries etc. In addition, mean data of the total population of 5898 persons, aged 0 to 75 years, have been used and categories may exist that consume considerable higher amounts of deep-frying fat.

Several authors have investigated mutagenicity of heated deep-frying fats, or deep-fat fried foods, applying the Salmonella/microsome assay. No mutagenicity has been detected in dimethyl sulphoxide (DMSO)-extracts of heated oil (Van Gastel et al., 1984), whereas mutagenicity of DMSO-extracts of fresh peanut oils has been reported to decrease after heating in another study, which has been suggested to be due to the presence of aflatoxins in the oils (Fong et al., 1980). Taylor et al. (1982; 1983) have shown mutagenic activity in the basic and acidic methylene chloride extracts of fried meat products, but not of potatoes and other starchy foods. Mutagenicity of basic methylene chloride extracts of deep-fat fried meat-products, which are considered to contain amino acid pyrolyzates, has been reported by these authors to be considerably lower as compared to pan-fried meats, indicating deep-fat irying is not a major source of dietary mutagenic amino acid pyrolyzates. Furthermore, these authors have reported great difficulties with testing of oxidized lipid fractions, due to insolubility of the lipid fractions in the test media and growth inhibition of the bacteria. Only one study has made an attempt to investigate mutagenicity of oxidized lipid fractions (Scheutwinkel-Reich et al., 1980), but data obtained in this study may be regarded as inconclusive due to toxic effects to the bacteria of oxidized lipid fractions. Since individual lipid oxidation products have been reported to possess genotoxic activity in the Salmonella/microsome assay (MacGregor et al., 1985; Yamaguchi and Yamashita, 1979; 1980), as well as in mammalian cells (Brambilla et al., 1986; Cajelli et al., 1987; Nakayama et al., 1986; Weitberg and Corvese, 1989), involvement of lipid oxidation products in mutagenicity of the diet cannot be excluded.

Assessment of the role of heat-processed fats in colon tumorigenesis will require analysis of tumor-initiating as well as tumor-enhancing properties of heat-processed dietary lipids. Since deep-frying oils represent a class of dietary lipids which may be heat-processed for long periods, which may produce biologically active lipid oxidation products, and which are consumed with deep-fat fried foods, deep-frying fats and deep-fried foods appear to be of primary interest with repect to health risk assessment of heat-processed lipids. Therefore, genotoxic and other biological effects associated with carcinogenic risk will have to be determined to provide data for a qualitative and quantitative evaluation of the contribution of heated deep-frying fats and deep-fried foods to the carcinogenic risk posed by the diet.

\section{Alm of the thesis}

Heat-processed lipids have been postulated to be possibly involved in tumorigenesis of the colon, since they may contain biologically active and 
genotoxic lipid oxidation products. As discussed previously, specific lipid oxidation products have been shown to possess genotoxic potential, in bacteria as well as in mammalian cells, indicating possible tumor-initiating properties. However, the relation between mutagenicity of the diet and presence of lipid oxidation products in heat-processed dietary lipids such as deep-frying oils, is not known. In addition to the generally applied Ames mutagenicity assay, use of eukaryotic and more specifically human cells in genotoxicity testing of dietary compounds is indicated especially for purposes of human genotoxic risk evaluation (Anonymous, 1988a). Detection of genetic damage in human cells, such as peripheral blood lymphocytes, will enable evaluation of genotoxic risk in cells which are likely to be exposed in vivo as well. Therefore, analysis of genotoxic activity of heated deep-frying fats in the Salmonella microsome assay, as well as in human lymphocytes, in relation to the presence of lipid oxidation products is the first alm of this thesis. For in vitro mutagenicity testing in human lymphocytes, a modified procedure for the detection of 6-thioguanineresistant lymphocytes has been developed, which is described in Chapter 2. Analysis of genotoxic potentiall of heated deep-frying fats, using the Salmonella/milcrosome assay as well as by measurement of mutagenicity and sister chromatid exchange (SCE) frequencies in human lymphocytes, in relation to the presence of lipid oxidation products is presented in Chapters 3,4 and 5 .

In this thesis it is also hypothesized that heat-processed lipids may be involved in colon tumorigenesis. In order to test this possibility, biological fate is assessed of dietary mutagens associated with heat-processing of lipids, by means of comparing intake with excretion in urine and faeces. Increased faecal mutagenicity has been shown to be associated with highfat and low-fiber consumption, and is considered a risk factor for colon cancer (Schiffman, 1988). Therefore, effects on faecal mutagenicity of consumption of multagens related to heat-processing of dietary fat appears to be of special relevance with respect to evaluation of a possible role in colon carcinogenesis. This requires good control of consumption of other diet-related mutagens, which may not always be possible in a human diet study. For this reason, evaluation of faecal and urine mutagenicity after consumption of fat-related dietary mutagens has been carried out in both humans and rats, and is presented in Chapters 6,7 and 8 .

Furthermore, biological effects of short-term consumption of heatprocessed deep-frying oils in rats will be examined in relation to lipid oxidation products, and to the occurrence of mutagens in the oils. Toxic effects, as well as effects on cell proliferation in the gastro-intestinal tract, which are considered to be a marker of tumor-enhancing effects, will be analyzed and are reported in Chapter 8 . Finally, in the general discussion presented in Chapter 9 , the data obtained in various studies will be used to evaluate the possible role of heat-processed fats in colon carcinogenesis. 


\section{References}

Aeschbacher H.U. and Ruch E. (1989). Effect of heterocyclic amines and beef extract on chromosome aberrations and sister chromatid exchanges in cultured human lymphocytes. Carcinogenesis 10, 429-433.

Alexander J.C. (1981). Chemical and biological properties related to toxicity of heated fats. لال Toxic. Environ. Heatth 7, 125-138.

Alexander J.C., Valli V.E. and Chanin B.E. (1987). Biological observations from feeding heated corn oil and heated peanut oil to rats. J.Toxic. Environ. Health 21, 295-309.

Alink G.M., Knize M.G., Shen N.H., Hesse S.P. and Felton J.S. (1988). Mutagenicity of food pellets from human diets in The Netherlands. Mutation Res. 206, 387-393.

Alink G.M., Kuiper H.A., Beems R.B. and Koeman J.H. (1989). A study on the carcinogenicity of human diets in rats: the infuence of heating and the addition of wegetables and fruit. Food Chem. Toxic. 27, 427-436.

Ames B.N. (1983). Dietary carcinogens and anticarcinogens. Oxygen radicals and degenerative diseases. Science 221, 1256-1264.

Andia A.M. and Street J.L. (1975). Dietary production of hepatic microsomal enzymes by thermally oxidized fats. J. Agric. Food Chem. 23, 173-1177.

Anonymous (1973). IARC Monographs on the evaluation of the carcinogenic risk of chemicals to humans. Volume $3,91-136$.

Anonymous (1983). IARC monographs on the evaluation of the carcinogenic risk of chemicals to humans. Volume $32,33-68$.

Anonymous (1984). Criteria for evidence of chemical carcinogenicity. Interdisciplinary panel on carcinogenicity. Science $225,682-687$.

Anonymous (1985a). IARC monographs on the evaluation of the carcinogenic risk of chemicals to humans. Volume $35,163-180$.

Anonymous (1985b). Factoren in de voeding en het ontstaan van kanker. Voedingsrazd. Commissie Voeding en Kanker, Den Haag. (in Dutch; summary in English)

Anonymous (1986). IARC monographs on the evaluation of the carcinogenic risk of chemicals to humans. Volume $40,223-228$.

Anonymous (1988a). De beoordeling van de carcinogeniteit van chemisctie stoftem 11. Gezondheidsraad, Den Haag. (in Dutch; summary in English)

Anonymous (1988b). Wat eet Nederland. Resultaten van een voedselconsumptiepeiling 1987-1988. Ministerie van Welzijn, Volksgezondheid en Cultuur en Ministerie van Landbouw en Visserij. (in Dutch; summary in English).

Apaja M. (1980). Evaluation of toxicity and carcinogenicity of malonaldehyde. Anat. Path Microbiol. 89, 1-61.

Archer V.E. (1988). Cooking methods, carcinogens, and diet-cancer studies. Nutr. Cancer $11,75-79$.

Artett C.F. and Cole J. (1988). The role of mammalian cell mutation assays in mutagenicity and carcinogenicity testing. Mutagenesis $3,455-458$.

Armstrong B. and Doll R. (1975). Environmental factors and cancer incidence and mortality in different countries with special reference to dietary practices. Im. J. Cancer 15, 617-631.

Barrett J.C., Oshimura M., Tsutsui T. and Tanaka N. (1988). Mutation and neoplastic transformation. Correlations and dissociations. Ann. N.Y. Acad. Sci. 534, 95-98. 
Bascoul J., Domergue N. Olle M. and Crastes de Paulet A. (1986). Autoxidation of cholesterol in tallows heated under deep-frying conditions: evaluation of oxysterols by GLC and TLC-FID. Lipids 21, 383-387.

Basu A. and Marnetl L.J. (1983). Unequivocal demonstration that malonaldehyde is a mutagen. Carcinogenesils 3, 331-333.

Bergan J.G. and Draper H.H. (1971), Absorption and metabolism of $1-14 \mathrm{C}$-methyl linoleate hydroperoxide. Lipids 5, 976-982.

Billek G. (1979). Heated oils - chemistry and nutritional aspects. Nutr. Metab. 24 (Suppl.1), 200-210.

Bird R.P. (1986). Effect of dietary components on the pathobiology of colonic epithelium: possible relationship with tumorigenesis. Lipids 21, 289-291.

Bird R.P. and Bruce W.R. (1984). Damaging effect of dietary components to colon epithelial cells in vivo: effect of mutagenic heterocyclic amines. J. Natl. Cancer Inst. 73, 237-240.

Bird R.P., Draper H.H and Valli V.E.D. (1982). Toxicological evaluation of malonaldehyde: a 12-month study in mice. J. Toxicol. Environm. Health 10, 897-905.

Brambilla G., Sciabá L., Faggin P. Maura A., Marinari U.M., Ferro M. and Esterbauer H. (1986). Cylotoxicity, DNA fragmentation and sister-chromatid exchange in Chinese hamster ovary cells exposed to the lipid peroxidation product 4-hydroxynonenal and homologous aldehydes. Mutation Res. 171, 169-176.

Bruce W.R. (1987). Recent hypotheses for the origin of colon cancer. Cancer Res. 47, 42374242 .

Bull A.W., Nigro N.D., Golembieski W.A., Crissman J.D. and Marnett L.J. (1984). In vivo stimulation of DNA synthesis and induction of ornithine decarboxylase in rat colon by fatty acid hydroperoxides, autioxidation products of unsaturated fatty acids. Cancer Res. 44 4924-4928.

Bull A.W., Nigro N.D. and Marnett L.ل. (1988). Structural requirements for stimulation of colonic cell proliferation by oxidized fatty acids. Cancer Res. 48, 1771-1776.

Byers T. (1988). Diet and cancer. Any progress in the interim? Cancer 62, 1713-1724.

Cajelli $E_{n,}$ Ferraris A. and Brambilla $G$. (1984): Mutagenicity of 4-hydroxynonenal in V79 Chinese thamster cells. Mutation Res. 190, 169-171,

Caroll K.K. (1987). Summation: which fathow much fat - animals. Prev. Med. 16, 510-515.

Chan R.I.M., Stich H.F., Rosin M.P. and Powrie W.D. (1982). Antimutagenic activity of browning reaction products. Cancer Lett. 15, 27-33.

Chang S.S., Peterson R.J. and Ho L.T. (1978). Chemical reactions involved in the deep fat frying of foods. J. Am. Oil Chem. Soc. 55, 718-727.

Couch D.B., Stuart E. and Heddle J.A. (1987). Effect of oral administration of mutagens found in food on the frequency of sister chromatid exchanges in the colonic epithelium of mice. Environ. Mol. Mutagen. 10, 205-200.

Cutler M.G. and Schneider R. (1973). Malformations in mice and rats caused by oxidized linoleate. Food Cosmet. Toxicol. 11, 935-942.

De la Iglesia F.A., Lake R.S and Fitzgerald J.A. (1980). Short-term tests for mutagenesis and carcinogenesis in drug toxicology: how to test and when to test is the question. Drug Metab. Fiev. 11"103-146.

Dolara P. and Bianchini F. (1987). Genotoxicity studies of cooked food. In: Nutritional and

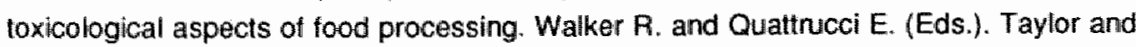


Francis, London, pp. 125-137.

Dollara P., Caderni G. Bianchini F. and Targarelli E. (1986). Nuclear damage of colon epithelial cells by the food carcinogen 2-amino-3-methylimidazo[4,5-f]quinoline (1Q) is modulated by dietary lipds. Mutation Res. 175, 255-258.

Dolara P., Salvadori M., Santori G. and Carderni G. (1985). Mammalian cell DNA damage by some heterocyclic food mutagens is correlated with their potency in the Ames test. Mutation Res. 144, 57-58.

Doll R. and Peto R. (1981). The causes of cancer: quantitiative estimates of avoidable risks of cancer in the United States today, New York, Oxtord University Press.

Douglas G.R., Blakey D.H. and Clayson D.B. (1988). IC.PEMC working paper no. 5. Genoloxicity tests as predictors of carcinogens: an analysis. Mutation Res: 196, 83-93.

Draper H.H. , Pollensek L., Hadley M. and McGirr L.G. (1984). Uninary malondialdehyde as an indicator of lipid peroxidation in the diet and in the tissues. Lipids $19,826-843$.

Eaton S.B. and Konner M. (1985). Paleolithic nutrition. A consideration of its nature and current implications. N. Engl. J. Med. 5, 283-289.

Eaton S.B., Konner M., Shostak M. (1988). Stone agers in the first lane: chronic degenerative diseases in evolutionary perspective. Am. J. Med. 84, 739-749.

Esterbauer H. (1982). Aldehydic products of lipid peroxidation. In: McBrien D.L.H. and Slater T.F. (Eds.). Free radicals, lipid peroxidation and cancer. Academic Press , Landon, pp $101-128$.

Farber E. (1987). Possible etiologic mechanisms in chemical carcinogenesis. Environ. Health Perspect. $75,65=70$.

Felton J.S., Bjeldanes L.F. and Hatch F.T. (1984). Isolation and characterization of mew mutagens from fried ground beef. Carcinogenesis 5, 95-102.

Fellon J.S., Knize M.G. Shen N.H., Lewis P.F., Andresen B.D., Happe J. and Haich F.T. (1986). The isolation and identification of a new mutagen from fried ground beef: 2 amino-1-methyl-6-phenyl-imidazo[4,5-b]pyridine (PhIP). Carcinogenesis 7, 1081-1086.

Frankel E.N. (1984). Lipid oxidation: mechanisms, products and biological significance. J. Am. Oil Chem. Soc. 61, 1908-1916.

Frankel E.N. (1987). Secondary products of lipid oxidation. Chem. Phys. Lipids 44, 73-85.

Frankel E.N. (1989). The antioxidant and nutritional effects of tocopherols, ascorbic acid and beta-carotene in relation to processing of edible oils. In: Nutritional impacts of lood processing. Somogyi J.C. and Müller H.R. (Eds.), Bibl. Nutr, Dieta, Basel, Karger, No. 43. 297-312.

Fong L.Y.Y., Ton C.C.T. and Koonaunwatchaidet P. (1980). Mutagenicity of peanut oils and effect of repeated cooking. Food Cosmet.Toxic. $18,467-470$.

Fox M. (1988). The case ofr retention of mammalian cell mutagenicity assays. Mutagenesis 3 . 459-461.

Fretheim K. (1983). Polycyclic aromatic hydrocarbons in grilled meat products - a review. Food Chem. 10, 129-139

Fuji, K., Nomoto K., Ishidate M. and Nakamura K. (1987) Chronic toxicity of charred fish meat in Wistar rats. Nutr. Cancer 9, 185-193.

Furihata C. and Matsushima T. (1986). Mutagens and carcinogens in foods. Ann. Rev. Nutr. 6, $67-94$.

Goldin B.R. (1986). The metabolism of the intestinal microflora and its relationship to dietary 
fat, colon and breast cancer. In: Dietary fat and cancer. Alan R. Liss, Inc. New York, pp. 665-685.

Gurr M.I. (1988). Lipids: products of industrial hydrogenation, oxidation and heatting. In: Nutritional and toxicological aspects of food processing: Walker $A$. and Quattrucci $E$. (Eds). Taylor and Francis; London, 139-155.

Gutteridge J.M.C. (1982). Free-radical damage to lipids, amino acids, carbohydrates and nucleic acids determined by thiobarbituric acid reactivity. Int. J. Biochem. 14, 649-653.

Ha Y.L., Grimm N.K. and Pariza M.W. (1987). Anticarcinogens from fried ground beet: heataltered derivates of linoleic acid. Carcinogenesis $B, 1881-1887$.

Halliwell B. and Gutteridge J.M.C. (1984). Oxygen toxicity, oxygen radicals, transition metals and disease: Biochem. J. 219, 1-14.

Hartman P.E. (1983). Review: putalive mutagens and carcinogens in foods. IV. Malonaldehycle (malondialdehyde). Environ. Mutagen. 5, 603-607.

Hatch F.F. and Felton J.S. (1986). Toxicologic strategy for mutagens formed in foods during cooking: status and needs. In: Genetic toxicology of the diet, Knudsen I. (Ed), Alan R. Liss, linc., New York, 109-131.

Hayatsu H. Arimoto S. and Negishl T. (1988). Dietary inhibitors off mulagenesis and carcinogenesis. Mutation Res. 202, 429-446.

Hayatsu $H_{\text {, }}$ Hayatsu T., Wataya $Y$. and Mower H.F. (1985). Fecal mutagenicity arising from ingestion of fried ground beef in the human. Mutation Res. 142, 207-211.

Hicks R.M. (1983). Pathological and biochemical aspects of tumour promotion. Carcinogenesis 4, 1209-1214.

Hill M.J. (1987). Dietary fat and human cancer (review). Anticancer Res. 7, 281-292.

Izaki Y., Yoshikawa S. and Uchiyama M. (1984). Effect of ingestion of thermally oxidized frying oil on peroxidative criteria in rats. Lipids 19, 324-331.

Jacobson E.A., Newmark H.L., Bird R.P. and Bruce W.R. (1983). Increased excretion of malonaldehyde equivalents in the urine after consumption of cooked, stored meats. Nutr. Rep. Int. 28, 509-517.

Jägerslad M., Grivas S., Olsson K., Laser Reuterswärd A., Negishi C. and Sato S. (1986). Formation of food mutagens via Maillard reactions. In: Genetic toxicology of the diet, Knudsen I. (Ed.), Alan R. Liss, Inc. Nlew York, 155-167.

Kanazawa K., Ashida H. Minamoto S. and Natake M. (1986). The effect of orally administered secondary products of linoleic acid on the activity of detoxifying enzymes in the rat liver. Biochim. Biophys. Acta 879, 36-43.

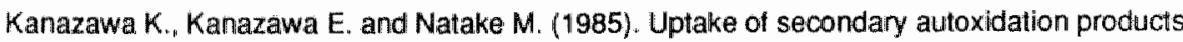
of linoleic acid by the rat. Lipids $20,412-419$.

Kato T., Migita H., Oghaki H., Sato S., Takayama S. and Sugimura T. (1989). Induction of fumors in the Zymbal gland, oral cavily, colon, skin and mammary gland of F344 rats by a mutagenic compound, 2-amino-3, 4-dimethylimidazo [4,5-f]quinoline. Carcinogenesis 10, $601-603$.

Kelsey M.I. and Pienta R.J. (1979). Transformation of hamster embyro celis by cholesterol-aepoxide and litocholic acid. Cancer Lett. 6, 143-149.

Keuning R. and Beek W.J. (1985). Towards healthful diets: The role of the food industry. In: Proc. Wth Eur. Nutr. Conf., Amsterdam 1983., Van den Berg ef al. (Eds.), Voorlichtingsbureau voor de Voeding, Den Haag, p. 51. 
Knize M.G. Andresen B.O., Healy S.K, Shen N.H., Lewis P.R., Bjeldanes LF., Hatch F.T., and Felton J.S. (1985). Effects of temperature, patty thickness and fat content on the production of mutagens in fried ground beef. Food Chem. Toxic. 23, 1035-1040.

Kroes R. (1987). Contribution of toxicology towards risk assessment of carcinogens. Arch. Toxicol. $60,224-228$.

Kuratsone M., Ikeda M. and Takaharu H. (1986). Epidemiology studies on possible health effects of intake of pyrolyzates of foods, with reference to mortality among Japanese Seventh-day Adventists. Environ. Health Perspect. 67, 143-146.

Kurechi T., Kikuglawa K. and Ozawa M. (1980). Effect of malonaldehyde on nitrosamine formation. Food Cosmet. Toxic. 18, 119-122.

Land H. Parada L. and Weinberg R.A. (1983). Cellular oncogenes and multistep carcinogenesis. Science 222, 771-778.

Larsen J.C. and Paulsen E. (1987). Mutagens and carcinogens in heat-processed food. In: Toxicological aspects of food. Miller K. (Ed.). Elsevier Applied Science, London, 205 252 .

Lyon J.L. and Mahoney A.W. (1988). Fried foods and the risk of colon cancer. Am. J. Epidemiol. 128, 1000-1006.

MacGregor J.T., Wilson R.E., Neft W.E. and Frankel E.N. (1985). Mutagenicity tests of lipid oxidation products in Salmonella typhimurium: monohydroperoxides and secondary oxidation products of methyll linoleate and methyl linolenate. Food Chem. Toxic. 23, 1041-1047.

Marnett L.J., Hurd H.K., Hollstein M.C., Levin D.E., Esterbauer H. and Ames B.N. (1985). Naturally occuring carbonyl compounds are mutagens in Salmonella tester strain TA104. Mutation Res. 148, 25-34.

Mauron J. (1989). Effects of processed food on food consumption patterns in industrial countries. In: Nutritional impact of food processing, Somogyi J.C. and Muller H.R. (Eds.). Bibl. Nutr. Dieta, Basel, Karger, No. 43, 107-124.

McManus M.E., Burgess W., Stupans I., Trainor K.J., Fenech M., Robson R.A., Morley A.A. and Snyderwine E.G. (1988). Activation of the lood-derived mutagen 2-amino-3methylimidazo[4,5-1]- quinoline by human-liver microsomes. Mutation Res. 204, 185-193.

Minkier J.L. and Carrano A.V. (1984). In vivo cytogenetic effects of the cooked-food-related mutagen Trp. P-2 and $1 Q$ in mouse bone marrow. Mutation Res. 140,49-53.

Mukal F.H. and Goldstein B.D. (1976). Mutagenicity of malonaldehyde, a decomposition product of peroxidized polyunsaturated fatty acids. Science 191, 868-869.

Nair P.P. (1988). Role of bile acids and neutral sterols in carcinogenesis. Am. J. Clin. Nutr. 48. $768-774$.

Nakayama T., Kaneko M. and Kodama M. (1986). Delection of DNA damage in cultured human fibroblasts induced by methyl linoleatle hydroperoxide. Agric. Biol. Chem. 50, 261-262.

Nakayasu M., Nakasato F., Sakamoto H., Terada M. and Sugimura T. (1983). Mutagenic activity of heterocyclic amines in Chinese hamster lung cells with diphteria toxin resistance as a marker. Mutation Res. 118, 91-102.

Negishi L., Yamazumi $Z$, and Sato S. (1989). Nucleic acid binding and mutagenicity of active metabolites of 2-amino-3,8-dimethylimidazol 4,5-f]quinoxaline. Mutation Res. 210, 127. 134. 
Nilsson L.E, Overvik L., Fredhoim L. Levin O., Nord C.E. and Gustafsson J.A. (1986). Influence of frying fat on mulagenicity in lean pork meat. Mutation Res. 171, 115-121.

Nishi $Y$, Miyakawa $Y$. and Kato K. (1989). Chromosome aberrations induced by pyrolysates of carbohydrates in Chinese hamster V79 cells. Mutation Fies. 227, 117-123.

Darada M., Miyazawa T. and Kaneda T. (1986). Distribution of ${ }^{14} \mathrm{C}$ after oral administration of (U-14 C) labeled methyl linoleate hydroperoxides and their secondary axidation products in rats. Lipids $21,150-154$.

O'Brien J: and Morrissey P.A. (1989). Nutritional and toxicological aspects of the Maillard browning reaction in foods. CAC Crit. Rev. Food. Sci. Nutr. 28, 211-249.

Pariza M.W., Ashoor S.H. Chu F.S. and Lund D.B. (1979). Effects of temperature and time on mutagen formation in pan-firied hamburger. Cancer Lett. 7, 63-69.

Pariza, M.W. (1988). Dietary fat and cancer risk: Evidence and research needs. Ann. Rev. Nutr. 8, 167-183.

Passmore $\mathbb{R}$. and Eastwoad M.A. (1986). Davidson and Passmore Human Nutrition and Dietetics, Eighth Edition. Churchill Livingstone, New York.

Perciballi M. and Pintauro R. (1985). The effects of fractionated thermally oxidized corn oil on drug-metabolizing enzyme systems in the rat. Food Chem Toxic. 23, 737-740.

Peters R.K., Garabrant D.H., Yu M.C. and Mack T.M. (1989). A case-control study of occupational and dietary factors in colorectal cancer in young men by subsite. Cancer Res. $49,5459-5468$

Piche L.A., Cole P.D., Hadley M. van den Berg R. and Draper H.H. (1988). Identification of Ne-(2-propenal)lysine as the main form of malonaldehyde in food digesta. Carcinogenesis 9, 473-477.

Pitot H.C. (1990). Mechanisms of chemical carcinogenesis: Theoreticall and experimental bases. In:Chemical carcinogenesis and mutagenesis I. Cooper C.S. and Grover P.L. (Eds.), Springer-Verlag, Berlin Heidellberg, pp.3-29.

Phillips D.H. (1983). Fitty years of benzo(a)pyrene. Nature 303, 468-472.

Phillips R.L., Gartinkel L., Kuzawa J.W., Beeson W.L., Latz T. and Brin B. (1980). Mortality among Severth-Day Adventists for selected cancer sites. J. Natl. Cancer Inst. 65, 1097 1107.

Powrie W.D., Wu C.H. and Molmud P. (1986). Browning reaction systems as sources of mutagens and anti-mutagens. Environ. Health Perspect. 67, 47-54.

Quattrucci $E$. (1988). Heat treatments and nutritional significance of maillard reaction products. In: Nutritional and toxicological aspects of food processing. Walker $\mathrm{R}$. and Quattrucci E. (Eds.) Taylor and Francis, London, 113-124.

Reddy B.S. (1987). Dietary fat and colon cancer. Animal models. Prev. Med. 16, 460-467.

Rogers A.E. and Longnecker M.P. (1988). Biology of disease. Dietary and nutritional influences on cancer. A review of epidemiologic and experimental data. Lab. Invest. 59 , $729-759$.

R.ose D.P., Eoyan A.P. and Wynder E.L. (1986). International comparisons of mortality rates for cancer of the breast, ovary, prostate and colon, and per capita food consumption. Cancer 58 ,2363-2371.

Sager R. (1986). Genetic suppression of tumor formation: A new frontier in cancer research Cancer Pes. 46, 1573-1580.

Sakaguchi M., Minoura T. Hiramatsu Y., Takada H. and Yamamura M. (1986). Effects of dietary 
saturated and unsaturated fatty acids on fecal bille acids and colon carcinogenesis induced by azoxymethane in rats. Cancer Res. 46,61-65.

Scheutwinkel-Reich M. Ingerowski G. and Stan H.-J. (1980). Microbiological studies investigating mutagenicity of deep frying fat fractions and some of their components Lipids $15,849-852$.

Schiffman M.H. (1986). Epidemialogy of fecal mutagenicity. Epidemiol . Rev. 8, 92-105.

Schut H.A.J., Putman K.L. and Randerath K.(1988). DNA adduct formation of the carcinogen 1-amino-3-methyl-imidazo[4,5,-f]quinoline in target lissues of the F-344 rat. Cancer Lelt. $41,345-352$.

Sebedio J.L., Prevost $\downarrow$. and Grandgirard A. (1987). Heat treatment of vegetable oills. 1. Isolation of cyclic fatty acid mononers from heated sunflower and linseed oils. J. Am. Oill Chem. Soc. 64, 1026-1032.

Shamberger F.J., Shamberger B.A. and Willis C. E. (1977). Matonaldehyde content of food. J. Nutr. 107, 1404-1407.

Siess M.H., Vernevault M.F., Grangirard A. and Sebedio J.L. (1988). Induction of hepatic drug-metabolizing enzymes by cyclic fatty acid inmonomers in the rat. Food Chem. Toxic. $26,9-13$.

Siu G.M. and Draper H.H. (1978). A survey of the malonaldehyde content of retail meats and fish. J. Food Sci. 43, 1147-1149.

Siu G.M., Draper H.H. and Valli V.E.O. (1983). Oral toxicity of malondialdehyde: a 90-day study in mice. J. Toxicol. Environ. Health 11, 105-119.

Smith L.L., Smart V.B. and Made Gowda N.M. (1986). Mutagenic steroll hydroperoxides. Mutation Res. 161, 39-48.

Smith L.L., and Johnson B.H. (1989). Biological activities of oxysterols. Free Radical Biol. Med. 7, 285-332.

Snyderwine E.G., Wirth P.J., Holler P.P., Adamson R.H., Sato S. and Thorgeirsson S.S. (1988). Mutagenicity and in vitro covalent DNA binding of 2-hydroxyamino-3methylimidazo[4,5-f]quinoline. Carcinogenesis 9, 411-418.

Springarn N.E. and Garvie C.T. (1979). Formation of mutagens in sugar ammonia model systems. J. Agric. Food Chem. 27, 1319-1321.

Springarn N.E., Garvie-Gould C., Vuolo L. and Weisburger J.H. (1981). Formation of mutagens in cooked toods. IV. Effect of flat content in fried beef patties. Cancer Lelt. 12, 93-97.

Stermmerman G.N., Nomura A.M.Y. and Heilbrun L.K. (198.4). Dietary flat and the risk of colorectal cancer. Cancer Res. 44, 4633-4637.

Stevenson S.G. Vaisey-Genser M. and Eskin N.A.M. (1984). Quality control in the use of deep frying oils. J. Am. Oil Chem. Soc. 61, 1102-1108.

Stowers, S.d., Maronpot R.R., Reynolds S.H. and Anderson M.W. (1987). The role of oncogenes in chemical carcinogenesis. Environ. Health Perspect. 75, 81-86.

Sugimura T. (1985). Carcinogenicity of mutagenic heterocyclic amines formed during the cooking process. Mutation Res. 150, 33-41.

Sugimura T. (1986) Past, present, and future of mutagens in caoked foods., Environ. Health Persp. 67, 5-10.

Sugimura T., Nagao M., Kawachi T., Honda M., Yahagi T. Ueno Y., Sato S., Matsumura N.. Matsushima T., Shirai A., Sawamura A. and Matsumoto H. (1977). Mutagen-carcinogens 
in food, with special reference to highly mulagenic pyrolytic products in broiled foods. In: Hiatt H.H., Watson J.D., Winsten J.A. (Eds.). Origins of Human Cancer, book C, Cold Spring Harbor. New Tork "pp. 1581-1576.

Sugimura T., Sato $S$. Oghaki H., Takayama $S$., Nagao M. and Wakabayashi $K$ (1986). Owerview: mutagens and carcinogens in cooked food. In: Genetic toxicology of the diet, Knudsen I (Ed.), Alan R. Liss, New York, 81-107.

Suzuki K., Bruce W.R., Baptista J., Furrer F., Vaughan D.J. and Krepinsky J.J. (1986). Characterization of cytotoxic steroids in human faeces and their putative role in the etiology of human colonic cancer. Cancer Lett. 33, 307-316.

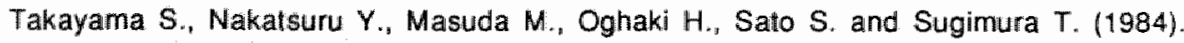
Demonstration of carcinogenicity in F344 rats of 2-amino-3-methyl-imidazo[4 ${ }_{2}$ flquinoline in rats. Jpn. J. Cancer Res. (Gann) 76, 570-576.

Taylor S.L., Berg C.M., Shoptaugh N.H. and Scott V.N. (1982). Lack of mutagens in deep-fatfried loods obtained at the retail tevel. Food Chem. Toxic. 20, 209-212.

Taylor S.L., Berg C.M. Shoptaugh N.H. and Traisman E. (1983). Mutagen formation in deepfat fried foods as a function of frying conditions. J. Am. Oil. Chem. Soc. 60, 576-580.

Thompson L.U. and Aust R. (1983). Lipid changes in French fries and heated oils during commercial deep frying and their nutritional and toxicological implications. Can. Inst. Food Scii. Technol. J., 16, 246-253.

Tennant R.W., Margolin B.H., Shelby M.D., Zeiger E., Haseman J.K., Spalding J., Caspany W., Resnick M., Stasiewisz S., Anderson B. and Minor R. (1987). Prediction of chemical carcinogenicity in rodents from in vitro genetic toxicity assays. Science 236, 933-941.

Tucker J.D., Carrano V., Allen N.A., Christensen M.L., Knize M.G. Strout C.L. and Felton J.S. (1989). In vivo cytogenetic effects of cooked food mutagens. Mutation Res. 224, 105113.

Tudek B., Bird R.P. and Bruce W.R. (1989). Foci of aberrant crypls in the colons of mice and rats exposed to carcinogens associated with foods. Cancer Res. 49, 1236-1240.

Vaca L.E., Wilhelm J. and Harms-Ringdahl M. (1988). Interaction of lipid peroxidation products wilh DNA A foview. Mutation Res. 195, 137-149.

Van Gastel A., Mathur R., Roy V.V. and Rukmini C. (1984). Ames mutagenicily tests of repeatedly healed edible oils. Food Chem. Toxic. 22, 403-405.

Vithayathil A.J., Strasik M. and Strasik L. (1983). Heat-induced mutagen formation from creatine and fat-soluble constituents of loods. Mutation Res. 121, 167-170.

Wargovich M.J., Goldberg M.T., Newmark H.L. and Bruce W.R. (1983). Nuclear aberrations as a short-term test for genotoxicity to the colon: evaluation of nineteen agents in mice. J. Natl. Cancer Inst. $71,133-137$.

Weiberg R.A. (1989). Oncogenes, antioncogenes, and the molecular bases of multistep carcinogenesis. Cancer Res., 49, 3713i3721.

Weinste in I.B. (1988). The origins of human cancer: molecular mechanisms of carcinogenesis and their implications for cancer prevention and treatment. Cancer Res. 48, 4135-4143.

Weisburger J.H., Barnes W.S. and Czemiak R. (1986). Mutagens and carcinogens in food. In: Diet, nutrition, and cancer: a critical evaluation. Vol. II. Micronutrients, nonnutritive dietary factors, and cancer. Reddy B.S. and Cohen L.A. (Eds.) CRC Press Inc., Boca Raton, Florida, pp.116-129.

Weitberg A.B. and Convese D. (1989). Hydroxy-and hydroperoxy-6,8,11,14-eicosatetraenoic acids induce DNA strand breaks in human lymphocytes. Carcinogenesis 10, 1029-1031. 
Wild D., Gocke E., Harnasch D., Kaiser G. and King M.T. (1985). Differential mutagenic activity of IQ in Salmonella typhimurium strains in vitro and in vivo, in Drosophila and in mice. Mutation Res. 156, 93-102.

Willet W. (1989). The search for the causes of breast and colon cancer. Nature $338,389-394$. Williams G.M. (1989). Methods for evaluating chemical genotoxicity. Annu. Rev. Pharmacol. Toxicol. 29, 189-211.

Yamaguchi T. and Yamashita $Y$, (1979). Mutagenic activity of autoxidized linoleic and linolenic: acid. Agric. Bioll. Chem. 43, 2225-2226.

Yamaguchi $T$. and Yamashita Y. (1980). Mutagenicity of hydroperoxides of fatty acids and some hydrocarbons. Agric. Biol. Chem, 44, 1675-1678.

Yashida D. and Okamoto H. (1980). Formation of mutagens by heating creatine or amino acids with addition or fatty acids. Agric. Biol. Chem. 44, 3025-3027.

Young T.B. and Wolf D.A. (1988). Case-control study of proximal and distal colon cancer and diet in Wisconsin. Int. J. Cancer 42, 167-175.

Zeiger E. (1987). Carcinogenicity of mutagens: predictive capability of the Salmonella mutagenicity assay for rodent carcinogenicity. Cancer Res. 47, 1287-1296. 


\title{
Chapter 2
}

\section{Detection of 6-thioguanine-resistant human peripheral blood lymphocytes using 5-bromodeoxyuridine labeling in combination with immunocytochemical staining: Application for in vivo and in vitro HGPRT-assay ${ }^{\prime}$}

\author{
G. Hageman, I. Welle and J. Klleinjans
}

\begin{abstract}
Resistance to 6-thioguanine (TG) is considered to originate from single gene mutations at the hypoxanthine guanine phosphoribosyltransferase (hgprt) locus. Screening of TGresistant (TG') human peripheral lymphocytes may thus provide a means for determination of genetic damage occurring in a population exposed to genotoxic chemicals or radiation. The currently applied clonal assays however, pose substantial technicall problems, and for application of the short-term autoradiography assays special facilities are required. Therefore a modified procedure was developed for the detection of $\mathrm{TG}^{r}$ human peripheral blood lymphocytes, using 5-bromodeoxyuridine (BrdU)-labeling in combination with immunocytochemical staining and whole blood culturing. The procedure was evaluated for its applicability in vivo using blood abtained from two healthy donors. After correction for the effects of spontaneously cycling lymphocytes (phenocopies) by means of cold storage of the blood for $24 \mathrm{~h}$ at $4{ }^{\circ} \mathrm{C}$, variant frequencies (VI's) of $2.7 \cdot 10^{-5}$ (donor V) and $3.4 \cdot 10^{-6}$ (donor II) were found, which were in the normal range reported in the literature.
\end{abstract}

Determination of induction of TG" T-lymphocytes may provide a test system for in vitro screening of potential mutagenic compounds, using human cells that are readily availaballe, easily cultured and allow human genotoxic risk estimation without problems of interspecies extrapolation due to differences in DNA repair capacities. Its applicability was validalted using the chemical mutagens ethyl methane sulphonate (EMS), N-ethyl-N-nitrosurea (ENU) and mitomycin $C$ (MMC), which were tested in 2 separate assays performed within a twowerek period using blood from the same donor. Dose-response effects were observed for ENU and $M M C$, although at considerable inter-assay variability.

It is concluded that the presented modified procedure for determination of $\mathrm{TG}^{\mathrm{r}} \mathrm{T}$ lymphocytes provides a simple, quick and widely applicable method for measurement of primary effects of genotoxic agents in wivo in man. In combination with other short-term genotoxicity assays, the in vitro HGPRT-assay using human lymphocytes may be useful for the assessment the genotoxic potential of xenobiotics.

1 based on a manuscript submitted for publication 


\section{Introduction}

Mutational lesions in mammalian DNA in both in witro and in wivo assays are usually determined to assess genotoxic properties of chemical and physical agents. Extrapolation of data obtained with non-human cells to human genotoxic risk however, may pose problems which are related to interspecies differences in cellular metabolism and DNA repair capacities (Fox, 1988; Fox and Roberts, 1987). Use of human cells is therefore preferred, for instance mitogen-stimulated lymphocytes (Kilby et al., 1984). Resistance to 6-thioguanine (6-TG) of human peripheral blood lymphocytes has been demonstrated to arise from somatic gene mutations at the hypoxanthine guanine phosphoribosyltransterase (hgprt) locus, and is used as a parameter in human mutagenicity monitoring (Albertini et al., 1985; Dempsey and Morley, 1983; Turner et al., 1985).

Generally, two assays have been developed to detect TG-resistant (TGr) lymphocytes, a short-term autoradiography assay and a clonal assay (Albertini et al., 1987; Morley et al., 1982). The latter method appears to be preferential for monitoring of mutational lesions derived in vivo and for elucidation of mutational mechanisms in vitro, since it allows for verification of HGPRT deficiency, selection of mutant colonies and determination of hgprt structural gene alterations at a molecular level (Albertini, 1985; Nicklas et al., 1987). However, the clonal assay requires long culturing periods and appears to pose substantial technical problems, resulting in poor cloning efficiency (Morley et al., 1985). The autoradiography assay may be used as an indication of elevated mutant frequencies, but since it does not allow verification of the nature of mutant cells or elucidation of mutational lesions. The autoradiography assay however, is less laborious as compared to the clonal assay, and better applicable for initial screening of large groups (Albertini ot al. 1987).

The use of bromodeoxyuridine (BrdU) which has been demonstrated to present a feasible alternative for tritiated thymidine, has made the hgprt somatic mutation assay available to any cytogenetic laboratory (OstroskyWegman et al., 1987). However, serious problems were encountered in our laboratory when BrdU-incorporation was used in combination with the fluorescence-plus-Giemsa method, as described by these authors. These are caused mainly by poor discrimination between nuclei which actually had incorporated BrdU and nuclei of non-proliferating cells. Therefore, the feasibility of an immunocytochemical staining method using mouse monocional antibodies against BrdU (Grazner, 1982), in combination with a peroxidase-conjugated secondary antibody, was tested. In addition, the HGPRT-assay was modified with respect to culturing of T-lymphocytes; instead of isolation of lymphocytes by gradient centrifugation prior to culturing (Albertini et al., 1985; Morley et al., 1985), whole blood was 
cultured corresponding to methods used in standard cytogenetic assays, which reduced the amount of blood required and resulted in a simple and quick procedure.

For in vitro mutagenicity testing human lymphocytes may provide an adequate tool, since these have been succesfully applied for in vitro determination of chromosomal damage, and are readily available and easily cultured. The applicability of the modified procedure as an in vitro assay for detection of genotoxic properties of chemical mutagens to human DNA, was therefore also evaluated.

\section{Materials and methods}

\section{Determination of in wivo variant frequency (Vf)}

In all experiments, blood samples $(10 \mathrm{ml})$ were collected from healthy, non-smoking volunteers, 1 male with a limited smoking history (donor 1 ) aged 34, and 1 female (donor 11 ). aged 29. Blood was drawn by venipuncture in heparinized tubes. Blood samples were kepl at room temperature for 3 to $4 \mathrm{~h}$, since we found that short-term storage of blood samples at room temperature yielded higher labeling indices as compared to culturing of fresh blood samples. Since separation of lymphacytes prior to culturing resulted in loss of large numbers of lymphocytes during harvesting of the cultures, whole blood culturing was applied to obtain sufficient numbers of cells and reduce the amount of blood required. Determination of in vivo derived $\mathrm{TG}^{\mathrm{r}}$ lymphocytes may be confounded by the presence of phenocopies resulting in 10-fold higher frequencies, and was demonstrated to be eliminated by cryopreservation or cold storage (Albertini and Sylwester, 1984). In separate sets of experiments therefore, the effects of cold storage on observed VI's, as well as the $V f$ of spontaneously cycling lymphocytes were determined. Effects of prolonged incubation with BrdU in order to increase the number of positive celis to obtain a more accurate assessment of the $V t$, were also evaluated.

The definitive protocol for determination of the in vivo mutant T-lymphocytes was as follows: Whole blood was diluted $(1: 10$, w/w) in RPMI 1640 medium (Gibco Europe, The Netherlands) without supplements, and kept at $4^{\circ} \mathrm{C}$ for at least $24 \mathrm{~h}$ in order to eliminate the effects of phenocopies, caused by BrdU incorporation in cells which are spontaneously cycling and not sensitive to 6-TG at the particular moment of labeling (Albertini and Sylwester, 1984). After cold storage, cells were collected by centrifugation and resuspended at a density equal to $0.4 \mathrm{ml}$ whole blood per $5 \mathrm{ml}$ medium, in RPMI 1640 medium supplemented with 100 $\mu \mathrm{g} / \mathrm{ml}$ streptomycin, $100 \mathrm{U} / \mathrm{ml}$ pericillin, $5 \mathrm{mM}$ L-glutamine, $50 \mathrm{U} / \mathrm{ml}$ heparin and $10 \%$ loetal calf serum (FCS) (all obtained from Gibco Europe).

Two cultures were set up to determine the control labeling index $\left(\mathrm{LI}_{\mathrm{C}}\right)$ and 4 to 8 cultures were used for TG-resistant (TGr) cell selection. To all $5 \mathrm{ml}$ cultures, $0.2 \mathrm{ml}$ phytohaem- 
agglutinin (PHA; Gibco Europe) was added; to the TGr selection cultures $0.1 \mathrm{ml}$ of a $1 * 10^{-2} \mathrm{M}$ TG stock in RPMI 1640 was added at a final concentration of $2 * 10^{-4} \mathrm{M}$. and to control cultures $0.1 \mathrm{ml}$ of FPMI 1640 adjusted to a pH equall to that of the TG stock. Cultures were incubated at $37^{\circ} \mathrm{C}$ for $24 \mathrm{~h}$, alter which $0.05 \mathrm{ml}$ of a filter-sterlized $2.5 \cdot 10^{-3} \mathrm{M}$ BrdU solution was added to a final concentration of $2.5 * 10^{-5} \mathrm{M}$. Cultures were incubated in presence of $\mathrm{BrdU}$ at $37^{\circ} \mathrm{C}$ for an additional $16 \mathrm{~h}$ period.

After a totall of 40 h of incubation, cells were harvested by centrifugation and pellets resuspended in $9 \mathrm{ml}$ hypotonic $75 \mathrm{mM} \mathrm{KCl}$ solution of $37^{\circ} \mathrm{C}$, and incubated at $37^{\circ} \mathrm{C}$ for 20 min. After centrifugation, pellets were resuspended by dropwise addition of fixative, methanol:acetic acid $(3: 1 \mathrm{v} / \mathrm{v})$, first to a volume of $2 \mathrm{mi}$. To increase density of nuclei in $T G$ cultures, at this point 2 to $4 \mathrm{TG}$ cultures were combined and the final volume was completed to $9 \mathrm{ml}$ with tixative. The control cullures were fixed by dropwise addition of $9 \mathrm{ml}$ fixative and not combined. After centrifugation, nuclei were rinsed twice with $9 \mathrm{ml}$ fixative and finally resuspended in 0.1 to $0.2 \mathrm{mll}$.

Nuclei were transferred to clean microscope slides which were pre-rinsed with ethanol; 2 drops of $10 \mu \mathrm{l}$ of the control cultures were pipetted on a slide. The complete suspension of combined TG cultures was transferred on one slide in $25 \mu$ portions, meanwhile determining the total volume of the TG culture. Thus, 2 slides were obtained from 2 to 4 originally set up 5 $\mathrm{ml} \mathrm{TG}$ test cultures, thereby maximizing the number of nuclei per TG slide. The number of nuciei on TG slides was counted in triplicate in $5 \mu$ of a 1:50 dilution in fixative.

\section{Immunocytochemical staining using monoclonal anti-BrdU}

Identification of nuclei that have incorporated BrdU, was achieved by immunochemical staining using mouse monoclonal antibodies against BrdU (Grazner, 1982), which were a gift from Dr. Bent Schutte (Department of Internal Medicine, University of Limburg, Maastricht, The Netherlands). The staining procedure was as follows: DNA was denatured by incubation of the slides in $4 \mathrm{~N} \mathrm{HCl}$ for $25 \mathrm{~min}$ at room temperature. The slides were rinsed wice with $0.1 \mathrm{~N}$ Borax buffer of pH 8.5, followed by phosphate buffered saline (PBS) of pH 7.4. After rinsing, $250 \mu \mathrm{l}$ all a solution of mouse monoclonal anti-BrdU antibodies in PBS containing $1 \%$ bovine serum albumin (PBS/BSA), were applied to the slides, which were carefully covered with a cover sllde, ensuring the ainti-BrdU layer was distributed over the whole area. The slides were incubated at $37^{\circ} \mathrm{C}$ in a humid atmosphere for $60 \mathrm{~min}$. Cover slides were carefully removed, atter which two rinsing steps with PBS followed. Next, $250 \mu$ of peroxidase-conjugated rabbit-anti-mouse immunoglobulin antibody (RAMPO, F114, Dakopatts, Denmark) solution in PBS/BSA were applied to the slides, which were covered with a cover slide and incubated, protected from light at room temperature for $60 \mathrm{~min}$. After careful removal of the cover slides, 2 rinsing steps with PBS followed. Finally, the slides were incubated in $0.05 \mathrm{M}$ Tris-KCl buffer of $\mathrm{pH} 7.6$ containing $0.04 \%$ (w/v) $3.3^{\circ}$-diaminobenzidine (Fluka Chemie, Switzerland) and $0.01 \%(w / w) H_{2} \mathrm{O}_{2}$ at room temperature in the dark for $10 \mathrm{~min}$. Slides were rinsed with destilled water and control slides were immediately counterstained by immersion in $3 \%$ Giemsa stain (BDH Chemicals, England) in $0.1 \mathrm{M}$ phosphate buffer of $\mathrm{pH} 6.8$ for $3 \mathrm{~min}$. In the first series of experiments, anti-BrdU control slides containing nuclel of PHA-stimulated cells incubated without BrdU, were also stained in order to determine non-specific anti-BrdU 
binding. Since non-specific anti-BrdU binding was not observed, these slides were included in later experiments only when new batches of anti-BrdU were used.

After staining, nuclei of non-proliferating cells appeared blue and BrdU-containing nuclei brown, and were clearly visible using normal light microscopy $(400 \mathrm{x})$. The slides of TG cultures were not immediately counterstained, but first encoded and screened for brown BraU. containing nuclei. The number of brown nuclei per slide was determined by two independent observers. Next, the TG slides were also counterstained and the number of brown nuclei per slide was contirmed by re-evaluation of the nuclei earlier identified as positive. The $\mathrm{LI}_{\mathrm{C}}$ was determined in duplicate by scoring 1000 nuclei per slide and was calculated as:

$\mathrm{L}_{\mathrm{C}}=$ number of brown nuclei per 1000 nuclei scored

1000

The labeling index of the TG culture $\left(L H_{t}\right)$ was determined as:

$L_{t}=$ number of brown nuclei an all $T G$ slides

total number of nuclei on all TG slides

The variant frequency $(\mathrm{Vf})$ of $\mathrm{TG}^{\mathrm{r}}$ mucleil (variants) was calculated as: $\mathrm{VI}=\mathrm{LI}_{\mathrm{t}} / \mathrm{LI}_{\mathrm{C}}$.

\section{Chemical induction of TGr T- Iymphocytes in vitro}

The applicability of the modified HGPRT-assay using whole blood culturing and BrdU incorporation for in witro screening of chemical mutagens was evaluated by determination of the induction of TGr T-lymphocytes by ethyl methanesulphonate (EMS), N-ethyl- $\mathrm{N}$ nitrosourea (ENU) and mitomycin C (MMC) (all mutagens obtained from Sigma Chemical Co. St Louis, Mo.). These mutagens were chosen for their known capability to induce $\mathrm{TG}^{r} \mathrm{~T}$. lymphocytes in witro in the clonal HGPRT-assay (Vijayalaxmi and Evans, 1984). Heparinized blood samples $(10 \mathrm{ml}$ ) were obtained by venipuncture from 2 healthy donors described earlier (donor I and donor II). Incubations with the chemical mutagens were set up using blood from one donor for each mutagen. Thus, EMS and MMC were tested with blood from donor II, while ENU was evaluated using blood of donor I. EMS and ENU were dissolved and diluted in destilled water and used immediately atter preparation. For MMC, which is relatively stable in medium (Vijialaxmi and Evans; 1984), FPM\| 1640 withoul supplements was used for dilution. To a sterile $10 \mathrm{ml}$ tube containing $5 \mathrm{ml}$ of RPM1 16.40 medium without supplements, $0.4 \mathrm{ml}$ of whole blood and $0.1 \mathrm{ml}$ of mutagen solution were added. Cullures were incubated at $37^{\circ} \mathrm{C}$ incubation times for EMS and MMC were $4 \mathrm{~h}$ and for ENU $30 \mathrm{~min}$, these incubation times were chosen since the biological halt-lives were reported to be $5.3 \mathrm{~h}$, many hours and $0.15 \mathrm{~h}$, respectively for EMS, MMC and ENU (Vijialaxmi and Evans, 1984). After mutagen treatment, the cells were rinsed with pre-warmed PBS of $37^{\circ} \mathrm{C}$ and resuspended in $5 \mathrm{ml}$ RPMI 1640 medium containing $0.2 \mathrm{ml} \mathrm{PHA}$. Per dose, a total of 6 cultures was set up; to 4 cultures $0.1 \mathrm{ml}$ of a $1: 10^{-3} \mathrm{M}$ TG stock and to 2 cultures $0.1 \mathrm{ml}$ of TG control medium was added. Cultures were incubated for $24 \mathrm{~h}$ at $37^{\circ} \mathrm{C}$, after which Brou was added to a final concentration of $2.5 \cdot 10^{-5} \mathrm{M}$. After an additional incubation of $16 \mathrm{~h}$ in presence of BrdU, cells were harvested, stained and evaluated as described previously for the in vivo determination of TGr $\mathrm{T}$. lymphocytes. In order to determine inter-assay variability, incubations with chemical mutagens were carried out in two separate experiments with blood obtained from the same donor, which 
were performed within a 2 week period.

\section{Statistical analyses}

Statistical evaluation of differences between Vit's was performed as described by Sylwester and Albertini (1985). VI's of different in vivo determinations and of different doses of chemical mutagens within one experiment, were compared by ratio using $95 \%$ or $99 \%$ binomial confidence interval tables (Sylwester and Abertini, 1985). Dose-response relations of chemical mutagens were evaluated using linear regression applied to non-toxic dose ranges.

\section{Results}

The effects of varying culturing conditions on the TGr T-lymphocyte frequency are presented in Table 2.1. Cold storage at $4^{\circ} \mathrm{C}$ for at least $24 \mathrm{~h}$ leads to a 2- to 6-1old decrease of the frequency of TGr T-lymphocytes, as is evident from comparion of Vf's obtained in experiments 2 and 3 with those of experiment 1. Without prior cold storage of the blood, the spontaneously cycling lymphocyte fraction contributed significantly to the Vf of donor II, possessing a $\mathrm{V} f$ of approximately $1 * 10^{-3}$ (Table 2.1). In experiment 1 (Table 2.1) a considerably higher Vf was found for donor I compared to donor II. After correction for spontaneously cycling lymphcytes, using cold storage in experiment $3, \mathrm{Vf}$ of donor I still showed a value which was approximately one order magnitude higher than the Vf of donor II. Incubation of the cultures with BrdU for $40 \mathrm{~h}$ in combination with increasing culturing time from 40 to $64 \mathrm{~h}$, yielded Vf's which did not differsignificantly from those observed for incubation with BrdU for $16 \mathrm{~h}$ and a total culturing time of $40 \mathrm{~h}$. This was indicated by Vf's obtained in experiments 2.a and 2.d, 1.b and 2.d, as well as those in $2 . b$ and $3 . b$ (Table 2.1).

In two seperate experiments, induction of TGr T-lymphocytes by known chemical mutagens was determined, which showed greatly varying Vf's between the experiments (Table 2.2). Standard deviations were found for non-toxic doses ranging from 30 to $50 \%$ of the observed mean. All mutagens were tested up to their cytotoxic limit, which is indicated by decreasing $L_{C}$ at high doses (Table 2.2). Significantly increased $V f$ 's were observed for ENU in experiment 2 at doses of $1 * 10^{-3} \mathrm{M}$ (alpha=0.05) and $5.0 * 10^{-3} \mathrm{M}$ (alpha=0.01) (Table 2.2). Dose-response curves of EMS, ENU and MMC are shown in Figure 2.1. Within non-toxic dose ranges, doseresponse curves obtained for ENU and MMC indicated linearity $(p<0.09$ and p<0.06, for ENU and MMC respectively). 


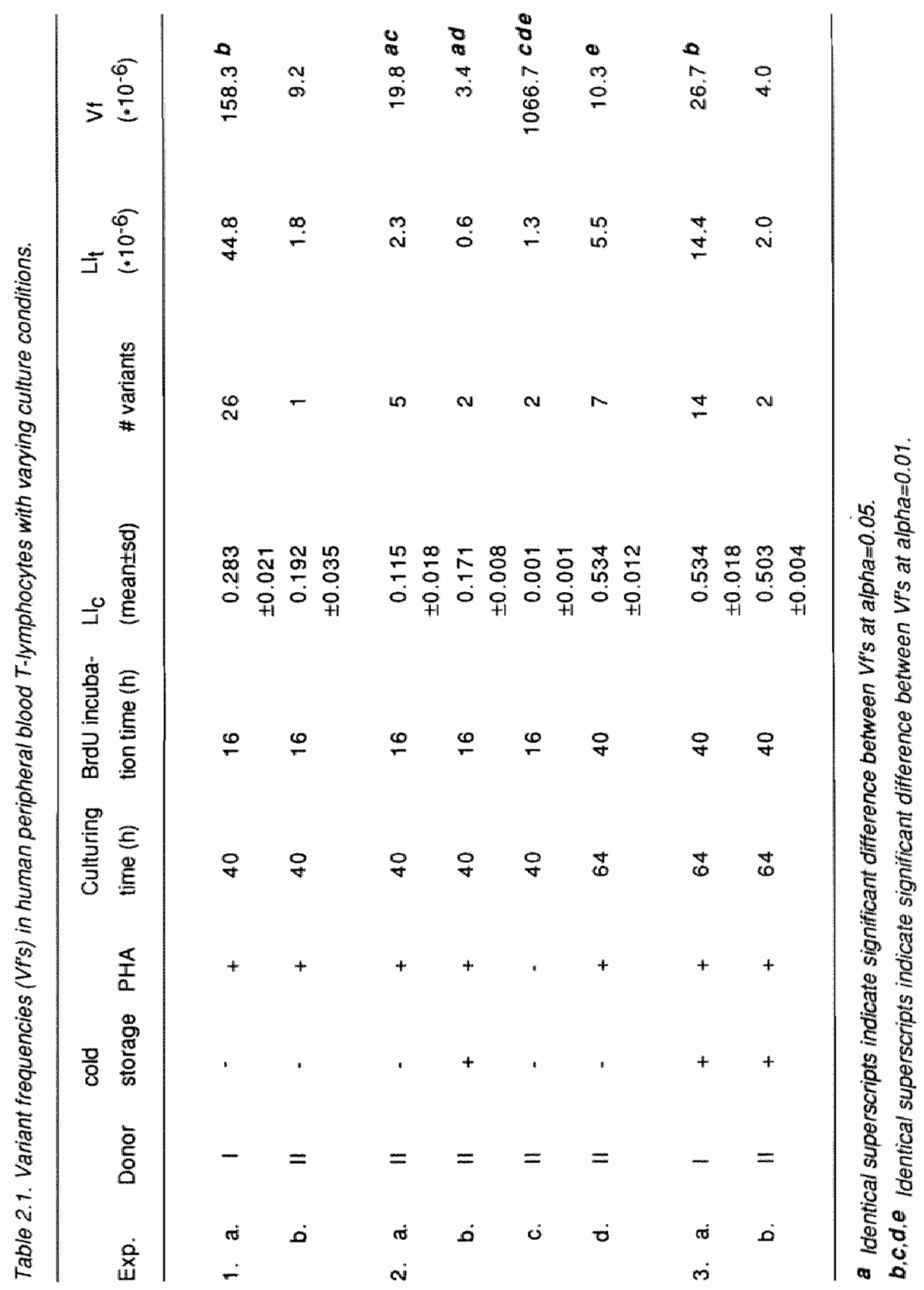




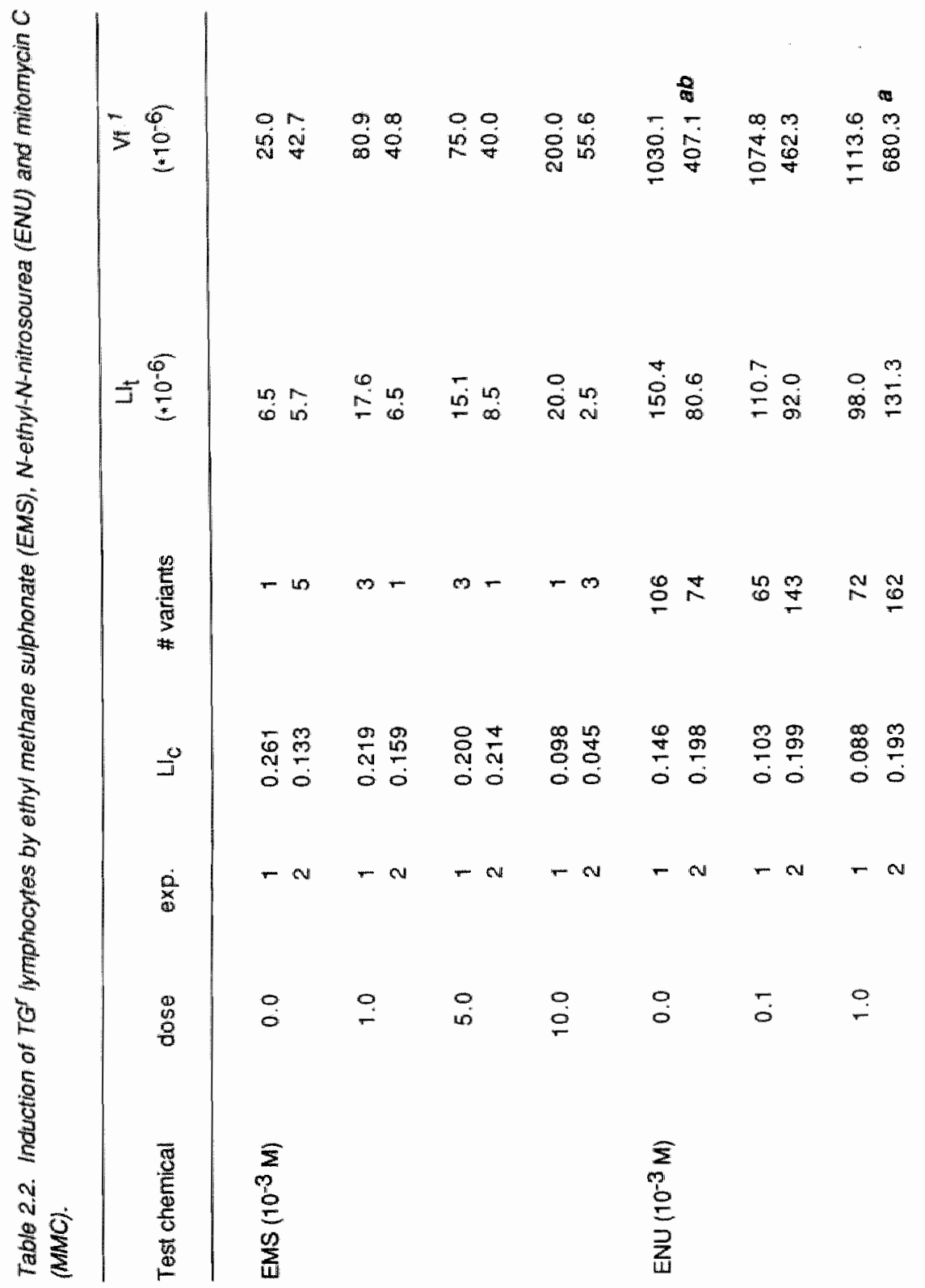




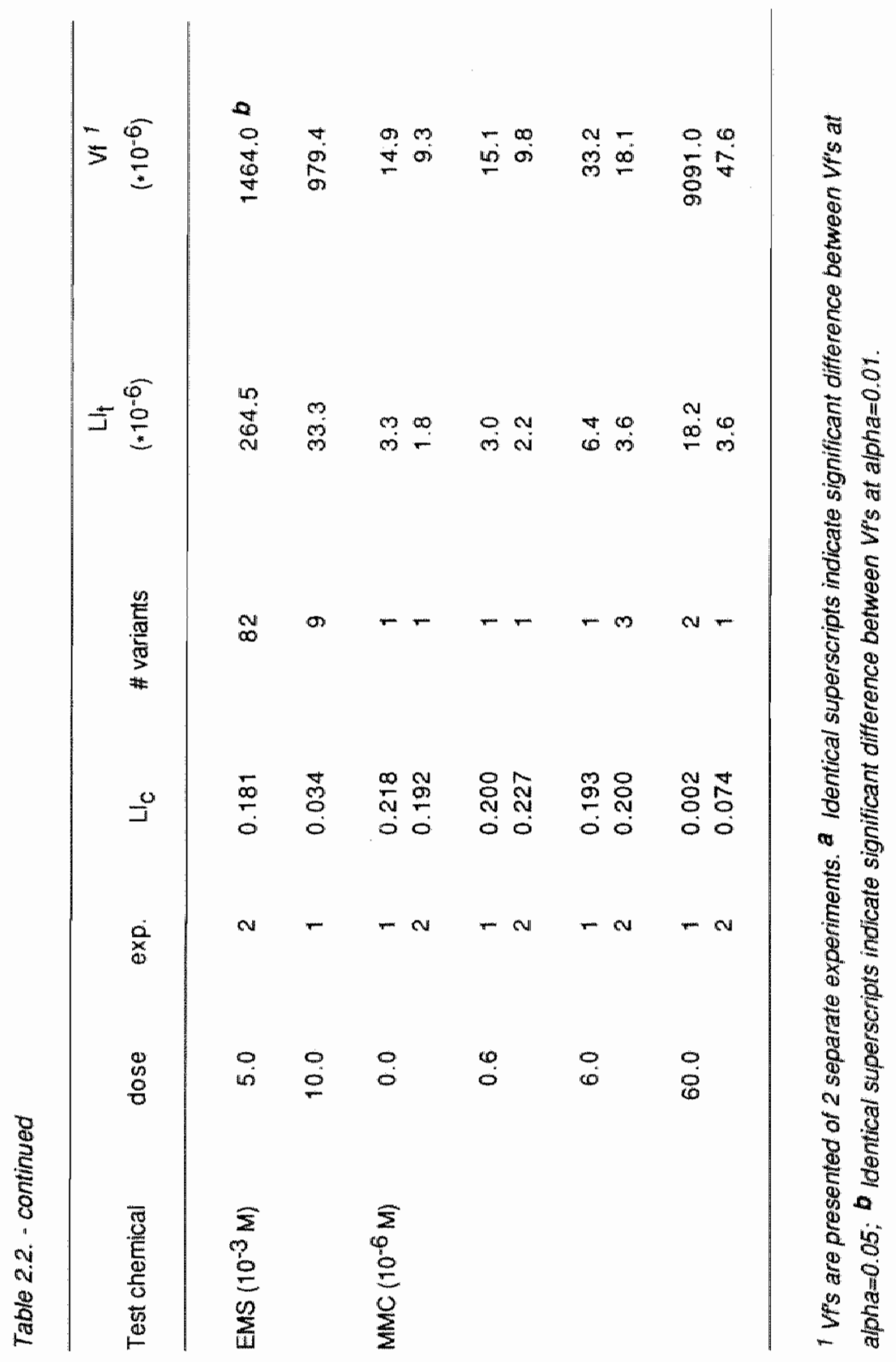




\section{Discussion}

\section{Effects of madifications in culturing conditions}

The modified procedure for detection of TGr mutants in human Tlymphocytes using whole blood culturing and BrdUl-labeling in combination with immunocytochemical staining, appears to provide a simple and generally applicable assay for the evaluation of genotoxic damage after in vivo and in vitro exposure to potential mutagens. The use of BrdU-labeling provides a reliable alternative for the autoradiography assay, as has first been demonstrated by Ostrosky-Wegman et al. (1987). When monoclonal anti-BrdU and peroxidase-conjugated secondary antibodies are used for detection of nuclei which have incorporated BrdU, a better contrast is observed between $\mathrm{TG}^{r}$ and non-proliferating cells.

Small numbers of mutant cells have been reported to lead to large variations in the estimation of Vf's (Albertini and Sylwester, 1984). In order to reduce this variability, conditions of the modified procedure presented in this paper may easily be improved by setting up more $5 \mathrm{ml}$ TG cultures, or by incubating larger cultures, for example $2 \mathrm{TG}$ test cultures of $40 \mathrm{ml}$. Another way of increasing the number of mutant cells per culture is elongation of the incubation time with BrdU to $40 \mathrm{~h}$, thus covering more than one cell cycle of stimulated T-lymphocytes, and enabling $T G r$-lymphocytes to amplify and incorporate BrdU (Bender et al., 1988; deFazio et al., 1988). Previously, Morley et al. (1982), showed that elongation of the total culturing time to 64 is feasible. As is shown in experiment 2 (Table 2.1), prolonged incubation in presence of $2.5 * 10^{-5} \mathrm{M}$ BrdU does not appear to result in increased $\mathrm{Vf}$ 's, although BrdU itself is considered a chemical mutagen to mammalian cells, and has been found to cause pseudomutational effects in a lymphoblast cell line (Liber et al., 1985).

Cold storage at $4^{\circ} \mathrm{C}$ for $24 \mathrm{~h}$ prior to culturing significantly reduces $\mathrm{Vf}$ 's compared to Vf's obtained without cold treatment, and appears to eliminate the effects of spontaneously cycling phenocopies, resulting in V $\mathrm{f}$ 's that are well within the range of $10^{-6}$ to $10^{-5}$ reported for autoradiography assays (Albertini et al.,1987; 1988; Morley et al., 1982). Since Vf's obtained in the short-term autoradiography assay and the clonal assay have been reported to be similar (Albertini et al., 1988), and the modified short-term assay presented in this paper is simple and applicable at large scale, it may be useful for initial screening of large groups. The use of immunofluorescence staining and flow cytometry for enumeration of BrdU-labeled TGr Tlymphocytes may eventually provide a more sophisticated and less laborious technique (deFazio and Tattersall, 1985; Matsson et al., 1985). 

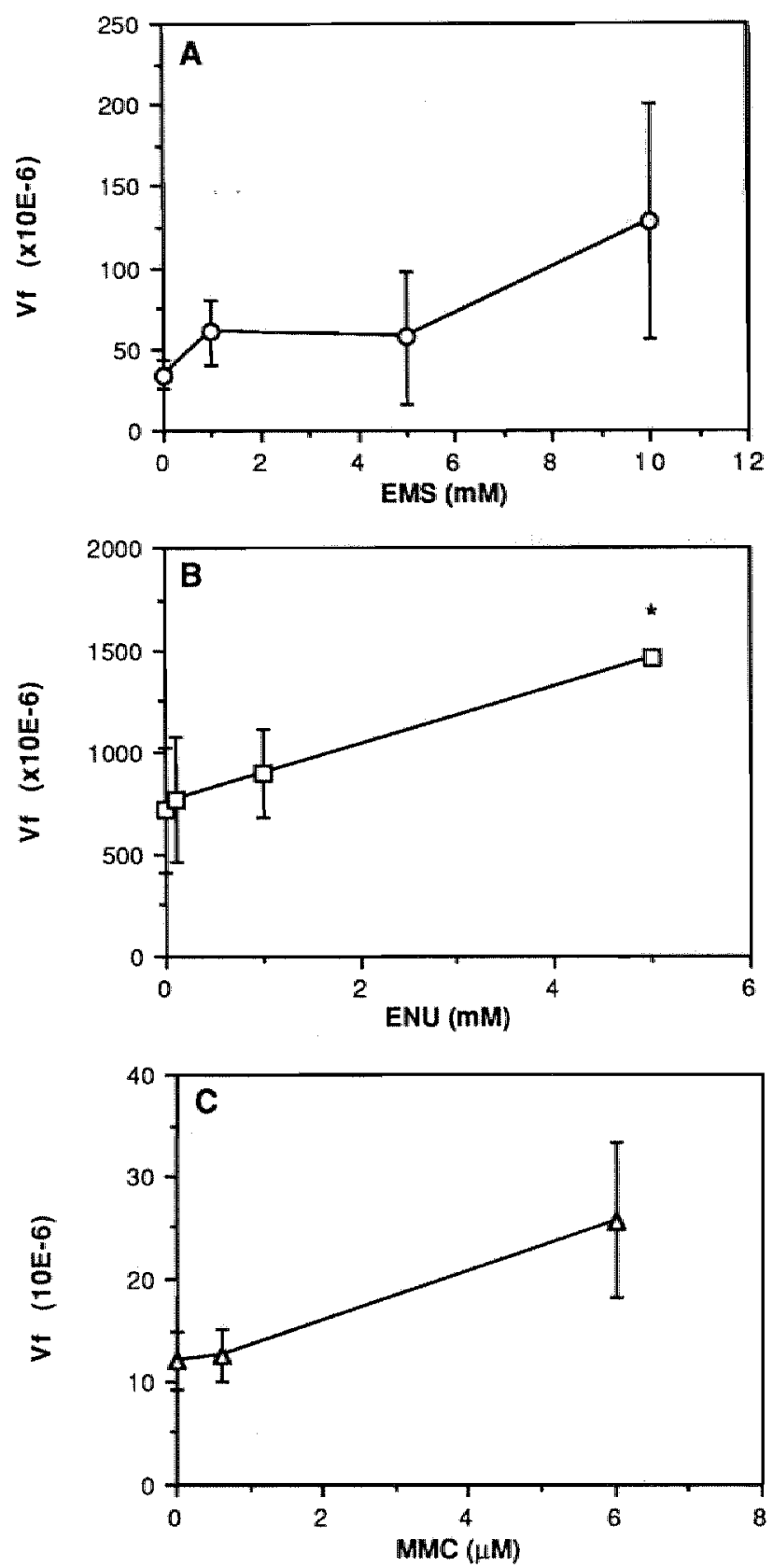

Figure 2.1. Dose-response cunves obtained for in vitro exposure of human peripheral $T$ lymphocytes to ethyl methane sulphonate (EMS: A), N-ethy/-N-nitrosourea (ENU; B) and mitomycin $C(M M C$; $C$ ). Data shown are the mean $\pm S E M$ based on results of 2 separate experiments. "significantly increased vf at alpha $=0.01$. 
Applicability for determination of in vivo derived variant T-lymphocytes

The autoradiography assay has been useful in determining the induction of TGr T-lymphocytes after chemotherapy treatment in cancer patients (Albertini et al., 1985; Lange and Prantner, 1982) and after cyclophosphamide infusion in multiple sclerosis patients (Ammenheuser et al., 1986). At present however, it is not clear whether detection of increased TGr T-lymphocytes in vivo is possible only shortly after exposure to chemical mutagens, since an in vivo selection against mutants appears to exist resulting in a decline of increased frequencies several months after exposure (Ammenheuser et al., 1986). However, TGr T-lymphocytes may also accumulate or even undergo clonal amplification upon in vivo stimulation, thereby leading to increased Vf's not induced by separate mutational events (Albertini et al., 1987; Lange and Prantner, 1982; Nicklas et al.,1987). When increased Vf's are observed, evaluation of the nature of mutations as well as determination of the origin of mutant T-lymphocytes will be necessary.

Since long-term exposure of nurses and pharmacists to cytostatic drugs has been reported to result in marginal increases of mutant frequencies as compared to the effects observed in treated patients (Chrysostomou et al., 1984), the applicability and sensitivity of determination of mutational lesions at the hgprt locus in T-lymphocytes as a screening method for the assessment of genetic damage remains to be established. The observed absence of pronounced effects of exposure to genotoxic agents on Vf's may also be due to presence of confounding factors. Screening of exposed populations will therefore require strict control of possible confounding variables, among which are age (Amnéus et al., 1982; Morley et al., 1982; Trainor et al., 1984; Vijayalaxmi and Evans, 1984), smoking habits and history (Albertini et al., 1986), and possibly alcohol consumption and use of oral contraceptives, since these factors have been reported to influence the detection of sister chromatid exchanges (SCE) as well (Das, 1988). It seems therefore relevant to validate the applicability of the HGPRT-assay by determination of frequency of TGr T-lymphocytes in a population of heavy smokers with strickt control of possible confounding variables.

Determination of variant T-lymphocytes after in vitro exposure to chemical mutagens

Chemical induction of TGr T-lymphocytes in vitro allows for evaluation of genotoxic effects of chemicals in human cells which are widely available and easily cultured. In addition, human lymphocytes allow determination of genetic damage to human DNA, and possess enzyme activities and DNA repair potentials which differ from other mammalian cells generally used in mutagenicity testing, as is illustrated by the lack of proficient $\mathrm{O}^{6}$-alkylguanine repair in Chinese hamster $\mathrm{CHO}$ fibroblast cell lines (Fox and Roberts, 1987). 
Normal lymphocytes have also been reported to be genetically more stable than malignant cells used in short-term assays (Seshadri et al., 1987). Furthermore, the use of whole blood cultures appears to provide experimental conditions which more closely resemble the in vivo situation. Recently, comparison of results of whole blood culturing in the in vitro human lymphocyte micronucleus assay to results obtained for purified lymphocytes has shown that the presence of erythrocytes may play an important role in metabolic activation or detoxification of xenobiotics (Migliore et al., 1989).

Vf's observed in separate experiments in the present study, as well as standard errors of $20-50 \%$ reported by Vijayalaxmi and Evans (1984) for the in vitro induction of TGr T-lymphocytes by EMS, ENU and MMC using the clonal assay, indicate that inter-assay variability between Vf's may be substantial. This variability is probably due to inter-individual variability between different blood donors, as well as to differences in sensitivity between different classes of lymphocytes, and is considered to reflect biological variabiltiy as it occurs within a population. For in vitro testing of chemical compounds this may pose problems with respect to reproducibility of results when lymphocytes of different donors are used, and statistical evaluation of results is therefore limited to comparsion within one assay. Dose-response curves obtained for ENU in separate assays in the present study also indicate variability in time course for lymphocytes obtained from one donor, which may be due to differences in sensitivity of lymphoytes to cytotoxic effects of ENU as is indicated by the decreased $\mathrm{LI}_{\mathrm{C}}$ at a dose of 0.1 $\mathrm{mM}$ in experiment 1 which has not been observed in experiment 2 (Table 2.2). Furthermore, the induction of anti-mutagenic repair systems after mitogenic stimulation of T-lymphocytes by PHA, may also influence the detection of mutagenic lesions, and may also vary between different assays.(Sanderson and Morley, 1986; Waldstein et al., 1982).

In spite of the observed variability, use the HGPRT-assay with human lymphocytes for the assessment of mutagenicity of chemical compounds in vitro, does have advantages such as relatively simple culturing procedures, short duration of the assay, as well as testing of chemicals under conditions which closely resemble the in vivo situation. Further modifications of the standardized protocol as applied in the present study for the in vitro HGPRT-assay using human lymphocytes, such as variation of mutagen exposure and mutant expression times, may increase its sensitivity, and remain to be determined. In combination with analysis of other genotoxic effects, including induction of SCE's and micronuclei, determination of mutation frequencies at the hgprt locus may prove useful in estimation of human genotoxic risk posed by xenobiotic compounds.

Summarizing, it is concluded that whole blood culturing in combination 
with BrdU-labeling prowides a simple and quick procedure for determination of TGr T-lymphocytes after in vitro exposure to potential mutagens; further studies will be needed however, to determine effects of varying culture conditions, including exposure, mutant expression and labeling times. Furthermore, the modified procedure provides a simple procedure for initial large scale screening of mutational lesions in DNA of high-risk human populations.

\section{References}

Albertini R. (1985). Somatic gene mutations in vivo as indicated by the 6 -thioguanineresistant T-lymphocytes in human blood. Mutation Res. 150, 411 -422.

Albertini R.J., Sullivan L.M. and Greene C.J. (1986). Human somatic gene mutations in vivo. III. Aultoradiographic assay for T-cell mutants. EMS Abstracts, 3.

Albertini R.J., Nicklas J.A., Sullivan L.M. Hunter T.C. and O'Neill J. (1987) HGPRT mutation in vivo in human T-lymphocyles: Quantitative considerations. In: Mammalian cell mutagenesis. Banbury Report 28, Cold Spring Harbor Laboratory. 139-147.

Albertini R.J., Sullivan L.M., Berman. J.K., Greene. L.J., Stewart J.A. Silveira. J.M. and O'Neill J.P. (1988). Mutagenicity monitoring in humans by autoradiographic assay for mutant Tlymphocyles. Mutation Res. 204, 481-492.

Albertini R.J. and Sylwester D.L. (1984). 6-Thioguanine-resistant lymphocytes in human blood. In: Kilbey B.J., Legator M., Nichols W. and Ramel C. (Eds.): Handbook of mutagenicity test procedures. Second edition. Elsevier Science Publishers BV, New York, pp. 357-372.

Ammenheuser M.M., Ward Jr. J.B. and Killian J.M. (1986). A longitudinal study of the frequency of 6-thioguanine-resistant lymphocytes from multiple sclerosis patients receiving cyclophosphamide. Environ. Mutagen. (suppl. 6) 8, 3.

Amnéus H., Matsson P and Zetterberg G. (1982). Human lymphocytes resistant to 6 thioguanine: Festrictions in the use of a test for somatic mutations arising in vivo studied by flow-cytometric enrichment of resistant cell nuclei. Mutation Res. 106, 163-178.

Bender M.A., Awa A.A., Brooks A.L., Evans H.J., Groer P.G., Littlefield L.G., Pereira C., Preston A.J. and Wachholz B.W. (1988). Current status of cytogenetic procedures to detect and quantify previous exposures to ratiation. Mutation Res. 196, 103-159.

Chrysosiomou A., Seshadri R. and Morley A.A. (1984). Mutation frequency in nurses and pharmacists working with cytotoxic drugs. Aust. NZ. J. Med. 14, 831-834.

Das B. C. (1988). Factors that influence tormation of sister chromatid exchanges in human blood lymphocytes. CRC Crit. Rev. Toxical. 19, 43-86.

deFazio A., Musgrove E.A. and Taltersall M.H.N. (1988). Flow cytometric enumeration of drug-resistant tumor cells. Cancer Res. 48, 6037-6043.

deFazio A. and Tattersall M.H.N. (1985). Rapid fluorometric detection of drug resistant tumour cells. Br. J. Cancer 52, 633-636.

Dempsey J.L. and Morley A.A. (1983). Evidence that thioguanie-resistant lymphocytes detected by autoradiography are mutant cells. Mutation Res. 119, 203-211. 
Fox M. (1988). The case for retention of mammalian cell mutagenicity assays. Mutagenesis 3 , 459-461.

Fox M. and Roberts J.J. (1987). Drug resistance and DNA repair. Cancer Metab. Rew. 6, 261381.

Grazner H.G. (1982). Monoclonal antibody to 5-bromo- and 5-iododeoxyuridine: A new reagent for detection of DNA replication. Science $218,474-475$.

Kilbey B.J., Legator M., Nichols W and Ramel C. (Eds.), 1984). Handbook of mutagenicity test procedures. Second edition. Elsevier Science Pulblishers BV, New York.

Lange B.J. and Prantner J.E. (1982). The emergence of 6-thioguanine resistant lymphocytes in pediatric cancer patients. Mutation Res. 94, 487.499.

Liber H.L. Call, K.M., Mascioli D.A. and Thilly W.G. (1985). Mutational and pseudomutational effects of 5-bromodeoxyuridine in human lymphoblasts. Mutation Res. 151, 95-108.

Matsson P., Amèus H. Djupsjöbacka M., Eriksson B., Feliner-Feldegg $H$. and Zetterberg $G$. (1985). Direct and indirect flow cytometric enumeration of 6-thioguanine-resistant human peripheral blood lymphocytes. Cytometry 6,648-656.

Morley A.A." Cox S., Wigmore D., Seshadri R. and Dempsey J.L. (1982). Enumeration of thioguanine-resistant lymphocytes useing autoradiography. Mutation Res. 95, 363-375.

Morley A.A. Trainor K.J." Dempsey J.L. and Seshadri R.S. (1985). Methods for the study of mutations and mutagenesis in human lymphocytes. Mutation Res. 147, 363-367.

Nicklas J.A., Hunter T.C., Sullivan L.M., Berman J.K., O'Neill J.P. and Albertini R.J. (1987). Molecular analyses of in vivo hprt mutations in human T-lymphocytes. I. Studies of low frequency "spontaneous" mutants by Southern blots. Mutagenesis 2, 34\%-347.

Ostrosky-Wegman P." Montero M.R., Cortinas de Nava C. Tice R.R. and Albertini R. (1987). The use of bromodeoxyuridine labeling in the human lymphocyte HGPRT somatic mutation assay. Mutation Res. 191, 211-214.

Sanderson B.J.S. and Morley A.A. (1986). Mitogenic stimulation may induce anti-mutagenic repair system in human lymphocytes. Mutagenesis 1, 131-133.

Sylwester D. and Albertini R.J. (1985). Confidence intervals and sample size calculations to compare variant trequencies. Environ. Mutagen. 7 Suppl. 4, 31-41.

Trainor K.J., Wigmore D.J., Chrysostomou A., Dempsey J.L., Seshadri R. and Morley A.A. (1984). Mutation frequency in human lymphocytes increases with age. Mech. Ageing Dev. 27, 83-86.

Turner D.R. "Morley A.A., Haliandros M., Kutlaca R. and Sanderson D.J. (1985). In vivo mutations in human lymphocytes frequently result from major gene alterations. Nature 315, 343-345.

Vijayallaxmi and Evans H.J. (1984). Induction of 6-thioguanine-resistant mutants and SCE's by 3 chemical mutagens (EMS, ENU and MMC) in cultured thuman blood lymphocytes. Mutation Res. 129, 287-289.

Waldstein E.A., Cao E.H., Bender M.A. and Setlow R.H. (1982). Abilities of extracts of human Iymphocytes to remove $0^{6}$-methylguanine from DNA. Mutation Res. 95, 405-416. 


\title{
Chapter 3
}

\section{Assessment of mutagenic activity of repeatedly used deep-frying fats}

\author{
G. Hageman, R. KIkken, F. ten Hoor and J. Kieinjans
}

Mutation Res. 204, 593-604, 1988

\begin{abstract}
Mutagenic activity of repeatedly used deep frying fats was evaluated in relation to chemical characteristics. Deep frying fat samples were collected from locall restaurants and snack bars after sensoric indication of abuse. A total of 20 deep frying fat samples and 2 unused control fat samples was tested. Fat samples were fractionated into non-polar and polair compounds by column chromatography. Amounts of polar compounds obtained ranged from $2 \%$ (by weight) for unused fat to $4.4 \%$ for used deep frying fat. Levels of di- and polymeric triglycerides (DPTG) were determined using gel permeation chromalography. DPTG concentrations of 13 used deep frying fat samples exceeded the treshold level of $10 \%$ above which fats are rejected for use. In addition thiobarbituric acid-reactive substances (TBA-RS) were measured. Amounts of TBA-AS were just above detection levels lor most fat samples. Five used fat samples however contained relatively high concentrations of TBA-RS, ranging from 82 to $177 \mathrm{nmol}$ malondialdehyde/g.
\end{abstract}

Non-polar and polar fractions were screened for mutagenic activity using the Ames mutagenicity assay. Mutagenic activity was found predominanlly in polar fractions at doses higher than $1 \mathrm{mg} / \mathrm{plate}$ in strains TA97, TA100 and TA104, variously with and without metabolic activation. Highest number of mutagenic samples was detected by strain TA97, which appeared to be most sensitive. Some samples exhibited loxic effects. Chromatography blanks, consisting of solvenis processed according to the same procedures as used for tat

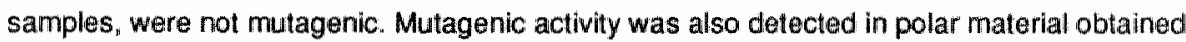
from unused frying fat. Non-polar fractions of unused frying fats showed no mutagenicity.

A frying experiment carried out under laboratory conditions indicated that during repeated and prolonged use of deep frying fat mutagenic polar substances were formed. Fat samples taken after 20 and 40 hours of frying contained increasing amounts of polar compounds. Mutagenic activity was highest after 20 hours of frying but was slightly decreased after 40 hours of frying. At this stage however mutagens also appeared in the non-polar fraction.

Mutagenic activity of polar fractions of used deep frying fats in strain TA97 was positively correlated with levels of TBA-RS, which may indicate the involvement of lipid oxidation products in mutagenicity of used deep frying fats. No significant correlations were found with other chemical characteristics. In the process of deep fat frying numerous degradation products are formed, which may include mutagenic heterocyclic amines and other pyrolyzates. The specific nature of mutagens formed during deep fat frying remains unclear. 


\section{Introduction}

Heating of foods with high protein concentrations has been found to cause formation of mutagenic and carcinogenic substances (Sugimura et al., 1986). These substances are believed to explain in part the typical pattern of cancer prevalence that occurs in countries where intake of protein and fat is high. Fat is generally thought to act as tumor promotor. However, heating of fats, in particular those rich in polyunsaturated fatty acids, will generate numerous oxidative degradation products that may be potentially genotoxic (Alexander, 1980; Stevenson et al., 1984).

In the process of frying fats and oils are repeatedly heated at high temperatures up to $180^{\circ} \mathrm{C}$ for prolonged periods of time. Under these conditions volatile and non-volatile oxidation products are formed (Stevenson et al., 1984) that may be absorbed by the food and subsequently eaten. Feeding experiments with laboratory animals have shown that thermally oxidized oils exent toxic effects in vivo. Consumption of heated oils or isolated fractions may cause growth retardation, increased liver and kidney weights, and cellular damage to liver, thymus, epidydimides and testes (Andia and Street, 1975; Billek, 1976; Alexander, 1981; Alexander et al., 1987).

Evaluation of the genotoxic potential of heated deep frying fats in vitro using the Ames assay yielded negative or inconclusive results (Scheutwinkel-Reich et al., 1981; Taylor et al., 1982; Van Gastel et al., 1984). Fong et al. (1980) however, did report increased mutagenic activity of heated peanut oils as compared to uncooked oils, which could not be attributed to the presence of aflatoxins. Various isolated lipid oxidation products like malondialdehyde, some alkenals, carbonyls and hydroperoxides of linoleic and linolenic acid have also been found to be mutagenic (Mukai and Goldstein, 1976; Yamaguchi and Yamashita, 1979; 1980; Marnett et al., 1984; MacGregor et al., 1985). No studies evaluating the carcinogenic potential of heated fats are available.

Health risks of food preparation by deep frying are currently discussed primarily because reliable cut off levels based on chemical analysis seem insatisfactory. In this study therefore, mutagenic activity of repeatedly used deep frying fats sampled at the retail level was evaluated in relation to chemical analyses used for quality control. In addition a frying experiment was carried out in the laboratory, in which the formation of mutagenic substances was followed during prolonged and repeated use. 


\section{Material and methods}

\section{Chemicals}

Analytical grade, stabilized (with $250 \mathrm{ppm}$ butylated hydroxytoluene) tetrahydrofuran used for HPLC-analysis of di- and polymeric triglycerides; analytical grade petroleum ether, boiling range $40-60^{\circ} \mathrm{C}$; methanol; acetic acid and silicagel 60 , particle size $0.063-0.20 \mathrm{~mm}$, used for fractionaling fat samples; trichloracetic acid; malonaldehyde bis-(diethylacetal); hydrochloric acid and 2-thiobarbituric acid, all of the highest chemical grade available, were purchased from Merck, Darmstadt, FRG. HPLC-grade diethyl ether and non-stabilized tetrahyrofuran used for dissolving fat fractions in mutagenicity testing were obtained from Fisons "Loughborough. England. All other chemicals and media used in the Ames mutagenicity assay were of the highest chemical grade commercially available.

\section{Sampling}

Deep frying fat samples were collected by officers of the Maastricht Office for Food Quality Control from local restaurants and snack bars after sensoric indication of abuse. Samples were taken according to internationally standardized procedures (ISO, 1983) and stored refrigerated untill further testing.

\section{Di- and polymeric triglycerides}

At the Office for Food Quality Control di- and polymeric triglycerides (DPTG) were determined as part of routine quality assessment (ISO, 1980). Amounts of DPTG were analyzed using gel-permeation HPLC. HPLC-equipment consisted of a RI detector and a Styrogel 500 A column, $300 \mathrm{~mm} \times 7.8 \mathrm{~mm}$ i.d. Degassedl, stabilized tetrahydrofuran (THF) was applied as mobile phase at a flow rate of $1 \mathrm{ml} / \mathrm{min}$. Samples of $200 \mathrm{ul}$ of fat, liquified by heating at $500 \mathrm{C}$, or oil were mixed with $3.0 \mathrm{ml}$ THF and 15 ul of this mixture was injected. Amounts of DPTG are calculated as follows:

$\%$ DPTG $=$ Sum of peak area's of DPTG $\times 100$.

Total sum of peak area's

\section{Fractionation of fat samples}

Out of 60 samples originally collected 20 samples were randomly chosen, fractionated into non-polar and polar fractions, analyzed for thiobarbituric acid-reactive substances and screened for mutagenicity. Fractionation of samples into polar and non-pollar components by column chromatography was modified from Billek et al. (1978), which procedure is proposed as an international standard (ISO, 1986). Briefly, one gram of fat was dissolved in $10 \mathrm{ml}$ of a mixture of petroleum ether (boiling point $40-60^{\circ} \mathrm{C}$ ) and diethyl ether, $87: 13 \mathrm{v} / \mathrm{v}$ (solvent 1 ). The fat solution and a $10 \mathrm{ml}$ rinsing were carefully introduced onto a silica gel column (45 $\mathrm{cm} x$ $2.1 \mathrm{~cm}$ i.d.), filled with 25 gram deactivated silicagel. The non-polar fraction was eluted using $150 \mathrm{ml}$ of solvent 1 . The eluate was collected in a flask and designated the non-polar fraction. Subsequently the polar fraction was eluted with $150 \mathrm{ml}$ diethyl ether acidified with $1 \% \mathrm{v} / \mathrm{v}$ acetic acid (solvent 2) and collected in a separate flask. Finally, very polar, yellow colored material was eluted with a mixture of methanol and water $(75: 25$, w/v) acidified with $1 \%(\mathrm{w} / \mathrm{v})$ acetic acid (solvent 3). Solvents were distilled off by vacuum evaporation al a maximum temperature of $60^{\circ} \mathrm{C}$. After evaporating most of the solvent, residues were transferred into 
pre-weighed screw top vessels. Remaining solvent was evaporated under a stream of nitrogen at room lemperature. Solvent 3 was evaporated in a vacuum oven at $50^{\circ} \mathrm{C}$. After complete waporation of the solvents vessels were weighed and the content calculated as percentage of total tat weight. Fractionated samples were kept under nitrogen and stored under retrigeration.

\section{Thiobarbituric acid-reactive substances}

As an index of lipid peroxidation thiobarbituric acid-reactive substances (TBA-RS) were determined. Approximately one gram of fat was extracted with $4.0 \mathrm{ml}$ of a reaction mixture consisting of $15 \%$ (W/W) trichloracetic acid and $0.375 \%$ (w/W) TBA in $0.25 \mathrm{~N} \mathrm{HCl}$ to which $0.02 \%$ butylated hydroxytoluene was added to prevent further fatty acid oxidation during the assay. The mixture was incubated in a shaking waterbad at $80^{\circ} \mathrm{C}$ during 40 minutes. After centrifugation the absorbance of the aqueous phase was measured at $532 \mathrm{~nm}$ as well as at $600 \mathrm{~nm}$ to correct for non-specific background absorption. TEA-PS are calculated as nmol malondialdehyde (MDA) per gram of fat, using a calibration curve of malonaldehyde bis(diethylacetal) dissolved in one gram of unused frying fat that contained no measurable TBARS.

\section{Mutagenicily testing}

Fractionated deep frying fat samples were dissolved in DMSO or THF. Some fractions required gentle heating (maximum temperature $50^{\circ} \mathrm{C}$ ) to facilitate dissolving. THF proved to be a more suitable solvent than DMSO; both non-polar and polar fractions were better dissolved in THF and suspended in the Ames incubation medium in the presence of THF. Doses were tested in duplicate or triplicate, total volumes of the solvents were $100 \mathrm{ull}$ for DMSO and 25 ul for THF. The Salmonella/microsome assay was performed according to Maron and Ames (1983) using the preincubation procedure; in a medium consisting of $0.5 \mathrm{ml}$ of S9 mix, that contained 50 ul of rat liver $\$ 9$ fraction from Arochlor treated rats, or $0.5 \mathrm{ml}$ of 0.1 $M$ phosphate buffer ( $\mathrm{pH} 7.4)$, the test dose and $0.1 \mathrm{ml}$ of an overnight grown culture were incubated during 20 minutes at $37^{\circ} \mathrm{C}$. after which suspensions were plated. After initial prescreening strains TA97, TA100 and TA104 were selected for mutagenicity testing. For practical reasons howewer, strain TA104 was withdrawn from the set of tester strains since strain TA100 appeared equally sensitive and yielded lower plate counts on account of the smaller number of spontaneous revertants. Plates were counted manually with visual discrimination between fat particles and revertant colonies. Toxicity was evaluated by observing bacterial growth of the background lawn.Solvent controls (DMSO and THF) and positive controls were included in each assay. Chromatography blanks consisting of solvents processed following the same procedures as used for fat samples were also screened for mutagenicity. In addition, two different brands of unused frying fal obtained from local supermarkets were chemically analyzed and included in the mutagenicity assay.

\section{Statistical anaysis}

Statistical analysis of the dala was performed using the method of least significant difference (LSD) as described by MacGregor et al. (1985). The least significant difference between test and control data was calculated from the variance between sets of replicate

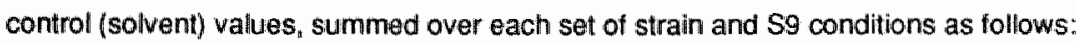


$\mathrm{LSD}=\mathrm{t} V 2 \mathrm{MS}$

where $t$ is the $t-s t a t i s t i c$ value at a given confidence level with the degrees of freedom equal to the number of control data sets, and MS is the overall variance of individual replicate determinations from each individual experiment summed over all experiments. $L S D$ values obtained in this study are at a confidence level of $p<0.01$ and $p<0.001$ respectively: for THF as solvent with TA97-S9, 126 and 220; TA97+S9 142 and 235; TA100-S9 82 and 154; TA100+S9 76 and 142: TA104-S9 696 and 1329; TA104+S9 655 and 1255; for DMSO as solvent, with TA97-S9 132 and 211; TA97+S9 243 and 389; TA104-S9 588 and 975 and TA104+S9 592 and 980 .

\section{Frying experiment}

A controlled frying experiment was performed under laboratory conditions. A batich of 2 $\mathrm{kg}$ of unused commercial brand frying fat was heated at $180 \pm 5^{\circ} \mathrm{C}$ during 10 hours per day on 4 consecutive days. Each day three portions of food: $100 \mathrm{~g}$ of meat croquettes, 2 egg rotes (150 g) and $100 \mathrm{~g}$ of sliced potatoes (French fries) were fried according to instructions provided by manufacturers. The fat was allowed to cool overnight and was not replenished. Fat samples were collected once a day after 2 and 4 days of frying. TBA-RS were determined and samples were fractionated into polar and non wpolar components, which were screened for mutagenic activity.

\section{Results}

\section{Chemical analyses}

Amounts of di- and polymeric triglycerides, polar compounds obtained with solvent 2, and TBA-RS of all samples tested are listed in Table 3.1. Of the twenty used deep irying fat samples chosen for mutagenicity testing thitteen showed concentrations of DPTG exceeding $10 \%$ (by weight) which is the treshold level above which fats are rejected for use. Amounts of polar compounds ranged from 3 to $44 \%$ (by weight) for used frying fats. Mean recovery after fractionating the samples into two fractions according to Billek et al. (1978) was $92 \pm 1 \%$ (SEM). After eluting the remaining very polar compounds applying solvent 3 mean recovery increased to $102 \pm 2 \%$ (SEM). Polar material obtained with solvent 2 and levels of DPTG were positively correlated $(r=0.86, p<0.01)$. Concentrations of TBA-RS are just above the detection level, $1.0 \mathrm{nmol} / \mathrm{g}$, in most frying fats with the exception of five fat samples that contained high levels ranging from 82 to $177 \mathrm{nmol}$ MDA per gram of fat (Table 3.1). The presence of TBA-RS in frying fat samples was not associated with amounts of DPTG or polar compounds

\section{Mutagenicity testing}

Dose-response curves describing mutagenic activity were determined by testing non-polar and polar fractions of six used frying fat samples at doses 
Table 31 Amount of di- and polymeric triglycerides (DPTG), polar compounds and TBAreactive substances (TBA-AS) of used deep frying fats

\begin{tabular}{|c|c|c|c|}
\hline $\begin{array}{l}\text { Sample } \\
\text { no. }\end{array}$ & $\begin{array}{l}\text { DPTG } \\
\text { (\% by weight) }\end{array}$ & $\begin{array}{l}\text { Polar } \\
\text { compounds } \\
\text { (\% by weight })\end{array}$ & $\begin{array}{l}\text { TBA-RS } \\
\text { nmoles MDA } \\
g \text { of tat }\end{array}$ \\
\hline 1 & 32 & 44 & 157 \\
\hline 2 & 10 & 25 & 10 \\
\hline 13 & 28 & 41 & 6 \\
\hline 14 & 12 & 32 & 6 \\
\hline 17 & $<1$ & 3 & 161 \\
\hline 18 & 31 & 40 & 82 \\
\hline 19 & 7 & 24 & 4 \\
\hline 21 & 10 & 27 & 10 \\
\hline 22 & 13 & 33 & 4 \\
\hline 25 & 8 & 14 & $<1$ \\
\hline 30 & 12 & 34 & 177 \\
\hline 35 & 11 & 34 & 18 \\
\hline 43 & 11 & 18 & 103 \\
\hline 44 & 32 & 38 & $\mathrm{ND}^{*}$ \\
\hline 45 & 8 & 26 & 44 \\
\hline 49 & 22 & 35 & 8 \\
\hline 50 & 2 & 7 & 4 \\
\hline 55 & 25 & 39 & 6 \\
\hline 56 & 22 & 35 & 6 \\
\hline 58 & 3 & 11 & 8 \\
\hline \multicolumn{4}{|c|}{ Unused frying fat } \\
\hline A & ND & 2 & 4 \\
\hline B & ND & 6 & 14 \\
\hline \multicolumn{4}{|c|}{20 hours of } \\
\hline frying (B) & ND & 28 & ND \\
\hline \multicolumn{4}{|c|}{40 hours of } \\
\hline Irying (B) & ND & 40 & 14 \\
\hline
\end{tabular}

* ND, not determined 


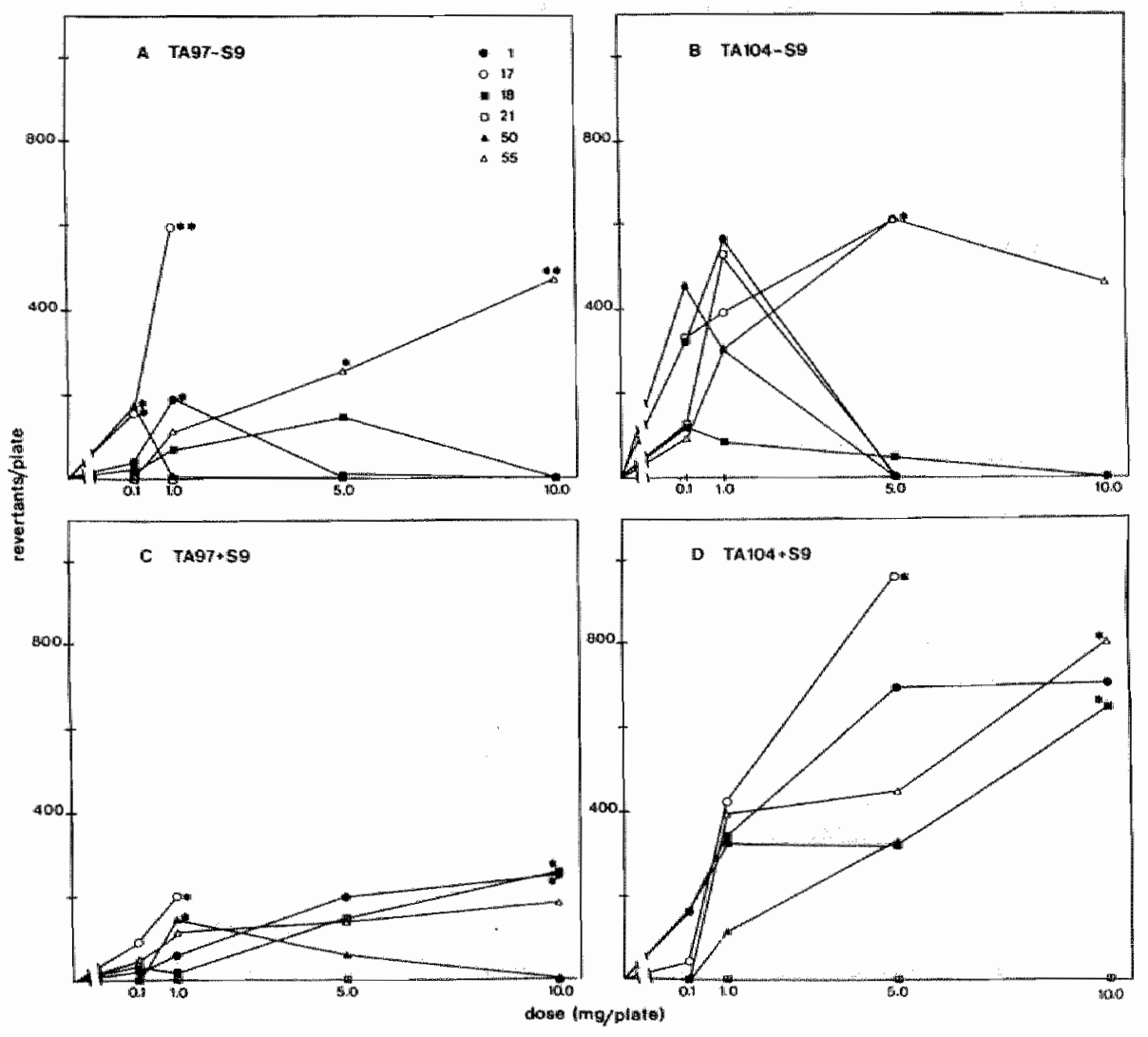

Figure 3.1. Mutagenic activity of polar fractions of used deep frying fat samples $1(0), 17(0)$. $18(\mathrm{D}), 2 \mathrm{f}(\mathrm{O}), 50(\mathrm{~A})$ and 55 ( $\triangle$ ) in (A) strain TA97.S9; (B) strain TA97+S9; (C) strain TA104-S9; (D) sirain TA104+S9. Samples 1, 55 and 18 were dissolved in DMSO; samples 17, 21 and 50 in THF. For DMSO as solvent mean numbers of spontaneous revertants of 134, 197, 504 and 476, and for THF of 152, 223,476, and 551 for strain TA97-S9, TA97+S9, TA104-S9 and TA104+S9 respectively have been subtracted." significantly different from control value, $p<0.01 ;$;" significantly different from control value, $p<0.001$. 
ranging from 0.1 to $10 \mathrm{mg}$ per plate. Mutagenic activity in strains TA97 and TA104 was found mainly in the second (polar) fraction at doses higher than $1 \mathrm{mg} / \mathrm{plate}$ (Figures 3.1 and 3.2). None of the very polar fractions that were eluted from the column using solvent 3 showed mutagenic activity (results not shown). In the absence of S9 mix polar fractions of three fat samples showed toxic effects at doses higher than $0.1 \mathrm{mg} / \mathrm{plate}$ (Figure.3.1.A). Addition of $\mathrm{S} 9$ mix to the polar fractions of two toxic samples (18 and 50 ) resulted in reduced toxicity and an increase in the number of revertants. In the presence of S9 mix however, mutagenic activity of the polar fractions of samples 55 and 17 showed a tendency to decrease in strain TA97. In strain TA104 addition of $\$ 9$ mix to polar fractions increased the number of revertants in all but one sample (Figure 3.1.C, D). Two fat samples with mutagenic polar fractions (samples 1 and 17) showed also mutagenic activity in their non-polar fractions (Figure 3.2).

Since mutagenicity was found predominantly in fractions eluted with solvents 1 and 2 at doses ranging from 1 to $10 \mathrm{mg} / \mathrm{plate}$, subsequent testing was performed with these only, applying doses of 5 and $10 \mathrm{mg} / \mathrm{plate}$. Table 3.2 shows mutagenicity results of polar fractions obtained with sixteen used and two unused frying fat samples. From this table it is apparent that all samples showed mutagenic activity in strain TA97 without S9 mix. The addition of a metabolic system enhanced mutagenicity in some fractions but produced inhibiting effects in others. Table 3.3 shows mutagenicity results of non-polar fractions. Non-polar fractions of eight used frying fat samples exhibited mutagenic activity in strain TA97; the numbers of revertants induced by positive samples were far below those of concomitant polar fractions. Addition of $S 9$ mix generally reduced mutagenicity of the non-polar fractions. Chromatography blanks showed no mutagenic activity, but polar fractions isolated from the unused frying fats induced increased numbers of revertants in all three tester strains without S9 mix. In strain TA97 the number of revertants induced by the polar fracton of unused fat $B$ reached statistical significance at a dose of $5 \mathrm{mg} / \mathrm{plate}$ (Table 3.2). Non-polar fractions of unused frying fats showed no mutagenic activity (Table 3.3). The number of significantly mutagenic fat samples detected was higher in strain TA97 than in strains TA100 or TA104, thus indicating that strain TA97 was most sensitive.

\section{Mutagenic activity in relation to oxidative indices}

Mutagenic activity of polar fractions of twenty samples to strain TA97 was calculated as number of revertants per $\mathrm{mg}$ in order to obtain a mutagenicity index. This was achieved by linear regression of dose-response curves, excluding toxic fractions. Calculated coefficients of correlation are shown in Table 3.4. Mutagenic activity of polar fractions was not significantly associated with levels of DPTG or polar components. Significant positive correlations were observed between mutagenicity and levels of TBA-RS for 
strain TA97. No significant associations were found between chemical indices and mutagenicity in strain TA100.

\section{Frying experiment}

The batch of frying fat (brand B) used for deep fat frying under controlled conditions was found to contain $6 \%$ (by weight) polar compounds. During frying this level increased to $28 \%$ and $40 \%$ after 20 and 40 hours of frying respectively (Table 3.1). No significantly increased formation of TBA-RS was observed after 40 hours of frying. Figure 3.3 shows mutagenicity results of the polar and non-polar fractions of fat samples taken during the frying experiment. Values are expressed as number of revertants per $\mathrm{mg}$, and were obtained by linear regression. Mutagenic activity of the polar fraction obtained with solvent 2 was increased after 20 hours of frying, but declined after 40 hours of frying when compared to 20 hours. The non-polar fraction contained mutagenic substances after 40 hours of frying. Mutagenicity of the polar fraction was reduced in the presence of $\$ 9 \mathrm{mix}$.

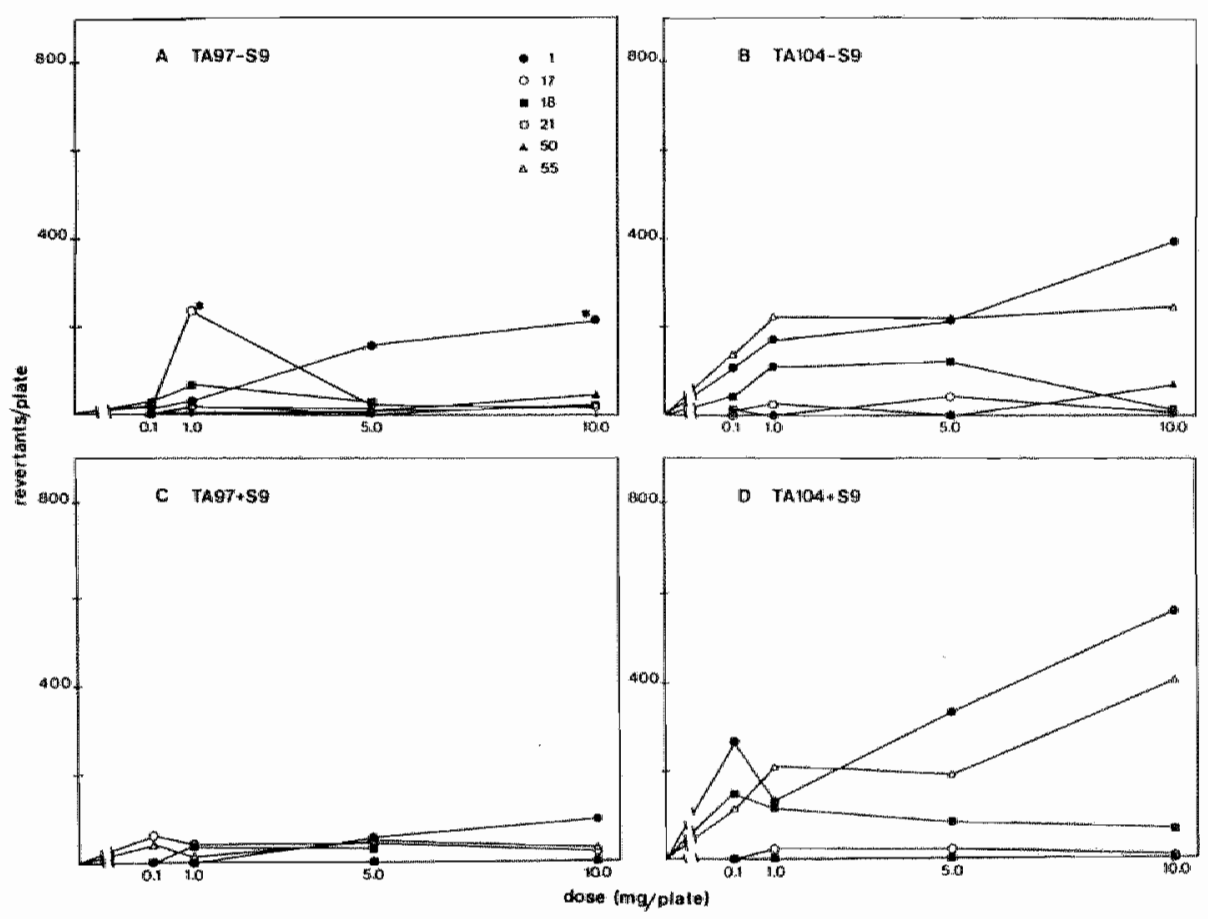

Figure 3.2. Mutagenic activity of non-polar fractions of used deep frying lat samples $1(-17), 17$

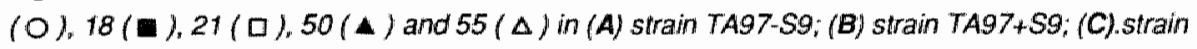
TA104-S9; (D) strain TA104+S9. For further information see legend of Figure 3.1. 
Table 3.2. Mutagenicity of polar fractions obtained from commercially used deep-frying tats

Number of hist revertants in strain:

\begin{tabular}{|c|c|c|c|c|c|}
\hline \multirow[b]{2}{*}{$\begin{array}{l}\text { Sample } \\
\text { no. }\end{array}$} & \multirow[b]{2}{*}{$\begin{array}{l}\text { Dose } \\
\text { (mgiplate) }\end{array}$} & \\
\hline & & $\begin{array}{l}\text { TA97 } \\
-S 9\end{array}$ & $\begin{array}{l}\text { TA97 } \\
+ \text { S9 }\end{array}$ & $\begin{array}{l}\text { TA100 } \\
-\$ 9\end{array}$ & $\begin{array}{l}\text { TA100 } \\
+ \text { S9 }\end{array}$ \\
\hline \multirow[t]{2}{*}{1.} & 5 & $341^{b}$ & $250^{b}$ & 21 & 0 \\
\hline & 10 & $248^{b}$ & $322^{b}$ & 9 & 11 \\
\hline \multirow[t]{2}{*}{2.} & 5 & 102 & 33 & (0) & NT \\
\hline & 10 & $30^{a}$ & 133 & (0) & NT \\
\hline \multirow[t]{2}{*}{13.} & 5 & 85 & 2 & 18 & 67 \\
\hline & 10 & $248^{b}$ & 132 & $154^{b}$ & $82^{a}$ \\
\hline \multirow[t]{2}{*}{14.} & 5 & $149^{a}$ & $162 a$ & 70 & 32 \\
\hline & 10 & $92 a$ & $208^{a}$ & $152^{a}$ & 58 \\
\hline \multirow[t]{2}{*}{19} & 5 & 80 & 95 & $249^{b}$ & $149^{b}$ \\
\hline & 10 & $335^{b}$ & $346 b$ & $236^{b}$ & $215^{b}$ \\
\hline \multirow[t]{2}{*}{22.} & 5 & $508^{b}$ & $517^{b}$ & $349^{b}$ & $122^{a}$ \\
\hline & 10 & $480^{b}$ & $284^{b}$ & $370 b$ & $136^{a}$ \\
\hline \multirow[t]{2}{*}{25.} & 5 & $184 a$ & 80 & $163^{b}$ & 21 \\
\hline & 10 & $250^{b}$ & 132 & $134^{a}$ & 0 \\
\hline \multirow[t]{2}{*}{30.} & 5 & $587^{b}$ & $447 b$ & $317^{b}$ & $200^{b}$ \\
\hline & 10 & $411^{b}$ & $1041^{b}$ & $475^{b}$ & $500^{b}$ \\
\hline \multirow[t]{2}{*}{35.} & 5 & $156^{a}$ & $204^{a}$ & $83^{a}$ & $139 a$ \\
\hline & 10 & $754^{b}$ & $490^{b}$ & 23 & $112^{a}$ \\
\hline \multirow[t]{2}{*}{43} & 5 & $346 b$ & $182^{a}$ & $146^{a}$ & 33 \\
\hline & 10 & $380^{b}$ & $299 b$ & $173^{b}$ & $303^{b}$ \\
\hline \multirow[t]{2}{*}{44.} & 5 & $176^{a}$ & $170 a$ & $81 a$ & $185^{b}$ \\
\hline & 10 & $239 b$ & $223^{a}$ & $239 b$ & $103 a$ \\
\hline
\end{tabular}


Table 3.2. - continued

Number of his ${ }^{+}$revertants in strain:

\begin{tabular}{|c|c|c|c|c|c|}
\hline \multirow{3}{*}{$\begin{array}{l}\text { Sample } \\
\text { no. }\end{array}$} & \multirow{3}{*}{$\begin{array}{l}\text { Dose } \\
\text { (mg/plate) }\end{array}$} & \\
\hline & & TA97 & TA97 & TA100 & TA100 \\
\hline & & $-\$ 9$ & +59 & $-\$ 9$ & $+S 9$ \\
\hline \multirow[t]{2}{*}{45} & 5 & 95 & $192^{a}$ & $115^{a}$ & 34 \\
\hline & 10 & $245^{b}$ & $310^{b}$ & $207^{b}$ & 61 \\
\hline \multirow[t]{2}{*}{49} & 5 & $327^{b}$ & $220^{a}$ & $99 a$ & 39 \\
\hline & 10 & $445 b$ & $416^{b}$ & $141 b$ & $94^{a}$ \\
\hline \multirow[t]{2}{*}{55.} & 5 & $257^{b}$ & $142^{a}$ & $92^{a}$ & 3 \\
\hline & 10 & $473^{b}$ & $185^{a}$ & $245^{b}$ & 43 \\
\hline \multirow[t]{2}{*}{56.} & 5 & 276 & 98 & $98^{a}$ & 35 \\
\hline & 10 & $720^{b}$ & $280^{b}$ & $9.4 a$ & 21 \\
\hline \multirow[t]{2}{*}{58.} & 5 & $193^{a}$ & 60 & 68 & 0 \\
\hline & 10 & $(68)$ & 79 & $159^{b}$ & $2: 2$ \\
\hline
\end{tabular}

Unused fat:

$\begin{array}{cccccc}\text { A } & 0.1 & 0 & 0 & \text { NT } & \text { NT } \\ & 1 & 108 & 0 & \text { NT } & \text { NT } \\ & & 232 b & 222^{a} & \text { NT } & 93 a\end{array}$

The number of spontaneous revertants (solvent controls) of 152,223,93 and 109 for TA9\%S9, TA97+S9, TA100-S9 and TA100+S9 respectively has been subtracted. Values are given in parentheses when foxic effects are observed. All fractions were dissolwed in THF with the exception of sample 55. "NT. Not tested; a significantly different from control values, $p<0.01, b$ significantly different from control values, $p<0.001$. 
Table 3.3. Mutagenicity of non-polar fractions obtained from commercially used deep-frying fats

Number of hist revertants in strain:

\begin{tabular}{|c|c|c|c|c|c|}
\hline \multirow{2}{*}{$\begin{array}{l}\text { Sample } \\
\text { no. }\end{array}$} & \multirow[b]{2}{*}{$\begin{array}{l}\text { Dose } \\
\text { (my/plate) }\end{array}$} & \\
\hline & & $\begin{array}{l}\text { TA97 } \\
-S 9\end{array}$ & $\begin{array}{l}\text { TA97 } \\
+S 9\end{array}$ & $\begin{array}{l}\text { TA100 } \\
-S 9\end{array}$ & $\begin{array}{l}\text { TA100 } \\
+\$ 9\end{array}$ \\
\hline \multirow[t]{2}{*}{2} & 5 & 63 & 12 & 6 & 0 \\
\hline & 10 & (0) & 62 & 16 & 8 \\
\hline \multirow{2}{*}{13.} & 5 & 101 & 53 & 22 & 7 \\
\hline & 10 & $135^{a}$ & 115 & 12 & $107^{a}$ \\
\hline \multirow{2}{*}{14.} & 5 & 54 & 0 & 31 & 8 \\
\hline & 10 & 68 & 77 & 16 & 40 \\
\hline \multirow{2}{*}{19.} & 5 & 24 & 25 & 13 & 35 \\
\hline & 10 & 38 & 77 & 28 & 60 \\
\hline \multirow[t]{2}{*}{22.} & 5 & $172^{a}$ & 36 & 11 & 0 \\
\hline & 10 & 104 & 40 & 54 & 20 \\
\hline \multirow[t]{2}{*}{25.} & 5 & 104 & 67 & 38 & 1 \\
\hline & 10 & $(49)$ & (0) & 37 & 23 \\
\hline \multirow[t]{2}{*}{30.} & 5 & 117 & 29 & 37 & 39 \\
\hline & 10 & $205^{a}$ & 22 & 34 & 42 \\
\hline \multirow[t]{2}{*}{35.} & 5 & 56 & 0 & 0 & 7 \\
\hline & 10 & $134 a$ & 47 & 12 & 0 \\
\hline \multirow[t]{2}{*}{43.} & 5 & 149 & $166^{a}$ & 21 & $77^{a}$ \\
\hline & 10 & 120 & 86 & 99 & 140 \\
\hline \multirow[t]{2}{*}{44} & 5 & $316^{b}$ & $211 a$ & 25 & 19 \\
\hline & 10 & $133^{a}$ & 76 & 5 & 6 \\
\hline
\end{tabular}


Table 3.3. - continued

Number of hist revertants in strain:

\begin{tabular}{lccccc}
$\begin{array}{l}\text { Sample } \\
\text { no. }\end{array}$ & $\begin{array}{l}\text { Dose } \\
\text { (mg/plate) }\end{array}$ & $\begin{array}{l}\text { TA97 } \\
-S 9\end{array}$ & $\begin{array}{l}\text { TA97 } \\
+S 9\end{array}$ & $\begin{array}{c}\text { TA100 } \\
-S 9\end{array}$ & $\begin{array}{l}\text { TA100 } \\
+S 9\end{array}$ \\
\hline & & & & & \\
45. & 5 & 100 & 50 & 37 & 0 \\
& 10 & 68 & 79 & 14 & 14 \\
& 59. & $191 a$ & 83 & 20 & 17 \\
& 10 & $287 b$ & $149 a$ & $105 a$ & 24 \\
56. & 5 & $211 a$ & 110 & 52 & $78 a$ \\
& 10 & $149 a$ & 296 & $121 a$ & 20 \\
58. & 5 & 53 & 46 & 14 & 13 \\
& 10 & 42 & 45 & 12 & 21
\end{tabular}

Unused fat

\begin{tabular}{cccccc} 
A & 5 & 4 & 0 & NT & NT \\
& 10 & 0 & 0 & NT & NT \\
B & 10 & 55 & 28 & 7 & 0 \\
\hline
\end{tabular}

The number of spontaneous revertants per plate have been subtracted. All fractions were dissolved in THF. For numbers of spontaneous revertants and an explanation of the used symbols, see legend of Table 3.2 .

\section{Discussion}

This paper presents the first evidence that mutagens are present in repeatedly used deep frying fats. Mutagenic activity of used deep frying fats appears to be detected most sensitively by strain TA97. This new tester strain, that is reverted by frameshift mutations at the G.C. base pairs, has previously been found to be very suitable for the detection of mutagenic pyrolyzates (Kuroda et al., 1985). Application of this strain may account for the discrepancy with other reports on mutagenicity of used deep frying fat fractions (Scheutwinkel-Reich et al., 1981; Taylor et al., 1982b; Van Gastel et al., 1984). Mutagenic activity of the frying fat samples cannot be explained 
by the presence of trace amounts of histidine in the frying fat. Increased reversion trequencies found for several samples in strain TA97 were not observed for the same samples using strain TA100. Also addition of S9 mix to non-toxic fractions often reduced the number of revertants which would not be observed if traces of histidine were present in the frying fat.

Deep frying fat fractions are weakly mutagenic, since significant mutagenic activity is found at high doses ranging from 1 to $10 \mathrm{mg}$. However, when numbers of revertants are calculated per gram of fat, mutagenic activity is ranging from $1 * 10^{3}$ to $3 * 10^{4}$ revertants per gram, approximating values that have been reported for fried beef fractions (Springarn et al., 1981; Taylor et al., 1982; 1983; Nilsson et al., 1986). In polar material isolated from unused frying fats mutagenicity is also detected, suggesting that during manufacturing or storage prior to use mutagenic substances are formed. Unused frying fats do not contain more than 2 to $6 \%$ polar compounds which implies that mutagenic activity per gram of unused frying fats is not exceeding $10^{3}$ revertants.

Results from our own frying experiment showed decreased mutagenicity in the polar fraction after 40 hours of frying as compared to 20 hours. This effect might be explained by the fact that mutagenic products formed during earlier stages of frying may be diluted or deactivated by other polar compounds. Also degradation of mutagenic substances during prolonged heating may have caused the observed decline in mutagenicity. Based on sensoric evaluation of the fried foods after 40 hours of use, the fat would have been found not suitable for consumption and discarded or replenished. Mutagenic activity of repeatedly used fining fat is likely to be caused by various substances, since addition of $\mathbf{S 9}$ mix to different samples resulted in both increase and inhibition of mutagenicity. It has previously been shown that fat enhances mutagen formation during frying of meat (Springarn et al.,1981; Nilsson et al., 1986). This enthancing effect is considered to be the result of a more efficient heat transfer, but a more specific role of fat in mutagen formation cannot be excluded.

The positive correlation observed between mutagenicity in strain TA97 and TBA-RS may indicate the involvement of lipid oxidation products in mutagen formation duting deep fat frying. Various oxidation products of fatty acids, including malondialdehyde, alkenals, carbonyls and hydroperoxides have already been found to be mutagenic (Mukai and Goldstein, 1976; Yamaguchi and Yamashita, 1979; 1980; Marnett et all., 1984; MacGregor et al., 1985). However, levels of TBA-RS in frying fats as shown in this study are generally low, which previously has been reported by Shamberger et al. (1977). Furthermore, since the TBA assay is non-specific, additional analysis elucidating the nature of mutagens formed during deep fat frying is necessary. Mutagenic heterocyclic amines may also be present in small 


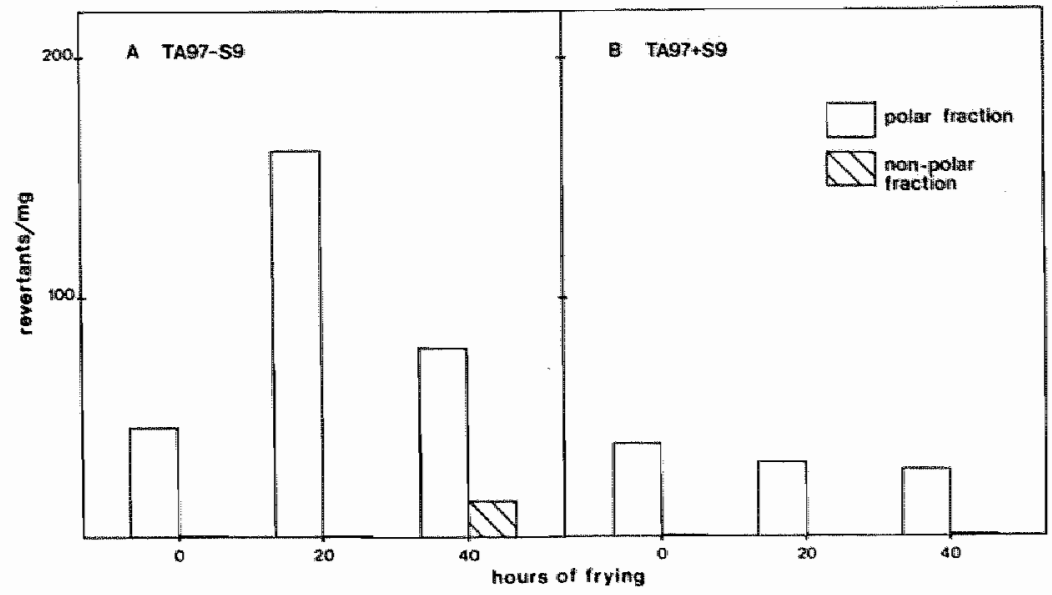

Figure 3.3. Mutagen formation during deep fat frying, (A) Mutagenic activity in strain TA97S9; (B) Mutagenic activity in strain TA97+S9.

Table 3.4. Correlations between mutagenicity of polar fractions and levels of di- and polymeric triglycerides (DPTG), polar compounds (PC) and thiobarbituric acid-reacting substances (TBA-RS) of used frying fat samples.

Coefficient of correlation with mutagenicity in strain:

\begin{tabular}{lcccc}
\hline Parameter & TA97-S9 & TA97+S9 & TA100-S9 & TA100+S9 \\
\hline \multirow{2}{*}{ DPTG } & -0.27 & -0.35 & -0.44 & -0.34 \\
& $(n=17)$ & $(n=19)$ & $(n=15)$ & $(n=15)$ \\
PC & -0.43 & -0.36 & -0.23 & -0.26 \\
& $(n=17)$ & $(n=19)$ & $(n=15)$ & $(n=15)$ \\
TBA-RS & $0.66 a$ & $0.58 a$ & -0.02 & 0.25 \\
& $(n=16)$ & $(n=18)$ & $(n=14)$ & $(n=14)$ \\
\hline
\end{tabular}

In parentheses the number of samples is given, toxic fractions have been excluded; significant correlation, $p<0.01$. 
quantities in the frying fat. Formation of these heterocyclic amines occurs during heating of mixtures of sugars, amino acids and creatinine at moderately high tempreatures (Sugimura et al., 1986). Heterocyclic amines and other pyrolyzates may be formed in the foods during deep fat frying and small amounts possibly migrate into the frying fat.

During deep fat frying the fat is absorbed by the fried food; a portion of French fried potatoes can absorb 5-10\% (by weight) of frying fat (Stevenson et al., 1984). Thus, consumption of one portion of French fried potatoes prepared in mutagenic frying fat may imply the intake of several grams of mutagenic polar compounds. Although repeatedly used deep frying fats are not highly mutagenic, chronic or large scale consumption may be of concern regarding possible health effects. Finally, mutagenicity of used deep trying fat samples appears not to be related to chemical indices currently used for quality assessment, emphasizing the need for a re-evaluation of applied chemical analyses with respect to biological effects.

\section{References}

Alexander, J.C. (1981). Chemical and biological properties related to toxicity of heated fats, J.

Toxixol. Environ. Health $7,125-138$.

Alexarider J.C., V.E. Valli and B.E. Chanin (1987). Biological observations from feeding heated corn oil and heated peanut oil to rats, J. Toxicol. Enwiron. Health 21, 295-309.

Andia; A.G. and J.C Street (1975). Dietary induction of thepatic microsomal enzymes by thermally oxidized fals, J. Agr. Food Chem. 23, 173-177.

Billek, G. (1976). Heated oils - Chemistry and nutritional aspects, Nutr. Metab. 24, 200-210.

Billek, G. , G. Guhr and J. Waibel (1978). Quality assessment of used irying fats: a comparison of four methods, J. Am. Oil Chem. Soc. 55, 728-733.

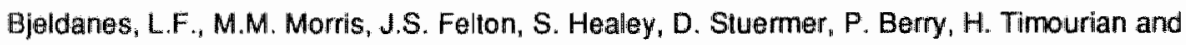
F.T. Hatch (1982a). Mutagens form the cooking of lood. II. Survey by Ames/Salmonella tesl of mutagen formation in the major protein-rich foods of the American diet, Fd Chem. Toxic. 20, 357-363.

Bjeldanes, L.F., M.M. Morris, J.S. Feiton, S. Healy, D. Stuermer, P. Berry, H. Timourian and F.T. Hatch (1982b). Mutagens from the cooking of food. Ill. Survey by Ames/Salmonella test of mutagen formation in secondary sources of cooked dietary protein "Fd Chem. Toxic. 20, 365-369.

Fong, L.Y.Y., C.C.T. Ton, P. Koonaunwatchaidet and D.P. Huang (1980). Mutagenicity of peanut oils and effect of repeated cooking. Fd Cosmet. Toxicol. 18, 467-470.

International Organization for Standardization - ISO (1986). Animal and vegetable fats and oils

- Determination of polar compounds, Final Draft Proposal DP 8420.

International Organization for Standardization - ISO (1980). Animal and vegetable fats and oils

- Preparation of tesit sample, First Edition. Ref. No. ISO-661-1980. International Organization for Standardization - ISO (1983). Animal and vegetable fats and oils - 
sampling, First Edition Ref. No. ISO-5555-1983.

lzaki, Y., S. Yoshikawa and M. Uchiyama (1984). Effects of ingestion of thermally oxidized frying oll on peroxidative criteria in rats, Lipids $19,324-331$.

Kuroda, M. D. Yoshida and S. Mitzusaki (1985). Mutagenicity of pyralyzates of natural substances toward Salmonella typhimuritum TA97, Agric. Biol. Chem. 49, 1893-1895.

MacGregor, J.T., D.E. Wilson, W.E. Neff and E.N. Frankel (1985). Mutagenicity test of lipid oxidation products in Salmonella typhimurium: monohydroperoxides and secondary oxidation products of methyl linoleate and methyl linolenate, Fd Chem. Toxic. 23, 1041 1047.

Marnett "L.J., H.K. Hurd, M.C. Hollstein, D.E. Levin, H. Esterbauer and B.N. Ames (1984). Naturally occurring carbonyl compounds are mutagenic in Salmonella tester strain TA104, Mutation Pes. 148, 25-34.

Maron, D.M. and B.N. Ames (1983). Revised methods for the Salmonella mutagenicity lest. Mutation Res. 113, 173-215.

Mukai, F.H. and B.D. Goldstein (1976). Mutagenicity of malonaldehyde, a decomposition product of peroxidized polyunsaturated fatty acids, Science 191, 868-869.

Nilsson, L., E. Overvik, L. Fredholm, O. Levin, C.E. Nord and J.A. Gustatsson (1986). Influence of frying fat on mutagenic activity in lean pork meat, Mutation Res. 171,115 121.

Scheutwinkel-Reich, M., G. Ingerowski and H.J. Stan (1981). Microbiological studies investigating mutagenicity of deep frying fat fractions and some of their components, Lipids $15,849-852$.

Shamberger, R.J., B.A. Shamberger and C.E. Willis (1977). Malonaldehyde content of food, J. Nutr. 107, 1404-1409.

Springarm, N.E., C. Garvie-Gould, L.L. Vuolo and J.H. Weisburger (1981). Formation of mutagens in cooked foods. IV. Effect of fat content in beef patties, Cancer Lett. 12, 93 97.

Stevenson, S.G. M. Vaisey-Genser and N.A.M. Eskin (1984). Quality control in the use of deep firying oils, J. Am. Oil Chem. Soc. 61, 1102-1108.

Sugimura, T., S. Sato, H. Oghaki, S. Takayama, M. Nagao and K. Wakabayashi (1986) Mutagens and carcinogens in cooked food. Overview, in: Genetic toxicology of the diet. Alan R. Liss, New York, pp. 85-107.

Taylor, S.L., C.M. Berg, N.H. Shoptaugh and V.N. Scotl (1982). Lack of mutagens in deepfat-fried loods obtained at the retail level, Fo Chem. Toxic. 20, 209-212.

Taylor, S.L., C.M. Berg, N.H. Shoptaugh and E. Traisman (1983). Mutagen formation in deep fat fried foods as a function of frying conditions, J. Am. Oil Chem. Soc 60, 576-580.

Van Gastel, A., R. Mathur, V.V. Roy and C. Rukmini (1984). Ames mutagenicity test of repeatedly heated edible oils, Fd Chem. Toxic. 22, 403-405.

Yamaguchi, $T$. and $Y$. Yamashita (1979). Mutagenic activity of autoxidized linolenic and linoleic acid, Agric. Biol. Chem. 43, 2225-2226.

Yamaguchi, $T$. and $Y$. Yamashita (1980). Mutagenicity of hydroperoxides of fatty acids and some hydrocarbons, Agric. Biol. Chem. 44, 1675-167. 


\title{
Chapter 4
}

\section{Linoleic acid hydroperoxide concentration in relation to mutagenicity of repeatedly used deep-frying fats}

\author{
G. Hagerman, F. KIkken, F. ten Hoor and J. Kleinjans
}

Lipids 24, 899-902, 1989

\begin{abstract}
A high-performance liquid chromatography procedure was developed to measure linoleic acid hydroperoxides (LAHPO) in 19 used deep-frying fat samples that were screened for mutagenicity. The detection limit of the method was found to be 10 minoll LAHPO/g of fat. $\ln 8$ samples "LAHPO were not detected, levels in the other samples ranged from 17 to 267 $\mathrm{nmol} / \mathrm{g}$ of fat. LAHPO were not detectable in unused hydrogenated fiying fat samples.
\end{abstract}

Concentrations of LAHPO correlated positively with mutagenicity to Salmonella tester strains TA97 and TA100, in presence of $\$ 9 \mathrm{mix}$ only; coefficients of correlation were respectively $r=0.48 \quad(p<0.05)$ and $r=0.24(n . s$.). Without metabolic activation no significant associations were observed.

These results suggest that metabolites or secondary autoxidation products of linoleic acid generated in presence of liver $\$ 9$ mix may contribute to mutagenicity of some of the used deep-frying fat samples. 


\section{Introduction}

Thermal and oxidative deterioration of fats and oils during deep-fat frying is of major concern with regard to possible adverse health effects, as well as the quality of foods prepared. When fed to laboratory animals, heated oils and lats have been reported to cause growth retardation, increase relative liver and kidney weights, induce detoxifying enzyme activities and lipid peroxidation in the liver, and produce cellular damage to liver, kidneys and epididymides $(1,2,3,4)$. Heating of fats and oils causes degradation of triglycerides, which may involve hydrolysis into free fatty acids as well as free radical mediated oxidation reactions of polyunsaturated fatty acids. Ultimately, di- and polymeric triglycerides as well as low molecular weight decomposition products are formed, both volatile and non-volatile (5). Isolated lipid oxidation products, autoxidation products of methyl linoleate and methyl linolenate, hydroperoxides of methyl linoleate, malondialdehyde and various other aldehydes and carbonyls have been found mutagenic in the Salmonella/microsome assay $(6,7,8,9,10)$.

Recently, we have also observed mutagenic activity in repeatedly used deep-frying fats, sampled from local snack-bars and restaurants (11). In our study, highest mutagenic activity has been found in the polar fraction of these fats, separated by means of silicagel column chromatography, which indicates that polar oxidation and degradation products are involved. The contribution of lipid oxidation products to mutagenicity of these used fats has also been implicated by the positive correlation between mutagenicity of the polar fraction to strains TA97 and TA100 and levels of thiobarbituric acidreactive substances (TBA-RS) of the fats (11). The thiobarbituric acid assay, however, is of limited value since it not only detects malondialdehyde but also other saturated aldehydes (12), as well as derivatives of amino acids, carbohydrates and nucleic acids that have been damaged by free radicals (13).

Since linoleic acid hydroperoxides (LAHPO) have been reported to exert mutagenic activity in the Salmonella/microsome assay using tester strains. TA97 and TA100 (6), the objective of the present study was to evaluate further the contribution of lipid oxidation products to mutagenicity of used deep-frying fats by quantifying the concentrations of LAHPO and relating these to mutagenicity of the fats. Therefore, we developed a highperformance liquid chromatography (HPLC) assay measuring the primary oxidation products LAHPO, which has been modified from the method described by Teng and Smith (14) 


\section{Experimental}

\section{Reagents}

Linoleic acid and soybean lipoxygenase, type $V$ (EC 1.13.11.12), were obtained from Sigma, St. Louis (MO, USA). Sodium borate and analytical grade glacial acetic acid were purchased from Merck, Darmstadt, FRG. Chromatography solvents, all of the highest purity available were obtained from Fisons, Loughborough, England.

\section{Preparation of LAHPO}

Hydroperoxides of linoleic acild were enzymatically prepared using linoleic acid as substrate, and purified by thin layer chromatography as described by Teng and Smith (14). Hydroperoxides were visualized using $\mathrm{N}_{1} \mathrm{~N}$-dimethyl-p-phenilene-diamine spray and recovered from simultaneously cleveloped chromatoplates by scraping oft the correspondent area's. LAHPO were extracted from the silicagel using diethyl ether. After evaporating the diethyl ether under a stream of nitrogen, LAHPO were dissolved in hexane and the concentration was determined spectrophotometrically at $234 \mathrm{~nm}$ using a molar extinction caefficient of $2.7 * 10^{4} \mathrm{l} / \mathrm{mol} . \mathrm{cm}(15)$.

\section{Determination of LAHPO in deep-frying fat samples}

Twenty deep-frying fat samples, that had been screened for mutagenic activity, were stored under refrigeration until the moment of analysis. Unused control samples were stored and processed under the same conditions. One sample was withdrawn from the experiment because the amount of material left after mutagenicity testing was not sufficient for further analyses. Deep-frying fat samples of $50 \mathrm{mg}$ were dissolved in $0.5 \mathrm{ml}$ hexane, after which the mixture was extracted 3 times with $0.5 \mathrm{ml}$ acetonitrile/water $(1: 1$, w/v). The combined aqueous extracts were subjected to HPLC analysis. Aliquots of $20 \mu \mathrm{l}$ were separated on a Chromsep LiChrosorb RP18 column, $200 \times 3.0$ ID with guard column (Chrompack, Mididelburg. The Netherlands) applying a quaternary eluent composed of tetrahydrofuran/acetonitrile$/$ water/acetic acid $(45: 100: 100: 1, v / v / v / v)$ at a flow rate of $0.2 \mathrm{~m} / \mathrm{min}$. Peaks were detectedi by an UV-detector (Spectroflow 783 UV, Kratos Analytical) sel at 234 nm. Positive identification of LAHPO was based on retention time and spiking of fat samples with a known amount of purified LAHPO. A callbration curve was obtained using enzymatically prepared and purified LAHPO, which were added to $50 \mathrm{mg}$ of unused deep-frying lat that contained no detectable LAHPO.

\section{Mutagenicity testing of deep-frying fat samples}

Sixty deep-frying fat samples were obtained from local snack-bars and restaurants. Twenty were selected based on presence of di- and polymeric triglycerides, 10 samples had concentrations exceeding $10 \%$ (by weight). Samples were separated into two major fractions by means of silicagel column chromatography (11); a non-polar petroleum ether fraction, which has been reported to consist of non-polar degradation products of fatty acids and unaltered triglycerides, and a polar acidified diethyl ether fraction, which has been found to contain polar oxidation and degradation products (16). Non-polar and polar fractions were screened for mutagenicity using Salmonella lyphimurium tester strains TA97 (20 samplles) and TA100 (14 samples) in absence and presence of liver $\$ 9$ mix obtained from Aroclor 
induced rats. Samples were dissolved in tertrahydrofuran and tested at doses ranging from $0.11010 \mathrm{mg} / \mathrm{plate}$ using a liquid preincubation of $20 \mathrm{~min}$ at $37{ }^{\circ} \mathrm{C}(17)$. Unused fat samples as well as solvent controls were also included. A more detailed description of the protocols used for mutagenicity testing has been given elswhere (11). The mutagenic actiwity of the nonpolar and polar fractions was estimated by extrapolation of the linear, non-toxic portion of dose-response curves applying linear regression. Mutagenicity per $\mathrm{g}$ of frying fat was calculated by summation of mutagenic activity of non-polar and polar fractions.

\section{Results and discussion}

Chromatograms of enzymatically obtained and purified LAHPO and of LAHPO extracted from a deep-frying fat sample are given in Figure 4.1. Isomers of LAHPO, cis-trans or trans-trans stereo isomers of 9-hydroperoxy10,12-octadecadienoate and 13-hydroperoxy-10,12-octadecadieno-ate, elute in three peaks, of which the exact conformation is not known. Confirmation of the hydroperoxide identity has been obtained by analysis of aliquots of the mixture of linoleic acid and lipoxygenase after $0,10,20$ and 30 minutes of incubation; heights of the three peaks have been found to increase as the reaction proceeded. The total amount of LAHPO is calculated from the chromatograms by summation of the three peak heights.

Figure 4.2 shows the calibration curve of LAHPO in deep-frying fat. Detection limit of the method is $10 \mathrm{nmol} / \mathrm{g}$ of fat. Purified LAHPO dissolved in hexane are detectable at concentrations of $0.1 \mathrm{nmol} / \mathrm{ml}$. Recovery of added LAHPO is determined for 4 concentrations of the calibration curve. Mean recovery $( \pm S D)$ is $94 \pm 6 \%$. Reproducibility of the method, as determined by triplicate extraction and analysis of $39.5 \mathrm{nmol}$ LAHPO added to $1 \mathrm{~g}$ of deepfrying fat, yields an intra-assay coefficient of variation of $3 \%$, and an inter-

Levels of LAHPO measured in repeatedly used deep-frying fat samples range from below the detection level to $267 \mathrm{nmol} / \mathrm{g}$ (Table 4.1). LAHPO are below the detection level in two different brands of unused hydrogenated deep-frying fat (data not given). Seventeen out of 19 repeatedly used deepfrying fat samples tested are mutagenic; mean mutagenicity in strain TA97 without S9 mix is 18128 revertants/g (range: $943-86065$ revertants $/ g$ ). In presence of $\mathrm{S} 9 \mathrm{mix} 12$ samples show mutagenic activity; mean mutagenicity is 16415 revertants/g (range: $5875-35671$ revertants $/ g$ ). Twelve out of 14 samples tested with strain TA100 show mutagenic activity without $\mathrm{S} 9$ mix; Inean mutagenicity is 8319 revertants/g (range: $1760-12210$ revertants/g). In presence of $S 9$ mix 7 samples are mutagenic; mean mutagenicity is
10558 revertants/g (range: $3740-17010$ revertants $/ g$ ). 


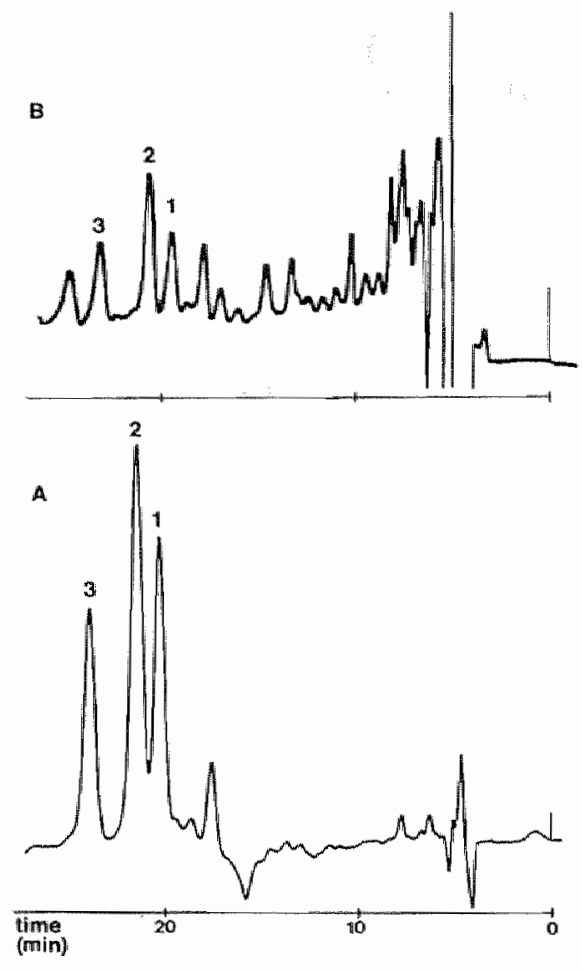

Figure 4.1. High-performance liquid chromatograms of hydroperoxides of linoleic acid (peaks 1, 2 and 3); (A) Enzymatically prepared and purified hydroperoxides of linoleic acid; (B) Hydroperoxides of linoleic acid extracted from a repeatedly used deep-frying fat sample.

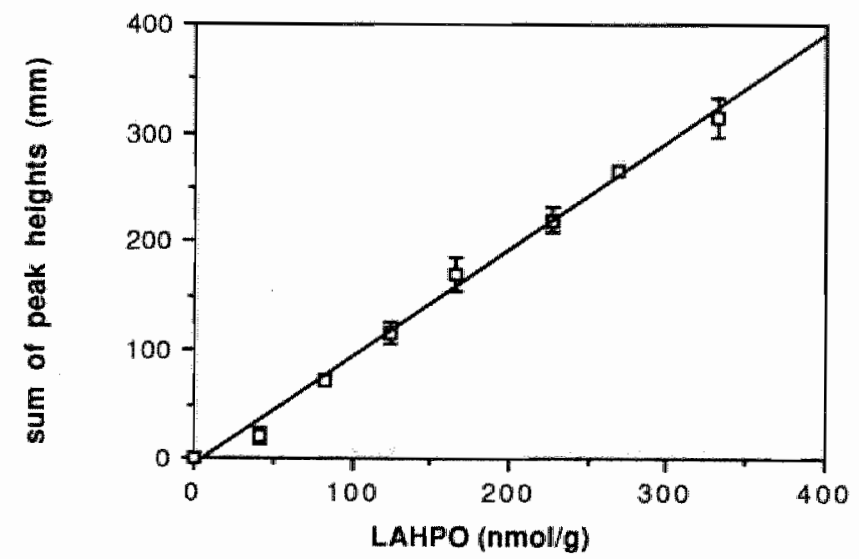

Figure 4.2. Calibration curve of enzymatically prepared and purified LAHPO adided to an unused deep-frying fat sample and extracted with acetonitrile:water $(1: 1 \mathrm{v} / \mathrm{v})$. The detection level is to nmol/g of fat. Results are expressed as mean $\pm S D$. 
Table 4.1. Linoleic acid hydroperoxide (LAMPO) concentrations of 19 used deep-frying fat samples (mean $\pm S D$ ).

Sample

LAHPO

(nmoles/g)

$\begin{array}{lc}1 & 65 \pm 1 \\ 2 & 78 \pm 4 \\ 13 & <10 \\ 14 & 200 \pm 5 \\ 17 & <10 \\ 18 & 170 \pm 12 \\ 19 & <10 \\ 21 & 20 \pm 8 \\ 22 & 17 \pm 1 \\ 25 & <10 \\ 30 & 257 \pm 10 \\ 35 & 160 \pm 16 \\ 43 & 107 \pm 3 \\ 45 & 267 \pm 2 \\ 49 & 49 \pm 1 \\ 50 & <10 \\ 55 & <10 \\ 56 & <10 \\ 58 & <10\end{array}$

Since LAHPO have been found to be present in non-polar as well as in polar fat fractions separated by silicagel column chromatography, mutagenic activity calculated per $g$ of frying fat has been compared with levels of LAHPO analyzed in unfractionated fat samples. LAHPO concentrations of repeatedly used deep-frying fat samples correlate positively with mutagenicity to Salmonella typhimurium tester strain TA97 in presence of S9 mix $(r=0.48, p<0.05, n=19)$. In absence of S9 mix, no statistically significant association is observed $(r=0.02)$. Correlations between LAHPO levels and mutagenicity to strain TA100 show the same tendency: without S9 mix mutagenicity of the fats to strain TA100 is not associated with LAHPO 
levels $(r=0.07, n=14)$, while in presence of $S 9$ mix a weak, but statistically insignificant positive correlation has been found ( $r=0.24)$. In addition, LAHPO concentrations and mutagenic activity to both strains TA97 and TA100, added together reflecting the overall mutagenic potency to induce frameshift as well as base pair mutations, revealed a similar relationship. In absence of $S 9$ mix total mutagenic potency and LAHPO concentrations showed no correlation $(r=0.05, n=14)$, whereas in presence of $S 9$ mix a positive, but statistically insignificant correlation was found $(r=0.48, n=14)$.

Fatty acid hydroperoxides are the first isolatable oxidation products of polyunsaturated fatty acids, which now are reported to be present in used deep-frying fat samples. Although most brands of deep-frying fats consist of hydrogenated oils and thus contain low amounts of polyunsaturated fatty acids, during deep-fat frying of various foods polyunsaturated fatty acids migrate from the food into the fat, thereby increasing the $\mathbb{P} / S$ ratio (18). During heating of the frying fat, hydroperoxides of linoleic acid and other polyunsaturated fatty acids may be formed and remain in the frying fat in detectable amounts after cooling down. This has actually been demonstrated in a separate experiment in our laboratory, in which increased levels of LAHPO have been observed after repeated use in a frying oil containing $60 \%$ linoleic acid. LAHPO are not detected in unused frying oil of this particular type, while after 10,20 and $30 \mathrm{~h}$ of frying LAHPO have been found to be present in a concentration of 17,55 and $62 \mathrm{nmol} / \mathrm{g}$, respectively. In this experiment it was also found that LAHPO in used deep-frying fats are stable for at least 2 weeks while stored under refrigeration. Stored fat samples analyzed within 3 days after frying and again after 2 weeks showed no systematically increased or decreased concentrations of LAHPO.

Whereas in general concentrations of TBA-RS (19) or the conjugated diene-fraction (20) are determined as an indication of lipid oxidation of fats or foods, identification of lipid oxidation products in relation to mutagenic activity requires more specific assays. In addition to determination of LAHPO, assays detecting unsaturated aldehydes and carbonyls appear to be of greater relevance (7). These oxidation products have been reported to possess mutagenic activity in Salmonella tester strain TA104 (7), and have also been detected in lipid oxidation studies in vitro using rat liver microsome preparations (21).

The positive correlation observed in the present study between LAHPO levels and mutagenic activity with $\mathrm{S} 9$ mix is in accordance with mutagenicity data obtained by other authors $(6,9)$, who report mutagenic acitivity of hydroperoxides of methyl linoleate and oxidized linoleic acid solutions with high peroxide values in presence of $\mathrm{S} 9 \mathrm{mix}$. The positive correlation found between mutagenicity of repeatedly used deep-frying fat samples in presence of S9 mix and LAHPO concentrations may be explained by three 
different mechanistic routes. Firstly, autoxidation of LAHPO and concomitant oxidation of other polyunsaturated fatty acids, is very likely to occur during incubation in the Salmonella mutagenicity assay due to the presence of trace amounts of iron or other transition metals (22), especially with S9 mix. It is not clear however, to what extent autoxidation may take place in $\mathrm{S} 9 \mathrm{mix}$. since $\$ 9$ homogenate also posesses free radical scavenging activities. Secondly, mutagenic metabolites of LAHPO may be derived as a result of degradation by cytochrome $P_{450}$ activities of LAHPO. Thirdly, oxidation of polyunsaturated fatty acids, present in fat samples or in microsomal membranes, by cylcooxygenase or lipoxygenase resulting in mutagenic intermediates, may be enhanced in presence of LAHPO, which specificly has been demonstrated by Marshall et al. (23) for the oxidation of arachidonic acid by cyclooxygenase in plasma.

Although used deep-frying fats have been observed to exert potent direct-acting mutagenic activity in some of these samples mutagenicity in presence of $\$ 9$ mix appears to be induced by metabolites or secondary autoxidation products of LAHPO as well. Future studies therefore, will be concentrated on isolation and identification of direct-acting mutagenic compounds as well as possible mutagenic metabolites or secondary axidation products of LAHPO in used deep-frying fats.

\section{References}

1. Alexander, J.C. (1981) J. Toxic. Environ. Health 7,125-138.

2. Alexander, J.C., Valli, V.E, and Chanin, B.E. (1987) J. Toxic. Environ. Health 21, 295309.

3. Izaki, Y., Yamashita, S., and Uchiyama, M. (1984) Lipids 19, 324-331.

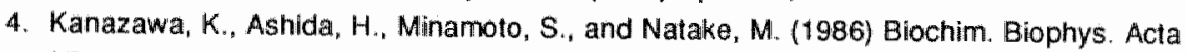
$879,36-43$.

5. Chang, S.S., Peterson, R.J., and Ho, C. (1978) J. Am, Oil Chem. Soc. 55, 718-727,

6. MacGregor, J.T. Wilson, A.E., Neff, W.E., and Frankel, E.N. (1985) Food Chem. Toxic. 23, 1044-1047.

7. Marnett, L.J., Hurd, H.K., Holstein, M.C., Levin, D.C., Esterbauer, H., and Ames, B.N. ("1985) Mutation Res. 148, 25-34.

8. Mukai, F.H., and Goldstein, B.D. (1976) Science 191, 868-869.

9. Yamaguchi, T., and Yamashita, Y. (1979) Agric. Biol. Chem. 43, 2225-2226.

10. Yamaguchi, $T_{\text {,; }}$ and Yamashita, $Y$. (1980) Agric. Biol. Chem. 44, 1675-1678.

11. Hageman, G., Kikken, R., Hoor, F. ten, and Kleinjans, J. (1988) Mutation Res. 204, 593604 .

12. Kosugi, $H_{2}$ and Kikugawa, K. (1986) Lipids 21, 537-542.

13. Gutteridge, J.M.C. (1982) Int. J. Biochem. 14,649-653.

14. Teng, J.l., and Smith, L.L. (1985) J. Chromatogr. 350, 445-451. 
15. Pryor, W.A.s and Castle, L. (1984) Methods Enzymol. 105, 293-299.

16. Billek, G., Guhr, G. and Waibel, J. (1978) J. Am. Oil Chem. Soc. 55; 728-733.

17. Maron, D.M., and Ames, B.N. (1983) Mutation Res. 113, 173-215.

18. Thompson, L.U., and Aust, R. (1983) Can. Inst. Food Scl. Technol. d. 16, 246-253.

19. Shamberger, R.J., Shamberger, B.A., and Willis, C.E. (1977) J. Nutr. 107, 1404-1409.

20. Brown, H.G., and Snyder, H.E. (1982) J. Am. Oil Chem. Soc. 59, 280-283.

21. Esterbauer, H., Cheeseman, K.H., Dianzani, M.U., Poli, G., and Slater, T.F. (1982) Biochem. J. 208, 129-140.

22. Frankel, E.N. (1987) Chem. Phys. Lipids 44, 73-85.

23. Marshall, P.J., Warso, M.A., and Lands, W.E.M. (1985) Anall. Biochem. 145, 192-199. 


\title{
Chapter 5
}

\section{Comparison of mutagenicity of repeatedly used deep- frying fats in the Salmonella/microsome assay with genotoxicity to human lymphocytes in vitro}

\author{
G. Hageman, I. welle, T. Volleberg ${ }_{n}$ B. van Agen and J. Kleinjans
}

\section{Abstract}

Production of mutagenic compounds in repeatedly used deep-frying fats was evaluated for different types of frying fat and frying of various food products. In two polyunsaturated latty acid (PUFA)-rich oils out of the three different fats tested in a first series of experiments and used for preparation of freshly sliced potatoes, extensive oxidative deterioration and toaming occurred after $30 \mathrm{~h}$ of use. These oils did not show significant direct-acting mutagenicity to strain TA97; one heated PUFA-rich oil increased numbers of revertants to strain TA97 in presence of $S 9$ mix. In a second series of experiments, four different brands of frying oil, specifically developed for deep-fat frying, were used for preparation of various foods, including meat and starchy products. After $30 \mathrm{~h}$ of use "increased mutagenicity to strain TA97 without metabolic activation was observed for all fats, which appeared not to be related to the amount of various polar oxidation products formed.

Three heated fats which showed highest mutagenicity in the Salmonella/microsome assay, were selected for further genotoxicity testing, which involved analysis sister chromatid exchange (SCE) frequencies and mutations at the hypoxanthine guanine phosphoribosyl transferase (hgprt) locus in human peripheral lymphocytes, in order to assess genotoxic risk of exposure to repeatedly used deep-frying fats. A dose-dependent, significant increase in SCE frequencies was observed after exposure of lymphocytes to the PUFA-rich frying oil, used for preparation of various foods. Other fats did not show dose-dependent increases in SCE frequencies. Significantly increased mutations at the hgprt locus were observed after exposure of human lymphocytes to frying oil used for preparation of polatoes, but upon retesting this could not be confirmed, which might have been due to degradation of instable. compounds during storage of the lat. Other heated fats did not significantly increase mutations at the HGPRT locus of lymphocytes. Two heated fats were observed to enhance cell proliferation of PHA-stimulated T-lymphocytes. No associations were observed between stimulation of cell proliferation, mutagenicity in the Salmonella/microsome assay, genotoxicity to human lymphocytes, and oxidative indices of repeatedly used deep-frying fats as determined by concentrations of di- and polymeric triglycerides, linoleic acid hydroperoxides and thiobarbituric-acid reactive substances.

The diversity of effects observed in the present study indicates that genotoxicity as well as other biological effects of repeatedly used deep-frying fats may be caused by various compounds not known at present, and may also be modulated by other tactors, such as the presence of natural antioxidants. More information on these subjects is needed before a reliable estimation can be made of health risks posed by consumption of deep-fat fried foods. 


\section{Introduction}

In a previous study performed at our laboratory, several repeatedly used deep-irying fats, sampled at local snack-bars and restaurants after sensory indication of abuse, were found to contain compounds that were mutagenic to Salmonella typhimurium tester strains TA97. TA100 or TA104 (Hageman ef al. 1988). Mutagenicity was observed mainly in the polar fraction (PF) of the fat, isolated by silicagel column chromatography, which has been reported to consist mainly of polar oxidation and degradation products of lipids (Billek et al., 1978). In the same study, frying of various foods under controlled conditions, applying a temperature of $180^{\circ} \mathrm{C}$ with repeated use of the fat and overnight cooling, was also demonstrated to result in increased mutagenicity of the polar fraction of the fat. Furthermore, mutagenic activity of repeatedly used deep-frying fats was found to be correlated with levels of thiobarbituric acid-reactive substances (TBA-RS), as well as with concentrations of linoleic acid hydroperoxides (LAHPO) of the fats, which suggests that lipid peroxidation products might be involved in mutagen formation during deep-fat frying (Hageman et al., 1988; 1989a).

Oxidative and thermal deteriloration of fats during heating has been reported to be influenced by numerous factors, including source and fatty acid composition of the fat, presence of antioxidants, both naturally present and added during processing, contamination with trace amounts of transition metals, presence of trace amounts of oxidized lipids (peroxides), heating temperatures applied, nature and amounts of foods prepared frying procedures followed, i.e. continuously heating versus intermittent heating, etc. (Stevenson et al., 1984; Chang et al., 1978; Pokorny et al., 1975). These factors may also be involved in mutagen formation, but only a few have been studied in this sense. Taylor et al. (1983) have shown that thermal abuse of frying oil, by heating at temperatures exceeding 200 o $\mathrm{C}$ or by over-cooking of foods, resulted in increased mutagenicity of the foods. The same authors have also reported that the nature of foods fried may influence mutagenicity of the fat and of deep-fat fried foods, since significant mutagenicity has been observed after frying of fish fillets with prolonged use of the oil, but not after frying of potatoes or onion rings.

Since we demonstrated significant mutagenic activity in lipid fractions isolated from commercially used deep-frying fat samples, as well as in commercially fried potatoes (Hageman et al., 1988; 1990), the first aim of the present study was to evaluate mutagen formation during deep-fat frying in relation to various deep-frying conditions. Factors of primary interest were nature of the frying tat, especially polyunsaturated fatty acid (PUFA)-content, and the nature of foods prepared. In a first series of experiments, effect of PUFA-content was investigated by measuring mutagen formation after frying of freshly sliced potatoes using standardized frying procedures, in 3 brands 
of commercially obtained fats with varying levels of PUFA. Mutagenicity of the fat was assessed in the Salmonella/microsome assay using strain TA97, which was previously found to be most sensitive in detecting mutagenic activity of used deep-frying fats (Hageman et al., 1988). In a second series, mutagen formation during frying of various foods, including meat products, was determined. Four commercial brands of fat which are specifically developed for deep-fat frying, were evaluated.

Mutagenicity of compounds, as assessed by the Salmonella/microsome assay, is considered an indication of possible carcinogenic risk. However, genotoxicity to human DNA, may be a more valuable tool in assessing carcinogenic risk to man. Therefore, the second aim of this study was to asess genotoxicity of used deep-frying fats in short-term assays, using human peripheral T-lymphocytes. For this purpose, those fats were selected for further analysis, which showed increased mutagenic activity in the Salmonella/microsome assay after repeated use. Genotoxicity in human lymphocytes after in vitro exposure was determined measuring sister chromatid exchange (SCE) frequencies and single gene mutations at the hypoxanthine guanine phosphoribosyltransferase (hgprt) locus, using a modified procedure developed at our laboratory (Hageman et al., 1989b).

Lipid oxidation products of linoleic and arachidonic acid were reported to exert genotoxic effects in various short-term assays using mammalian cells (Brambilla et al., 1986; Nakayama et al., 1986; Cajelli et al., 1987; Vaca et al., 1988; Weitberg et al., 1989). Furthermore, we previously found that mutagenicity of used deep-frying fats in the Salmonella/microsome assay was associated with presence of lipid oxidation products (Hageman et al., $1988 ; 1989 \mathrm{a})$. Therefore, concentrations of di- and polymeric triglycerides (DPTG), TBA-RS and LAHPO were determined in the fats selected for further genotoxicity testing with human lymphocytes, in order to evaluate the possible involvement of these lipid oxidation products.

\section{Materials and methods}

\section{Frying procedures}

Mutagen fiormation during frying was followed in two different experiments, using 6 different brands of frying fat, which were obtained trom local supermarkets. Batches of 3 to 10 $\mathrm{kg}$ were purchased and stored at $4^{\circ} \mathrm{C}$ until use, which was within one week. The following types of frying fat were evaluated: I. Frying oil, consisting of vegetable oils (> $60 \%$ polyunsaturated fatty acids; PUFA), anti-foaming agent E900 (dimethyl polysiloxane) added; III. partly hydrogenated vegetable oils, anti-foaming agent added; lll sunflower seed oil; IV. fractionated beef tallow (stearine fraction removed); $V$. coconut oil; $V /$ hydrogenated vegetable and animal fats, anti-foaming agent added (all specifications as declared by 
manulacture rs).

In the first series of frying experiments, lats $\|$ (batch A) to III were heated in a home-style temperature-contralled firyer al $180^{\circ} \mathrm{C}$, for $10 \mathrm{~h}$ per day during 3 consecutive days. Every $2 \mathrm{~h}_{\mathrm{v}}$ alternating, $250 \mathrm{~g}$ portions off freshly peeled potatoes, or portions of $2 \mathrm{~h}$ earlier pre-fried potatoes were fried for $4 \mathrm{~min}$. Actual frying temperatures ranged from 160 to $190^{\circ} \mathrm{C}$. After 30 h of trying excessive foaming occurred, which did not allow prolonged use of the fats. Unused lat, as well as heated flat samples were stored at $4^{\circ} \mathrm{C}$ until analysis. In a second series of experiments fats I (new batch; B), and IV to VI were heated in a similar way as the initially heated fats, but instead of frying of potatoes, various foods were prepared according to manutacturers" instructions, including $300 \mathrm{~g}$ of treshly sliced polatoes, $300 \mathrm{~g}$ of meat croquettes, $300 \mathrm{~g}$ of hamburgers, $300 \mathrm{~g}$ of sausages and $250 \mathrm{~g}$ of pre-fried potatoes. For comparison with results of the first experiment, heating of the lat was limited to $30 \mathrm{~h}$.

\section{Salmonella mutagenicity testing}

Mutagenicity of the fat samples in the Salmonella/microsome assay was determined as described prewiously (Hageman et al., 4988). For initial screening, mutagenic activity of fats heated for 30 th was compared to the unheated control samples, using strain TA97, which was found to be most sensitive in detecting mutagenic activity of heated frying lats (Hageman et al. 1988). Briefly, fat samples were separated into non-polar (NPF) and polar fractions (PF), using silicagel column chromatography. NPF and PF were dissolved in tetrahydrofuran (THF). which was destilled before use. Mutagenicity of NPF and PF was ewaluated applying doses of $0.11,1.0,5.0$ and $10.0 \mathrm{mg}$ per plate, using Salmonella typhimurium tester strain TA97 for initial screening. Additional screening of mutagenicity in strain TA100 was applied only to fats selected for further analysis of genotoxicity. Lipid fractions were incubated both with and without liver S9 mix (50 $\mu$ ll of homogenate/plate) obtained from Aroclor induced rats. Chromatography and solvent controls as well as positive controls were included as described previously (Hageman et al., 1988). Statistical analysis of imutagenicity data was performed using the method of least significant difference (LSD; MacGregor et als, 1985). Doses of NPF or $\mathrm{PF}$ inducing numbers of revertants that exceeded the correspondent solvent control by LSD values at a confidence level of $p<0.05$, were considered mutagenic. LSD values obtained in this study were at a confidence level of $p<0.05$ for THF as solvent with TA97-S9, 120; TA97+S9, 105; TA100-S9, 146; TA100, S9, 114. Mean numbers of revertants observed for THF (solwent control) were for TA97-S9, 176; TA97+S9, 209; TA100-S9, 98; TA100+S9, 104. Mutagenic activity of the NPF and PF of frying tat was assessed applying linear regression to non-toxic portions of dose response curves of NPF and PF separately. Multiplication of the mutagenic activity per mg of NPF or PF, by the amount of the respective fraction present per $g$ ol fat, yielded mutagenic activity per $g$ of fat.

\section{Chemical analyses}

Several indices of oxidative deterioration were determined in lats selected for further genotoxicity testing, including measurement of DPTG by means of gel-permeation high performance liquid chromatography (HPLC), analysis of TBA-RS using a colorimetric assay, and HPLC analysis of LAHPO, all pertormed as described previously (Hageman el al., $1988 ; 1989 a)$. 


\section{SCE frequency analysis}

Induction of SCE in human T-lymphocytes in vitro after exposure to used deep-irying fats was evaluated according to the procedure described previously (Kleinjans et al, 1989). Briefly, heparinized blood samples were obtained from a healthy female donor, who was not under medication including use of oral contraceptives, and who had no history of smoking. An aliquot of $0.4 \mathrm{ml}$ of whole blood was added to $4.5 \mathrm{ml}$ RPMI 1640 complete medium. Cell proliferation was stimulated by addition of $0.2 \mathrm{ml}$ of phytohemagglutinin (PHA). After a $24 \mathrm{~h}$ incubation period at $37^{\circ} \mathrm{C}, 5$-bromodeoxyuridine (BrdU) was added to the lymphocyte culture to a final concentration of $58 \mu \mathrm{M}$. After $48 \mathrm{~h}$ of incubation, suspensions of frying fats were added to the cultures. Fats were suspended in sterile culture tubes with screw caps, in RPM 1640 medium without supplements, under sonification at $50^{\circ} \mathrm{C}$ for $30 \mathrm{~min}$. Dilutions of the emulsions were made immediately after sonification, and $0.5 \mathrm{ml}$ volumes were added to the cultures. Fat samples were tested at doses of $0.1,1.0$ and $10.0 \mathrm{mg} / \mathrm{mll}$. After $72 \mathrm{~h}$, metaphases were arrested by addition of colcemid (final concentration $0.2 \mu \mathrm{g} / \mathrm{ml}$ ) and subsequent incubation for $2 \mathrm{~h}$. Nuclei were collected using a hypotonic KCl solution (75 m) and fixed in methanol:acetic acid $(3: 1, w / v)$, after which slides were prepared. All test doses were evaluated in duplicate; a solvent control (RPMI treated by sonification) and a positive control (mitomycin $\mathrm{C}, 3 * 10^{-8} \mathrm{M}$ ) were also included. Since the mutagienic potency in the Salmonella/microsome assay of direct-acting compounds present in repeatedly used deep frying fat samples was observed to be higher as compared to mutagenicity in presence of liver S9 mix (Hageman et al., 1988; 1990), genotoxic activity in thuman lymphocytes was not evaluated in presence of rat liver $\$ 9$ mix.

Slides were stained using the fluorescence-plus-Giemsa method according to Perry and Wolff (1974). Slides were coded, after which 20 metaphases per cell culture were analyzed; a total of 40 metaphases was evaluated per test dose. All metaphases were analyzed by a single person; $10 \%$ of the slides was evaluated by a different observer, which revealed no systematic errors in scoring of SCE frequencies. SCE frequencies of test doses were compared to controls, statistical significance of differences was evaluated using Students' t" test for unpaired values. Linear trend of dose-response curves was assessed applying regression analysis.

\section{In vitro HGPAT assay with human lymphocytes}

Induction of TGr T-lymphocytes by heated fats in vitro (HGPRT assay) was determined using a procedure developed at our laboratory (Hageman et al. 1989b). Since a considerable. inter-assay variation was found in the HGPRT assay, fats were tested in 2 separate assays within a 1-week period. Brielly, heparinized blood samples were obtained from the same donor providing the blood for the SCE assay. Suspensions of the fats were prepared as described tor the SCE assay. In a pillot study initially performed (experiments 1 and 2), fat I A, both fresh and heated, was evaluated at a concentration of $1 \mathrm{mg} / \mathrm{ml}$, which is well within the range of triglyceride levels found in human blood (Anonymous, 1981). In a second series of tests (experiments 3 and 4), heated fat I A was evaluated at a dose range of 0.01 to $1.0 \mathrm{mg} / \mathrm{ml}$ Fats I $B$ and $V$, tested in experiments 5 and 6 , which were performed within 1 month after the frying experiments, were evaluated at a dose range of 0.1 to $10.0 \mathrm{mg} / \mathrm{ml}$. Solvent control cultures, consisting of RPMI medium which was uttrasonically treated, were also included in 
each assay. Cultures consisting of $0.4 \mathrm{ml}$ heparinized blood, $4.5 \mathrm{ml}$ RPMI medium without supplements and $0.5 \mathrm{ml}$ of fat suspension were incubated at $37^{\circ} \mathrm{C}$ for $4 \mathrm{~h}$, which was the maximum incubation period used in the standardized protocols (Hageman et al. 1989b). After multagen treatment, cells were washed with pre-warmed PBS of $37^{\circ} \mathrm{C}$ and resuspended in $5.0 \mathrm{ml}$ RPMI complete medium to which $0.2 \mathrm{ml} \mathrm{PHA}$ and $0.1 \mathrm{ml}$ of a $10 \mathrm{mM}$ TG solution in RPMI (TG culture), or $0.1 \mathrm{ml}$ of TG control RPMI solution (control culture) were addled. Per test dose, a total of 6 cultures was sel up 2 cultures for measurement of the labeling index ( $\left(\mathrm{L}_{\mathrm{C}}\right.$ ), and 4 cultures for the enumeration of TG' T-lymphocytes. Cultures were incubated at $37^{\circ} \mathrm{C}$ for $24 \mathrm{~h}$, atter which BrdU was added to a final concentration of $10 \mu \mathrm{M}$. After an additional incubation period of $16 h$, cells were harvested, nuclei prepared , fixed in methanol:acetic acid $(3: 1$, viv), and transferred to clean microscope slides. Two drops of $10 \mu \mathrm{l}$ af the control cultures were pipetted onto one slide for determination of the $\mathrm{LI}_{\mathrm{C}}$. During fixation, $2 \mathrm{TG}$ cultures were combined in order to maximize number of nuclei per slide. In a 1.50 diluted suspension the number of nuclei present in the combined culture was determined in triplicate. The complete combined $\mathrm{TG}$ culture was transferred onto one slide in $25 \mu \mathrm{l}$ portions, meanwhile determining the volume. lert-Butylhydroperoxide $(\mathrm{tBOOH})$, representing the class of mutagenic hydroperoxides and regarded as a possible positive control, was screened for its potential to induce TGr T-lymphocytes in vitro. $\mathrm{tBOOH}$ was dissolved in sterile destilled demineralized water shorly before use and tested up to its toxic limit, at doses ranging from $1 * 10^{-6}$ to $1 * 10^{-3}$ $M$.

TG and control slides were stained using mouse monoclonal antibodies against BrdU in combination with peroxidase-conjugated secondary antibodies. In short "DNA was denatured using $4 \mathrm{~N} \mathrm{HCl}$, after which slides were incubated at $37^{\circ} \mathrm{C}$ for $1 \mathrm{~h}$ with mouse monoclonal antiBrdU antibodies (clone IIBV), which were a gift from Dr. Bert Schutte, Department of internal Medicine, University of Limburg, Maastricht, The Nietherlands. Next, BrdU-containing nuclei were labeled by means of incubation with peroxidase-conjugated rabbit anti-mouse IgG antibadies (RAMPO; F114, Dakopatts, Denmark). BrdU-containing nuclei were stained brown by immersing the slides in $0.05 \mathrm{M} \mathrm{Tris/HCl}$ buffer of $\mathrm{pH} 7.6$, containing $0.04 \%(\mathrm{w} / \mathrm{v}) 3,3^{2}$ diamiriobenzidine (Fluka Chemie, Switzerland) and $0.01 \%$ (v/v) $\mathrm{H}_{2} \mathrm{O}_{2}$, protected from light at room temperature. Non proliferating nuclei of control slides were counterstained using Giemsa stain. TG slides were not immediately counterstained, but coded first, after which all $\mathrm{TG}^{r}$ nuclei were enumerated using normal light microscopy $(400 \mathrm{x}) . \mathrm{L}_{C}$ was determined by evaluation of at least 1000 nuclei per control culture, at total of least 2000 nuclei was evaluated per test dose.

Variant frequency (Vt) of TG" lymphocytes per test dose was calculated as:

$\mathrm{Vf}=$ number of BroU-containing nuclej;

number of evaluable nuclei,

the number of evaluable nuciei being derived from the totall number of nuclei present on TG slides, multiplied by the $\mathrm{LI}_{\mathrm{C}}$. Differences between VI's of control and test doses within one experiment were statistically evaluated using $95 \%$ binomial confidence intervals of the ratio of Vf's, as described by Sylwester and Albertini (1985). 


\section{Results}

In the first series of frying experiments, use of fats I and III had to be terminated after $30 \mathrm{~h}$ of heating due to excessive foaming during irying of sliced potatoes. Therefore, heating time of $30 \mathrm{~h}$ was chosen for comparison of mutagenic activity of all used fats to the unheated control samples " as shown in Table 5.1. The amounts of polar material found after $30 \mathrm{~h}$ of use appear to be highest in fats $\| \mathrm{A}$ and $\| I$, indicating a relation between oxidative deterioration and practical cut-off points for use. Frying of freshly sliced potatoes appeared to enhance oxidative deterioration of the frying oils, especially if these contained high levels of polyunsaturated fatty acids (PUFA).

Polar fractions of used fats $\left|B_{n}\right| V, V$ and $V \mid$ exhibited significant mutagenicity to strain TA97 without $\$ 9$ mix, polar fractions of unused fats II and $V I$ were also found to be mutagenic. Furthermore, it was observed that mutagenic activity found in unused fat II was decreased after $30 \mathrm{~h}$ of use. Mutagenicity of used fats I B, IV, VI and of unused fats II and VI appeared to be reduced in presence of $S 9$ mix. Fat I A, botth used and unused, contained compounds that exhibited toxic effects to the bacteria. Upon testing of this oil in presence of $\mathrm{S} 9 \mathrm{mix}$, mutagenicity was detected in the polar fraction of the heated oil which appeared to be highest of all samples tested. Results presented in Table 5.1, indicated that mutagenicity of repeatedly used deepfrying fats was not related to the amount of polar oxidation products present. With the exception of results of fat I A, which might be confounded by the presence of toxic compounds, frying of various foods appeared to enhance mutagen formation as compared to frying of freshly sliced potatoes. indicated by the larger proportion of samples showing increased mutagenicity after repeated use for preparation of various foods.

Since the purpose of this study was to compare mutagenicity of repeatedly used deep-frying fats in the Salmonella/microsome assay with genotoxicity in human lymphocytes, fats I B and $V$ were selected for further analyses. These fats fullfilled the selection criteria, since unused fats I B and $V$ were not mutagenic, and showed highest mutagenicity after repeated use, whereas mutagenic activity appeared to be reduced in presence of $\mathrm{S} 9$ mix. which was observed in most of the mutagenic fats studied previously (Hageman et al., 1988: 1990). Therefore, these fats were considered to be representative of the group of mutagen-containing repeatedly used deepfrying fats. Fat I A was included in genotoxicity testing in human lymphocytes for comparison with fat I B, as well as for its apparent incompatibility with the Salmonella/microsome assay. 
Table 5.1. Amounts of polar material (polar fraction; PF), and mutagenicity of unheated and heated deep-frying fats to Salmonella tester strain TA97.

mutagenic activity in strain TA97

\begin{tabular}{llll} 
Fat Heating & PF & without $S 9$ mix \\
time(h) & (revig of fat) & $\begin{array}{l}\text { with } 59 \text { mix } \\
\text { (revig of fat) }\end{array}$ \\
\hline
\end{tabular}

\begin{tabular}{|c|c|c|c|c|}
\hline \multirow[t]{2}{*}{ IA } & 0 & 3.1 & to 1 & $10 x$ \\
\hline & 30 & 30.0 & tox & 4067 \\
\hline \multirow[t]{2}{*}{ 11 } & 0 & 3.5 & 1371 & $\mathrm{~nm}^{2}$ \\
\hline & 30 & 16.6 & 614 & $\mathrm{~nm}$ \\
\hline \multirow[t]{2}{*}{\|\|} & 0 & 2.8 & $\mathrm{~nm}$ & $\mathrm{~nm}$ \\
\hline & 30 & 25.3 & $\mathrm{~nm}$ & $\mathrm{~nm}$ \\
\hline \multirow[t]{2}{*}{$\| B$} & 0 & 3.5 & $\mathrm{~nm}$ & $\mathrm{~nm}$ \\
\hline & 30 & 14.9 & 3200 & 2549 \\
\hline \multirow[t]{2}{*}{ IV } & 0 & $<1$ & $\mathrm{~nm}$ & $\mathrm{~nm}$ \\
\hline & 30 & 17.9 & 1754 & 1074 \\
\hline \multirow[t]{2}{*}{$V^{\prime}$} & 0 & 5.2 & $\mathrm{~nm}$ & $\mathrm{~nm}$ \\
\hline & 30 & 10.8 & 3775 & $\mathrm{~nm}$ \\
\hline \multirow[t]{2}{*}{ WI } & 0 & 2.0 & 1018 & 776 \\
\hline & 30 & 18.0 & 1728 & 1368 \\
\hline
\end{tabular}

Fats I A to III were used exclusively for frying of potatoes, while in fats I B to WI various foods were prepared. Mutagenicity was determined separately in non-polar (NPF) and polar (PF) fractions of the fats. Mutagenic activity per $g$ of fat was obtained applying linear regression to non-toxic portions of dose-response curves of NPF and PF exthibiting significant mutagenicity. Contribution of the tractions to mutagenicity per $g$ of fat was estimated by multiplying mutagenic activity per mg of fraction with the total amount of NPF or PF present pergof fat.

1: toxic to the tester strain

2: not mutagenic 
Mutagenic activity of unused and used fats I $B$ and $V$ was also studied using strain TA100. Unused fats and heated fat $V$ did not show significant mutagenicity in strain TA100, neither in absence nor in presence of $\mathrm{S} 9 \mathrm{mix}$. Polar fractions of used fat I B exhibited significant mutagenicity to strain TA100, either with and without metabolic activation. Numbers of revertants induced were 1851 and 1315 , in absence and presence of metabolic activation respectively. Since fat I $A$ was found to be toxic to the bacteria and was considered to yield unreliable results in the Ames mutagenicity assay, this fat was not further tested using strain TA100.

Results of chemical analyses for determination of the extent of oxidative deterioration of the fats selected for further testing are presented in Table 5.2. Highest concentrations of DPTG, TBA-RS and LAHPO after were observed in heated fat I $A$, whereas lowest levels were observed in heated fat $V$. Concentrations of TBA-RS in fats $I B$ and $V$ were just above the detection limit of $1 \mathrm{nmol} / \mathrm{g}$. Results of chemical analyses indicated that frying of freshly sliced potatoes under the conditions used in our laboratory resulted in higher oxidative deterioration than frying of various foods.

SCE frequencies induced in human lymphocytes after in vitro exposure to frying fats are presented in Table 5.3. Elevated $(p<0.05)$ SCE frequencies were found in fat I A at a doses of $0.1 \mathrm{mg} / \mathrm{ml}$ and in fat $V$ at a dose of 1.0 $\mathrm{mg} / \mathrm{ml}$, but failed to show dose-dependent increases at higher concentrations. Heated fat I B significantly increased SCE frequencies at a dose of $10.0 \mathrm{mg} / \mathrm{ml}(p<0.01)$. A linear dose-dependent increase can be observed over the doses ranging from $0.1-10.0 \mathrm{mg} / \mathrm{ml}$, inducing an increase in SCE frequencies of $1.0,0.4$ and 1.6 , respectively $(p<0.001)$. Unheated fats did not significantly increase SCE frequencies at doses of $10.0 \mathrm{mg} / \mathrm{ml}$. Mitomycin $C\left(3 * 10^{-8} \mathrm{M}\right)$, which was included as the positive control

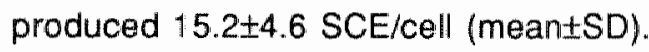

Results of the HGPRT assay using human lymphocytes in vitro are presented in Table 5.4. Significant increase in frequency of TGr $T$ lymphocytes was observed for heated fat I A, tested at a dose of $1.0 \mathrm{mg} / \mathrm{ml}$, whereas unheated fat appeared without activity (experiment 1 and 2). However, when analyzed in a separate series of experiments ( 3 and 4 ), performed 4 weeks later, no significantly increased frequencies were observed at doses ranging from 0.01 to $1.0 \mathrm{mg} / \mathrm{ml}$. Heated fats | $B$ and $V$, did not significantly increase $\mathrm{Vf}$ when tested at doses ranging from 0.1 to 10.0 $\mathrm{mg} / \mathrm{ml}$. Heated fats I A and $\mathrm{V}$, and unheated fat I B appeared to stimulate cell proliferation of PHA-activated T-lymphocytes, whereas heated fat I B decreased $\mathrm{LI}_{\mathrm{C}}$ at high doses, indicating cytotoxic activity (Figure 5.1). Due to severe oxidative damage to erythrocytes in whole blood cultures, highest evaluable dose of $t \mathrm{BOOH}$ appeared to be $100 \mu \mathrm{M}$. $\mathrm{tBOOH}$ did not significant- 
Table 5.2. Concentrations of di- and polymeric triglycerides (DPTG), thiobarbituric acidreactive substances (TBA-RS) and linoleic acid hydroperoxides (LAHPO) measured in unheated and heated deep-frying lats.

\begin{tabular}{llll}
\hline Fat $\begin{array}{lll}\text { Heating } \\
\text { time }(\mathrm{h})\end{array}$ & $\begin{array}{l}\text { DPTG } \\
\text { (\% by weight) }\end{array}$ & $\begin{array}{l}\text { TBA-RS } \\
(\mathrm{nmol} \\
\text { MDAg) }\end{array}$ & $\begin{array}{l}\text { LAHPO } \\
(\mathrm{nmol} / \mathrm{g})\end{array}$ \\
\hline
\end{tabular}

$\begin{array}{ccccc}\text { IA, } & 0 & <11 & 1.5 \pm 0.1 & <2 \\ & 30 & 26.8 \pm 1.0 & 16.5 \pm 0.4 & 62 \pm 4 \\ \text { IB. } & 0 & <1 & <1 & <2 \\ & 30 & 6.4 \pm 0.2 & 2.1 \pm 0.3 & 4 \pm 2 \\ \text { V. } & <1 & <1 & <2 \\ & 30 & <1 & 3.5 \pm 0.3 & <2\end{array}$

Fat IA was used exclusively for frying of potatoes, while in fats $I B$ and $V$ various foods were prepared. Results are presented as mean $\$ S D$.

1: not detectable; detection limits of the methods are 1\% (by weight) for HPLC determination of DPTG; 1 nmolig for colorimetric measurement of TBA-AS; and 2 nmollg for HPLC determination of $L A H P O$.

ly increase Vf's at evaluable doses. At this dose however, $\mathrm{tBOOH}$ was found to enhance cell proliferation (Table 5.4).

Genotoxicity of heated fats as assessed in the Salmonella/microsome assay, as well as by induction of SCE frequencies and single gene mutations in human lymphocytes appeared not to be related to parameters of oxidative deterioration. No associations appeared to exist between induction of SCE frequencies, mutations at the HGPRT locus, and mutagenicity in the Salmonella/microsome assay either. 


\section{Discussion}

Results obtained in the present study indicated that formation of products mutagenic in the Salmonella/microsme assay may be dependent on a number of variables, of which only a few could be elucidated. Frying of freshly sliced potatoes was observed to enhance formation of polar oxidation products especially in fats I A and III which were PUFA-rich, but failed to increase mutagenicity in strain TA97. Toxic effects exerted by fat I A to the bacteria prohibited reliable mutagenicity testing in the Salmonella/microsome assay. Comparison of oxidative indices of fats I A and I B indicated that frying of potatoes was more deleterious with respect to oxidative degradation as well as autoxidation of PUFA. Enhanced formation of DPTG during frying of potatoe slices as compared to veal cutlets, was previously reported by Pokorny'et al. (1975), who suggested that thiols, sul-

Table 5.3. Frequencies of sister chromatid exchanges (SCE) induced in vitro by repeatedly used deep-frying fats.

\begin{tabular}{|c|c|c|c|c|}
\hline \multicolumn{2}{|c|}{ Test compound } & $\begin{array}{l}\text { dose } \\
(\mathrm{mg} / \mathrm{ml})\end{array}$ & SCElcell & SD \\
\hline \multirow[t]{5}{*}{1.} & RPMI medium & 8.0 & 2.2 & \\
\hline & fat $\mid A$, untheated & 10.0 & 8.9 & 3.0 \\
\hline & fat I A, heated & 0.1 & $9.3^{a}$ & 3.1 \\
\hline & & 1.0 & 8.2 & 2.1 \\
\hline & & 10.0 & 8.7 & 2.3 \\
\hline \multirow[t]{9}{*}{2.} & APMI medium & & 7.2 & 2.8 \\
\hline & fat $\mid \mathrm{B}$, unheated & 10.0 & 7.7 & 3.8 \\
\hline & fat I $B$, heated & 0.1 & 7.3 & 2.2 \\
\hline & & 1.0 & 7.6 & 2.7 \\
\hline & & 10.0 & $8.8^{b}$ & 2.3 \\
\hline & fat $V$, unheated & 10.0 & 7.3 & 2.7 \\
\hline & & 0.1 & 7.8 & 2.7 \\
\hline & & 1.0 & $8.5^{a}$ & 2.5 \\
\hline & & 10.0 & 8.0 & 3.2 \\
\hline
\end{tabular}

Fats were heated for $30 \mathrm{~h}$; fat I $\mathrm{A}$ was used exclusively for frying of potatoes, while in fat I $B$ and $V$ various foods were prepared. Significant differences as compared to concurrent controls are indicated by superscripts: ${ }^{a} p<0.05 ;{ }^{b} p<0.01$. 


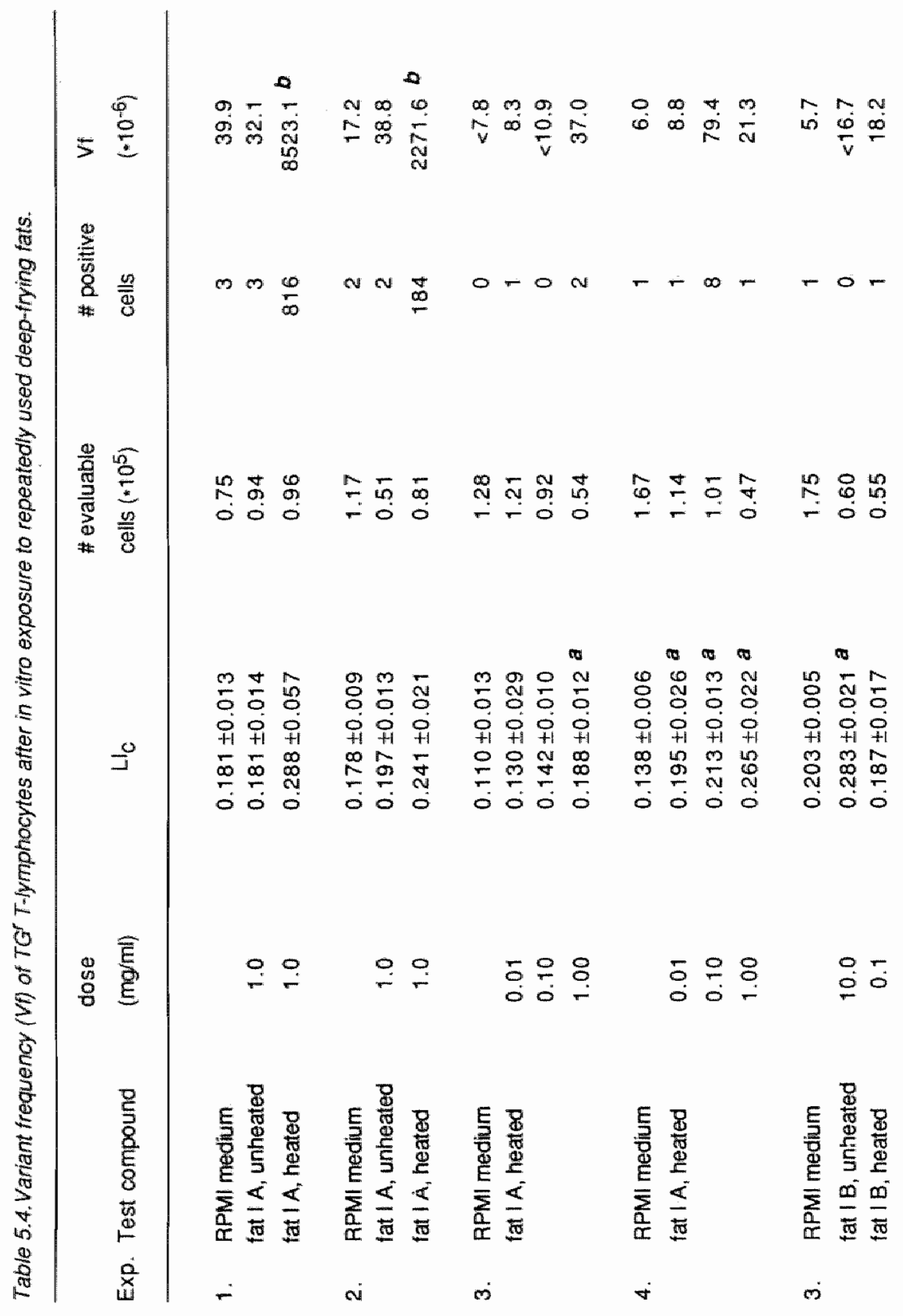




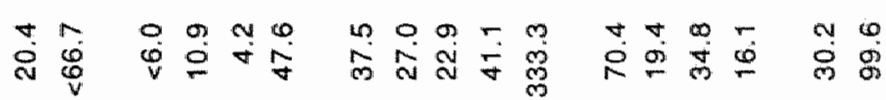

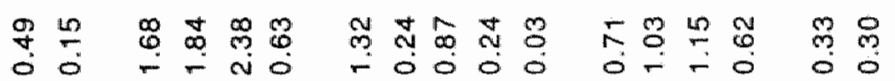

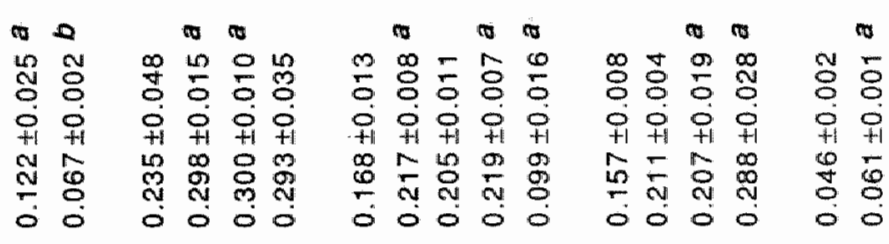

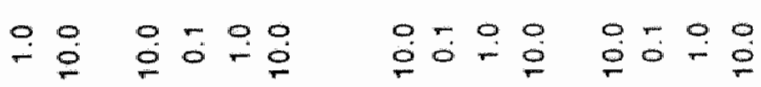

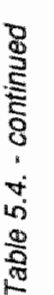
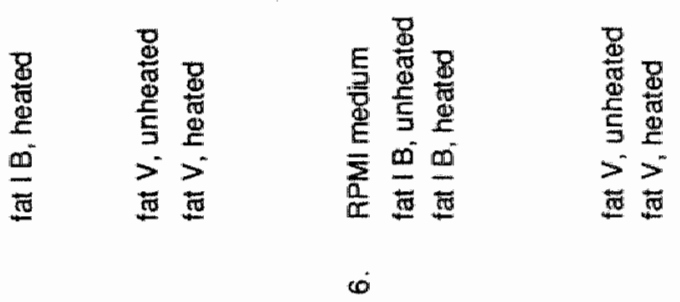
phides or amines present in proteinaceous foods either inhibit autoxidation by free-radical scavenging activities or by binding of oligomers or their precursors.

Frying of various foods including proteinaceous meat products however, did increase mutagenic activity to strain TA97 of all repeatedly used fats evaluated. Previously Taylor et al. (1983) reported that frying of fish fillets, with repeated use of the fat, did result in mutagen formation in the fat, as well as in foods prepared after prolonged use of the fat, whereas after frying of potatoes or onion rings no increased mutagenicity was observed. Results of previous studies performed at our laboratory showed that the degree of mutagenicity was considerably higher in fat used for preparation of various foods (Hageman et al., 1988), than in a different batch of the same type of fat used for frying of potatoes (Hageman et al., 1990). This finding, in combination with results obtained in the present study, suggests that frying of various foods in the same fat enhances mutagen formation in the fat. Numbers of revertants induced in strain TA97 by the repeatedly used fats in the present study were in the lower range of those found in a previous study in which commercially, and presumably abused fat samples were found to induce $1 * 10^{3}$ to $1 * 10^{4} \mathrm{rev} / \mathrm{g}$ of fat (Hageman et al., 1988). It is therefore concluded that deep-fat frying of foods, by applying recommended frying practices, i.e. with frying temperatures not exceeding $180^{\circ} \mathrm{C}$, and limited heating times, is not likely to cause significant mutagenicity of the fat, independent of the nature of the fat.

Since mutagen formation was observed not to be consistently related to oxidative deterioration, PUFA concentration of the fats, or occurrence of mutagenic compounds present in unused fats, it was suggested that mutagen formation during deep-fat frying may be modulated by other factors including presence of antioxidants, both naturally occurring and synthetic (Pongracz, 1988; Stevenson et al., 1984). Evidence for an inhibiting effect of antioxidants was recently obtained at our laboratory. Polar fraction of a fat, which was commercially used for preparation of various foods, increased numbers of revertants in strain TA97 without S9 mix to 4 times the number of spontaneous revertants at a dose of $10 \mathrm{mg} /$ plate. A dose-dependent decrease in mutagenicity was observed after addition of 10,20 and $50 \mu \mathrm{g}$ of beta-carotene per plate. Almost complete inhibition of mutagenicity was observed after addition of the highest dose. Other antioxidants evaluated, including alpha-tocopherol, ascorbic acid, glutathione, and butylated hydroxyanisole also exhibited reducing activity, but were less effective than beta-carotene on a molar base.

In addition, anti-mutagenic compounds might also have been produced during heating. Antioxidative as well as antimutagenic activities were 

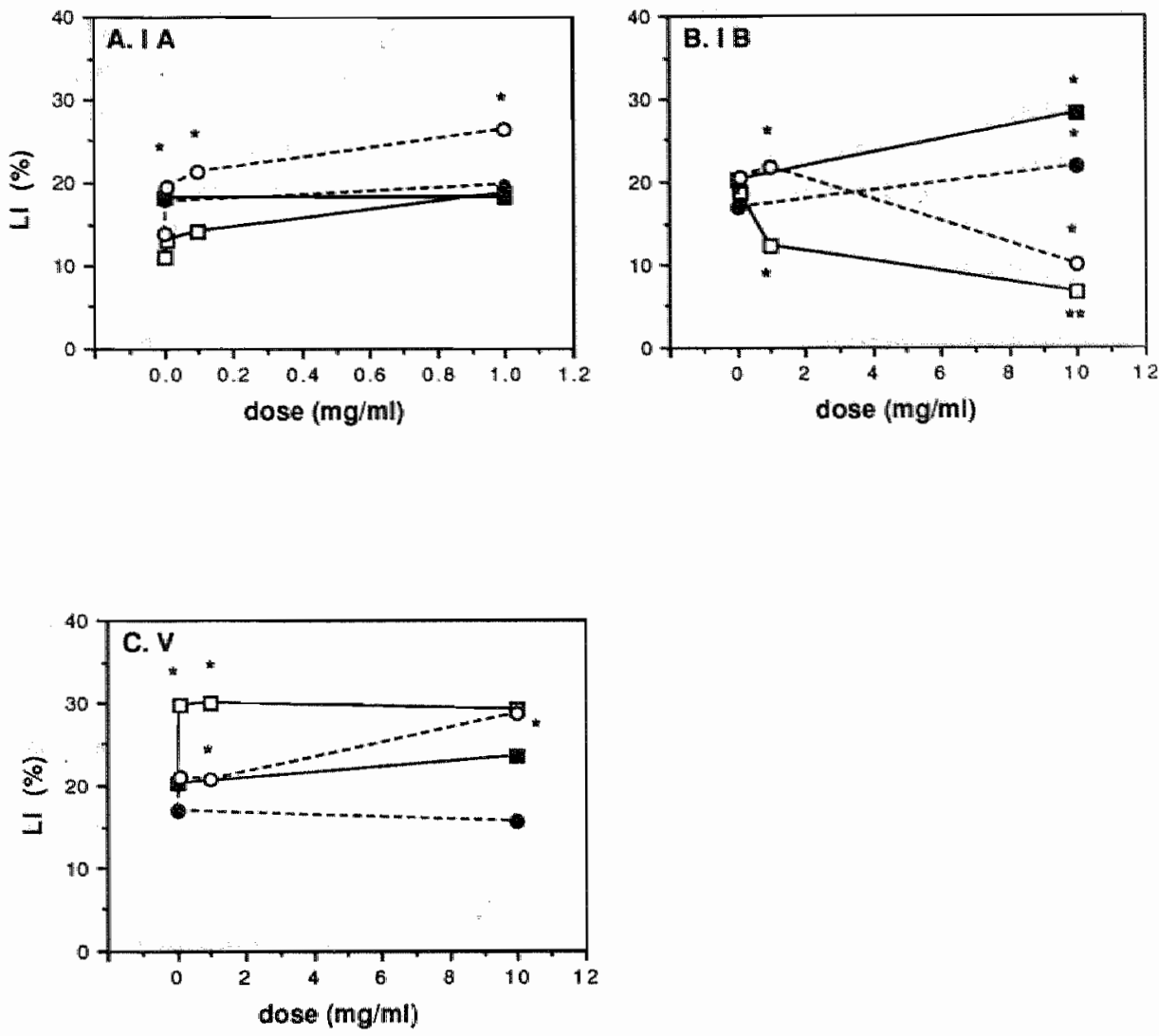

Figure 5.1. In vitro exposure to heated fats of PHA-stimulated human T-lymphocyles; effects on cell proliferation as determined by the $L I_{C}$ of control cultures of the HGPRT assay. In $A$. $L_{G}$ 's are shown of fat $/ A$, of unheated samples tested in experiments 1 ( $)$ ) and $2(\cdot-$ ), and of heated samples in experiments $3(-\square)$ and $4(-O)$; in $B, L L_{C}$ 's are shown of fat $I B$, of unheated samples in experiments $5(-)$ and $6(\cdot)$ ), and of heated samples in experiments $5(\square)$ and 6 $(-O)$; in $C, L_{C}$ 's are shown of fat $V$, of heated samples in experiments $5(-6)$ and $6(-4)$, and of heated samples in experiments $5(-1-)$ and $6(\cdot 0 \cdot)$. "significantly different from the RPMI control at $p<0.05$; " significantly different from the RPMI control at $p<0.01$. 
reported for oleic, linoleic acid and saturated fatty acids (Hayatsu et al., 1981; 1988; Negishi et al., 1984; Diplock et al., 1988; Anonymous, 1989), which are likely to occur in frying fats due to hydrolysis of the triglycerides during heating (Stevenson et al., 1984). Moreover, certain oxidative derivatives of linoleic acid, containing a conjugated double-bond system (CLA), have been isolated from fried ground beef, and were demonstrated to exert anti-mutagenic as well as anti-carcinogenic activities ( $\mathrm{Ha}$ et al., 1987). Therefore, mutagenicity testing of non-fractionated fat samples seems to be of greater relevance than testing of isolated fractions, since this would allow determination of a net overall effect. Regretfully, mutagenicity testing of unfractionated fat samples appeared practically not feasible, since the required doses of 50 to $100 \mathrm{mg}$ do not dissolve in $25 \mu \mathrm{l}$ THF, which is the maximum non-toxic volume of this solvent. Subsequently, suspending of the fats in sterile tubes in a sterile phosphate-buffered saline (PBS) solution, at $50{ }^{\circ} \mathrm{C}$ under sonification was applied. However, poor solution of the fats in top agar solution, resulting in poor discrimination between fat particles and revertant colonies at high doses did not allow reliable evaluation of mutagenic activity of unfractionated fat samples in the Salmonella/microsome assay.

Since mutagenicity results obtained with the Salmonella/microsome assay are considered insufficient evidence for possible carcinogenic risk, genotoxic effects of heated fats were determined using human lymphocytes. Determination of genotoxic damage in human lymphocytes was recently applied in order to assess carcinogenic risk of amino acid pyrolysates, which were isolated from broiled meats and found to be extremely potent bacterial mutagens as well as carcinogens in rodents (Sugimura, 1985; Kato et al., 1989), but of which carcinogenic potency in man is still unclear at present. The potent bacterial mutagens 2-amino-3-methylimidazo[4,5- $f]$ quinoxaline (IQ) and 2-amino-3,8-dimethylimidazo-[4,5-f]quinoxaline (MelQx) were reported to be considerably less active inducers of sister chromatid exchanges (SCE) or chromosome aberrations in human lymphocytes (Aeschbacher and Ruch, 1989), and $1 Q$ at realistic exposure levels did not cause detectable increases in mutations at the HGPRT locus or increases in micronuclei in human lymphocytes (McManus et al., 1988). Thus it was implicated that human cells with intact DNA repair and enzyme systems may be more relevant for evaluation of human genotoxic risk.

Genotoxicity testing of heated fats in the present study involved determination of the potency of repeatedly used fat samples to induce SCE, and single gene mutations at the HGPRT locus. SCE frequencies were slightly increased in lymphocytes exposed to heated fat samples, but the results obtained for the different fats appeared not consistent. A dose-related increase in SCE frequencies was observed for fat I B, however, the maximum increase measured was $1.6 \mathrm{SCE} /$ cell, indicating weak potency of 
this fat. However, effects were observed at concentrations which were close to possible realistic exposure levels.

Determination of the capacity of heated fats to induce single gene mutations in the hgprt locus of human lymphocytes yielded variable and inconsistent results. Initially, significantly increased Vf's were observed for fat I A in 2 separate experiments performed within one week. This first series of experiments was performed 2 weeks after frying, but when the same fat sample was tested approximately 1 month later, no significantly increased $\mathrm{Vf}$ was found. The initially observed increases cannot be explained by instable autoxidation products of linoleic acid, which may be subject to degradation during storage of the fat. Subsequent analyses of LAHPO in this fat I A performed in the second and fourth week after frying, did not indicate significant changes in LAHPO concentration. Heated fats I B and V did not significantly increase mutations at the HGPRT locus in human lymphocytes under the conditions tested.

Heated fats $\mid A$ and $V$, as well as the unheated fat I $B$, induced increased labeling indices in PHA-stimulated T-lymphocytes, indicating enhancing effects on cell proliferation. Since proliferation and activity of T-lymphocytes in vitro have been reported to be stimulated in the presence of free fatty acids (Spieker-Polet et al., 1981; Cuthbert et al., 1986), enhanced proliferation observed in our study might be ascribed to the presence of free fatty acids. However, autoxidation or degradation products of fatty acids could also have contributed to the observed stimulation cell proliferation, since after intra-rectal administration in rats, these products were demonstrated to enhance cell proliferation of the colonic mucosa (Bull et al. $1984 ; 1988$ ). Furthermore, the increased $\mathrm{LI}_{\mathrm{C}}$ observed for $\mathrm{tBOOH}$ in our study suggests that oxidative species may be involved in enhancement of cell proliferation. Effects on cell proliferation in the gastro intestinal tract after oral administration of autoxidized lipids have not been studied yet, but may be relevant since stimulation of cell proliferation is considered to facilitate tumorigenesis (Hicks, 1983; Weitberg, 1989).

In the present study, no associations appeared to exist between the observed biological effects and concentrations of DPTG, TBA-RS or LAHPO of the fats. It is therefore concluded that not only oxidation products of PUFA are involved in genotoxicity of heated frying fats. Reaction products of oxidized fats with proteins or carbohydrates, which are abundant in most deep-fat fried foods, likely contribute to genotoxicity of repeatedly used deep-frying fats as well, since preparation of various foods was observed to produce significant mutagenicity of repeatedly used deep-frying fats in the Salmonella/microsome assay. In addition, results obtained in the present study, suggest that repeatedly used deep-frying fats showing mutagenic activity in the Salmonella/microsome assay, may also exert genotoxic effects 
to human lymphocytes in vitro. Furthermore, heated fats appeared to stimulate cell proliferation of PHA-stimulated T-lymphocytes. The nature of these biologically active compounds, however remains to be established.

\section{Acknowledgements}

The contributions made to this study by mrs. S. Otto, and the HPLCanalyses of DPTG carried out by mr. J. Bex and P. Koken of the Maastricht Office for Food Quality Control, are gratefully appreciated.

\section{References}

Aeschbacher H.U. and Ruch E. (1989). Effect of heterocyclic amines and beef extract on chromosome aberrations and sister chromatid exchanges in cultured human lymphocytes. Carcinogenesis 10, 429-433.

Anonymous (1981). Wissenschaftliche Tabellen Geigy, Teilband Hămatologie und Humangenetik, 8. Auflage, Ciba-Geigy, Basel.

Anonymous (1989). Inhibition of lipid peroxidation by monounsaturated fatty acids. Nutr. Rev. $47,126-128$.

Billek G., Guhr G. and Waibel J. (1978). Quality assessment of used fying fats: a comparison of four methods. J. Am. Oil Chem.Soc. 55, 728-733.

Brambilla G., Sciaba L., Faggin P., Maura A., Marinari U.M., Ferro M. and Esterbauer H. (1986). Cyloxicily, DNA fragmentation and sister-chromatid exchange in Chinese hamster ovary cells exposed to the lipid peroxidation product 4-hydroxynonenal and homologous aldehydes. Mutation Res. 171, 169-176.

Bull A.W., Nigro N.D., Golembieski W.A., Crissman J.D. and Marnett L.J. (1984). In vivo stimulation of DNA synthesis and induction of ornithine decarboxylase in rat colon by fatty acid hydroperoxides, autoxidation products of unsaturated tatty acids. Cancer Res. 44, 4924-4928.

Bull A.W., Nigro N.D. and Marnett L.J. (1988). Structural requirements for stimulation of colonic cell proliteration by oxidized fatty acids. Cancer Res. 48, 1771-1776.

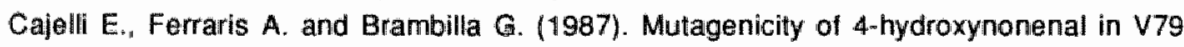
Chinese harmster cells. Mutation Res. 190, 169-171

Chang S.S., Peterson R.J. and Ho C. (1978), Chemical reactions involved in the deep-fat frying of foods. J. Am. Oil Chem. Soc. 55, 718-727.

Cuthbert J.A. and Lipsky P.E. (1986). Promotion of human T lymphocyte activation and proliferation by fatty acids in low density and high density lipoproteins. J. Biol. Chem. 261, 3620-3627.

Diplock A.T., Balasubramanian K.A., Manohar M., Mathan V.I. (1988). Purification and chemical characterization of the inhibitor of lipid peroxidation from intestinal mucosa. Biochim. Biophys. Acta 962, 42-50. 
Frankel E.N. (1987). Secondary products of lipid oxidation. Chem. Phys. Lipids 44, 73-85.

Ha Y.L., Grimm N.K. and Pariza M.W. (1987). Anticarcinogens from fried ground beef: Heataltered derivative of linoleic acid. Carcinogenesis $8,1881-1887$.

Hageman G., Kikken R., ten Hoor F. and Kleinjans J. (1988). Assessment of mutagenic activity of repeatedly used deep-frying fats. Mutation Res. 204, 593-604.

Hageman G., Kikken R., ten Hoor F. and Kleinjans J. (1989a). Linoleic acid hydroperoxide concentration in relation to mutagenic activity of repeatedly used deep-frying lats. Lipids 24, 899-902.

Hageman G., Hermans R., ten Hoor F. and Kleinjans J. (1990). Mutagenicity of deep-frying fat, and evaluation of urine mutagenicity after consumption of fried potatoes. Fd Chem Toxic., in press.

Hageman G., Welle I. and Kleinjans J. (1989b). Bromodeoxyuridine labeling and monoclonal antibody-peroxidase staining for the detection of 6-thioguanine resislant human lymphocytes. Pharmac. Wkbl. Sci. Ed., 11, B7.

Hayatsu H., Arimoto S. and Negishi T. (1988). Dietary inhibitors of mutagenesis and carcinogenesis. Mutation Res. 202, 429-446.

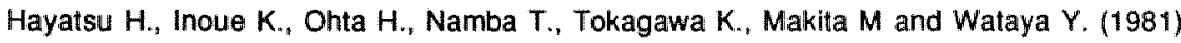
Inhibtion of the mutagenicity of cooked-beet basic fraction by its acidic fraction. Mutation Res. 91, 437-442.

Hicks R.M. (1983). Pathological and biochemical aspects of tumour promotion. Carcinogenesis 4, 1209-1214.

Kato T. Migita H., Oghaki H., Sato S., Takayama S. and Sugimura T. (1989). Induction of tumors in the Zymbal gland, oral cavity, colon, skin and mammary gland of $F 344$ rats by a mutagenic compound, 2-amino-3,4-dimethylimidazo[4,5-f]quinoxaline. Carcinagenesis $10,601-603$.

Kleinjans J.C.S., Janssen Y.M.W., van Agen B. , Hageman G.J. and Scheurs J.G.M. (1989). Genotoxicity of coal fly ash, assessed in vitro in Salmonella typhimurium and human lymphocytes, and in vivo in an occupationally exposed population. Mutation Res. 224, 127-134.

MacGregor J.T., Wilson D.E., Neft W.E. and Frankel EN. (1985). Mutagenicity test of lipild oxidation products in Salmonella typhimurium: monohydroperoxides and secondary oxidation products of methyl linoleate and methyl linolenate. Fd Chem. Toxic. 23, 1041 1047.

McManus M.E., Burgess W., Stupans I., Trainor K.J., Fenech M. Robson R.A., Morlley A.A. and Snyderwine E.G. (1988). Activation of the tood-derived mutagen 2-amino-3methylimidazo[4,5-f]quinoxaline by human-liver microsomes. Mulation Res. 204, 185193.

Nakayama T., Kaneko M. and Kodama M. (1986). Detection of DNA damage in cullured human fibroblasts induced by methyl linoleate hydroperoxide. Agric. Biol. Chem. 50, 261-262.

Negishi T. and Hayatsu H. (1984). Inhibitory effect of saturated fatty acids on the mutagenicity of N-nitrosodimethylamine. Mutation Res. 135, 87-96

Perry P. and Wolff S. (1974). New Giemsa method for the differential staining of sister chromatids. Nature 25, 156-158.

Pokorny'J., Kundu M.K. and Jani'cek G. (1975). Reactions of oxidized lipids with protein. Pant 
$\mathrm{XI}$. Changes of polymeric oxidation products during deep fat frying. Die Nahrung $191, \mathrm{~K} 7$ $K 9$.

Pongracz G. (1988). Hitzestabilität der Tocopherole. Fat Sci. Technol, 90. Jahrgang 7, 247. 251.

Spieker-Polet H. and Polet H. (1981). Requirements of a combination of a saturated and an unsaturated free fatty acid and a fatty acid carrier protein for in vitro growth of lymphocyttes. J. Immunol, 126, 949-954.

Stevenson S.G., Vaisey-Genser M. and Eskin N.A.M. (1984). Quality control in the use of deep frying oils, J. Am. Oit Chem. Soc. 61, 1102-1108.

Sylwester D. and Albertini R.J. (1985). Confidence intervals and sample size calculations to compare wariant frequencies. Environ. Mlutagen. 7, Suppl. 4, 31-41.

Taylor S.L., Berg C.M., Shoptaugh N.H. and Traisman E. (1963). Mutagen formation in deep fat fried floods as a function of frying conditions. J. Am. Oil Chem. Soc. 60, 576-580.

Vaca C.E. Wilhelm J. and Harms-Ringdahi M. (1988). Interaction of lipid peroxidation products with DNA. A review. Mutation Res. 195, 137-149.

Weitberg A.B. and Corvese D. (1989). Hydroxy- and hydroperoxy-6,8,11,14-eicosatetraenoic acids induce DNA strand breaks in human lymphocytes. Carcinogenesis 10, 1029-1031. 


\title{
Chapter 6
}

\section{Mutagenicity of deep-frying fat, and evaluation of urine mutagenicity in man after consumption of fried potatoes}

\author{
G. Hageman, R. Hermans, F. ten Hoor and J. Kieinjans
}

Food Chem. Toxicol., in press

\begin{abstract}
Mutagen formation during deep-fat frying was evaluated using standard frying conditions. Portions of pre-fried, sliced potatoes obtained at the relail level, were fried in a commercial brand of hydrogenated vegetable frying fat which was used repeatedly and for a prolonged period of time. Concentrations of polar oxidation and degradation products, and of di- and polymeric triglycerides (DPTG) were found to increase in the frying fat as well as in fried potatoes with prolonged use of the fat. Thiobarbituric acid-reactive substances (TBA-RS) were not detectable, neither in the frying fat nor in fried potatoes.
\end{abstract}

Polar fractions of repeatedly used frying fat significantly increased the number of revertants in strain TA97 without 59 mix. In presence of S9 mix mutagenic activity was reduced. As a consequence of ongoing formation of polar degradation and oxidation products, mutagenicity of the tat increased after repeated use. Polar fractions of lipids extracted from commercially obtained pre-fried potatoes, as well as from fried potaloes marginally increased the number of revertants in strain TA97 without S9 mix. Mutagenicity of the lipid fractions of fried potatoes was not related to heating time of the fat. Methanol (Me)extracts of fat-free residues of fried potatoes significantly increased numbers of reveittants in strain TA97 after metabolic activation, indicating that a different class of mutagens had been isolated. Mutagenicity of Me-extracts was not increased after prolonged use and repeated use of the fat either.

Urine samples of 6 healthy, non-smoking volunteers collected during 24 hours after consumption of portions of fried potatoes prepared in repeatedly used frying fat showed no increased mutagenicity as compared to control samples. Since the exact identity of mutagens formed during deep-fat frying, as well as their metabolic tate in man is unclear at present " evaluation of possible adverse biological effects associated with consumption of fried foods will require strictly controlled metabolic studies. 


\section{Introduction}

Repeatedly used deep-frying fat sampled at the retail level has been found to exert mutagenic activity in the Salmonella/microsome assay in a previous study performed in our laboratory (Hageman et all., 1988). Mutagenic activity was present mainly in the polar fraction of deep-frying fats, which has been reported to contain oxidation and heat degradation products of fatty acids (Billek et al., 1978). We also demonstrated that mutagenic activity of the fat increased after prolonged and repeated frying of various foods, under standard frying conditions according to manufacturers' instructions. Mutagenicity of the used deep-frying fats was positively correlated with thiobarbituric acid-reactive substances (TBA-RS) present in the fats, indicating that lipid peroxidation products might be involved in mutagenicity (Hageman et al., 1988).

In feeding experiments with laboratory animals growth retardation, increased liver and kidney weights and cellular damage in various organs have been observed after administration of oxidized fats and oils (Andia and Street, 1975; Billek, 1976; Alexander et al., 1987). In rats, consumption of thermally oxidized oils induced peroxidative deterioration of tissue lipids, as was shown by increased levels of TBA-RS in hepatic tissue, which correlated positively with concentrations of polar degradation products and the peroxidative value of the ingested fats (Izaki et al., 1984).

Previous evaluation of mutagenicity of deep-fat fried foods by Taylor et al. (1982) revealed weak mutagenic activity of basic methylene chloride extracts of fried foods. Mutagenic acitivity of deep-fat fried foods fried under laboratory conditions was detected only after severe abuse of the frying fat (Taylor et al, 1983). Since we found significant mutagenic activity in polar iraction of commercially used frying fat samples, the present study was undertaken to evaluate mutagenicity of various lipid fractions of deep-fat fried potatoes. In addition an attempt was made to assess endogenous exposure of humans to mutagenic and peroxidative products after consumption of fried poatoes prepared in repeatedly used deep-frying fat. Urines were screened for mutagenicity and analyzed for TBA-RS, which in animal studies have been found to be indicative of the extent of lipid oxidation in the diet and in tissues (Draper et al., 1984).

\section{Materials and methods}

\section{Chemicals}

Analytical-grade, stabilized (with $250 \mathrm{ppm}$ butylated hydroxytoluene) tetrahydrofuran (THF) used for high-performance liquid chromatography (HPLC) analysis of di- and polymeric triglycerides (DPTG); acetic acid and silicagel 60 , particle size $0.063-0.20 \mathrm{~mm}$, used for fractionating fat samples; XAD-2 resin; analytical grade acetone; trichloracetic acid: 
malondialdehyde bis-(diethylacetal); hydrochloric acid and 2-thiobarbituric acid "all of the highest chemical grade available, were purchased from Merck, Darmstadt (F.R.G). HPLCgrade petroleum ether, boiling range $40-60^{\circ} \mathrm{C}$; methanol, diethyl ether ${ }_{4}$ and non-stabillzed THF used for dissolving fat fractions in mutagenicity testing were obtained from Fisons, Loughborough (Great Brittain). All other chemicals and media used in the Ames assay were of the highest chemical grade available.

\section{Frying experiment}

Mutagen fromation during deep-fat frying was studied in a frying experiment under standard conditions that closely resemble usual frying practices. A batch of $2 \mathrm{~kg}$ of hydrogenated vegetable frying fat, obtained from a local supermarket, was used for preparation of fried potatoes. The fat was heated in a home-style fryer at a temperature of $180_{ \pm} 5^{\circ} \mathrm{C}$ during 8 hours each day on 5 consecutive days, allowed to cool overnight and not replenished. Fat samples were taken alter $0,8,28$ and $40 \mathrm{~h}$ of use.

Five $1 \mathrm{~kg}$ packages of frozen "pre-fried sliced potatoes, also commercially obtained, were divided in $200 \mathrm{~g}$ portions and stored at $-20^{\circ} \mathrm{C}$ until the moment of preparation. Portions of frozen potatoes were fried every $4 \mathrm{~h}$, commencing after $4 \mathrm{~h}$ of heating of the fat. Frying time was $5 \mathrm{~min}$, actual frying temperatures ranged from 160 to $182^{\circ} \mathrm{C}$.

\section{Urine collection}

Six healthy, non-smoking male wolunteers, aged 22 to 42 years, were asked to collect 24 $\mathrm{h}$ urine samples before and after consumplion of $200 \mathrm{~g}$ portions of fried potaloes. The subjects were asked not to consume other fried or grilled foods and not to drink alcoholic beverages while collecting urine samples. A 24-h control sample and 24-h urine samples collected immediately after consumption of fried potatoes on day 1,3 and 5 of the experiment, prepared in fat that had been used for 8,24 or $40 \mathrm{~h}$ respectively, were screened for mutagenicity. The samples were stored under refrigeration and processed within a dlay, or frozen at $-200 \mathrm{C}$.

Aliquats of $200 \mathrm{ml}$ of urine were concentrated on XAD-2 resin colums, the colums were eluted with $100 \mathrm{ml}$ of distilled water to remove traces of histidine and extracted with $10 \mathrm{ml}$ of analytical-grade acetone as decribed by Yamasaki and Ames (1977). Acetone extracts were evaporated under a stream of nitrogen and stored under refrigeration until mutagenicity testing.

\section{Chemical analysis}

Portions of fried potatoes were freeze-dried, after which $10 \mathrm{~g}$ of dry material was homogenized with $10 \mathrm{~g}$ of anhydrous sodium sulphate. Lipids were isolated by overnight Soxhlet extraction with petroleum ether (PE). A second overnight extraction was performed using methanol (Me). PE and Me-extracts were concentrated on a rotary evaporator after which soivent residues were evaporated under a stream of nitrogen at room temperature.

DPTG in the frying fat and PE-extracts of tried potatoes were determined by getpermeation HPLC (Hageman et al, 1988). In short, $200 \mu \mathrm{l}$ of fat, liquified by heating at temperatures not exceeding $50^{\circ} \mathrm{C}$, was mixed with $3.0 \mathrm{ml}$ of stabilized THF, after which 15 wll 
of this mixture was injected on a Styrogel 500 A column, $300 \mathrm{~mm} \times 7.8 \mathrm{~mm}$ ID Mobile phase consisted of degassed, stabilized THF at a ilow rate of $1.0 \mathrm{mU} / \mathrm{min}$; peaks were monitored using a refractive index (RI)-detector. Concentrations of DPTG were calculated as percentage of total peak area.

Fractionation of deep-frying fat samples and PE-extracts into non-polar and pollar compounds by column chromatography was carried out as described previously (Hageman ell al. 1988 . Bifiefly $1 \mathrm{~g}$ of fat was dissolved in $10 \mathrm{ml}$ of a mixture of petroleum ether: diethyl ether $(87: 13,4 / v$; solvent 1$)$. The mixture was carefully applied to a slilcagel column, after which the non-polar traction was eluted with $150 \mathrm{ml}$ of solvent 1 . The polar traction was obtained by elution with $150 \mathrm{ml}$ of diethyl ether acidified with $1 \%$ acetic acid (solvent 2 ). Solvents were distilled off using a rotary evaporator.

TBA-RS of deep-Irying fat samples and PE-extracts of fried potatoes were determined as described earlier (Hageman et al., 1988). To assess whether consumption of repeatedly used trying fats increases whole body lipid peroxidation, urine TBA-RS were also determined before and atter consumption of fried poatatoes as follows: in a screw top tube $2.0 \mathrm{ml}$ of urine was mixed with $2.0 \mathrm{ml}$ of a $10 \%$ trichloracetic acid solution and $0.5 \mathrm{ml}$ of a $1 \%$ TBA suspension in distilled water. Samples were incubated in a waterbath at $100^{\circ} \mathrm{C}$ duiring $20 \mathrm{~min}$, cooled and centrifuged, after which absorption was measured at $532 \mathrm{~nm}$ and at $600 \mathrm{~nm}$. The difference between the absorption is a measure for the concentration of TBA-RS. Detection limit of the method is 0.1 nmol of malondialdehyde (MDA)/ml of urine.

\section{Mutagenicity testing}

Mutagenicity testing of deep-frying fat iractions, lipid fractions and methanol extracts of fried potatoes, and urine extracts was performed according to standard protocols (Maron and Ames, 1983) applying the liquid preincubation procedure during 20 min at $37^{\circ} \mathrm{C}$. Since strain TA97 appeared to be most sensitive in detecting mutagenic activity of used deep-frying fat, only this strain was used for mutagenicity testing of fat fractions as well as urine extracts. Liver S9 fraction, with a protein concentration of $34 \mathrm{mg} / \mathrm{ml}$, was prepared from Aroclor 1.254 treated rats, and added in a concentration of $50 \mu$ per plate.

Fractionated fat samples were dissolved in analytical grade, unstabilized THF and tested at dloses ranging from 0.1 to $10.0 \mathrm{~m}$ g/plate; the volume of the dose was $25 \mu \mathrm{l}$. Me-extracts of fried potatoes were suspended under sonitication in distilled water, since Me-extracts appeared to be better dissolved in water than in dimethyl sulphoxide (DMSO). Me-extracts were tested at doses ranging from 0.1 to $10.0 \mathrm{mg} / \mathrm{plate}$.

Urine concentrates were dissolved in DMSO and equivalents of 5.0,10.0,12.5 and 25.0 $\mathrm{ml}$ were tested both in absence and presence of lliver $\$ 9$ mix. Mutagenicity of 24-h urine samples was calculated using linear regression of dose-response curves. Extractions of fried potatoes and separation of fats into non-polar and polar fractions as well as mutagenicity testing were repeated at least once, including unheated unused control samples. Solvent controls, chromatography and extraction solvents, processed according to the protocols used tor sample preparation, were also screened for mutagenic activity. All doses were tested 
in duplicate or triplicate with and without metabolic activation. Estimation of mutagenic activity per $g$ of frying fat or fried potatoes samples and urinary mutagen excretion per $24 \mathrm{~h}$ was achieved by linear regression of dose-response curves.

\section{Statistical analyses}

Stalistical analysis of mutagenicity data of fats, extracts of fried potatoes and urines was performed using the method of least significant difference (LSD) (MacGregor et all. 1985). LSD values obtained in this study are at contidence levels of $p<0.05$ and $p<0.01$. respectively: for THF as solvent (lipid fractions) TA97-S9 256 and 388, TA97+S9 186 and 292; for distilled water as solvent (Me-extracts) TA97-S9 120 and 189, TA97+S9 142 and 215; for DMSO as solvent (urine extracts) TA97-S9 112 and 175, TA97+S9 92 and 144. Differences in urine mutagenicity between control and experimental samples were statistically analyzed using Student's t-test for paired values.

\section{Results}

During deep-fat frying and with prolonged use of the fat, the polar fraction representing oxidation and thermal degredation products of fatty acids, increased limearly with increasing heating time (Figure 6.1). The polar fraction isolated from PE-extracts of fried potatoes showed a similar tendency, but the polar fraction comprised a smaller percentage of the lipids as compared to the corresponding frying fat samples (Figure 6.1). PEextracts of pre-fried frozen potatoes contained approximately $8 \%$ (by weight) of polar material. After frying in relatively fresh frying fat used for up to $24 \mathrm{~h}$, polar fraction of fried potaotes was found to be decreased when compared to the pre-fried potatoes. DPTG present in the frying fat as well as in PEextracts of fried potatoes samples are listed in Table 6.1. DPTG were detected in both deep-frying fat samples and in PE-extracts of fried potatoes after prolonged use of the fat. Neither the deep-frying fat nor the PE-extracts of fried potatoes contained defectable amounts of TBA-RS (data not shown).

Polar fractions of the frying fat samples taken after 8,28 and 40 h of frying significantly $(p<0.05)$ increased the number of revertants at doses higher than $1 \mathrm{mg} / p$ late. Non-polar fractions did not significantly increase the number of revertants and as a consequence, mutagenic activity estimated per $\mathrm{g}$ of fat was caused mainly by compounds present in the polar fractions (Table 6.2). Mutagenicity of the frying fat was increased after prolonged heating. In presence of $\mathrm{S} 9 \mathrm{mix}$, mutagenicity of the polar fractions was reduced. 


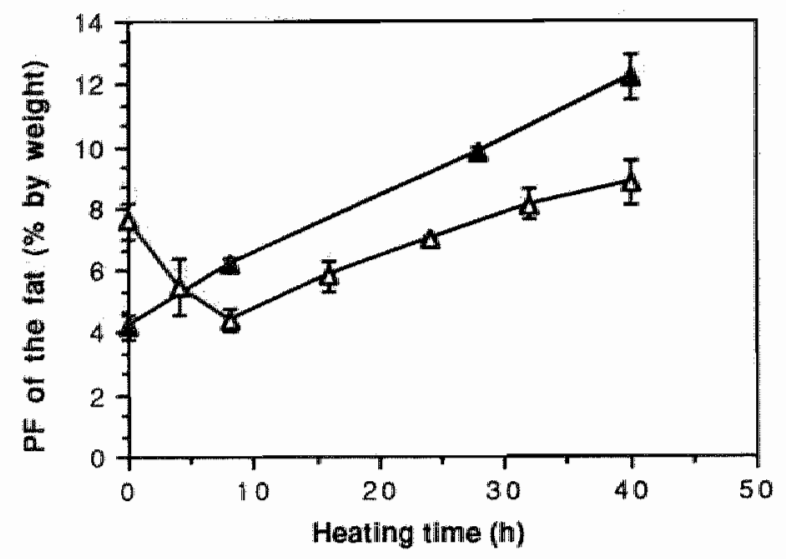

Figure 6. 1. Formation of polar degradation products (PF) in deep-frying fat 1 -) and in lipids extracted from fried potatoes $(-\Delta)$ as function of heating time. Results are expressed as meantSD.

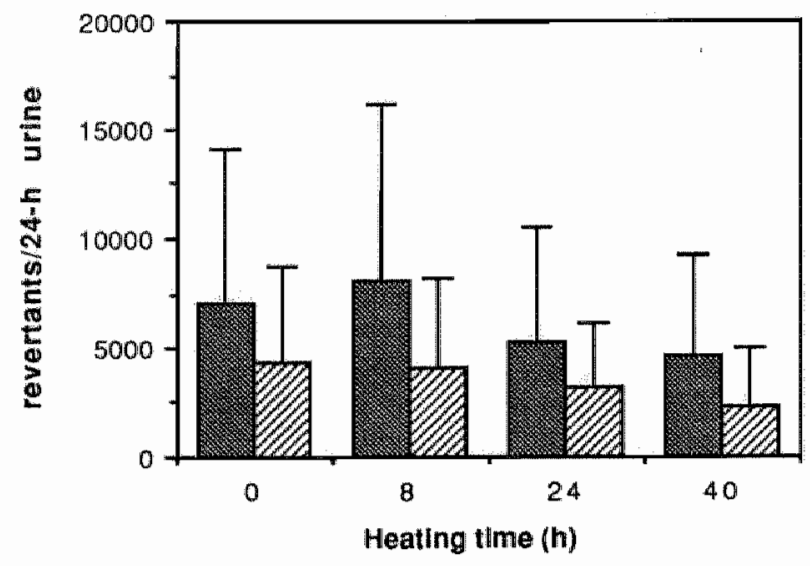

Figure 6.2. Mutagenicity to strain TA97-S9 mix ( ) and to strain TAS7+S9 mix ( 6 ) of 24-h urine samples collected before and after consumption of fried potatoes prepared in repeatedly used frying fat. Results are expressed as mean $4 S D$ of 6 subjects. 
Table 6.1. Occurrence of di-and polymeric triglycerides (DPTG) in deep-frying fat and fried' potatoes.

\begin{tabular}{lll}
\hline Sample & $\begin{array}{l}\text { Heating time of } \\
\text { the frying fat }(\mathrm{h})\end{array}$ & $\begin{array}{l}\text { DPTG } \\
\text { (\% by weight) }\end{array}$ \\
\hline
\end{tabular}

Frying fat

Control

$\begin{array}{rl}0 & <1 \\ 8 & <y \\ 28 & 2.5 \pm 0.3 \\ 40 & 3.3 \pm 0.3\end{array}$

Fried potatoes

Control

$\begin{array}{rl}0 & \text { NA }^{*} \\ 4 & <1 \\ 8 & \text { NA } \\ 16 & \text { NA } \\ 24 & 2.4 \pm 0.2 \\ 32 & 2.4 \pm 0.3 \\ 40 & \text { NA }\end{array}$

*NA, not analyzed

Polar fractions of pre-fried sliced potatoes insignificantly increased numbers of revertants, with the exception of the fried potatoes sample taken after $8 \mathrm{~h}$ of use. For this sample at a dose of $5 \mathrm{mg} / \mathrm{plate}$ a significant $(p<0.05)$ increase was observed. Mutagenicity of polar fractions isolated from fried potatoes was also reduced in the presence of $\mathrm{S} 9 \mathrm{mix}$. Mutagenicity of polar fractions of fried potatoes varied considerably and appeared not to be related to the heating time of the fat used for preparation of the potatoes. The non-polar fractions of PE-extracts of fried potatoes did not significantly increase numbers of revertants.

Me-extracts of fried potatoes showed no significant mutagenic activity without S9 mix, but significantly increased numbers of revertants were observed in 3 samples in the presence of $\$ 9 \mathrm{mix}$. At doses of $10 \mathrm{mg} / \mathrm{plate}$ mutagenic activity was observed in $\mathrm{Me-extracts}$ of potatoes fried after 8 $(p<0.05), 24(p<0.01)$ and $32(p<0.01) h$ of use. Me-extracts of potatoes prepared after $40 \mathrm{~h}$ of use showed weak toxic effects. Mutagenic activity of Me-extracts was not clearly increased after prolonged and repeated use of the fat either. 
Table 6.2. Estimated mutagenicity of frying tat and contribution to mutagenicitiy of fried potatoes of petroleum ether (PE) extracts (polar and non-polar fractions) and methanol (Me)-extracts.

\begin{tabular}{|c|c|c|c|c|c|}
\hline \multirow[b]{4}{*}{ Sample } & \multirow{4}{*}{$\begin{array}{l}\text { Heating time } \\
\text { of the frying } \\
\text { fall (h) }\end{array}$} & \multicolumn{4}{|c|}{ Mutagenicitiy (rev/g) of } \\
\hline & & \multicolumn{2}{|c|}{ FauPE-extracts } & \multicolumn{2}{|c|}{ Me-extracts } \\
\hline & & TA97 & TA97 & TA97 & TA97 \\
\hline & & $-\$ 9$ & $+S g$ & $-\$ 9$ & $+\$ 9$ \\
\hline \multicolumn{6}{|c|}{ Frying fat } \\
\hline \multirow[t]{4}{*}{ Control } & 0 & 672 & 588 & & \\
\hline & 8 & 2160 & 324 & & \\
\hline & 28 & 2392 & 920 & & \\
\hline & 40 & 3451 & 2032 & & \\
\hline \multicolumn{6}{|c|}{ Fried potatoes } \\
\hline \multirow[t]{7}{*}{ Control } & pre-fried & 192 & 72 & 200 & 395 \\
\hline & 4 & 464 & 72 & 242 & 224 \\
\hline & 8 & 1078 & 134 & 242 & 263 \\
\hline & 16 & 168 & 252 & 133 & 115 \\
\hline & 24 & 735 & 390 & 354 & 348 \\
\hline & 32 & 195 & 0 & 183 & 648 \\
\hline & 40 & 352 & 128 & 151 & 244 \\
\hline
\end{tabular}

Mutagenic activity per $\mathrm{g}$ of fried potatoes was estimated by extrapolating dose-response curves of non-polar and polar fractions, and of Me-extracts (Table 6.2). Without $\mathrm{S9} \mathrm{mix}$, a five-fold increase in mutagenicity was observed in fried potatoes prepared in fat used for $8 \mathrm{~h}$. After repeated heating of the fat mutagenicity of the fried potatoes varied considerably, without reaching the peak level observed at the end of the first day. Mutagenic activity of the lipid iraction of fried potatoes was reduced in the presence of $\mathrm{S9}$ mix. Me-extracts of fried potatoes induced significant mutagenic activity in presence of $\mathrm{S} 9 \mathrm{mix}$ only, however no relation was found with heating time of the fat. 
To determine whether substances naturally occurring in potatoes could be responsible for the observed mutagenic activity of PE and Me-extracts of fried potatoes, $500 \mathrm{~g}$ of freshly peeled potatoes have been freeze-dried, extracted and tested according to protocols used for fried potatoes. No significantly increased numbers of revertants have been observed for either PE-extracts or Me-extracts, representing $50 \mathrm{~g}$ of fresh potatoes. In addition, portions of freshly peeled and sliced potatoes have been fried in fresh nonmutagenic deep-frying fat, and in fat that had been used for $100 \mathrm{~h}$. Lipids extracted from these fried potatoes samples have been observed to contain respectively $4.2 \pm 0.1$ and $32.2 \pm 2.4 \%$ (by weight) of polar components: Mutagenic activity of the fried potatoes to strain TA97 without $\$ 9$ mix significantly increased from 0 in the control sample to 736 revertants/g of fried potatoes in the $100 \mathrm{~h}$ sample.

Urine mutagenicity of six volunteers after consumption of $200 \mathrm{~g}$ of fried potatoes prepared in repeatedly used frying fat was not significantly different from control levels, neither tested in absence nor in presence of liver $\$ 9$ mix. At high doses representing $25 \mathrm{ml}$ of urine, most samples were toxic, inducing a decreased response. After linear regression was applied to lower doses only, urine mutagenicity varied from 0 to 8 revertants per $\mathrm{ml}$ of urine. Extrapolated to 24-h volumes, urine mutagenicity ranged from 0 to $10^{4}$ revertants in control as well as in experimental samples. Urine mutagenicity varied both intra- and interindividually and appeared not to be related to heating time of the fat used for preparation of the fried potatoes consumed (Figure 6.2). TBA-RS were detected in all urine samples, with concentrations ranging from 0.1 to 2.5 nmoles of MDA $/ \mathrm{ml}$. TBA-RS of urines following consumption of fried potatoes however, did not differ from control levels (data not shown).

\section{Discussion}

Prolonged heating and repeated use of deep-frying fat under standard conditions as employed in this study increases mutagenicity of polar fat fraction. Mutagenic activity of the frying fat which was used for preparation of fried potatoes only, appears to be moderate, reaching levels of 2,500 to 3,500 revertants per $\mathrm{g}$ of fat in strain TA97 without $\mathrm{S} 9$ mix. In our previous study, mutagenic activity of frying fat sampled at local restaurants and tested according to the same protocols, has been found to range from 1,000 to 30,000 revertants per $g$ of fat (Hageman et al., 1988).

The mutagenicity results reported here differ from those descibed by Taylor et al. (1983), who did observe very low or even anti-mutagenic activity in lipid fractions of fat used for frying potatoes. This may be caused by differences in frying procedures, as well as fractionation and mutagnicity sceeening of fat samples. Taylor ef al. (1983) fried 15 portions of potatoes per day as opposed to a maximum of 8 per day in our experiment. Thermal 
abuse of the fat as a consequence of small amounts of food prepared, however, appeared to be minimal in our experiment since temperatures were found not to ecxeed $182{ }^{\circ} \mathrm{C}$. Mutagenic activity of the polar fat fractions in our experiment was detected most sensitively by Salmonella tester strain TA97 without $S 9$ mix, and applicating the liquid preincubation procedure (Maron and Ames, 1983). Taylor et al. (1983) screened mutagenicity of lipid fractions using strain TA98 with $\$ 9$ mix, probably detecting different classes of mutagens. These differences in fractionating and testing procedures together with endogenous properties of the fats used for frying, very likely explain the remarkable differences between mutagenicity results as reported by Taylor et al. (1983) and those observed in the present study.

Mutagenic activity of the polar fraction of PE-extracts of fried potatoes does not increase with prolonged heating time in a similar mode as the polar fraction of the frying fat. Mutagenic activity of polar fractions of fried potatoes varies from levels equal to those found for pre-fried potatoes to 2 to 4 times increased mutagenicity. This variation in mutagenic acitivity may reflect different mulagenic, or possibly antimutagenic properties of fried potatoes as compared to frying fat. A second extraction with methanol does only slightly improve isolation of possibly remaining direct-acting mutagens from the fried potatoes, since all methanol extracts have been found to marginally increase numbers of revertants in absence of $\mathrm{S} 9 \mathrm{mix}$. Mutagenicity of PE and $\mathrm{Me}$-extracts added together as an estimation of total mutagenic activity of fried potatoes, was not related to heating time of the fat. Extraction with methanol may have isolated a different class of mutagenic compounds, as is suggested by their metabolic activation.

The nature of mutagens formed during deep-fat frying remains to be established. Additional analyse of DPTG in non-polar and polar deep-frying fat fractions has shown that DPTG are present in the polar fraction and that non-polar fractions contain no detectable amounts of DPTG. Amounts of DPTG in the polar fraction of the fat have been found to increase from less than $1 \%$ to $30 \%$ (by weight) after $40 \mathrm{~h}$ of frying. Polymerized oxidation and degradation products of fatty acids, however, are not likely to be responsible for the observed mutagenic activity since mutagenicity of the polar fraction of the frying fat does not increase with increasing levels of DPTG. In our previous study, mutagenicity of deep-frying fat samples has not been found to correlate with DPTG either (Hageman et al., 1988).

Compared to meat products, potatoes contain low amounts of protein and no creatinin, and since the frying fat in the present study has been used for deep-frying of potatoes exclusively, substantial formation of amino-acid pyrolysates seems very unlikely. Furthermore, mutagenicity of amino-acid pyrolysates has been reported to require metabolic activation (Sugimura et al., 1986), whereas mutagens formed during deep-fat frying of potatoes and present in the polar tractions are direct-acting and deactivated by rat liver $\mathrm{S} 9$ mix. Mutagenicity of Me-extracts of fat-free residues however, is enhanced after hepatic metabolism and may be due to the presence of more polar 
pyrolysis products. The absence of TBA-RS in the frying fat as well as in lipids extracted from fried potatoes appears to reject a possible contribution to mutagenic activity of MDA or other lipid oxidation products in this frying experiment.

Evaluation of endogenous exposure in humans of mutagens formed during deep-fat frying has been attempted by screening urine mutagenicity. Weak mutagenicity was found not only in urine samples collected after consumption of fried potatoes, but also in samples collected when subjects were consuming their habitual diet with the restriction of alcoholic drinks and fried or grilled foods. Since increased urine mutagenicity has also been observed by Sasson et al. (1985) in urine of subjects on a vegetarian diet, it is concluded that detection of marginally increased urine mutagenicity requires strictly controlled conditions with standardized diets and occuptional and physical activity.

The absence of increased urine mutagenicity after consumption of fried potatoes may also indicate metabolic deactivation prior to excretion of lack of absorption by the digestive tract. Both possibilities are supported by data from feeding studies with laboratory animals (Oarada et a., 1986; Kanazawa et al., 1985). In these studies, rats fed $\left(U-{ }^{14} \mathrm{C}\right)$-labeled secondary oxidation products of linoleic acid metabolized low molecular weight product but poorly absorbed polymeric degradation products which remained in the lumen. Consequently, screening of mutagenic activity and chemical analysis of faeces after consumption of oxidized deep-frying fat may elucidate metabolic fate of mutagenic polar compounds of the fat.

Epidemiological studies have shown a positive correlation among countries between fat consumption and cancer prevalence (Carroll and Khor, 1975). In industrialized countries fats contribute significantly to dietary fat intake. Based on household consumption expenditure statistics in the Netherlands (CBS, 1987), mean consumption of deep-fat fried food is estimated to contribute at least $6 \%$ to the daily fat intake. Assuming a mean level of $5 \%$ of polar fraction of the frying fat, daily intake per person of polar compounds will exceed $100 \mathrm{mg}$. Since processed dietary fat may possess tumor initiating as well as tumor promoting acitivity, the fate and exact nature of mutagens consumed with various deep-fat fried foods prepared in repeatedly used deep-frying fat, is of great interest with respect to possible health consequences and will be further evaluated.

\section{References}

Alexander, J.C., Valli V.E. and Chanin B.E (1987). Biological observations from feeding heated corn oil and heated peanut oil to rats. J. Toxicol. Environ. Heallh 21, 295-309.

Andia A.G. and Street J.C. (1975). Dietary induction of hepatic microsomal enzymes by thermally oxidized fats. ل. Agr. Fd Chem. 23, 173-177. 
Biflek G. (1976). Heated oits. Chemistry and rutritional aspects. Nutr. Metab. 24, 200-210.

Billek G., Guhr G. and Waibel 1. (1978). Quality assessment of used irying fats: a comparison of four methods. J. Am. Oil Chem. Soc. 55, 728-733.

Carroll K.K. and Khor H.T. (1975). Dietary fat in relation to tumorigenesis. In: Prog. Blochem. Pharmacol. Edited by K.K. Carroll. pp 308-353. Vol. 10 Lipids and Tumors. Karger, Basell

Central Bureau of Statistics - CBS- (1987). Budgetsurvey. Final consumption expenditure of households 1985. Statistic. Bull. 33 (in Dutch).

Draper H.H., Polensek L., Hadley M. and McGirr L.G. (1984). Urinary malondialdehyde as an indicator of lipid peroxidation in the diet and in the tissues. Lipids 19, 836-843.

Hageman G. Kikken R.., Ten Hoor F. and Kleinjans J. (1988). Assessment of mutagenic activity of repeatedly used deep-firying fats. Mutation Res. 204, 595-604.

Izaki $Y$., Yoshikawa S. and Uchiyama M. (1984). Effects of ingestion of thermally oxidized Irying oll on peroxidative criteria in rats. Lipids 19, 324-33\%.

Kanazawa K., Kanazawa $\mathrm{E}$. and Nalake $\mathrm{M}$. (1985). Uptake of secondary autoxidation products of linoleic acid by the rat. Lipids $20,412-419$.

MacGregor J.T., Wilson D.E., Neff W.E. and Frankel E.N. (1985). Mutagenicity test of lipid oxidation products in Salmonella typhimurium: monohydroperoxides and secondary oxidation products of methyl linoleate and methyll linolenate. Fd Chen. Toxicol. 23, 1041. 1047

Maron D.M. and Ames B.N. (1983). Revised methods for the Salmonelia mutagenicity test. Mutation Res. 113, 149-157.

Oarada M., Miyazawa T. and Kaneda $T_{\text {. }}(1986)$. Distribution of ${ }^{14} \mathrm{C}$ after oral administration of (U-14C) labeled methyl linoleate hydroperoxides and their secondary oxidation products in rats. Lipids 21, 150-154.

Sasson I.M., Coleman D.T., LaVole E.J. Hotfman D. and Wynder E. (1985). Mutagens in human urine: effects of cigarette smoking and diet. Mutation Res. 113, 173-175.

Stevenson S.G., Vaisey-Genser M. and Eskin N.A.M. (1984). Quality control in the use of frying oils. J. Am. Oil Chem. Soc. 61، 1102-1108.

Sugimura T., Sato S., Oghaki H., Nagao M. and Wakabayashi K. (1986). Mutagens and carcinogens in cooked food. Overview. In: Genetic Toxicology of the Diet. pp 85-107. Alan A. Liss, New York.

Taylor S.L., Berg C.M., Shoptaugh N.H. and Scott V.N. (1982). Lack of mutagens in deep-fatfried foods obtained at the retail level. Fd Chem. Toxicol. 20, 209-212.

Taylor S.L., Berg C.M., Shoptaugh N.H. and Traisman E. (1983). Mutagen formation in deep. fat-fried foods as a function of frying conditions. J. Am. Oil Chem. Soc. 60, 576-580.

Yamasakl $E$ and Ames B.N. (1977). Concentration of mulagens from urine by adsorplion with the nonpolar resin XAD-2: Cigarette smokers have mutagenic urine. Proc. Natl. Acad. Sci. USA $74,3555-3559$. 


\title{
Chapter 7
}

\section{Evaluation of faecal and urine mutagen excretion in man: effects of consumption of mutageric, repeatedly used deep-frying oil}

\author{
G. Hageman, T. Volleberg, F. ten Hoor and J. Klelnjans
}

\begin{abstract}
Effects on mutagenicity of urine and faeces of consumption of fried potatoes prepared in repeatedly used mutagenic coconut oll, were determined in 14 healthy volunteers. Using a cross-over design, volunteers consumed daily a $250 \mathrm{-g}$ portion of tried potatoes during a 5 day period; during a 5-day control period, volunteers consumed daily a portion of mashed potatoes to which unused frying oil was added. The lipid fractions of fried potatoes showed significant mutagenic actiwity to Salmonella tester strain TA.97 in absence of 59 mix ${ }_{i}$ estimated to amount to $1.5 \times 10^{5}$ reviportion. Lipid fractions of fried potatoes were not found to contain detectable amounts of lipid oxidation products. Mutagenic activity was found in lipid fractions of mashed potatoes as well, which was estimated to amount to $2.6 * 10^{4}$ rew/pontion. During the experiment all foods were supplied by the investigators and lood consurnption was recorded daily. Urine and faeces were collected on days 4 and 5 of each period. In addition, faeces was sampled on the first day of the experiment, in order to determine faecal mutagenicity of the participants during consumption of their free-choice diets.

Mutagenicity of dichloromethane (DCM)- or acetone-concentrates of urine to strains TA97 and TA100 without $S 9 \mathrm{mix}$ was not found to be increased after daily consumption of a portion of fried potatoes as compared to consumption of mashed potatoes. Neilher was consumption of fried potatoes obsierved to increase mutagenic activity of DCM-extracts of faeces to these strains as compared to mashed potatoes. No eflects of consumption of fried potaloes were observed on plasma clinical biochemical parameters of blood stamples taken on the sth day of each period, nor on urinary excretion of lipid oxidation products.
\end{abstract}

DCM-extracts of faeces samples collected during the experimental periods however. showed significantly increased mutagenicity to strain TA100 as compared to samples collected after free-choice diets of the volunteers. Mutagenicity of faecal extracts to strain TA100 was not associated with dietary intake of macro-nutrients, including fat. P/S ratio of lipids and fiber, but did show a significant positive correlation with faecal $\mathrm{pH}(r=0.45, \mathrm{p}<0.02)$. Since faecal mutagen excretion was not found to be related to the pattern of mutagenicity of deep-fried potatoes, results of the present study do not indicate a contribution of consumption of mutagenic deep-frying oils to faecal mutagenicity. Faecal mutagen excretion or production appeared to be related to the diet, but the dietary factors affecting mutagenicily of taeces remain to be determined. Results obtained in the present study indicate that consumption of deep-fried potatoes prepared in mulagenic oil, containing low levels of lipid oxidation products " does not appear to pose a serious risk to human health. 


\section{Introduction}

Dietary factors have been suggested to be strongly related to human cancer incidence (Doll and Peto, 1981). Epidemiologic data have indicated that prevalence of colorectal cancer is increased in developed countries as compared to many developing countries, and immigrants from low-incidence countries have been observed to assume cancer risk of their new homelands (Armstrong and Doll, 1975; Correa and Haenszel, 1978; Rose et al., 1986). Most, but not all epidemiologic studies have shown that high consumption of dietary fat and meat is associated with an increased risk for colon cancer (Byers, 1988; Hill, 1987; Willet, 1989). Recently it has been found in epidemiologic studies that high intake of fried meats (Young et al., 1988), as well as of fat-rich deep-fried foods (Peters et al., 1989) is associated with increased risk for colon cancer, which suggests that these food products contain compounds which may be causally related to colon tumorigenesis.

Dietary constituents are considered to act on the colonic mucosa largely via faeces, which may contain tumor-initiating, -promoting as well as inhibiting factors (Bruce, 1987). Tumor-initiating compounds are generally considered to be genotoxic, and application of the Salmonella mutagenicity assay provided a relatively fast and simple method for determination and identification of possible carcinogens in the faecal stream. Persons at high risk for developing colon cancer, as well as populations consuming high-fat, low-fiber diets, have been reported to show high faecal mutagenicity, while vegetarians and populations consuming high-fiber, low-fat diets tend to have low levels of faecal mutagenicity (Ehrig et al., 1979; Kuhnlein et al., 1981; Mower et al., 1982).

fecapentaenes, very potent direct-acting bacterial mutagens, have been succesfully isolated and identified from human faeces (Gupta et al., 1979). In addition, the existence of several not yet identified mutagens has been demonstrated, since faecal extracts have been observed to possess nonfecapentaene mutagenicitiy to Salmonella tester strains (Schiffmann et al.. 1989 ), and have also been reported to contain pre-mutagenic compounds which require microsomal metabolism to become acitve (Reddy et al., 1984; Schiffman, 1986). Diet intervention studies have led to the identification of some determinants of faecal mutagenicity. Consumption of fried meat, which has been found to contain mutagenic amino acid pyrolyzates (Furihata and Matsushima, 1986), has been observed to increase faecal mutagenicity (Kuhnlein et al., 1983; Hayatsu et al., 1985b). In a pilot study, the addition of extra fat to a typical Western diet has been reported not to result in increased faecal mutagenicity (Vennit et al., 1986). In addition, supplementation of diets with fiber, vitamin $C$ and vitamin $E$ has been demonstrated to reduce faecal mutagenicity (Dion et al., 1982; Reddy et al., 1987, Vennit et al., 
1986). In another study however, supplementation of vitamin $C$ or vitamin $E$ has not been observed to affect fecapentaene production (Wilkins et al., 1981), thus indicating other compounds also contribute to faecal mutagen production. Effects of consumption of mutagen containing foods, other than fried meats, on faecal mutagen excretion have not yet been described.

In a previous study performed in our laboratory, repeately used, commercial deep-frying fat samples were found to exhibit mutagenicity to Salmonella typhimurium tester strains TA97, TA100 and TA104 (Hageman et al., 1988). Mutagenicity of most of the fat samples was observed to be reduced by microsomal metabolism. Mutagenic activity of these fat samples also showed a positive association with lipid oxidation products of polyunsaturated fatty acids (PUFA) determined in the fats (Hageman et al., $1988 ; 1989$ ). Subsequent studies revealed that fats, which do not contain lipid oxidation products, also exhibit mutagenic activity, indicating that other mutagens, possibly also oxidation products, are formed during frying as well (Hageman et al., 1990; results shown in Chapter 5). It was also observed that consumption of potatoes prepared in repeatedly used, mutagenic deepfrying fat, did not increase urine mutagen excretion in 6 healthy volunteers (Hageman et al., 1990). It was therefore concluded that mutagens consumed with fried potatoes are either inactivated in vivo, or that mutagens may not be excreted in urine, but in faeces.

The present study was undertaken to determine primarily whether consumption of potatoes prepared in repeatedly used, mutagenic deepfrying fat affects faecal mutagenicity. For this purpose, 14 healthy volunteers were asked to consume daily, during a period of 5 days, a portion of fried potatoes, prepared in mutagenic deep-frying fat; during a 5-day control period, the same subjects consumed daily a portion of mashed potatoes, to which an equal amount of unheated frying fat was added. A cross-over design was used with equal food consumption during both 5-day periods. Diet was controlled with respect to consumption of known mutagencontaining foods, since increased mutagen excretion was repeatedly reported in urine as well as in faeces after consumption of fried meats and fish (Baker et al., 1982; Dolara et al., 1984; Hayatsu et al., 1985a, 1985b; Ohyama et al., 1987; Sousa et al., 1985). Therefore, all foods consumed by the participants of the study, were supplied by the investigators. Food consumption was recorded daily. Fried meats and meat extracts were excluded from the diet to prevent interference of genotoxic amino acid pyrolyzates (Alink et al., 1988; Furihata and Matsushima, 1986) with mutagenicity of compounds present in lipid fractions of deep-fat fried potatoes. For the same reason fried potatoes, and not meat snacks, were chosen to serve as a carrier of mutagens formed during deep-fat frying.

Urine and faeces samples were collected on the fourth and fifth day of 
each diet period. Samples were tested for mutagenicity to strain TA97 in order to determine biological fate of direct-acting mutagens present in lipid fractions of fried potatoes. Mutagenicity to strain TA100 was analyzed to detect effects of mutagens acting by base-pair substitution which were also found to be present in heated deep-frying fats (Hageman et al., 1988). Urinary $\mathrm{pH}$ was determined, to investigate a possible relationship with mutagenicity. In addition, the influence of the change from free-choice to experimental diets on faecal mutagenicity was studied. For this purpose, faeces samples were collected on the first day of the experiment as well. Blood was collected at the end of each diet period and plasma clinical biochemical parameters were measured to determine possible adverse effects of daily consumption of repeatly used deep-frying fat on hepatic and renal tissues (Billek et al., 1979, Kanazawa et al., 1986). Excretion of thiobarbituric acid-reactive substances (TBA-RS) was measured as an index of whole body lipid oxidation, which was reported to be related with endogenous lipid oxidation, as well as with dietary lipid oxidation (Draper et al., 1984). Elevated faecal $\mathrm{pH}$ and increased mutagenicity are considered to be indicators for increased colon cancer risk; therefore, faecal $\mathrm{pH}$ was measured and related to mutagenicity (Bruce, 1987).

\section{Materials and methods}

\section{Frying procedure}

A batch of $10 \mathrm{~kg}$ of coconut oil was commercially obtained. According to the manufacturer (personal communication) the fat did not contain additives. Seven $\mathrm{kg}$ of the oill was used for frying, and was healed at $180^{\circ} \mathrm{C}$ for $10 \mathrm{~h}$ per day during 3 consecutive days. Various fried foods were prepared, including meat products, breaded products and fresthy sliced potatoes. After $30 \mathrm{~h}$ of heating, the polar fraction of the fat was found to be mutagenic, and at this point, $25 \mathrm{~kg}$ of treshly sliced potatoes were pre-tried in portions of $500 \mathrm{~g}$ during $4 \mathrm{~min}$ at $180^{\circ} \mathrm{C}$, using the mutagenic oil. After the complete batch was pre-fried, potatoes were fried again for $3 \mathrm{~min}$. Actual frying temperatures ranged from $16010180^{\circ} \mathrm{C}$. Fried potatoes were mixed into a homogeneous batch, and in portions of $2 \mathrm{~kg}$ frozen at $-20^{\circ} \mathrm{C}$ until consumption, which was within 3 weeks.

\section{Diet intervontion study}

Participants (7 males and 7 females) of the diet intervention study were selected from 25 volunteers using the following criteria: good health, aged between 18 and 30 , non-smoker, no use of medication other than oral contraceptives, no abdominal complaints, regular stools (at least once per day), no extreme dietary habits, moderate alcohol consumption (maximally 2 glasses per day). Before entering into the study, volunteers were medically examined and a blood sample was collected for measurement of standard biochemical and hematological plasma parameters. A dietary history was obtained using a standard questionnaire. Energy and nutrient intake on free choice diet was calculated using the Dutch computerized food 
composition lable (Hautvast, 975 ). The data obtaned from the food questionnaire were used for composition of diets during the intervention period. The test protocol was approved by the Medical Ethical Commision of the Unwersily of Limburg, and all volunteers signed an informed consent.

During 2 periods of 5 days (monday thi triday) of 2 consecutive weeks participants consumed a diet consisting of regular food products, with excluston of fried or baked meat products, nuts, cacao products, meat extracts, and other heat processed loods rion in fat fcontectioneries, cake, etc.), as well as alcohol. Participants received one hot meal dally at the institute between 12 and $14 h$, which consisted of meat prepared in a microwave-oven without the use of browning plates, cooked as well as raw vegetables, thult and a dairy product for desert. One period of 5 days participants consumed $250 \mathrm{~g}$ of ried potatoes with their thot meal (Period 1). Fried potatoes were thawed at room temperature and heated in a stove for 15 min at $150^{\circ} \mathrm{C}$ prior to consumption. During the other period (Period $M, 250 \mathrm{~g}$ of mashed potatoes were consumed to which an amount of unused frying lat was added after cooking of the potatoes, equal to that present in fried potatoes. Mashed potatoes were prepared fresh daily and heated in a microwave-oven prior to consumption. Daily, participants received foods for breakfast and evening meals (whole wheal bread, margarine, preserves, cheese, low lat milk and fresh fruth, as well as snack foods (low-tat biscuits, raisin bread, etc). Cotfee, tea and soft-drink consumption were free, but subjects were asked to maintain their habits at a constant level during the study period. Food consumption during the experimental period was recorded daily. Menu's were equal during both periods of 5 days, and if possible, same batches of food products were used. A cross-over design was applied, with 7 participants (3) males, 4 lemales) starting with consumplion of tried potatoes and 7 (4 males, 3 lemales) with mashed polatoes. During the weekend in between both periods, subjects were allowed to consume their free-choice diet.

faeces samples were collected in polypropylene bags on the first day of the experiment, as well as on days 4 and 5 of each period, and stored in dry-ice boxes at the homes of the participants. Samples were transferred to the laboratory and stored all $-20^{\circ} \mathrm{C}$ unlil analysis. Urine samples were collected on days 4 and 5 ; collection started immediately after the hot meal and was divided in 2 periods of $12 \mathrm{~h}$. Urine samples were stored under retrigeration and brought to the laboratory on the following day, where the samples were stored at $-20^{\circ} \mathrm{C}$ until analysis. On the fifth day of each period, blood was collected by venipuncture in heparinized fubes. Plasma was obtained by centrifugation at $2000 \mathrm{~g}$ for $10 \mathrm{~min}$, and stored at $-20^{\circ} \mathrm{C}$ until analysis.

\section{Chemical analyses}

Concentrations of TBA-RS were determined colorimetrically, and amounts of di- and polymeric trigllycerides (DPTG) by gell permeation high performance liquid chromatography (HPLC), and were pertormed as described previously (Hageman et al. . 1988). TBA-RS and DPTG were measured in irying oll and PE-extracts of fried and mashed potatoes. Unused frying oil did not contain detectable amounts of TBA-RS and DPTG. Frying oil used for preparation of fried potatoes was found to contain 3.5 nmoles of MDAg. Urinary excretion of TBA-RS was measured as described previously (Hageman et al.. 1990). Faecal pH was 
determined potentiometrically in $0.5 \mathrm{~g}$ wot faeces which were homogenized with $2.0 \mathrm{mll}$ of saline solution $\left(0.9 \% \mathrm{NaCl}_{\text {; }}\right.$ w/v) using a turrax mixer.

\section{Determination of plasma clinical biochemical parameters}

Clinical biochemistry of plasma consisted of determination of total protein, ureum (blood urea nitrogen; BUN), creatinin (Cr), lactate dethydrogenase (LDH; E.C. 1.1.27), alkaline phosphatase (AP: E.C. 3.1.3.1), creatine phosphokinase (CP; E.C. 2.7.3.2), glutamic oxaloacetic transaminase (GOT: E.C. 2.6.1.1) and glutamic pyruvic transaminase (GPT; E.C. 2.6.1.2). which were analyzed routinely using a centrifuge analyzer (type Cobas Bio, Hoffmann LaRoche)

\section{Mutagenicity testing}

Mutagenicity of the oll was evaluated after the fat was fractionated into a non-polar and a polar fraction using silicagel column chromatography, as described previously (Hageman et al., 1988). Unused coconut ail did not exhibit mutagenicity to Samonella strain TA97, while after $30 \mathrm{~h}$ of use the polar fraction of the oil showed significant mutagenic activity, inducing approximately $4 \cdot 10^{3}$ revertants/g of fat. Before mutagenicity testing, fried potatoes as well as mashed potatoes containing unheated coconut oil, were lyophilyzed. Lipids were extracted from $20 \mathrm{~g}$ of dried product with $200 \mathrm{mi}$ of petroleum ether ( $\mathrm{PE}$; boiling range $40-60^{\circ} \mathrm{C}$ ) by overnight Soxhlet extraction. Most of the PE was removed by vacuum evaporation, extracts were completely dried under a stream of nitrogen. Fat-free residues of fried and mashed potatoes were subsequently extracted with $200 \mathrm{mi}$ of methanol (Me) to obtain more polar components which were previously shown to exhibit mutagenic activity as well (Hageman et al., 1990). PE extracts were separated into non-polar and polar fractions using silicagel column chromatograhpy (Hageman et al., 1988), and tested for mutagenic activity using the liquid pre-incubation procedure as described previously (Hageman et al., 1990). In brief, nonpolar and polar fractions were dissolved in tetrahydrofuran (THF), Me-extracts in methanol and tested in triplicate at doses of $0.1,1.0,5.0,10.0 \mathrm{mg}$ per plate " using Salmonella tester strains TA97 and TA100 with and without addition of liver $\$ 9$ mix ( $50 \mu$ of homogenate/plate). obtained trom Aroctor induced rats. Aliquots of $25 \mu \mathrm{l}$ of the THF solution, and $100 \mu \mathrm{l}$ of the methanol solutions were applied to the plates. Negative controls, consisting of chromatography and extraction solvents processed according to the procedures used for lipld fractions were also included in mutagenicity testing. Mutagenicity testing of lipid fractions was repeated at least once in a separate assay.

Urine samples were thawed and vacuum filtered through a Whatman no. 4 filter. An aliquot representing $15 \%$ of the total $12-\mathrm{h}$ volume was concentrated on XAD-2 resin as described previously (Hageman et al., 1990). In a previous study, acetone extracts of urine were not found to contain mutagenic activity after consumption of fried potatoes prepared in mutagenic frying fat. Since urine might possibly contain very polar mutagens derived from polar oxidation products of irying fat, extraction with dichloromethane (DCM) prior to acetone was applied to separate polar from non-polar compounds. DCM and acetone extracts were dried under a stream of nitrogen, stored at $4^{\circ} \mathrm{C}$, and analyzed for mutagenicity within a week. Prior to mutagenicity testing, urine extracts were dissolved in $0.6 \mathrm{ml}$ dimethyl sulphoxide (DMSO). Aliquots of $100 \mu \mathrm{l}$ (representing $2.5 \%$ of the total volume), and $100 \mu$ of $1: 3$ diluted extracts 
(0.8\% of the total volume) were tested in duplicate for mutagenicity using strans TA97 and TA100. Negative controls consisting of $10 \mathrm{ml}$ of DCM or acetone which were passed through XAD-2 resin, evaporated and dissolved in DMSO, were also included in mutagenicity testing. Urine mutagenicity was not evaluated in the presence of $\$ 9 \mathrm{mix}$, since mutagenicity of repeatedly used deep-frying fats as well as of deep-fried potatoes was not found to be enhanced in presence of liver S9 mix as compared to results obtained in absence of $59 \mathrm{mix}$ (Hageman et al., 1988; 1990).

Faeces samples were thawed and homogenized in polypropylene bags using a stomacher lab blender (Seward Laboratory, Londan, Great-Britain). Homogenized samples were lyophylized, after which $1 \mathrm{~g}$ of dry fasces was extracted twice with $10 \mathrm{ml}$ DCM under vigorous shaking for $30 \mathrm{~min}$ at room temperature. In a pilot study, it was observed that DCM was more efficient than diethyl ether, acetone, or methanol in extracting mutagenic substances from dry faeces. DCM-extracts were combined, filtered through a Whatman no. 4 fitter and dried under a stream of nitrogen. Dry extracts were stored at $-20^{\circ} \mathrm{C}$, and tested for mutagenicity within 2 days. Prior to mutagenicity analysis faecal extracts, representing $1.5 \mathrm{~g}$ equivalent of dry faeces, were dissolwed in $1 \mathrm{ml}$ methanol; alliquots of $100 \mu \mathrm{l}$ were tested per plate using strain TA97 and TA100 using the standard plate assay (Maron and Ames, 1983). Since consumption of mutagenic deep-frying fat was considered to influence taecal excretion of direct-acting mutagens, as well as possible production of pre-mutagenic compounds in faeces for instance by the intestinal microflora, mutagenicity of faecal extracts was evaluated in absence as well as in presence of $\|$ iver $\$ 9 \mathrm{mix}$ (50 $\mu$ l/plate). Negative controls consisting of DCM which was evaporated and subsequently dissolved in methanol, as well as positive controls were also included in mutagenicity testing. Urine or faecal extracts of all samples obtained from a particular participant in bath periods, were tested in the same assiay.

\section{Statistical analyses}

Significance of mutagenicity results of lipid fractions and of Me-extracts was determined by the method of least significant differences (LSD) as described previously (Hageman et al., 1988). LSD values for THF as solvent (solvent control of non-polar and polar lipid tractions) were at a significance level of $p<0.05$ for strain TA97-S9 mix, 120: for strain TA97 \&S9 mix. 105; for strain TA100-S9 mix, 146; and for strain TA100+S9 mix, 114. For methanol as solvent LSD values $(p<0.05)$ were for strain TA97-S9 mix, 106 ; for strain TA97+S9 mix, 142; for strain TA100-S9 mix, 91; and for strain TA100+S9 mix 94. Mutagenicity per mg of polar or non-polar fraction was estimated applying linear regression to non-10xic portions of doseresponse curves, showing significant mutagenicity at one or more dose levels. LSD values for urine extracts were for DMSO as a solvent at a significance level of $p<0.05$ in strain TA97-S9, 114; and in strain TA100-S9, 57. LSD values of faecal extracts at significance levels of $p<0.05$ and $p<0.01$ respectively, were for strain TA97-S9 mix, 56 and 99; for strain TA97+S9 mix, 54 and 96; for strain TA100-S9 mix, 42 and 74; and for sirain TA100+S9 mix, 60 and 106.

Differences between the 2 periods in food consumption, urinary and faecal mutagen excretion, excretion of TBA-RS in urine, faecall $\mathrm{pH}$, and plasma clinical biochemical parameters were statistically analyzed using Sludents' tlest for paired values. Differences between sexes and between the 2 groups of the cross-over design, were evaluated using Students' t-test for 
unpaired values. Statistical significance of differences in frequencies of mutagenic faeces samples between diet periods was analyzed using Fisher's exact test. Associations between dietary intakes and mutagenicily of urine and faeces, as well as between different paramaters measured, were evaluated by Pearson's coefficient of correlation.

\section{Results}

Results of nutrient intake of the participants during their free-choice diets, and during both experimental periods are shown in Table 7.1. Intake of energy, macro-nutrients and fiber was not found to differ between both experimental periods. In addition, energy intake, as well as consumption of protein, carbohydrates, fat and dietary fibre were not found to be significantly changed during the experimental periods as compared to the free-choice diet (Table 7.3). The P/S ratio of triglycerides consumed during the experimental period however, was significantly lowered $(p<0.01, n=14)$ as compared to the P/S ratio of fats consumed during free-choice diets. Since only three participants reported regular alcohol consumption, differences in alcohol consumption between free-choice and experimental diets were obvious for these three only (Table 7.1).

Amounts of oxidation and degradation products of lipids in fried and mashed potatoes, are shown in Table 7.2. Fried potatoes were found to contain increased levels of polar oxidation products as well as Meextractable compounds. DPTG and TBA-RS were not detectable in PEextracts of fried and mashed potatoes. Results of mutagenicity testing of lipid fractions and Me-extracts are listed in Table 7.3. Mutagenicity was observed to be highest for fried potatoes to strain TA97 without S9 mix, although mashed potatoes were also found to possess mutagenic activity to strain TA97 without S9 mix. Significantly increased numbers of revertants in TA97 and TA100 in presence of $S 9 \mathrm{mix}$, were detected for polar lipid fractions and Me-extracts obtained from fried as well as from mashed potatoes, but mutagenicity per $\mathrm{g}$ of food product was considerably lower in mashed potatoes as compared to fried potatoes due to small amounts of these fractions present in mashed potatoes. Mutagenicity to strain TA97 of polar lipid fractions and Me-extracts was found to be reduced in presence of S9 mix. No mutagenicity was detected in lipid fractions and Me-extracts using strain TA100 without S9 mix, which for Me-extracts was found to be due to toxic effects to the bacteria. Mutagen intake due to consumption of fried potatoes, as determined with strain TA97 without S9 mix, was estimated to be equavalent to $1.5 * 10^{5} \mathrm{rev} /$ day, whereas mutagen intake with mashed potatoes approximately amounted to $2.6 * 10^{4} \mathrm{rev} / \mathrm{day}$. 
Table 7.1. Energy and nutrient intake of participants on their freewhoice diets and during the experimental periods in which either a portion of tried potatoes (Period l) or mashed potatoes (Period II) was consumed daily.

\begin{tabular}{|c|c|c|c|c|c|c|}
\hline \multirow[b]{2}{*}{ Daily intake } & \multicolumn{2}{|c|}{ Free-choice diet } & \multicolumn{2}{|c|}{ Period I } & \multicolumn{2}{|c|}{ Period II } \\
\hline & males & females & males & females & males & formales \\
\hline \multirow[t]{2}{*}{ Energy $(M J)$} & 16.1 & 8.9 & 13.6 & 8.6 & 13.3 & 8.7 \\
\hline & \pm 4.8 & \pm 2.0 & \pm 2.1 & \pm 1.3 & \pm 1.6 & \pm 1.5 \\
\hline \multirow[t]{2}{*}{ Protein (g) } & 117 & 69 & 121 & 73 & 134 & 80 \\
\hline & \pm 25 & \pm 12 & \pm 23 & \pm 10 & \pm 38 & \pm 13 \\
\hline \multirow[t]{2}{*}{ Carbohydrates (g) } & 428 & 266 & 409 & 280 & 401 & 335 \\
\hline & \pm 117 & \pm 62 & \pm 80 & \pm 46 & \pm 85 & \pm 54 \\
\hline \multirow[t]{2}{*}{ Lipids $(g)$} & 179 & 83 & 122 & 68 & 117 & 73 \\
\hline & \pm 74 & \pm 25 & \pm 29 & \pm 11 & \pm 19 & \pm 14 \\
\hline P/S of triglyce- & 0.50 & 0.52 & 0.33 & 0.35 & 0.35 & $0.31 a$ \\
\hline rides & \pm 0.23 & \pm 0.22 & \pm 0.09 & \pm 0.07 & \pm 0.09 & \pm 0.05 \\
\hline \multirow[t]{2}{*}{ Dietany fibre (g) } & 43 & 31 & 39 & 26 & 37 & 26 \\
\hline & \pm 8 & \pm 7 & \pm 6 & \pm 3 & \pm 5 & \pm 3 \\
\hline \multirow[t]{2}{*}{ Alcohol (g) } & 2 & 1 & 0 & 0 & 0 & 0 \\
\hline & \pm 4 & \pm 3 & & & & \\
\hline
\end{tabular}

Results are presented as mean $\pm S D$ of each group of 7 maves or 7 females. significantly different from free-choice diet, $p<0.05$.

Consumption of fried potatoes by 14 human volunteers did not affect excretion of TBA-RS in urine, nor urinary and faecal $\mathrm{pH}$ as compared to consumption of mashed potatoes containing unheated frying oil (Table 7.4). Urinary excretion of TBA-RS were not significantly changed during the first $12 \mathrm{~h}$ after the hot meals as compared to urine samples collected $12-24 \mathrm{~h}$ after the hot meals (Table 7.4); no effect of consumption of heated vs. unheated oil was observed in either. The $\mathrm{pH}$ of faeces samples collected 
immediately after the free-choice diets was not found to be significantly different from the $\mathrm{pH}$ of faeces samples collected during both experimental periods. Daily consumption during 5 days of fried potatoes prepared in repeatedly used deep-frying oil was not found to cause adverse effects as judged by results of plasma clinical biochemical parameters, which did not differ from results obtained tor plasma of blood samples collected after daily consumption of mashed potatoes containing unheated frying oil (Table 7.5). Plasma clinical biochemical parameters measured during both periods, were found to be in the normal range reported in the literature (Anonymous, 1981).

Table 7.2. Results of chemical analyses of petroleum ether (PE)-extracts and methanol (Me)extracts of fried and mashed potatoes.

\begin{tabular}{llc}
\hline Parameter & Mashed & Fried \\
& potatoes & potatoes \\
\hline
\end{tabular}

$\begin{array}{lcc}\text { dry matter } & 29.3 & 5.8 .0 \\ \text { (\% by weight) } & 10.1 & 14.2 \\ \begin{array}{l}\text { lipids } \\ \text { (\% by weight) }\end{array} & & \\ \text { polar fraction } \\ \text { (\% by weight) } \\ \begin{array}{l}\text { Me-extractable compounds } \\ \text { (\% by weight) }\end{array} \\ \begin{array}{l}\text { DPTG in PE-extracts } \\ \text { (\% by weight) }\end{array} \\ \begin{array}{l}\text { TEA-AS in PlE-extracts } \\ \text { (nmoles of MDAv) }\end{array}\end{array}$

"Detection limit for analysis of di-and polymeric triglycerides (DPTG) is 1\% (by weight), and for determination of thiobarbituric acid-reactive substances (TBA-RS) $1.0 \mathrm{nmol}$ malondialdehyde (MDA)/g of fat. 
Neither DCM- nor acetone-concentrates of individual urine samples collected during the first $12 \mathrm{~h}$ after the hot meal, significantly increased numbers of revertants in strains TA97 and TA100. Acetone concentrates slightly, but statistically not significantly, increased numbers of revertants in both tester strains, whereas DCM-concentrates induced numbers of revertants equal to the solvent control. Urine samples of four participants collected 12 to $24 \mathrm{~h}$ after the meal were analyzed, but since these were not found to induce increased numbers of revertants either, further analysis of urine samples collected 12 to $24 \mathrm{~h}$ after the hot meal was omitted. Mean mutagenicity of acetone extracts of urine samples collected during the first $12 \mathrm{~h}$ after the hot meal did not differ between the two diet periods (Figure 7.1), indicating that increased intake of mutagens with fried potatoes did not result in increased urine mutagenicity.

DCM-extracts of individual faeces samples of some, but not all participants, collected during the experimental periods were found to exhibit significant mutagenicity to strains TA97 and TA100. Mutagenicity results of DCM-extracts of faeces however, showed considerable inter- as well as intra-individual variation; intra-individual variations were found to range from reduced numbers of revertants to levels reaching 3 times the number of spontaneous revertants for 2 consecutive samples. In addition significantly reduced $(p<0.05)$ numbers of revertants were found for faecal extracts tested using strain TA97 in presence of $\mathrm{S} 9 \mathrm{mix}$, which could not be ascribed to toxic effects since the background lawn did not show growth inhibition. Therefore, mean mutagenicity results of samples obtained on day 4 and 5 of each experimental period was determined and used for statistical analyses of the data. Incidences of mutagenic faeces samples are shown in Figure 7.2. Frequencies of faeces samples showing significant mutagenicity to strains TA97 and TA100 as compared to the solvent controls $(p<0.05)$ were found to be highest during period I when daily a portion of fried potatoes was consumed, but did not differ significantly from frequencies of mutagenic samples observed during free-choice diet and period II.

Mutagenicity of DCM-extracts of faeces to strains TA97 and TA100, tested with and without S9 mix, was not found to be increased during period I as compared to period II (Figure 7.3). However, significant differences were observed between mutagenicity of faecal extracts of samples reflecting excretion on free-choice diet and mean mutagenicity samples collected during Period 1. Mutagenicity of the latter samples was significantly increased in strain TA100, tested both with and without $\$ 9$ mix $(p<0.05)$. In contrast, mutagenicity of faecal extracts collected during period I showed significantly reduced mutagenicity in strain TA97 in presence of 59 mix $(p<0.05)$ as compared to the sample collected immediately after the freechoice diet. Results indicated that increased mutagen consumption with fried potatoes as determined by strain TA97, did not lead to increased taecal 
Table 7.3. Mutagenicity to Salmonella typhimurium tester strains TA97 and TA100 of lipid fractions and methanol (Me)-extracts, obtained from mashed and fried potatoes.

Mutagenicity to strain:

TA97-89 TA97+S9 TA100-S9 TA100+S9

\section{Mashed potatoes:}

Polar lipid fraction

(revig of product)

Non-polar lipid fraction

(rev/g of product)

Me-extract

(rev/g of product)

Total mutagenicity

(rev/g of product)

Fried potatoes:

Polar lipid fraction

(rev/g of product)

Non-polar lipid fraction

(revig of product)

Me-extract

(rev/g of product)

Total mutagenicity

(rev/g of product)
28

$\mathrm{nm}$

74

102

160

$\mathrm{nm}$

422

582
112

$\mathrm{nm}$

$\mathrm{nm}$

$\mathrm{nm}$

$\mathrm{nm}$

$\mathrm{nm}$

nim

tox 2

tox

112

$\mathrm{nm}$

$\mathrm{nm}$

180

$\mathrm{nm}$

92

$\mathrm{nm}$

$\mathrm{nm}$

$\mathrm{nm}$

$\mathrm{nm}$

tox

to*

180

$\mathrm{nm}$

92

Mutagenicily of isolated fractions was estimated by determination of mutagenic activity per mg of polar and nompolar fractions and Me-extracts, applying linear regression to dose response curves. Contribution of the respective tractions to mutagenicity per $g$ of product. was calculated by multiplication of mutagenicity per $\mathrm{mg}$ of fraction, with the total amount of this fraction present in one $g$ of product.

"not mutagenic.

2 toxic to the tester strain. 
mutagenicity, but instead reduced faecal mutagenicity as compared to results obtained for samples representing excretion during free-choice diets. In addition, results of mutagen excretion as determined with strain TA100, indicated that the change of diet does affect the excretion of mutagens, which are not related to consumption of deep-fried potatoes:

Mutagenicity of urine and faeces samples, as well as results of other parameters tested were not found to differ between both groups formed in the cross-over design, and neither between the sexes. Use of oral contraceptives was not found to influence mutagenicity results, nor other parameters measured. A significant positive correlation was observed between mutagenicity of faecal extracts tested using strain TA100 with S9 mix, and $\mathrm{pH}$ of faeces samples $(r=0.45, p<0.02)$. Weak, but statistically insignificant positive correlations were also observed between faecal $\mathrm{pH}$ and mutagenicity of faecal DCM-extracts to strains TA97-S9 $(r=0.33)$ and TA100-S9 $(r=0.34)$. A significant positive correlation was found between TA97 mutagenicity of faecal DCM-extracts and faecal mutagenicity to strain TA100 in absence of $S 9$ mix $(r=0.79, p<0.001)$, which was found within separate periods as well as when all faecal samples were included. Mutagenicity of urine extracts to strain TA97 was not found to be associated with mutagenicity to strain TA100. Mutagenicity of faecal extracts, as well as of urine extracts, was not found to be associated with any other relevant parameter measured, including dietary intake of fat, type of fat ( $\mathrm{P} / \mathrm{S}$ ratio) and fiber, indicating other dietary factors which were not determined in the present study may determine faecal mutagen excretion.

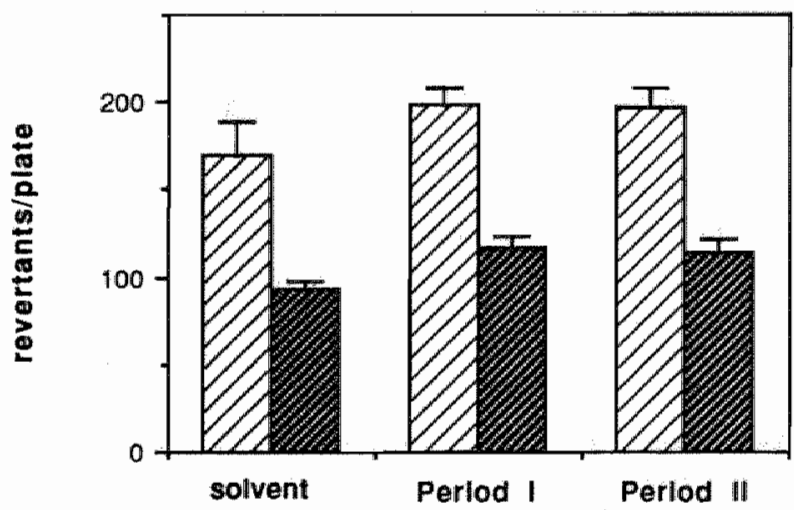

Figure 7.1. Mean mutagenicity of acetone extracts $(0.8 \%$ of the total volume) of urine samples collected during the first $12 \mathrm{~h}$ after consumption of fried potatoes (Period I) or mashed potatoes (Period II). Results shown are the mean $\pm S D$ of mutagenicity results of 14 volunteers abtained for strains TA97 ( $\mathrm{D})$ and TA100 ( $\mathrm{Z}$ ). 
Table 7.4. Excretion of thiobarbituric acid-reactive substances (TBA-AS) inurine, and $\mathrm{pH}$ of urine and faeces samples collected after daily consumption of fried potatoes, prepared in repeatedly used coconut oil (Period 1), and consumption of mashed potatoes containing unused coconut oil (Period II).

\begin{tabular}{|c|c|c|c|}
\hline Parameter & $\begin{array}{l}\text { Free-choice } \\
\text { diet }\end{array}$ & Period I & Period II \\
\hline Urinary TBA-RS excretion1-12 h & n.a 1 & 2.77 & 2.63 \\
\hline after the hot meal ( $\mu$ molesof MDA) & & \pm 0.85 & \pm 1.13 \\
\hline Urinary TBA-RS excretion 12-24 h & n.a. & 2.08 & 2.04 \\
\hline after the hot meal ( $\mu$ moles of MDA) & & \pm 0.74 & \pm 0.64 \\
\hline \multirow[t]{2}{*}{ Urinary pH } & n.a. & 7.03 & 6.74 \\
\hline & & \pm 0.50 & \pm 0.49 \\
\hline \multirow[t]{2}{*}{ Faecal pH } & 7.0 .4 & 7.14 & 7.15 \\
\hline & \pm 0.59 & \pm 0.34 & \pm 0.23 \\
\hline
\end{tabular}

1 nat analyzed.

Results are expressed as mean $\pm S D$ of all participants. Mean urinary excretion of TBA-RS. and mean urinary and faecal pH during periods 1 and $1 /$ were determined per person using samples of days 4 and 5 . Group means were calculated using mean values of each porson.

\section{Discussion}

In the present study effects of consumption of mutagen containing deepfrying fats on urinary and faecal mutagen excretion were determined in human volunteers, to assess endogenous exposure and biological fate of mutagens produced during deep-fat frying. For this purpose, freshly sliced potatoes were prepared in repeatedly used coconut oil showing significant mutagenicity to Salmonella tester strain TA97, and $250 \mathrm{~g}$-portions were consumed daily by 14 healthy volunteers during 5 consecutive days. Results obtained were compared to effects observed after daily consumption of unheated coconut oil, which was mixed through mashed potatoes. Intake of mutagenic compounds showing activity to strain TA97 without S9 mix, was found to be approximately 5 times higher during the period in which fried potatoes were consumed as compared to consumption of mashed potatoes. In contrast to a previous study (Hageman et al., 1990), in which Me-extracts of fried potatoes exhibited increased mutagenicity in presence of S9 mix, in 

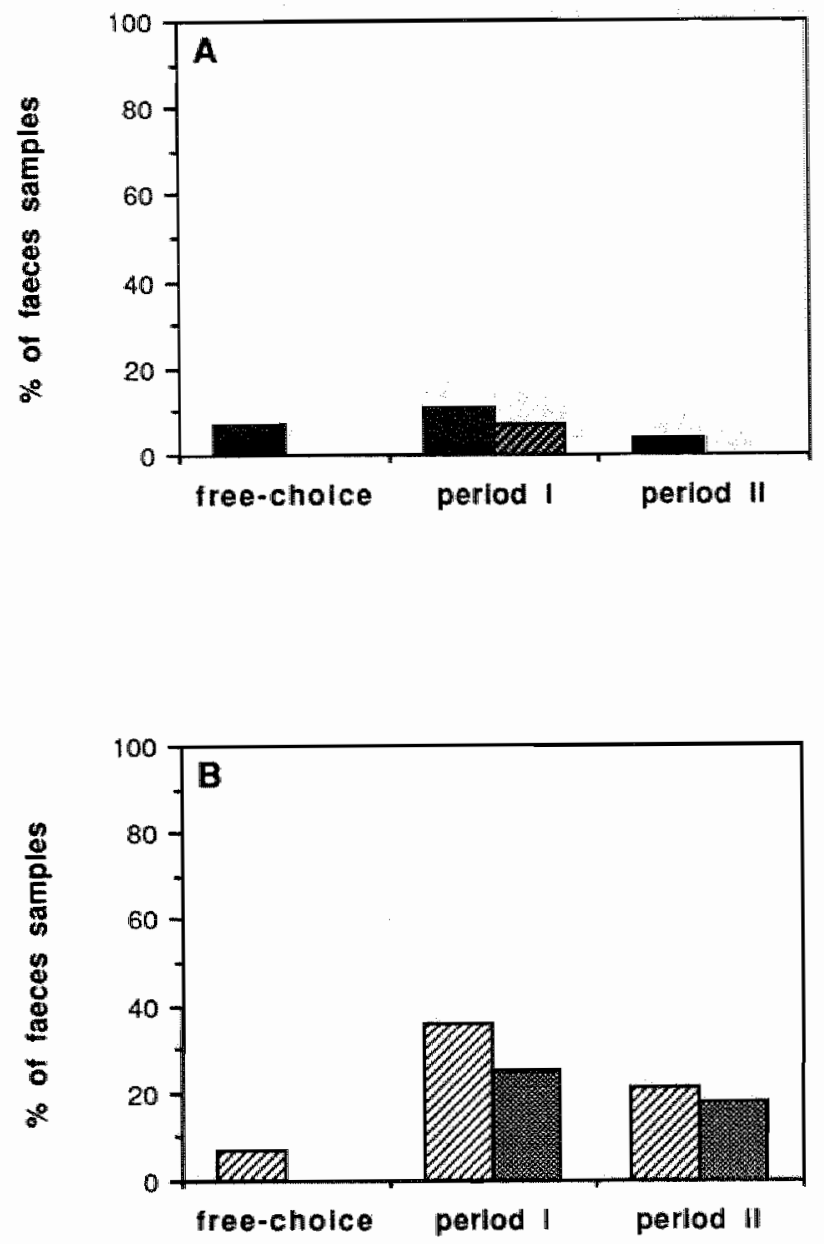

Figure 7.2. Frequencies of faeces samples showing significant mulagenicity as compared to solvent controls $(0<0.05)$ of 14 volunteers consuming their free-choice diets, and the experimental diets containing fried potatoes (Period 1), or mashed potatoes (Period II). In (A), results are shown for strain TA97-S9 (D) and TA97+S9 (Q); in (B), frequencies of mutagenic faeces samples to strain TA100-S9 ( $Z$ ), and TA100+S9 (国) are presented. Total number of samples tested was 14 for the free-choice diet period, and 28 for periods 1 and 11 . 

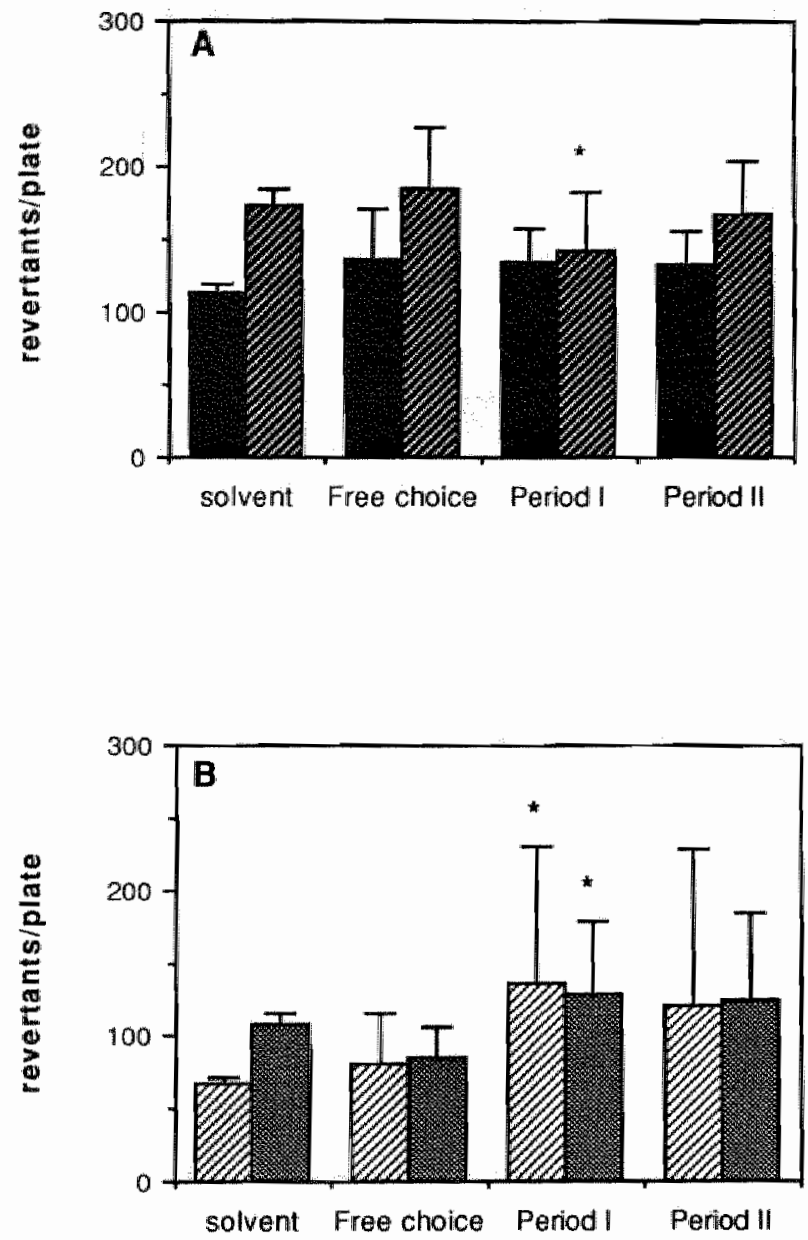

Figure 7.3. Mean mutagenicity to strain TA97 (A) and TA100 (B) of DCM-extracts of faeces samples (150 mg-equivalent of dry faeces), representing mutagen excretion on free-chaice diets, and during both experimental periods. Results shown are the meantSD of results of 14 volunteers obtained for strains TA97-S9 (D), TA97+S9 (B) . TA100-S9 (回), and $T A 100+S 9$ ( ). "significantly different from results obtained for samples representing the free-choice diet $(p<0.05)$. 
Table 7.5. Results of plasma clinical biochemical parameters of blood samples of 14 volunteers, taken after daily consumption during 5 days of fried potatoes prepared in repeatedly used frying oil (Period 1$)$, and mashed potatoes containing unhealed frying oil (Period 1).

Parameter

Period 1

Period II

Glutamic oxaloacetic transaminase

9.2

10.3

(GOT; U/I)

$\pm 2.0$

$\pm 2.3$

Glutamic pynwic transaminase

5.6

5.3

(GPT; U/I)

$\pm 2.2$

$\pm 2.4$

Creatine phosphokinase

(CPK; U/l)

$\begin{array}{rr}66 & 65 \\ \pm 44 & \pm 47\end{array}$

Alkaline phosphatase

83

85

$(A P ; L / I)$

$\pm 19$

$\pm 22$

Lactate dehydrogenase

211

208

(LDH; U/l)

$\pm 67$

$\pm 40$

Plasma creatinin

76

85

(Cr; $\mu$ molll)

$\pm 13$

$\pm 13$

Plasma ureum

5. 1

5.2

(BUN; umol/l)

$\pm 1.4$

$\pm 0.9$

Plasma protein $(g / l)$

66

65

$\pm 2$

$\pm 3$

Results are expressed as mean $\pm S D$ of all participants $(n=14)$.

the present study. Me-extracts were found to show direct-acting mutagenicity to strain TA97. This difference may be caused by the use of different types of fat in both studies, or by the nature of the fried potatoes. Compounds naturally present in potatoes may influence mutagenicity as well, since Meextracts of mashed potatoes in this study also showed weak mutagenic 
activity. PE-extracts of fried potatoes were not found to contain detectable amounts of DPTG or TBA-RS, thus excluding a significant contribution of lipid oxidation to mutagenicity of polar fractions of PE-extracts. Me-extracts were observed to contribute approximately $80 \%$ to mulagenicity of fried potatoes, indicating that this fraction may contain mutagenic compounds produced during deep-fat frying of potatoes. The nature of these compounds however, remains to be determined.

Daily consumption of heated coconut oil with fried potatoes during five days was not found to cause adverse effects as compared to daily consumption of unheated coconut oll with mashed potatoes, as evaluated by changes in plasma clinical biochemical parameters. This may be due to the fact that lipid fraction of fried potatoes did not contain detectable amounts of oxidation products of polyunsaturated fatty acids, which were reported to increase plasma activities of GOT and GPT, and cause cellular damage to liver and kidneys after oral administration to rats (Alexander, 1981; Billek, 1979; Kanazawa et al., 1986). In the present study, urinary excretion of TBARS of human volunteers was not found to differ either between both diet periods, indicating that endogenous exposure to lipid oxidation products was not increased after consumption of fried potatoes prepared in repeatedly heated coconut oil as compared to consumption of unheated coconut oil. This may also be considered to be due to the fact that concentrations of TBA-RS and DPTG in PE-extracts of potatoes in the present study were below detection limits. In a previous study, repeatedly used deep-frying fats were found to contain concentrations of TBA-RS up to $161 \mathrm{nmoles}$ of MDA/g of fat and levels of DPTG as high as $32 \%$ (by weight; Hageman et al., 1988). Effects of daily consumption of fried foods prepared in heated fats containing extremely high levels of lipid oxidation products, on faecal and urine mutagenicity, on excretion of TBA-RS, as well as on tissues in liver and kidneys remain to be determined.

Urine mutagenicity was not found to be significartly increased after consumption of fried potatoes, which is in agreement with results found in our previous study (Hageman et all., 1990). Although the frequency of faeces samples showing significant mutagenicity was increased during the period in which fried potatoes were consumed as compared to the period in which mashed potatoes were consumed, no consistent changes in faecal mutagen excretion were found between the periods within individuals as evaluated with students' t-test for paired values. Mutagenicity to strain TA100 of faeces samples collected after consumption of fried potatoes did show increased mutagenicity as compared to samples representing free-choice diets. Since $\mathrm{P} / \mathrm{S}$ ratio of fats consumed by the participants was significantly decreased during the experimental periods, a relation with increased faecal mutagenicity to strain TA100 was suggested. However, no significant correlations were found between P/S ratio of dietary lipids and faecal 
mutagenicity, neither was the intake of other dietary compounds measured found to be associated with faecal mutagen excretion.

Faecal mutagenicity is considered an index of carcinogenic risk for the colon/rectum, since the high-risk Western-type of diet (low-fiber, high-fat) has been related to increased faecal mutagenicity (Ehrig et al., 1979; Kuhnlein et al., 1981; Mower et al., 1982). However the relation between presence of faecal mutagens, as well as mutagenicity-inhibiting factors detected in faecal extracts, to tumorigenesis in colon/rectum still remains to be established (Bruce, 1987; Hayatsu et al., 1981; Schiffman, 1988). In the present study, the change from free-choice to experimental diet marked the increase in faecal mutagenicity to strain TA100, but this increase appeared not to be related to the known high-risk dietary factors such as high-fat and low-fiber intake. Previously, Venitt et al. (1986) did not observe enhancing effects of increased intake of dietary fat either. This finding, as well as the results obtained in the present study suggest that other diet-related factors, which are not known at present, may be interacting. Since faecal pH in the present study was related to increased faecal mutagenicity, it is suggested that possible tumor-initiating factors may be produced at high faecal $\mathrm{pH}$. The nature of faecal mutagens to strain TA100 remains to be determined. Since fecapentaenes were reported to possess direct-acting mutagenicity to strain TA100, and mutagenicity of fecapentaenes is reduced in presence of S9 mix (Gupta et al, 1983; Wilkins et al., 1981), the pattern of faecal mutagenicity obtained in the present study indicates that besides fecapentaenes other mutagens were present in faeces collected during the experimental periods.

Since daily consumption of mutagen containing deep-fat fried potatoes was not associated with increased urine or faecal mugenicity in the present study, and mutagenicity of lipid fractions of fried potatoes was found to be reduced in presence of $S 9 \mathrm{mix}$, it appears likely that mutagens present in deep-fried potatoes are inactivated in vivo. A possible retention of mutagenic compounds within the tissues however, cannot be excluded. No acute toxic effects on liver or kidneys appeared to be exerted by daily consumption of approximately $35 \mathrm{~g}$ of heated fat either, since no changes were observed in serum clinical biochemical parameters either. It may be concluded from the present study that daily consumption for a short period of time of mutagenic deep-frying fat, containing low levels of lipid oxidation products, does not appear to pose serious health risks.

\section{Acknowledgements}

The authors gratefully appreciate the contributions made to this study by mrs. R. van Houwelingen, mrs. E. Brouwer, mr. G. van Kranenburg, mr. P. 
Koken of the Maastricht Office for Food Quality Control, and all volunteers.

\section{References}

Alexander J.C. (1981). Chemical and biological properties related to toxicity of heated fats. $J$. Toxic. Environ. Health 7, 125-138.

Alink G.M., Knize M.G., Shen N.H. Hesse S.P. and Felton J.S. (1988). Mutagenicity of food pellets from human diets in The Netherlands. Mutation Res. 206, 387-393.

Anonymous (1981). Wissenschaftliche Tabellen Geigy, Teilband Hämatologie und Humangenetik, 8. Auflage, Ciba-Geigy, Basel.

Armstrong B. and Doll R. (1975). Enwironmental factors and cancer incidence and mortality in different countries with special reference to dietary practices. Int. J. Cancer 15, 617-631.

Baker R., Arlauskas A."Bonin A. and Angus D. (1982). Detection of mutagenic activity in human urine following fried pork or bacon meals. Cancer Lett. 16, 81-89.

Biltek G., Guhr G. and Sterner W. (1979). Fütterungsversuche mit erhitzten Fett und Fettraktionen. Fette. Seifen. Antrichm. 81, 562-566.

Bruce W.R. (1987). Recent hypotheses for the origin of colon cancer. Cancer Res. 47, 4237 . 4242.

Correa P. and Haensze! W. (1978). The epidemiology of large-bowel cancer. Adv. Cancer Res. 26, 1-141.

Dion P.W., Bright-See E.B., Smith C.C. and Bruce W.R. (1982). The effects of dietary ascorbic acid and alpha-tocopherol on faecal mutagenicity. Mutation Res. 102, 27-37.

Dolara P. Caderni G., Salvadori M. Tringate L. and Lodovici M. (1984). Urinary mutagens in humans after fried pork and bacon meals. Cancer Lett. 22, 275-280.

Doll R. and Peto. R. (1981). The causes of cancer: Quantitative estimates of avoidable risk of cancer in the United States today. New York, Oxford University Press.

Draper H.H., Polensek L., Hadley M. and MCGirr L.G. (1984). Urinary malondlaldehyde as an indicator of lipid peroxidation in the diet and in the tissues. Lipids 19, 836-843.

Ehrig M., Aswell J.E., van Tassell R.L. and Wilkins T.D. (1979). Mutagens in the feces of 3 South-African populations at different levels of risk for colon cancer. Mutation Res. 64 , $231-240$.

Furihata C. and Matsushima T. (1986). Mutagans and carcinogens in foods. Ann. Rev. Nutr. 6, $67-94$.

Gupta I., Baptista J., Bruce W.F., Che C.T., Gingerich J.S., Grey A.A., Marai L., Yates P. and Krepinsky J.J. (1983). Structures of fecapentaenes, the mutagens of bacterial origin isolated from human teces. Biochemistry $22,241-245$.

Hageman G., Hermans R., ten Hoor F. and Kleinjans J. (1990). Mutagenicity of deep-frying fat, and evaluation of urine mulagenicity after consumption of fried potatoes. Fd Chem. Toxic., in press.

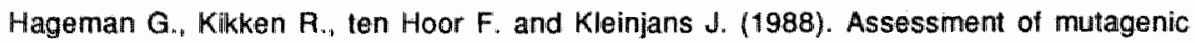
activity of repeatedly used deep-frying fats. Mutation Res. 204, 593-604.

Hageman G., Kikken R., ten Hoor F. and Kleinjans J. (1989). Linoleic acid hydroperoxide concentration in relation to mutagenicity of repeatedly used deep-frying fats. Lipids. 24 , 
889-902.

Hautvast J.G.A.J. (1975). Development of a system for processing data obtained from nutrition questionnaires with the aid of a computer (in Dutch). Voeding (Neth. J. Nutr.)36. $356-360$.

Hayatsu H., Arimoto S., Togawa K. and Makita M. (1981). Inhibitory effect of the ether extract of human feces on activities of mutagens; Inhibition by oleic and linoleic acids. Mutation Res. 81, 287-293.

Hayatsu H., Hayatsu T. and Ohara Y. (1985a). Mutagenicity of human urine caused by ingestion of fried ground beef. Jpn. J. Cancer Res. (Gann) 76, 445-448.

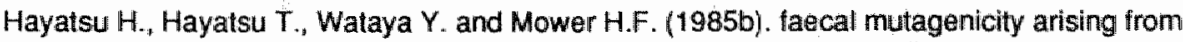
ingestion of fried ground beef in the human. Mutation Res. 143, 207-211.

Hill M.J. (1987). Dietary fat and human cancer (review). Anticancer Res. 7, 281-292.

Jacobsen E.A., Newmark H.L., Bird R.P. and Bruce W.IR. (1983). Increased excretion of malonaldehyde equivalents in the urine after consumption of cooked stored meats. Nutr. Rep. Int. 28, 509-517.

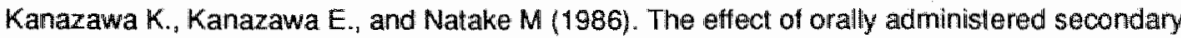
products of linoleic acid on the activity of detoxifying enzymes in the rat liver. Biochem. Biophys. Acta 879, 36-43.

Kuhnlein U., Bergstrom D. and Kuhnlein H. (1981). Mutagens in feces from wegetarians and non-vegetarians. Mutation Res. 85, 1-12.

Kuhnlein H.V., Kuhnlein U. and Bell P.A. (1983). The effect of short-term dietary modification on human faecal mutagenic activity. Mutation Res. 113, 1-12.

Maron D.M. and Ames B.N. (1983). Revised methods for the Salmonella mutagenicity test. Mutation Res. 113, 173-215.

Mower H.F., Ichinotsubo D., Wang L.W., Mandel M. . Stemmerman G., Nomura A., Heilbrun L. Kamiyama S. and Shimada A. (1982). faecal mutagens in two Japanese populations with different colon cancer risks. Cancer Res. 42, 1164-1169.

Ohyama S., Inamasu T., Ishizawa N. and Matsuura K. (1987). Mutagenicity of human urine after the consumption of fried salted salmon. Fod Chem. Toxic. 25, 147-153.

Peters F.K., Garabant D.H., YU M.C. and Mack T.M. (1989). A case-control study of occupational and dietary factors in colorectal cancer in young men by subsite. Cancer Res. 49, 5459-5.468.

Reddy B.S., Sharma C., Mathews L. and Engle A. (1984), faecal mutagens from subjects consuming a mixed-western diet. Mulation Res 135, 11-19.

Reddy B.S., Sharma C. Simi B., Engle A., Laakso K., Puska P. and Korpela R. (1987). Metabolic epidemiology of colon cancer: Effect of dietary tiber on faecal mutagens and bile acids in heatthy subjects. Cancer Ries. 47, 644-648.

Reddy B.S., Sharma C. Mathews L., Engle A., Laakso K., Choi K., Puska P. and Korpella A. (1985). Metabolic epidemiology of colon cancer: faecal mutagens in healthy subjects from rural Kuopio and urban Helsinki, Finland. Mutation Res. 152, 97-105.

Schiffman M.H. (1986). Epidemiology of fecal mutagenicity. Epidem. Rev. 8, 92-105.

Schiffmann M.H., Andrews A.W., Van Tassell R.L., Smith L., Daniel J., Robinson A., Hoover R.N., Rosenthal J., Weil R., Nair P.P. Schwartz S., Pettigrew H., Batist G., Shaw A. and Wilkins T.D. (1989). A case-control study of colorectal cancer and faecal mutagenicity. Cancer Res. 49, 3420-3424. 
Sousa $\|_{1}$ Nath J. Tucker J D. and Ong T.-M. (1985). Dietary factors affecting the urinary mutagenicity assay system. I. Detection of mutagenic activity in human urine following a fried beef meal. Mutation Res. 149, 365-374.

Venitt $S$. (1982). Mutagens in human faeces. Are they relewant to cancer of the large bowel? Mutation Res. 98, 265-286.

Venitt S., Bosworth D. and Alldrick A.J. (1986). Pillot study of the effect of diet on the mutagenicity of human taeces. Mutagenesis 1, 353-358.

Willet $W$. (1989). The search for the causes of breast and colon cancer. Nature $7.338,389-$ 394.

Wilkins T.D., Lederman M., Van Tassel R.L. (1981). lisolation of a mutagen produced in the human colon by bacterial action. In: Bruce W.R., Correa P., Lipkin M. et al. (Eds.). Banbury Feport 7. Gastrointestinall cancer: endogenous factors. Cold Spring Harbor Laboratory. pp. 205-226.

Young T.B. and Wolf D.A. (1988). Case-control study of proximal and distal colon cancer and diet in Wisconsin. Int. J. Cancer 42, 167-175. 


\title{
Chapter 8
}

\section{Effect of short-term feeding of mutagenic used deep- frying oils on cell proliferation in the gastro-intestinal tract and the excretion of mutagens in urine and faeces of rats 1}

\begin{abstract}
Effects of short-term feeding of mutagen containing, healted deep-frying oils on urinary and faecal mutagenicity, plasma clinical biochemical parameters and cell protiferation in the gastro-intestinal tract were determined in rais. Repeatedly used frying oils, il.e. a coconut oil (CO), containing $<10 \%$ polyunsaturated flatty acids (PUFA) and a PUFA-rich irying oil (PO) were administered to groups of 7 rats at a level of $10 \%$ (by weight) in the diet for 4 weeks; control groups received an equal dose of unheated oils. Both heated oils showed directacting mutagenicity to Salmonella tester strain TA97; healed PO was also mutagenic to strain TA100. Unheated oils were not found to be mutagenic. Heated PO contained higher amounts of polar oxidation products as well as polymerized triglycerides and hydroperoxides of linoleic acid, as compared to unheated oils and heated $\mathrm{CO}$. Thiobarbituric acid-reactive substances (TBA-RS), indicating presence of lipid oxidation products, were detected in heated $C O$ as well as in heated $P O$.
\end{abstract}

Rats receiving heated PO showed increased activities of plasma glutamic pyruvic transferase $(p<0.05)$ and alkaline phosphatase $(p<0.01)$ as compared to the control FOgroup, which may indicate cellular injury in liver and kidneys. Urinary and faecal excretion of TBA-RS were increased in rats fed heated FO; excretion of TBA-RS was minimal as compared to intake ${ }^{\text {being }} 0.1 \%$ of the dose received with diet. Feeding of heated $\mathrm{CO}$ did not result in increased plasma enzyme activities or excretion of TBA.AS. Mutagenicity of urine and faeces to strain TA97 was not lound to be increased in groups fed heated oils as compared to unheated oils. Faecal mutagenicity to strain TA100 was not observed to be increased after consumption of heated oils either. Urinary mutagen excretion detected with Salmonella strain TA100, was significantly increased in rats fed heated PO only; recovery in urine and faeces of the mutagenic load received with diel, was found 10 be $7 \%$. Rats fed heated $\mathrm{CO}$ did nol show increased mutagen excretion to strain TA100 as compared to the control group.

Labeling indices in tissues of besophagus and forestomach were signiticantly increased in rats fed heated $\mathrm{PO}$ as compared to their control group, indicating a stimulation of cell proliferation. Tissues of glandular stomach and colon/rectum did not show signiflicanily enhanced cell proliferation in the group receiving heated $\mathrm{PO}$. Feeding of heated $\mathrm{CO}$ did not result in increased cell prollferation of gastro-intestinal tissues. No differences in cell kinetic parameters were observed between groups receiving unheated oils, indicating that the type of fat did not affect cell proliferation. Riesults obtained in this study indicate that consumption of oils containing oxidation products of linoleic acid does enhance cell proliferation predominantly in the upper gastro-intestinal tissues.

1 based on a manuscript submitted for publication 


\section{Introduction}

The relationship between dietary fat and intestinal cancer has been studied intensively in laboratory animals using initiation-promotion models. High intake of dietary fat has been found to promote chemically induced colon cancer in rats, but the type and source of the fat appears to be of importance as well, since fish oils containing long-chain polyunsaturated fatty acids (PUFA) of the linolenate type ( $n-3)$ have been observed to inhibit colonic tumorigenesis, while fatty acids of the linoleate type (n-6) have been reported to exert enhancing effects and are reported to be essential in tumor development (Carroll, 1987; Ip et al. 1985; Pariza, 1988; Reddy, 1987). Studies determining modulating effects of dietary fat and fiber on chemically induced tumors, showed enhanced cell proliferation of colonic mucosa in association with increased tumor incidence (Deschner et al., 1983; Jacobs and Lupton, 1986). Thus a mechanism was proposed for the promoting effect of high dietary fat on colon tumorigenesis, involving chronic irritation and stimulation of cell proliferation of the colonic mucosa, either directly or indirectly via excretion of bile acids (Bruce, 1987; Wargovich and Lointier, 1987).

Studies determining the effect of high fat diets on colonic cell proliferation in rats and mice however, have led to inconsistent results. Feeding of a diet containing $30 \%$ (by weight) corn oil for 10 or 15 weeks, was shown to increase colonic cell proliferation in mice as compared to feeding of $5 \%$ corm oil (Bird and Stamp, 1986), whereas feeding of diets with the same amount of corn oil or lard for 4 weeks was not found to significantly affect mitotic acitivity of the colon (Caderni et al., 1988; 1989; Jacobs, 1983). Furthermore, it is has been demonstrated that the amount of starch, calcium and type of fiber in the diet modulate cell proliferation of the colon, which may explain the conflicting results obtained with high-fat diets containing different sources of starch and fiber (Caderni et al., 1988; 1989; Jacobs, 1988; Wargovich et al. 1984). In addition, stimulation of cell proliferation of the colonic mucosa was observed after intra-colonic installation of the fatty acids oleate, linoleate and arachidonate, as well as after rectal administration of hydroperoxy-and hydroxy-derivatives of linoleic acid (Bull et al., 1984; 1988; Craven and Rubertis, 1988), suggesting that oxidation products of unsaturated fatty acids may be involved. Effects of short-term oral administration of autoxidized fats on cell proliferation in the gastro-intestinal tract have not yet been determined. Neither have tumor-promoting or initiating effects of heat-processed lipids containing oxidized fatty acids been evaluated.

Feeding of thermally oxidized oils, or isolated oxidation products was found to cause adverse biological effects in laboratory animals, including growth retardation, teratogenicity, increased weights and tissue damage of 
liver and kidneys, cellular damage to testes and epididymides, and increased peroxidation of membrane and tissue lipids (Alexander et al., 1981; 1987; Billek et al., 1979; Cutler and Schneider, 1973; lzaki et al., 1984; Kanazawa et al., 1985). Short-term feeding of thermally oxidized corn oil has been reported to induce drug-metabolizing enzyme systems in rat liver (Andia and Street, 1975). Furthermore, administration of fractions of oxidized corn oil by gastric intubation has been observed to induce benzola]pyrene hydroxylase activity in the colon, indicating the colon may be a target for biological effects of oxidation products of lipids (Perciballi and Pintauro, 1985).

In addition to these biological effects exerted in vivo by oxidized oils, we previously obsenved that repeatedly used deep-frying fats were mutagenic in the Salmonella/microsome assay (Hageman et al., 1988). Recently, we also found that in vitro exposure of lymphocytes to heated deep-frying oils enhanced cell proliferation (results presented in Chapter 5). Therefore, the present study was therefore undertaken to investigate the possible role of mutagenic oxidation and heat degradation products occurring in used deepfrying fats, in intestinal turmorigenesis. For this purpose, the effects of shortterm fleeding of heated deep-frying oils were determined on mutagen excretion in urine and faeces, and on cell proliferation in the gastro-intestinal tract of rats. Two types of heated oils were compared: a coconut oil (CO), containing less than $10 \%$ PUFA, and a PUFA-rich $(>60 \%)$ frying oil (FO). These oils had been heated at $180^{\circ} \mathrm{C}$ during 30 hours and used for preparation of fried foods, applying normal frying practices. These oils appeared not rejectable for human consumption based on chemical and sensory evaluation, but were found to contain varying amounts of different oxidative degradation products, and exhibited mutagenic activity in the Salmonella/microsome assay.

Heated as well as unheated oils were included at a concentration of $10 \%$ (by weight) in semi-purified diets which also contained $5 \%$ sunflower oil, and were fed to the rats for a period of 4 weeks. Urinary and faecal mutagen excretion and $\mathrm{pH}$ were determined. Thiobarbituric acid-reactive substances (TBA-AS) in urine and faeces were analyzed to assess biological fate of lipid oxidation products consumed as well as possible endogenous production (Draper et al., 1984). In addition, toxicity of heated oils was evaluated by analysis of plasma clinical biochemical parameters, and determination of relative liver and kidney weights. The effects on cell kinetic parameters were determined applying immunocylochemistry in combination with flow cytometry for the upper gastro-intestinal tissues and immunohistochemistry for the collon/rectum.. 


\section{Experimental}

\section{Frying oils}

Batches of $10 \mathrm{~kg}$ of CO (<10\% PUFA) and PUFA-riclh PO (>60\% PUFA) were obtained from local supermarkets and used for frying of various food products, including starchy foods and meats, applying recommended frying practices. Amounts of $3.5 \mathrm{~kg}$ of the fats were heated at $180^{\circ} \mathrm{C}$ for $10 \mathrm{~h}$ per day during 3 consecutive days, and were allowed to cool owernight; actuall frying temperatures ranged from 155 to $181^{\circ} \mathrm{C}$. Unheated oils as well as heated oils were stored at $4{ }^{\circ} \mathrm{C}$ untill analysis or use in the experimental diets. Oxidative deterioration of the oils was assessed by analysis of levels of di-and polymeric triglycerides (DPTG) using gel-permeation high performance liquid chromatography (HPLC), by determination of the amounit of the polar oxidation and degradation products (polar fraction; PF) using silicagiel chromatography, and by measurement of concentrations of thiobarbituric acid-reactive substances (TBA-RS) using a colorimetric assay, all performed as described previously (Hageman et al. 1988). Linoleic acid hydroperoxides (LAHPO) were determined by HPLC as described previously (Hageman et al, 1989a). Concentrations of oxidation products of unheated and heated oils are presented in Table 8.1.

Mutagenicity of the oil samples in the Ames mutagenicity assay was determined as described previously (Hageman et al. 1988). Briefly, fat samples were separated into nonpolar (NPFs) and polar (PFs) fractions using sillicagel column chromatography. NPFs and PFs were dissolved in tetrahydrofuran and mutagenic activity was determined testing doses of 0.1 to $10.0 \mathrm{mg}$ per plate, using Salmonella typhimurium tester strains TA97 and TA100 with and withoul Aroclor induced rat liver S9 mix. Chromalography and solvent controls as well as positive controls were included in mutagenicity testing. NPFs of both unheated and heated oills did nol show multagenicily under the conditions used for mutagenicity testing, neither did PFs of unused oils. PFs of heated $\mathrm{CO}$ and PO exhibited mutagenic activity to strain TA97 when tested without S9 mix; mutagenicity was estimated to amount to 3775 and 3200 revertants per g of lat. In presence of $\$ 9$ mix mutagenicity in strain TA97 was reduced; PF of heated $C O$ was not mutagenic, while PF of heated PO did show mutagenic activity, amounting to 2549 revertants per $\mathrm{g}$ of fat. The $\mathrm{PF}$ of heated $\mathrm{PO}$ was also mutagenic to strain

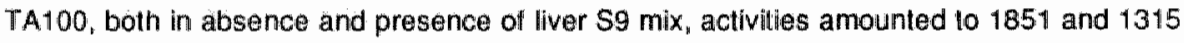
revertants per $\mathrm{g}$ of fat, respectively. PF of unheated oils and heated $\mathrm{CO}$ did not exhibit mutagenic activity to strain TA100.

\section{Feeding study with rats}

Twenty elight male Wistar rats (Winkelmann, Borchem, FRG), weighing $82 \pm 3 \mathrm{~g}$ (meantSD), were randomly divided into 4 groups of 7 animals. Rats were housed individually in metabolic cages in an air-conditioned environment at $22{ }^{\circ} \mathrm{C}, 50 \%$ humidity and a 12 -h light/dark cycle. Powdered regular lab chow (Hope Farms, Woerden, The Netherlands) and tap water were allowed ad libitum for a 1-week acclimatization period. Experimental diets were made fresh weekly; fats were added to a fat-free basal diet (Hope Farms, Woerden, The Netherlands) at a concentration of $10 \%$ (by weight); $5 \%$ sunflower oil was included to prevent possible essential latty acid deficiency. The composition of the purified diets is shown in Table 8.2. Fatty acid compasition of the diets is presented in Table 8.3. Experimental diets 
Table 8.1. Concentrations of polar fraction (PF), di- and polymeric triglycerides (DPTG), thiobarbituric acid-reactive substances (TBA-RS, expressed as nmoles of malondialdehycle (MDA) per $g$ of fat) and linoleic acid hydroperoxides (LAHPO) of unheated and heated CO and $\mathrm{PO}$.

\begin{tabular}{lcccc}
\hline Oil sample & $\begin{array}{l}\text { PF } \\
(\% \text { by weight) }\end{array}$ & $\begin{array}{l}\text { DPTG } \\
\text { (\% by weight) }\end{array}$ & $\begin{array}{l}\text { TBA-AS } \\
\text { (nmol MDAg) }\end{array}$ & $\begin{array}{l}\text { LAHPO } \\
\text { (nmolg) }\end{array}$ \\
\hline $\begin{array}{l}\text { Co, unheated } \\
\text { CO, theated }\end{array}$ & 5.2 & $<1$ & $<1$ & $<2$ \\
PO, unheated & 3.5 & $<1$ & 3.5 & $<2$ \\
PO, heated & 14.9 & $<1$ & $<1$ & $<2$ \\
\hline
\end{tabular}

Detection limits of the methods are $1 \%$ (by weight) for HPLC analysis of DPTG, 1.0 nmoles of MDAlg for colorimetric determination of TBA-RS, and 2 nmoles of LAHPO/g for HPLC determination of hydroperoxides of linoleic acid.

were fed for a period of 4 weeks, food consumption was recorded daily, body weights were measured 3 times per week. During the third week of the experimental period, urine and faeces were collected daily and stored at $-20^{\circ} \mathrm{C}$ until analysis.

After 4 weeks on the experimental diet, rats received i.p. $1 \mathrm{ml}$ of $7.5 \mathrm{mg} / \mathrm{ml} 5$ bromodeoxyuridine (BrdU; Serva, Heidelberg, FRG) dissolved in saline solution (0.9\% $\mathrm{NaCl}$ ), between 8 and 10 a.m., and were sacrificed $4 \mathrm{~h}$ later. The rals were killed under ether anaesthesia by exsanguination. Blood was collected in heparinized tubes and centrifuged 10 min at $2000 \mathrm{~g}$, plasma was stored at $-20^{\circ} \mathrm{C}$ unit analyses. Intestinal organs were dissected, opened lengithwise, cleaned from their contents, rinsed in saline solution, fixed in $70 \%$ ethanol, and stored at $4{ }^{\circ} \mathrm{C}$ in the dark. Liver and kidneys were removed, rinsed, blotted dry, and weighed.

\section{Clinical biochemistry of plasma}

Clinical biochemistry parameters were determined in rat plasma routinely using a centrifuge analyzer (type Cobas Bio, Hoffmann LaFloche), and comprised urea, creatinin, lactate dehydrogenase (LDH; E.C. 1.1.1.27), alkaline phosphatase (A.P; E.C. 3.1.3.1), creatine phosphokinase (CPK; E.C. 2.7.3.2), glutamic axaloacetic transaminase (GOT; E.C. 2.6.1.1) and glutamic pyruvic transaminase (GPT; E.C. 2.6.1.2). 
Table 8.2. Composition of purified experimental diets

Ingredient \% in diet

(by weighti)

$\begin{array}{lr}\text { Acid casein } & 25.5 \\ \text { Corn starch } & 48.0 \\ \text { Cellulose } & 4.3 \\ \text { Sunflower oil } & 5.0 \\ \text { Frying fat } & \\ \text { Mineral mix } 2 & 10.0 \\ \text { Standard vitamin mix } 3 & 4.6 \\ \text { Standard trace element mix } 3 & 1.0 \\ \text { dll-methionine } & 1.0 \\ \text { Choline Chloride } 50 \% & 0.2 \\ \end{array}$

Energy density of the diet was $15.75 \mathrm{~kJ} / \mathrm{g}(3.75 \mathrm{kcal} / \mathrm{g})$.

1. Added frying fat was either $\mathrm{CO}$, unheated (control) or heated, or $\mathrm{PO}$, unheated (control) or heated.

2. Mineral mix supplied $0.71 \% \mathrm{Ca}, 0.55 \% \mathrm{P}, 0.17 \% \mathrm{Mg}, 0.12 \% \mathrm{Na}, 0.59 \% \mathrm{~K}$ and $0.53 \% \mathrm{Cl}$ to the diet.

3. Standard vitamin and trace element mixes supplied per $\mathrm{kg}$ of diet: 18,000 $\mathrm{N}$ vitamin $\mathrm{A}$ (retinyl acetate); $2,000 \mathrm{l} / \mathrm{cholecalciferol;} 10 \mathrm{mg}$ menadione sodium bisulfite; $6.25 \mathrm{mg}$ dlalpha-tocopherol acetate; $20 \mathrm{mg}$ thiamine monocitrate; $12 \mathrm{mg}$ riboflavin; $15 \mathrm{mg}$ pyridoxine $\mathrm{HCl} ; 40 \mathrm{mg}$ niacin: $35 \mathrm{mg} \mathrm{Ca}$ dl-panthothenate; $50 \mu \mathrm{g}$ cyanocobalamin; 300 $\mu \mathrm{g}$ biotin; $8 \mathrm{mg}$ folic acid; $500 \mathrm{\mu g}$ inositol; $115 \mathrm{mg} \mathrm{Fe;} 16.5 \mathrm{mg} \mathrm{Cu} 62 \mathrm{mg} \mathrm{Mn;} 47 \mathrm{mg} \mathrm{Zn}$; $180 \mu \mathrm{g} \mathrm{Se} ; 0.50 \mathrm{Cr} ; 0.90 \mathrm{mg} F ; 0.38 \mathrm{mg} \mathrm{l}$.

\section{Analyses of urine and faeces}

All urine and faeces samples collected during the third week of the experimental diet were pooled per rat prior to analysis. TBA.AS in urine and faeces were coinsidered to reflect excretion of various lipid oxidation products (Gutteridge, 1982; Esterbauer and Zolner, 1989). TBA-RS in urine were determined as described previously (Hageman et al,, 1989b). Urinary $\mathrm{pH}$ was determined by potentiometry. Faecal TBA-RS excretion was determined as follows: 1 $\mathrm{g}$ of faeces was homogenized with $5 \mathrm{ml} 5 \%$ (w/V) trichloroacetic acid (TCA). Suspensions were centrifuged, after which $1 \mathrm{ml}$ of TBA reagent $(0.5 \%$ (w/v) TBA and $0.01 \%$ butylated hydroxytoluene in $2.5 \%$ (W/V) TCA solution) was added to $1 \mathrm{ml}$ of supernatapt. The reaction mixtures were heated at $100^{\circ} \mathrm{C}$ for $1 \mathrm{~h}$. After cooling, reaction mixtures were extracted with 2 $\mathrm{mll}$ n-butanol. Absorption of the butanol extracts was determined spectrophotometrically at $532 \mathrm{~nm}$, and at $520 \mathrm{~nm}$ for correction of non-specific baseline absorption. A calibration curve was determined with concentrations of malondialdehyde-bis (diethylacetate) using the same procedure. Concentrations of TBA-AS were calculated as nmoles of malondialdehyde per $g$ of faeces. Faecal pH was measured in supernatant of $1 \mathrm{~g}$ material which was homogenized 1:2 in saline solution. 
Mutagenicity screening of urine and laeces

Acetone extracts of urine were prepared as follows: XAD-2 resin was washed as described by Yamasaki and Ames (1982). Volumes of 5-18 mil, represienting 40\% of the weekly excreted volume were concentrated on a column containing $1 \mathrm{~m} \|$ of XAD-2 resin,

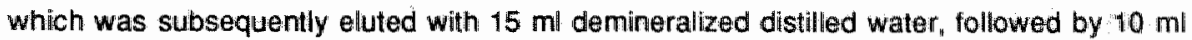
acetone. Acetone extracts were dried under a stream of nitrogen, and residues were dissolved in $0.6 \mathrm{ml}$ dimethylsulphoxide (DMSO) prior to mutagenicity testing. A solvent control prepared by concentrating and extracting $10 \mathrm{ml}$ phosphate-buffered saline according to the protocoll used for urine samples, was also included in mutagenicity testing. Mutagenicity of aliquots of $0.1 \mathrm{ml}$ extracts dissolved in DMSO was determined in triplicate: using Salmonella tester strains TA97 and TA100 as described previously (Hageman et al., $1989 \mathrm{~b})$. Since PF of frying oils was not activated in the presence of a liver metabolizing system, urine extracts were tested without $\$ 9$ mix.

Table 8.3. Fatty acid composition of triglycerides of the experimental diets.

\begin{tabular}{llllll}
\hline Fatty acid & $\begin{array}{l}\text { SSO } \\
\text { unheated }\end{array}$ & $\begin{array}{l}\text { CO } \\
\text { unheated }\end{array}$ & $\begin{array}{l}\text { CO } \\
\text { heated }\end{array}$ & $\begin{array}{l}\text { PO } \\
\text { unheated }\end{array}$ & $\begin{array}{l}\text { PO } \\
\text { heated }\end{array}$ \\
\hline
\end{tabular}

\begin{tabular}{|c|c|c|c|c|c|}
\hline c10:0 & - & 2.6 & 2.4 & - & - \\
\hline $\mathrm{C} 12: 0$ & 0.1 & 42.2 & 42.5 & 0.3 & 0.2 \\
\hline $\mathrm{C} 14: 0$ & 0.2 & 19.7 & 19.7 & 0.2 & 0.2 \\
\hline C16:0 & 7.6 & 10.8 & 11.0 & 7.3 & 7.9 \\
\hline C.16:1 & 0.2 & 0.1 & 0.1 & 0.2 & 0.3 \\
\hline$C 18: 0$ & 5.7 & 3.8 & 3.9 & 5.4 & 5.6 \\
\hline$C 18: 1$ & 21.3 & 10.0 & 10.2 & 20.6 & 21.5 \\
\hline C.18:2 & 61.9 & 9.9 & 9.2 & 63.3 & 61.0 \\
\hline C.18.3 & 0.2 & 0.1 & 0.1 & 0.1 & 0.1 \\
\hline $\mathrm{C} 20: 0$ & 0.5 & 0.1 & 0.1 & 0.5 & 0.5 \\
\hline $\mathrm{C} 20: 1$ & 0.3 & - & - & $\sim$ & - \\
\hline $\mathrm{C} 22: 0$ & 1.0 & * & - & - & - \\
\hline $\mathrm{C} 24: 0$ & 0.1 & - & - & - & - \\
\hline unidentified & 0.7 & 0.7 & 0.8 & 2.1 & 2.7 \\
\hline
\end{tabular}

Values are expressed as percent of total triglycerides. Experimental diets contained 10\% (by weight) unheated or heated coconut oil (CO) or PUFA-rich frying oil (PO) and $5 \%$ unheated sunflower seed oil (SSO). Fatty acid composition of triglycerides was determined by gas liquid chromatography (GLC) of the methyl esters of fatty acids. Triglycerides were hydrolyzed and fatty acids were methylated using a $14 \%$ ( $w / v)$ boron trifluoride $\left(B F_{3}\right.$, Sigma, St. Louis, MO) solution in methanol. Methyl esters were analyzed by GLC as described by Rand et al (25). 
Faecal extracis for mutagenicity testing were prepared as follows: In a flask, $2 \mathrm{~g}$ of faeces and $2 \mathrm{~g}$ of anhydrous sodium sulphate were homogenized in $10 \mathrm{ml}$ dichloromethane (DCM) using a turrax mixer for $30 \mathrm{~s}$, under cooling with ice. Contents was transferred to a centrifuge tube, and after centrilugation and filtration of the supernatant through Whatman no. 4 tilter paper, the residue was dried under a stream of nitrogen. Residues were dissolved in $0.8 \mathrm{ml}$ methanol prior to mutagenicity testing. Solvent control was prepared by extraction of $2 \mathrm{~g}$ anhydrous sodium sulphate with $10 \mathrm{ml}$ dichloromethane according to the protocol used for faecal extracts. Aliquots of $0.1 \mathrm{ml}$ of faecal extracts in methanol were screened for mutageniclty in duplicate using strains TA97 and TA100, in absence as well as in presence of $89 \mathrm{mix}$ in order to determine presence of possible pre-mutagens excreted or produced in laeces.

\section{Preparation of tissues for determination of cell proliferation}

Oesophagus, forestomach and glandular stomach tissues were processed for determination of the labeling index (LI) and potential doubling time (Tpot) by fllow cytometry as described by Verhagen et al. (1988). Briefly, 4 samples per tissue per rat were randomly taken from the ethanol-fixed tissues and minced, after which single nuclei were released by pepsin digestion. Suspensions were filtered to remove cellular debris, and subsequently DNA was denatured by treatment with $2 \mathrm{~N} \mathrm{HCl}$. Remaining nuclei were incubated with monoclonal antiBrdU (clone IIB5; Schutte el al., 1987), followed by fluorescein-conjugated rabbit-anti-mouse IgG-FITC antibodies (F313; Dakopatts, Denmark). Total ONA was stained with propidium iodide (Calbiochem, Behring Diagnostics, San Diego, CA). Double stained nuciei were analyzed on a FACS IV cell sorter (Becton and Dickinson, CA). The LI was determined as the percentage of BrdU-positive cells. Tpot was calculated as described by Begg et al. (1985).

Since analysis by flow cytometry of colon/rectum was found to be not feasible, LI of this tissue was determined by immunohistochemistry " applying peroxidase-conjugated secondary antibody to detect BrdU-containing cells as described previously (Schutte et al., 1987: Verhagen et al., 1989). Brielly, 5 samples equally distributed over the full length of the colon/rectum were dissected and embedded in paraffin, after which $4 \mu \mathrm{m}$ sections were cut and mounted to microscope slides. Before staining, slides were cleared of paraffin with xylene and treated with $0.3 \% \mathrm{H}_{2} \mathrm{O}_{2}$ in methanol for 10 min to block endogenous peroxidases. Pepsin digestion and denaturation of DNA were essentially the same as described for flow cytometry. Instead of using rabbit-anti-mouse lgG-FITC antibodies, tissue sections were finally incubated with peroxidase-conjugated rabbit-anti-mouse IgG antibodies (F114, Dakopatts. Denmark) for $1 \mathrm{~h}$ at room temperature. The antibody binding sites were visualized by immersing the slides in $0.04 \% 3,3$-diaminobenzidine in $0.05 \mathrm{M}$ Tris/ $\mathrm{HCl} \mathrm{pH} 7.6$ containing $0.01 \% \mathrm{H}_{2} \mathrm{O}_{2}$. Finally, sections were counterstained with haematoxylin. BrdU-positive cells appeared brown, whille non-labeled cells were colored blue. Slides were coded and 20 full crypts per colon/rectum were evaluated by 2 independent observers. The total number of cells per crypt, as well as the number of BrdU-positive cells and the position of the uppermost labeled ceil in the crypt column were recorded. LI was calculated as the percentage of positively stained cells, using data of both observers. 


\section{Statistical analyses}

Differences between groups were evaluated using single-factor analysis of variance: in addition, multiple comparisons were made between groups using Dunnett's 1-test. Comparisons were made between groups receiving unheated and heated olls: unused $\mathrm{CO}$ vs. heated $C O$ and unused $P O$ ws. heated $P O$, as well as between groups receiving unused oils: unheated $\mathrm{CO}$ vs. unheated $\mathrm{PO}$, and between groups fed heated oils: heated $\mathrm{CO}$ vs. heated $\mathrm{PO}$, to determine specific effects to the type of oil. Associations between various biological effects and characteristics of the oils consumed were analyzed using Spearman's rank correlation coefficient.

\section{Results}

\section{General indices of toxicity}

Feeding of deep-frying oils, heated for $30 \mathrm{~h}$ and used for preparation of various foods, at a level of $10 \%$ in the diet of rats did not result in growth retardation, since mean food consumption and weight gain were similar in all groups (Table 8.4). No pathologic conditions were indicated by relative liver and kidney weights, which were not found to differ between groups fed heated and unheated oils. Compared to the group fed unheated PO, significantly increased plasma activities of GPT ( $p<0.05)$, and AP $(p<0.01)$ were observed in the group fed heated $P O$, possibly indicating adverse effects on cells in liver and kidneys. Plasma AP was also increased $(p<0.01)$ in rats consuming heated $\mathrm{PO}$ as compared to the group fed heated $\mathrm{CO}$. Concentration of urea in plasma of the group consuming heated $\mathrm{CO}$ was significantly increased $(p<0.05)$ as compared to the group fed unheated $C O$. Plasma creatinin was significantly lower $(p<0.05)$ in the group fed unheated $\mathrm{PO}$ as compared to the group receiving unheated $\mathrm{CO}$. Although some differences were noted, plasma clinical biochemical parameters were within the normal range reported in the literature (Benirschke et al., 1978). Generally, rats fed heated PO showed a higher plasma clinical biochemical parameters related to hepatic and renal cellular damage, than rats fed unheated oils and heated $\mathrm{CO}$.

\section{TBA-RS and $\mathrm{pH}$ in urine and faeces}

Excretion of TBA-RS in urine was found to be significantly increased $(p<0.01)$ in the group consuming heated $P O$ as compared to unheated PO (Table 8.5). No difference in urinary excretion of TBA-RS was observed between groups fed unheated and heated $\mathrm{CO}$, nor between the 2 control groups. Rats receiving heated $P O$ excreted significantly higher $(p<0.05)$ amounts of TBA-RS in urine as compared to rats consuming heated CO. No differences in faecal excretion of TBA-RS were found between the groups (Table 8.5). Urinary pH was found to be slightly, but not significantly elevated in groups fed heated fats in comparison to the control groups (Table 8.5). 
Table 8.4. Food consumption, weight gain. and results of general toxicity testing after shortterm consumption of diets containing $10 \%$ unheated or heated frying oils by rats.

\begin{tabular}{|c|c|c|c|c|}
\hline \multirow[b]{2}{*}{ Parameter } & \multicolumn{4}{|c|}{ Diet group } \\
\hline & $\begin{array}{l}\mathrm{co} \\
\text { control } \\
(n=7)\end{array}$ & $\begin{array}{l}\text { co } \\
\text { heated } \\
(n=7)\end{array}$ & $\begin{array}{l}\text { PO } \\
\text { control } \\
(n=7)\end{array}$ & $\begin{array}{l}\text { PO } \\
\text { heated } \\
(n=7)\end{array}$ \\
\hline Mean food consumption & 12.5 & 2.8 & 12.4 & 12.6 \\
\hline$(g / d a y)$ & \pm 0.3 & \pm 0.3 & \pm 1.2 & \pm 0.8 \\
\hline Mean weight gain & 168 & 168 & 175 & 171 \\
\hline (g) & \pm 12 & \pm 10 & \pm 21 & \pm 16 \\
\hline Relative liver weight & 3.46 & 3.53 & 3.46 & 3.46 \\
\hline (\% body weight) & \pm 0.22 & \pm 0.16 & \pm 0.17 & \pm 0.21 \\
\hline Relative kidney weight & 0.72 & 0.76 & 0.76 & 0.75 \\
\hline (\% body weight) & \pm 0.06 & \pm 0.06 & \pm 0.05 & \pm 0.04 \\
\hline Glutamic pyruvic trans- & 12.9 & 12.3 & 11.2 & $14.4^{a}$ \\
\hline aminase $(\mathrm{U} / \mathrm{l})$ & \pm 2.3 & \pm 5.2 & \pm 2.7 & \pm 2.8 \\
\hline Glutamic oxaloacetic & 39.9 & 36.3 & 40.0 & 43.5 \\
\hline transaminase $(\mathrm{U} / 1)$ & \pm 6.6 & \pm 9.4 & \pm 8.9 & \pm 6.7 \\
\hline Creatine phosphokinase & 188 & 117 & 211 & $205^{c}$ \\
\hline$(\mathrm{U} / 1)$ & \pm 65 & \pm 70 & \pm 111 & \pm 69 \\
\hline Alkaline phosphatase & 407 & 375 & 357 & $464 b d$ \\
\hline$(\mathrm{U} /)$ & \pm 77 & \pm 37 & \pm 68 & \pm 55 \\
\hline Lactate dehydrogenase & 601 & 340 & 719 & 565 \\
\hline$(\mathrm{U} / 1)$ & \pm 214 & \pm 270 & \pm 330 & \pm 224 \\
\hline Plasma urea & 3.4 & $4.0^{a}$ & 4.0 & 4.9 \\
\hline$(\mathrm{mmol})$ & \pm 0.3 & \pm 0.6 & \pm 0.8 & \pm 1.3 \\
\hline Plasma creatinin & 35.4 & 34.1 & $3 \pi .3^{c}$ & 36.1 \\
\hline$(\mu \mathrm{mol}(\mathrm{l})$ & \pm 4.5 & $\Psi 4.5$ & \pm 4.8 & \pm 3.9 \\
\hline
\end{tabular}

Values are expressed as meantSD. Significant differences between groups are indicated with superscripts: $C O$ control vs. CO heated, and PO control vs. PO heated: $a$ : $p<0.05 ; b$ : $p<0.01 ; C 0$ control vs. PO control, and CO heated ws. PO heated: $c ; p<0.05 ; d ; p<0.01$. 
Table 8.5. Excretion of thiobanbituric acid-reactive substances (TBA-RS) and pH in urine and faeces of rats fed diets containing $10 \%$ untheated or heated frying oills.

\begin{tabular}{|c|c|c|c|c|}
\hline \multirow[b]{2}{*}{ Parameter } & \multicolumn{4}{|c|}{ Diet group } \\
\hline & $\begin{array}{l}\mathrm{CO} \\
\text { conitrol } \\
(\mathrm{n}=7)\end{array}$ & $\begin{array}{l}\mathrm{co} \\
\text { healed } \\
(n=7)\end{array}$ & $\begin{array}{l}\text { PO } \\
\text { control } \\
(n=7)\end{array}$ & $\begin{array}{l}\text { PO } \\
\text { healed } \\
(n=7)\end{array}$ \\
\hline TBA-RS urine & 0.11 & 0.11 & 0.12 & $0.14 b c$ \\
\hline (nmol MDAwk) & \pm 0.04 & \pm 0.03 & \pm 0.02 & \pm 0.01 \\
\hline TBA-RS faeces & 1.35 & 1.33 & 1.44 & 1.52 \\
\hline (nmol MDAnwk) & \pm 0.13 & \pm 0.44 & \pm 0.21 & \pm 0.19 \\
\hline \multirow[t]{2}{*}{ pH urine } & 8.02 & 8.70 & 8.30 & 8.89 \\
\hline & \pm 1.10 & \pm 0.43 & \pm 1.31 & \pm 0.46 \\
\hline \multirow[t]{2}{*}{$\mathrm{pH}$ faeces } & 8.29 & 8.10 & 8.33 & $8.14^{b}$ \\
\hline & \pm 0.16 & \pm 0.25 & \pm 0.06 & \pm 0.13 \\
\hline
\end{tabular}

Results are expressed as meantSD. Significant differences between groups are indicated with superscripts, for an explanation of symbols used, see legend of Table 8.4.

Faecal $\mathrm{pH}$ was lower in groups receiving heated fats; a significantly lower $(\mathrm{p}<0.05)$ faecal $\mathrm{pH}$ was observed in the group fed heated $\mathrm{PO}$ as compared to unheated PO (Table 8.5).

\section{Mutagenicity of urine and faeces}

Mutagenic activity of acetone extracts of urine is shown in Figure 8.1. All urine extracts exhibited significant mutagenic activity to strain TA97 when compared to the solvent control, but excretion of mutagens did not differ between the experimental groups. All urine extracts were less mutagenic to strain TA100; significantly increased mutagenic activity was detected exclusively in urine extracts of rats fed heated PO (Figure 8.1). Excretion of mutagens detected by strain TA100 was significantly increased $(p<0.05)$ in the group fed heated $\mathrm{PO}$, as compared to the group receiving unheated $\mathrm{PO}$. DCM-extracts of faeces exhibited no significantly increased mutagenic activity to strain TA97 as compared to the solvent control (Figure 8.2.A). Numbers of revertants appeared to be slightly, but not significantly, reduced in faecal incubations.

Comparison between groups showed significantly increased numbers of 
revertants in strain TA97 without S9 mix for faecal extracts of rats fed heated PO as compared to their control group $(p<0.05)$, as well as compared to the group fed heated $\mathrm{CO} \quad(\mathrm{p}<0.01)$. No differences were observed between mutagenicity of faecal extracts to strain TA97 in presence of $\mathrm{S} 9$ mix (Figure 8.2.A). Faecal extracts of all groups, did not significantly increase numbers of revertants in strain TA100, both in absence and presence of $S 9$ mix, as compared to the solvent controls (Figure 8.2.B). Feeding of heated $\mathrm{CO}$ nor of heated $P O$ resulted in increased faecal mutagenicity to strain TA100 as compared to the unheated oils. The number of reventants to strain TA100 induced by faecal extracts of rats fed heated $P O$ was however, significantly increased as compared to faecal extracts of rats fed heated $C O$, both in absence and in presence of $\$ 9 \mathrm{mix}$ ( $p<0.05$ and $p<0.01$, respectively). Mutagenicity of faecal extracts to strain TA97 and TA100 appeared not to be influenced by the addition of the hepatic enzyme system (Figure 8.2). Data indicate that faecal mutagenicity was not affected by intake of mutagenic deep-frying oils. However, consumption of heated PO, which was the only oil showing mutagenic activity to strain TA100, was found to increase urinary mutagenicity to this strain.

\section{Effects on cell proliferation}

Labeling index (LI) and potential doubling time (Tpot) of oesophagus, forestomach and glandular stomach as measured by flow cytometry, and LI and number of cells per crypt of colon/rectum as determined by immunohistochemistry, are presented in Table 8.6. LI and Tpot of the tissues of the gastro-intestinal tract of rats fed heated $\mathrm{CO}$ did not differ significantly from those of the control group receiving unheated $\mathrm{CO}$. Rats fed heated PO showed increased LI's and decreased Tpot's in the oesophagus $(p<0.01)$ and forestomach $(p<0.05)$ as compared to rats fed unheated PO. LI of glandular stomach and colon/rectum of the group fed heated PO were not statistically significantly increased. The number of cells/crypt was significantly decreased $(P<0.05)$ in rats fed heated PO as compared to their control group. No differences were observed between the groups with respect to the position of the uppermost labeled cells in colonic crypts. Comparison between the two groups fed heated oils, revealed significantly increased LI's and decreased Tpot's in the upper gastro-intestinal tissues of the group fed heated PO, which were significant for the oesophagus $(p<0.05)$ and glandular stomach $(p<0.01)$. No differences were observed between labeling indices of intestinal tissues of the groups fed unheated oils, indicating that the type of unheated oil had no effect on cell proliferation in the gastro-intestinal tract. Results indicated that consumption of heated PO stimulated cell proliferation in the upper gastro-intestinal tissues of rats. 


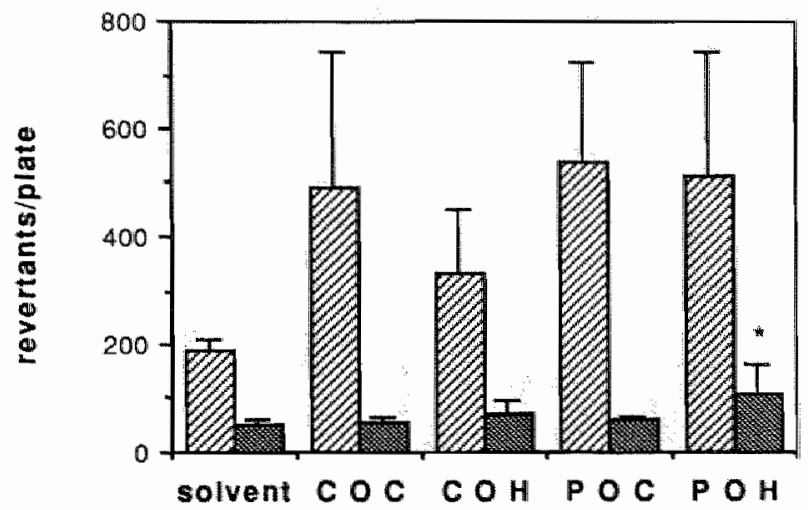

Figure 8.1: Mutagenic acitivity of acetone extracts of urine to strain TA97 ( ) and TAY00

(图). The equivalent of $6.5 \%$ of the weekly excreted volume was tested per plate, dissolved in $0.1 \mathrm{~m} / \mathrm{DMSO}$. Results are shown as mean $\pm S D$ of groups fed unheated controi $C O$ (COC). unheated control PO (POC), heated $\mathrm{CO}(\mathrm{COH})$ and heated PO (POH); solvent control (control) is expressed as mean $n_{ \pm} D$ of 3 plates. Significant differences between groups are indicated as follows: $\mathrm{COH}$ vs. $C O C$, and $\mathrm{POH}$ vs. $\mathrm{POC}$ : " $p<0.05$.

\section{Origin of mutagen and TBA-RS excretion}

In Table 8.7 weekly intake and excretion of mutagens and TBA-RS are compared. Mutagen intake, which varied considerably between groups, appeared not to explain mutagen excretion in urine and faeces as determined with strain TA97, since all groups excreted similar levels of mutagenicity. Data presented in Table 8.7 also show that mutagens to strain TA97, which were found to be induced during heating of the oils, were not recovered from urine and faeces after consumption. Mutagen excretion in urine and faeces determined with strain TA 100 appeared to associated with intake, since the group fed heated $\mathrm{PO}$, exhibiting mutagenic acitivity in strain TA100, showed increased mutagen excretion in both urine and faeces. However, recovery of mutagenicity to strain TA100 was low, being $4 \%$ in urine and $3 \%$ in faeces. Excretion of TBA-RS in urine and faeces was not found to be related to dietary intake. TBA-RS were detected in urine and faeces of groups fed unheated $\mathrm{CO}$ and PO as well, indicating these may be derived from endogenous sources. Highest excretion of TBA-RS was observed in urine and faeces of the group fed heated PO. After correction for endogenous production of TBA-RS using values of groups fed unheated oils, effects of dietary TBA-RS on excretion appeared to be minimal, since only $0.1 \%$ of TBA-RS of heated PO was recovered from urine and faeces. Consumption of TBA-RS present in heated $\mathrm{CO}$ did not lead to increased excretion in urine of faeces, in spite of a higher dose as compared to heated PO. 

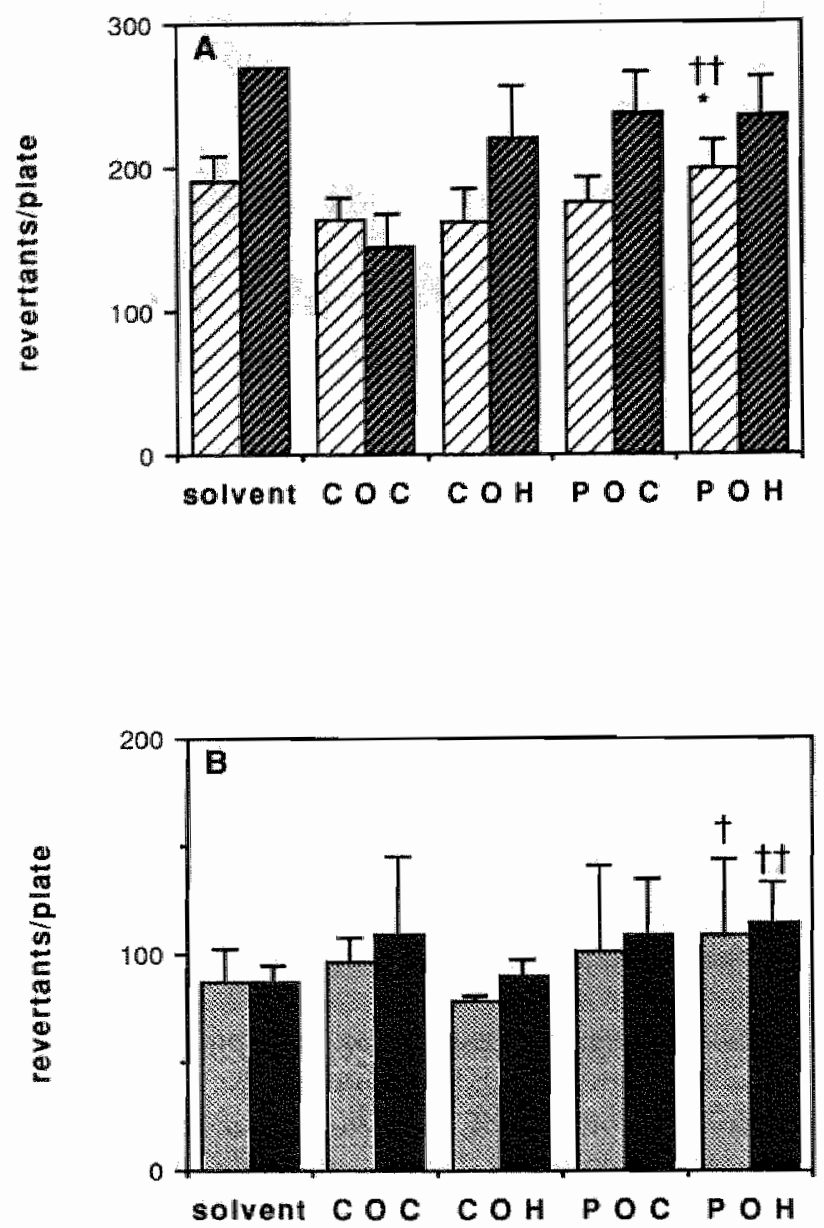

Figure 8.2. Mutagenic activity of dichloromethane extracts of taeces: (A) to strain TA97

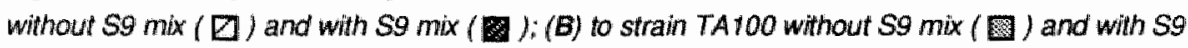
mix ( The equivalent of $0.22 \mathrm{~g}$ taeces was tested per plate. Signiticant differences between groups are indicated as follows: $\mathrm{COH}$ vs. $C O C$, and POH vs. $P O C$ : " $P<0.05 ; \mathrm{POC}$ vs. $C O C$, and POH vs. COH: $+p<0.05,++p<0.01$. For an explanation of abbreviations used, see legend of Figure 8.1. 
Table 8.6. Cell kinetic parameters in oesophagus, forestomach, glandular stomach and colon/rectum of rats fed diets containing $10 \%$ of unheated or heated frying oils for 4 weoks.

\begin{tabular}{|c|c|c|c|c|c|}
\hline \multirow[b]{2}{*}{ Tissue } & \multirow[b]{2}{*}{ Parameter } & \multicolumn{4}{|c|}{ Diet group } \\
\hline & & $\begin{array}{l}\mathrm{CO} \\
\text { control }\end{array}$ & $\begin{array}{l}\mathrm{CO} \\
\text { heated }\end{array}$ & $\begin{array}{l}\mathrm{PO} \\
\text { contral }\end{array}$ & $\begin{array}{l}\text { PO } \\
\text { heated }\end{array}$ \\
\hline \multirow[t]{4}{*}{ Desophagus } & U $(\%)$ & 8.5 & 8.5 & 7.8 & $9.9 b c$ \\
\hline & & \pm 1.4 & \pm 1.1 & \pm 1.3 & \pm 1.1 \\
\hline & Tpot (days) & 2.8 & 2.7 & 2.8 & $2 . \| b c$ \\
\hline & & \pm 0.5 & \pm 0.4 & \pm 0.5 & \pm 0.1 \\
\hline \multirow[t]{4}{*}{ Forestomach } & $\mathrm{LI}(\%)$ & 9.1 & 10.0 & 7.8 & $9.8 a$ \\
\hline & & \pm 2.3 & \pm 2.2 & \pm 1.3 & \pm 2.0 \\
\hline & Tpot (days) & 2.8 & 2.4 & 2.8 & 2.3 \\
\hline & & \pm 0.9 & \pm 0.8 & \pm 0.6 & \pm 0.5 \\
\hline \multirow{4}{*}{$\begin{array}{l}\text { Glandular } \\
\text { stomach }\end{array}$} & $L(\%)$ & 3.4 & 3.6 & 3.7 & 4.3 \\
\hline & & \pm 0.9 & \pm 0.7 & \pm 0.6 & \pm 0.8 \\
\hline & Tpot (days) & 7.5 & 7.2 & 5.6 & $5.0^{d}$ \\
\hline & & \pm 2.6 & \pm 1.5 & \pm 1.1 & \pm 0.8 \\
\hline \multirow[t]{6}{*}{ Colon/rectum } & $\mathrm{LI}(\%)$ & 9.9 & 9.1 & 9.8 & $10.8^{c}$ \\
\hline & & \pm 2.5 & \pm 1.4 & \pm 1.4 & \pm 1.5 \\
\hline & Cells/crypt & 67.5 & 66.4 & 68.7 & 64.8 \\
\hline & & \pm 3.9 & \pm 3.0 & \pm 4.2 & \pm 2.0 \\
\hline & Upper labeled & 13.7 & 14.2 & 14.1 & 13.4 \\
\hline & $\begin{array}{l}\text { cell in crypt } \\
\text { (position) }\end{array}$ & \pm 1.3 & \pm 0.8 & \pm 1.5 & \pm 1.2 \\
\hline
\end{tabular}

Results are expressed as meantSD. LI and Tpot of oesophagus, forestomach and giandular stomach were measured by flow cytometry: $L$ and number of cells per crypt of colonirectum were determined by immunohistochemistry. Significant differences are indicated with superscripts, for an explanation of symbols used, see legend of Table 8.4. 
Table 8.7. Comparison of intake and excretion of mulagens and lipid oxidation products of rats fed diets with $10 \%$ unheated or heated oils.

\begin{tabular}{|c|c|c|c|c|}
\hline \multirow[b]{2}{*}{ Parameter } & \multirow[b]{2}{*}{ Diet group } & \multirow{2}{*}{$\begin{array}{l}\text { Intake } \\
\text { diet }\end{array}$} & \multicolumn{2}{|l|}{ Excretion } \\
\hline & & & urine & faeces \\
\hline \multirow{8}{*}{$\begin{array}{l}\text { Mutagenicity to } \\
\text { TA97-S9 } \\
\text { (x 104 rev/wk) }\end{array}$} & CO, unheated & ND 1 & 0.37 & -0.19 \\
\hline & & & \pm 0.31 & \pm 0.24 \\
\hline & Co, heated & 3.39 & 0.16 & -0.12 \\
\hline & & \pm 0.06 & \pm 0.15 & \pm 0.06 \\
\hline & $\mathrm{PO}$, unheated & ND & 0.38 & -0.07 \\
\hline & & & \pm 0.63 & \pm 0.06 \\
\hline & PO, heated & 2.81 & 0.40 & 0.01 \\
\hline & & \pm 0.19 & \pm 0.29 & \pm 0.07 \\
\hline \multirow{8}{*}{$\begin{array}{l}\text { Mutagenicity to } \\
\text { TA100-S9 } \\
\left(\times 10^{4} \text { rew/wk) }\right.\end{array}$} & $\mathrm{CO}$, unheated & ND & 0.00 & 0.02 \\
\hline & & & \pm 0.01 & \pm 0.04 \\
\hline & $\mathrm{CO}$, heated & ND & 0.02 & -0.04 \\
\hline & & & \pm 0.03 & \pm 0.01 \\
\hline & PO, unheated & ND & 0.00 & 0.03 \\
\hline & & & \pm 0.01 & \pm 0.14 \\
\hline & $P O$, theated & 1.60 & 0.06 & 0.08 \\
\hline & & \pm 0.08 & \pm 0.07 & \pm 0.12 \\
\hline \multirow{8}{*}{$\begin{array}{l}\text { TBA-RS } \\
\text { (nmolles MDAwwk) }\end{array}$} & $\mathrm{CO}$, unheated & ND & 0.11 & 1.35 \\
\hline & & & \pm 0.04 & \pm 0.13 \\
\hline & $\mathrm{CO}$, heated & 31.6 & 0.11 & 1.33 \\
\hline & & \pm 1.3 & \pm 0.03 & \pm 0.44 \\
\hline & PO, unheated & ND & 0.12 & 1.44 \\
\hline & & & \pm 0.02 & \pm 0.21 \\
\hline & $\mathrm{PO}$, heated & 18.5 & 0.14 & 1.52 \\
\hline & & \pm 1.2 & \pm 0.01 & \pm 0.19 \\
\hline
\end{tabular}

Values are expressed as meantSD.

'ND, not detectable. 
Lipid oxidation, mutagenicity and cell proliferation

Using data of individual rats, neither urinary $\mathrm{pH}$, nor excretion of TBA-RS were found to be associated with mutagenicity of acetone extracts of urines. Neither was mutagenicity of faecal extracts observed to be correlated with faecal pH and excretion of TBA-RS. Individual intake of mutagens, TBA-RS, LAHPO nor DPTG was found to be associated with urinary and faecal mutagen and TBA-RS excretion, no significant correlations were found when data of the group fed heated PO, containing DPTG and LAHPO, were processed only. LI of the upper gastro-intestinal tissues was not found to be associated with mutagen and TBA-RS excretion in urine or faeces, hor with intake. No significant correlations were observed between $\mathrm{LI}$ and number of cells per crypt of the colon/rectum, and mutagencity of faecal extracts or intake of mutagens, TBA-RS, LAHPO and DPTG, neither when data of the group fed heated PO were analyzed separately. $\mathrm{LI}$ and number of cells per crypt of colon/rectum were not found to be associated with faecal pH or TBARS concentration either.

\section{Discussion}

Short-term feeding of heated fats commonly used for frying of foods, did not appear to cause growth retardation, nor increase liver and kidney weights when administered to rats a level of $10 \%$ in the diet during 4 weeks. Slightly, but significantly increased plasma activities of GPT and AP, which were observed in the group fed heated $\mathrm{PO}$ as compared to the other experimental groups, however, suggested that short-term feeding of oxidized frying fats may affect cells in liver and kidneys. Lipid oxidation products are considered to cause the observed effects, since it has been reported that feeding rats with polar fraction of heated sunflower oil at a dose of $20 \%$ in the diet during 18 months caused growth retardation, elevated levels of GPT and GOT, and increased liver and kidney weights (Billek et al., 1979). A single dose of $1.2 \mathrm{~g}$ of secondary autoxidation products of linoleic acid to rats was also found to increase plasma GPT, liver weight and hepatic concentrations of lipid peroxides (TBA-RS) 12 to $24 \mathrm{~h}$ later (Kanazawa et al., 1985; 1986). The fact that the doses of oxidation products of linoleic acid administered in the present study, which were estimated by loss of linoleic acid in heated oils to be maximally $20 \mathrm{mg} / \mathrm{day}$, were considerably lower, and the presence of alpha-tocopherol in the experimental diets, may explain the absence of an effect on liver and kidney weights and the marginal effects observed on plasma clinical biochemical parameters. TBA-RS of heated frying oils appeared not to be associated with adverse affects, since feeding of heated $\mathrm{CO}$ which contained slightly higher amounts of TBA-RS as compared to heated PO, did not show elevated levels of GPT and AP. Since LAHPO and DPTG were present in heated PO 
but not in heated $\mathrm{CO}$, it is suggested that lipid oxidation products derived from linoleic acid may specifically be associated with the observed effects on plasma clinical biochemical indices.

In the present study, feeding of heated PO was shown to enhance cell proliferation in tissues of oesophagus and forestomach, whereas heated $\mathrm{CO}$ did not affect cell proliferation of the gastro-intestinal tract. Stimulation of cell proliferation by heated $\mathrm{PO}$ appeared to be exerted predominantly in the upper gastro-intestinal tract; the decreased number of cells/crypt in the colon/rectum of rats fed heated PO was found to originate from a decrease of the non-proliferating compartment and may indicate an adaptive response to lytic effects caused by heated PO during the first week(s) of feeding of the experimental diet (Wargovich and Lointier, 1987). Enhancing effects exerted on cell proliferation by heated PO in tissues of oesophagus and forestomach, but not in glandular stomach and colon, indicated that these effects might have been caused by substances which were either highly reactive and not stable enough to reach the lower gastro-intestinal organs, or that were readily absorbed by mucosal cells of the oesophagus and forestomach. The nature of these substances is not clear at present, but may be related to oxidation and degradation products originating from linoleic acid, which was indicated by the presence of LAHPO in heated PO. The upper part of the gastro-intestinal tract may be considered as possible target tissues for effects observed after oral administration of LAHPO, since it has been reported that 12 to $24 \mathrm{~h}$ after administration of a single dose of ${ }^{14} \mathrm{C}$ labeled methyl linoleate hydroperoxide by gastric intubation to rats, appreciable amounts of radioactivity were recovered in stomach, liver and urine, but recovery in the large intestine was only 3-5\% (Bergan and Draper, 1971; Oarada et al., 1986). In contrast, ${ }^{14} \mathrm{C}$ labeled polymeric oxidation products were observed to be excreted largely in faeces $(53 \%)$, although the stomach still contained approximately $1 \%$ of the orally administered labeled compounds $12 \mathrm{~h}$ after administration (Oarada et al,, 1986). Since no significant stimulation of cell proliferation was observed in the colon of the group fed heated $\mathrm{PO}$, it is suggested that DPTG present in heated PO may not be biologically active in the colon.

Hydroperoxides of linoleic acid or other oxidative degradation products and metabolites of polyunsaturated fatty acids were considered to be involved in stimulation of cell proliferation observed in the upper gastrointestinal tissues of rats fed heated $P O$, since these have been reported to be capable of enhancing cell proliferation in intestinal tissues (Bull et al.,1984; 1988; Craven et al., 1987; Craven and Rubertis, 1988). Increased cell proliferation, DNA synthesis and induction of ornithine decarboxylase were reported in the colon after acute intrarectal administration of hydroperoxy and hydroxy-derivatives of unsaturated fatty acids dissolved in $1.0 \mathrm{ml}$ saline solution at concentrations ranging from 5 to $10 \mathrm{mM}$ (Bull et 
al.,1984; 1988). In addition, it was demonstrated that intracolonically installed free arachidonate, linoleate and oleate dissolved in $2.0 \mathrm{ml}$ saline at concentrations of 1-5 mM increased colonic DNA synthesis and mucosal ornithine decarboxylase activity (Craven et al.,1987; Craven and Rubertis, 1988). In the present study, mean daily consumption of LAHPO was approximately 5 nmoles with the diet containing heated $\mathrm{PO}$, and was found to be below the dose needed for in situ stimulation of cell proliferation in the colon. This may indicate a higher sensitivity of tissues of the forestomach and oesophagus for cell proliferation enhancing effects of lipid oxidation products. The absence of a correlation between individual consumption of LAHPO, TBA-RS and DPTG, and labeling indices, and the fact that shortterm consumption of heated deep-frying oil does increase cell proliferation in the upper gastro-intestinal tissues, suggests that other oxidation or degradation products which were not determined in our study, may have been involved. These may also include free oleic and linoleic acids which may be produced by hydrolysis of triglycerides during heating of oil (Stevenson, 1984).

Stimulation of mucosal cell proliferation in the colon by high-fat diets is generally considered to be a secondary response to cell loss caused by nonspecific tissue injury by fatty acids or bile acids (Bruce, 1987; Wargovich and Lointier, 1987). Lipid oxidation products and oxidized fats however, were reported to damage tissues of liver and kidneys after oral administration (Izaki et al., 1983; Kanazawa et al., 1986; 1987), and therefore a similar mechanism may be considered to be involved in the enhancing effects exerted on oesophagal and forestomach tissues by heated $\mathrm{PO}$ in the present study. The mechanism by which unsaturated fatty acids stimulate cell proliferation in the intestine has also been postulated to involve activation of protein kinase $\mathrm{C}$ (Craven et al ${ }_{\text {, }} 1988$ ), a regulator of cell growth and many other functions (Anderson et al., 1985). Activation of protein kinase $C$ may be mediated either through reactive oxygen species which has been reported for tumor promotors of the phorbolester type (Craven et al., 1987; Weinstein, 1988), as well as by increased phosphoinositide breakdown, resulting in the release of diacylglycerols which directly activate protein kinase C (Rozengurt, 1984). Stimulation of cell proliferation may also be mediated through prostaglandin synthesis (Craven et al., 1983; Narisawa et al., 1987), and reactive oxygen species generated in cyclooxygenase or lipoxygenase pathways (DeRubertis et all., 1984; Craven et al., 1986). Since heated frying oils may contain precursors for several of the proposed stimulating mechanisms, and none of the oxidative parameters measured in diet as well as in urine and faeces, was found to be associated with stimulation of cell proliferation, no conclusion can be drawn with respect to the mechanisms by which heated PO enhanced cell prolferation in the present study. Neither mutagenicity of heated oils, nor mutagenicity of urine and faeces were found to be 
associated with cell proliferation in gastro-intestinal tissues, indicating that compounds causing mutagenic activity of the oils were not involved in enhancement of cell proliferation.

Excretion of TBA-RS in urine and faeces was found to be minimal as compared to TBA-RS present in diet, being maximally $0.1 \%$ of the dose consumed. These data indicate that $>99 \%$ of oxidation products were either retained in the tissues or inactivated by in vivo; these data do not suggest induction of in vivo lipid oxidation after short-term consumption of heated oxidized oils. It should be noted however, that levels of TBA-RS and LAHPO in heated oils in the present study were low in comparison with concentrations observed in a previous study in commercially used deepfrying oils, which contained levels of TBA-RS up to $161 \mathrm{nmoles} \mathrm{MDA} / \mathrm{g}$ of fat (Hageman et al., 1988), and concentrations of LAHPO up to $267 \mathrm{nmoles} / \mathrm{g}$ of fat (Hageman et al., 1989a). Since the present data showed that consumption of low amounts of oxidation products significantly increased urinary concentrations of TBA-RS in combination with increased plasma activities of GPT and AP in rats fed heated $P O$ as compared to rats fed

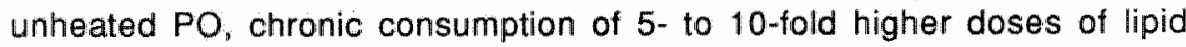
oxidation products may beof concern with repect to oxidative damage to tissues.

Mutagenicity occurring in heated PO which was analyzed specifically by strain TA100, appeared to be detectable in urine and faeces after oral intake, and amounted to $7 \%$ of the ingested dose. This suggests that compounds present in heated frying oils and causing base-pair mutations in strain TA100, may not be totally inactivated after absorption. Consumption of frying oils containing TA97 mutagens did not increase excretion in urine and faeces ${ }_{i}$ suggesting frame-shift mutagens may either be efficiently deactivated in vivo, or retained in the tissues. Although urine extracts exhibited significant mutagenicity to strain TA97, this was not related to mutagenicity of the oils consumed by the rats. Since no significant correlations were found between urine mutagenicity to either strain TA97 or TA100, and urinary pH or excretion of TBA-RS, the nature of these excreted mutagens remains to be determined.

Concluding, results of the present study indicate that heated deep-frying oils, containing autoxidation products, are capable of stimulating cell proliferation in the gastro-intestinal tract. The proliferation enhancing effects observed in this study however, do not appear to be extended to the colon/rectum, and are not directly pointing to an involvement of heatprocessed lipids in colon tumorigenesis. Since data obtained in this study are limited to testing of a single dose of frying oils, and the nature of active compounds exerting an effect in the upper gastro-intestinal tissues is still unclear at present, determination of effects of thermally oxidized oils on 
colon tumorigenesis therefore, requires further investigation. For a reliable risk estimation these studies will also have to include determination of interactions of heated oxidized lipids with other dietary factors, both possible initiators as well as inhibitors, that may be involved in the process of colon carcinogenesis (Bruce, 1987).

\section{Acknowledgements}

The excellent assistance and valuable contributions to this study of mrs. E. Fransen, mr. F. Weekers, mr. G. van Kranenburg and mrs. M. Simonis are gratefully appreciated.

\section{References}

Alexander J.C. (1981). Chemical and biological properties related to toxicity of heated fats. J. Toxic. Environ. Health 7, 125-138.

Alexander J.C., Vallh V.E. and Chanin B.E. (1987). Biological observations irom teeding heated corn oil and heated peanut oil to rats. J. Toxicol. Environm. Health 21, 295-309.

Anderson W.B., Estival H., Tapiovaara H. and Gopalkrishna R. (1985). Altered subcellular distribution of protein kinase $\mathrm{C}$ (a phorbolester receptor). Possible role in tumor promotion and the regulation of cell growth: relationship to changes in adenylate cyclase activity. Adv. Cyclic Nucleotide Protein Phosphorylation Res. 19, 287-306.

Andia A.M.G. and Street J.C. (1975). Dietary induction of hepatic microsomal enzymes by thermally oxidized fats. J. Agr. Fo Chem. 23, 173-177.

Begg A.C., MclNally N.J., Shrieve D.C. and Karcher H. (1985). A method to measure the duration of DNA symthesis and the potential doubling-time from a single sample. Cytometry 6, 620-626.

Benirschke K., Garner F.M. and Jones T.C. (Eds.) (1978). Pathology of laboratory animals. Volume II. Springer-Verlag, New York.

Bergan J.G. and Draper H.H. (1971). Absorption and metabolism of $1 .^{14} \mathrm{C}$-methyl linoleate hydroperoxide. Lipids 5, 976-982.

Billek G., Guhr G. and Sterner W. (1979). Fütterungsversuche mit erhitzten Fett und Fettraktionen. Fette. Seifen. Anstrichm. 81, 562-566

Bird R.P. and Stamp D. (1986). Effect of high fat diet on prolfferative indices of murine colonic epithelium. Cancer Lett. 31, 61-67.

Bruce W.R. (1987). Recent hypotheses for the origin of colon cancer. Cancer Res. 47, 42374242.

Bull A.W., Nigro N.D., Golembieski W.A., Crissman J.D. and Marnett L.J. (1984). In wivo stimulation of DNA synthesis and induction of omilhine decarboxylase in rat colon by fatty acid hydroperoxides, autoxidation products of unsaturated fatty acids. Cancer Res. 44 , 4924-4928. 
Bull A.W., Nigro N.D: and Marnett L.J. (1988). Structural requirements for stimulation of colonic cell prolfferation by oxidized fatty acids. Cancer Res. 48, 1771-1776.

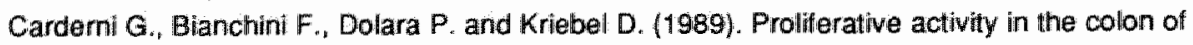
the mouse and its modulation by dietary starch; fal and cellulose. Cancer Res. 49, $1655-$ 1659.

Caderni G., Stuart EW. and Bruce W.R. (1988). Dietary factors affecting the proliferation of epithelial cells in the mouse colon. Nutr. Cancer 11, 147-150.

Carroll K.K. (1987) Summation: Which fatiHow much fat - Animals. Prevent. Med. 16, 510515.

Craven P.A. and DeRubertis F.R. (1988). Role of activation of protein kinase $C$ in the stimulation of colonic epithelial proliferation by unsaturated fatty acids. Gastroenterol. 95 . 676-685.

Craven P.A., Ptansthel J. and DeRubert is F.R. (1986). Role of reactive oxygen in bile salt stimulation of colonic epithelial proliteration. J.Clin. Invest. 77, 850-859.

Craven P.A., Pfanstiel J. and DeRubertis F.R. (1987). Role of activation of protein kinase $\mathrm{C}$ in the stimulation of colonic epthelial proliferation and reactive oxygen formation by bile acids. J. Clin. Invest. 79, 532-541.

Craven P.A., Saito R. and DeRubertis F.R. (1983). Role of local prostaglandin synthesis in the modulation of proliferative activity of rat colonic epithelium. J. Clin. Invest. 72, 1365-1375.

Cutler M.G. and Schneider $\mathbb{R}$. (1973). Maltormations produced in mice and rats by oxidized linoleate. Fd Cosmet. Toxicol. 11, 935-942.

DeRubertis F.R., Craven P.A. and Saito R. (1984). Bille salt stimulation of colonic epithelial proliferation. Evidence for involvement of lipoxygenase products. J. Clin. Invest. 74, $1614-1624$.

Deschner E.E., Long F.C., Hakissan M. and Hermann S.L. (1983). Differential susceptibility of $A K R, C 57 B 1 / 6 \sqrt{ }$, and CF1 mice to 1,2-dimethylhydrazine-induced colonic tumor formation predicted by proliferative characteristics of colonic epithelial cells. J. Natl. Cancer Inst. 70, 279-282.

Draper H.H., Polensek L., Hadley M. and McGirr L.G. (1984). Urinary malondialdehyde as an indicator of lipid peroxidation in the diet and in the tissues. Lipids $19,836-843$.

Esterbauer $H$. and Zolner h. (1989). Methods for determination of aldehydic lipid oxidation products. Free Rad. Biol. Med. 7, 197-203.

Gutteridge J.M.C. (1982). Free-radical damage to lipids, amino acids, carbohydrates and nucleic acids determined by thiobarbituric acid reactivity. Int. J. Biochem. 14,649-653.

Hageman G., Hermans F., ten Hoor F. and Kleinjans J. (1989b). Mutagenicity of deep-frying fat, and evaluation of urine mutagenicity after consumption of fried potatoes. Food Chem. Toxic, in press.

Hageman G. Kikken R. Ten Hoor F. and Kleinjans J. (1988). Assessment of mutagenic activily of repeatedly used deep-lirying flats. Mutation Res. 204, 593-604.

Hageman G., Kikken R., Ten Hoor F. and Kleinjans J. (1989a). Linoleic acid hydroperoxide concentration in relation to mutagenic activity of repeatedly used deep-frying fats. Lipids 24, 899-902.

Ip C., Carter C.A. and Ip M. (1985). Requirement of essential fatty acid for mammary tumorigenesis in the rat. Cancer Res. 45, 1997-2001.

Izaki Y., Yoshikawa S. and Uchiyama M. (1984) Effect of ingestion of thermally oxidized frying 
oil on peroxidative criteria in rats. Lipids $5,324-331$.

Jacobs L.R. (1983). Effect of short-term dietary fat on cell growth in rat gastro-intestinal mucosa and pancreas. Am. J. Clin. Nutr. 37, 361-367.

Jacobs L.R. (1988). Role of dietary factors in cell replication and colon cancer. Am. J. Clin. Nutr. $48,775-779$.

Jacobs L.R. and Lupton J.R. (1986). Relationship between colonic luminal $\mathrm{pH}$, cell proliferation ${ }_{n}$ and colon carcinogenesis in 1,2-dimethylhydrazine treated rats fed high fiber diets. Cancer Res. 46, 1727-1734.

Kanazawa K., Ashida H. Minamoto S. and Natake M. (1986). The effect of orally admintstered secondary autoxidation products of linoleic acid on the activity of detoxifying enzymes in the rat liver. Biochim. Biophys. Acta 879, 36-43.

Kanazawa K., Kanazawa E. and Natake M. (1985) Uplake of secondary autoxidation products of linoleic acid by the rat. Lipids 20, 412-419.

Narisawa T., Takahashi M., Niwa M., Fukahara Y. and Wakiuzaka A. (1987). Involvement of prostaglandin $E_{2}$ in bile acid-caused promotion of colon carcinogenesis and antipromotion by the cyclooxygenase inhibitor indomethacin. Jpn. J. Cancer Res. (Gann) 78, $791-798$.

Oarada M., Miyazawa T. and Kaneda T. (1986). Distribution of ${ }^{14} \mathrm{C}$ after oral administration of $\left(\mathrm{U}-{ }^{14} \mathrm{C}\right)$ labeled methyl linoleate hydroperoxides and their secondlary oxidation products in rats. Lipids $21,150-154$.

Pariza M.W. (1988). Dietary fat and cancer risk: evidence and research needs. Ann. Rev. Nutr. $8,167-183$.

Perciballi M. and Pintauro S.J. (1985). The effects of fractionated thermally oxidized corn oil on drug-metabolizing enzyme systems in the rat. Food Chem. Toxicol. 23, 737-740.

Rand M.L., Hennissen A.A.H.M. and Hornstra G. (1986). Effects of dietary sunflower seed oil and marine oil on platelet membrane fluidity, arterial thrombosis and platelet responses in rats. Atherosclerosis $62,267-276$.

Reddy B.S. (1987). Dietary tat and colon cancer: Animal models. Prev. Mled. $16,460-467$.

Rozengurt E., Rodrigues-Pena A., Coombs M. and Sinnett-Smith J. (1984). Diacylglycerol stimulates DNA synthesis and cell division in mouse 3 T3 cells: role of $\mathrm{Ca}^{2+}$ sensitive phospholipid dependent protein kinase. Proc. Natl. Acad. Sci. USA 81, 57481-5752

Schutte B., Reynders M.M.J, Van Assche C.L.M.V.J. Hupperts P.S.G.J., Bosman F.T. and Blijham G.H. (1987). An improved method for the immunocytochemical detection of BrdU-labeled nuclei using flow cytometry. Cytometry $8,372-376$.

Schutte B., Reynders M.M.J., Bosman F.T., and Blijharn G.H. (1987). The effect of tissue fixation on anti-bromodeoxyuridine immunohistochemistry. J. Histochem. Cytochem. 35, 13.43-1345.

Stadler J., Stern H.S., Yeung K.S., McGuire V., Furrer R., Marcon N. and Bruce W.F. (1988). Effect of high fat consumption on cell proliferation activity of colorectal mucosa and on soluble feacal bile acids. Gut 29, 1326-1331.

Stevenson S.G., Vaisey-Genser M. and Eskin N.A.M. (1984), Quality control in the use of deep trying oils. J. Am. Oil Chem. Soc. 61, 1102-1108.

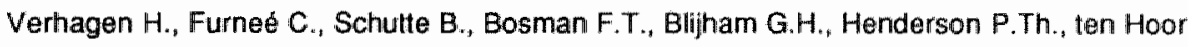
F. and Kleinjans J.C.S. (1989). Dose-dependent effects of short-term dietary administration of the food addditive butylated hydroxyanisole on cell kinetic parameters in 
rat gastro-intestinal tract. Submitted.

Verhagen $H_{\text {, s }}$ Schutte B., Reynders M., Bijham G.H. Ten Hoor F. and Kleinjans J.C.S. (1988). Effect of shon-term dietary administration of butylated hydroxyanisole on cell kinetic parameters in rat gastro-intestinal tract, assessed by immunocytochemistry ano flow cytomelry. Carcinogenesis 9, 1107-1109.

Wargowich M.J. and Lointier P.H. (1987). Calcium and vitamin D modulate mouse colon epithelial proliferation and growth characteristics of a human colon tumor cell line. Can. J. Physiol. Pharmacol. 65, 472-477.

Wargowich M.J., Eng V.W.S. and Newmark H.L. (1984). Calcium inhibits the darnaging and compensatory proliferative effects of fatty acids on mouse colon epithelium. Cancer Lett. 23, 250-258.

Weinstein 1.B. (1988). The arigin of human cancer: molecular mechanisms of carcinogenesis and their implications for cancer prevention and treatment. Cancer Res. 48, 4135-4143.

Yamasaki E and Ames B.N. (1977). Concentration of mutagens from urine by adsorption with the non-polar resin $X A D-2$ : Cigarette smokers have mutagenic urine. Proc. Natl Acad Sci. USA $74,3555-3559$. 


\section{Chapter 9}

\section{General discussion and concluding remarks}

\section{Heat-processing of food and colon cancer}

High-meat and high-fat consumption have been recognized as dietary factors associated with increased cancer mortality and incidence of colonic and mammary tumors in populations of industrialized countries as compared to developing countries (Armstrong and Doll, 1975; Rose et al., 1986). Only a few dietary components however, have been isolated and identified which possess carcinogenic properties and may be causally related to tumorigenesis. Heat-processing of foods may be a factor of special importance since during heat-treatment degradation products are formed, which may possess toxic properties. With respect to intake of meat and meat products it appears of relevance that frying and broiling of proteinaceous foods has been demonstrated to result in formation of carcinogenic amino acid pyrolyzates (Sugimura et al., 1986), and at extremely high temperatures during broiling and roasting of meats and other foods, carcinogenic polycyclic aromatic hydrocarbons (PAHs) may be produced (Phillips, 1983). These compounds are considered to pose a serious risk to human health, but strong epidemiological or human toxicological evidence for a causal relation between high intake of heat-processed meat and tumor incidence is still lacking (Archer, 1988; Byers, 1988; Rogers and Longnecker, 1988; Willet, 1989). High intake of dietary fat has also been associated with increased cancer risk, especially of the colon/rectum, but epidemiologic studies have shown inconsistent results (Byers, 1988; Hill, 1987; Willet, 1989).

In this thesis is has been hypothesized in Chapter 1 that heat-processing of lipids may be one of the factors of relevance for the relation between dietary fat and cancer of the colon/rectum. It has been argued that thermal degradation and oxidation products of dietary lipids which possess mutagenic properties may be involved in tumorigenesis. With the exception of malondialdehyde (MDA), fatty acid oxidation and degradation products have not been tested for carcinogenicity. MDA, a secondary product of lipid oxidation has been reported to induce hepatic neoplasia in mice (Draper et al., 1982; Siu and Draper, 1983). Furthermore, experimental studies with animals have revealed a promoting effect on colon tumorigenesis of high intake of various dietary fats (Carroll, 1987; Reddy, 1986; Rogers and Longnecker, 1988), but tumor enhancing or initiating activities of heat degradation products of dietary lipids have not yet been studied. The aim of this thesis was therefore to investigate the possible involvement of heat- 


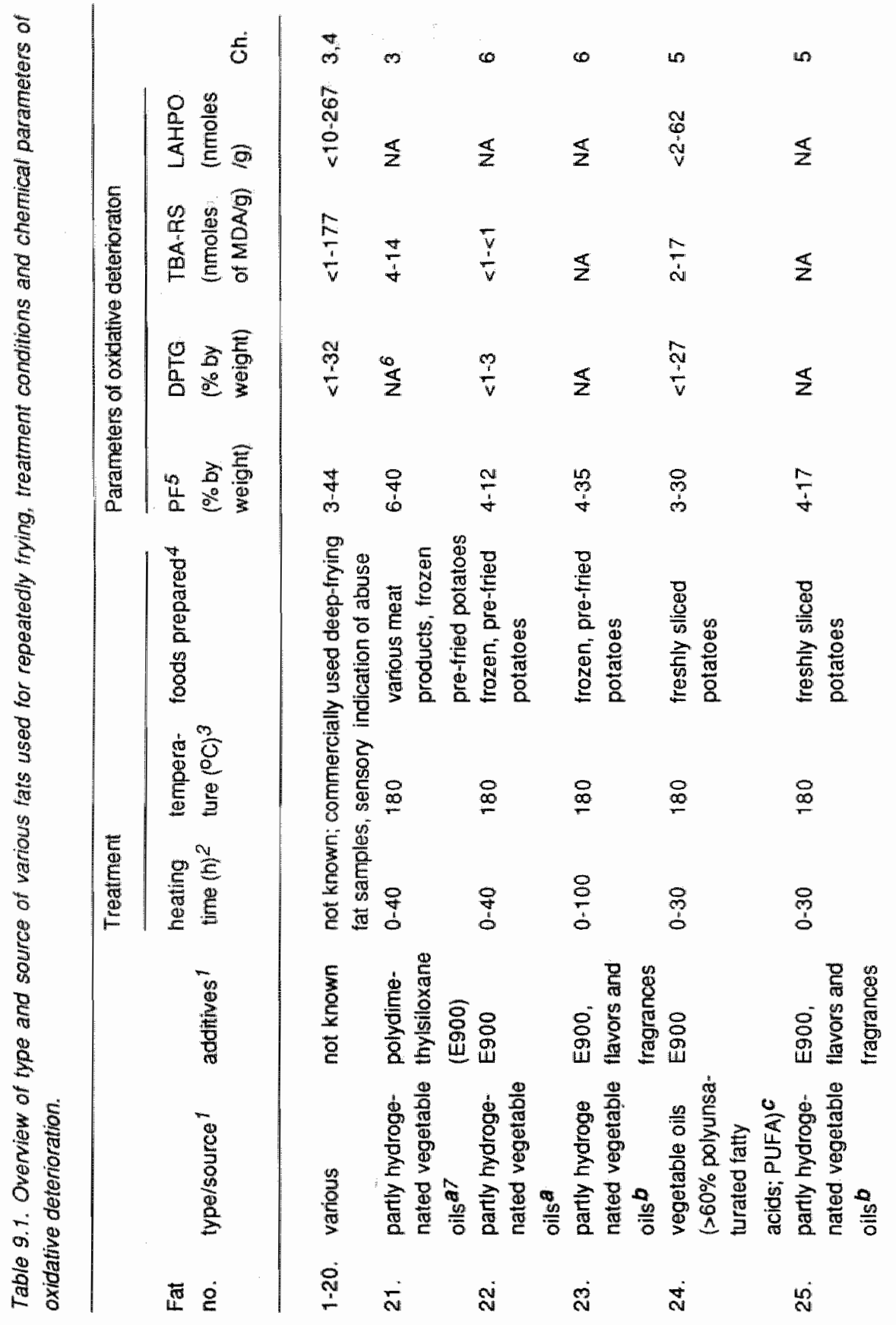




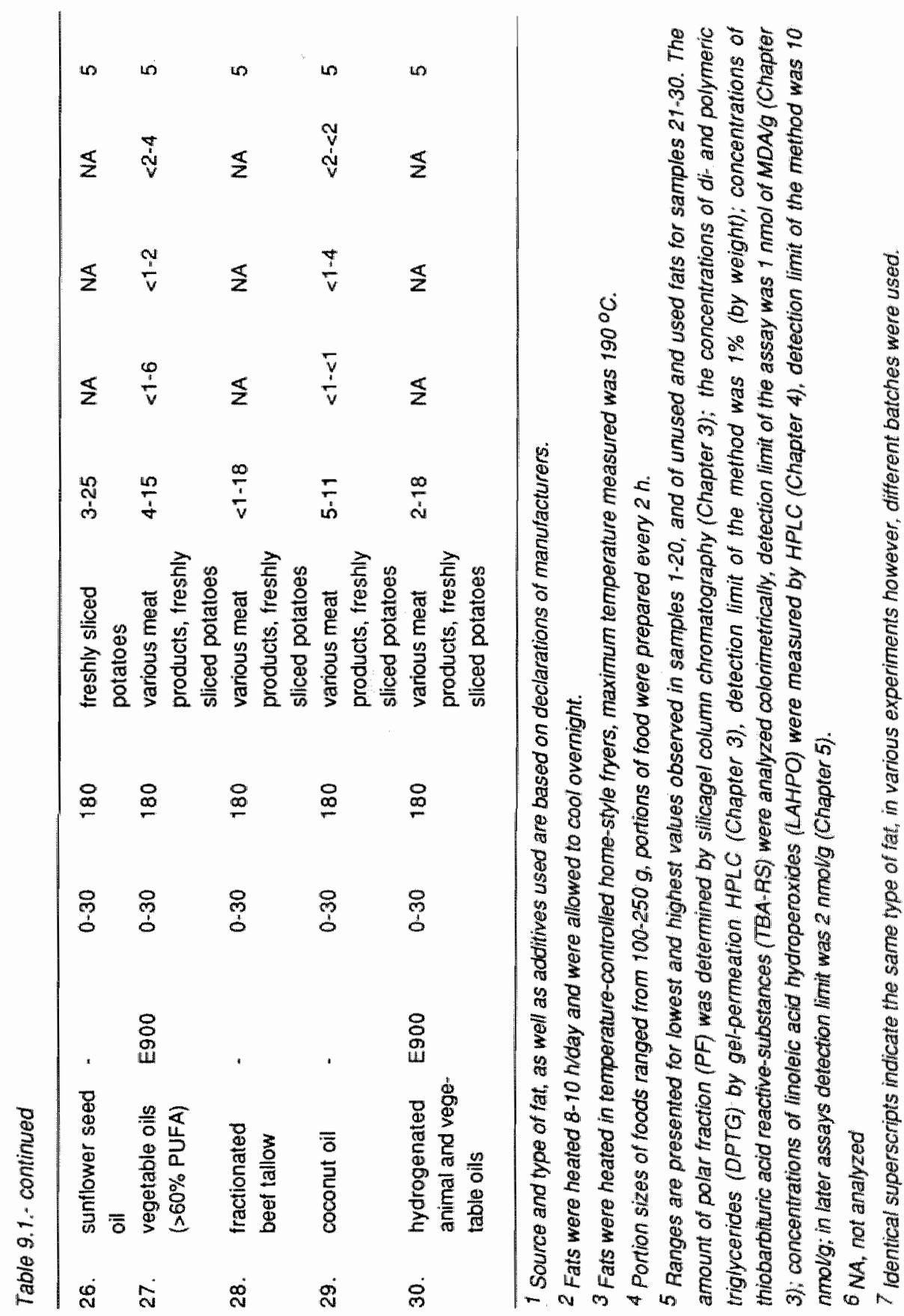




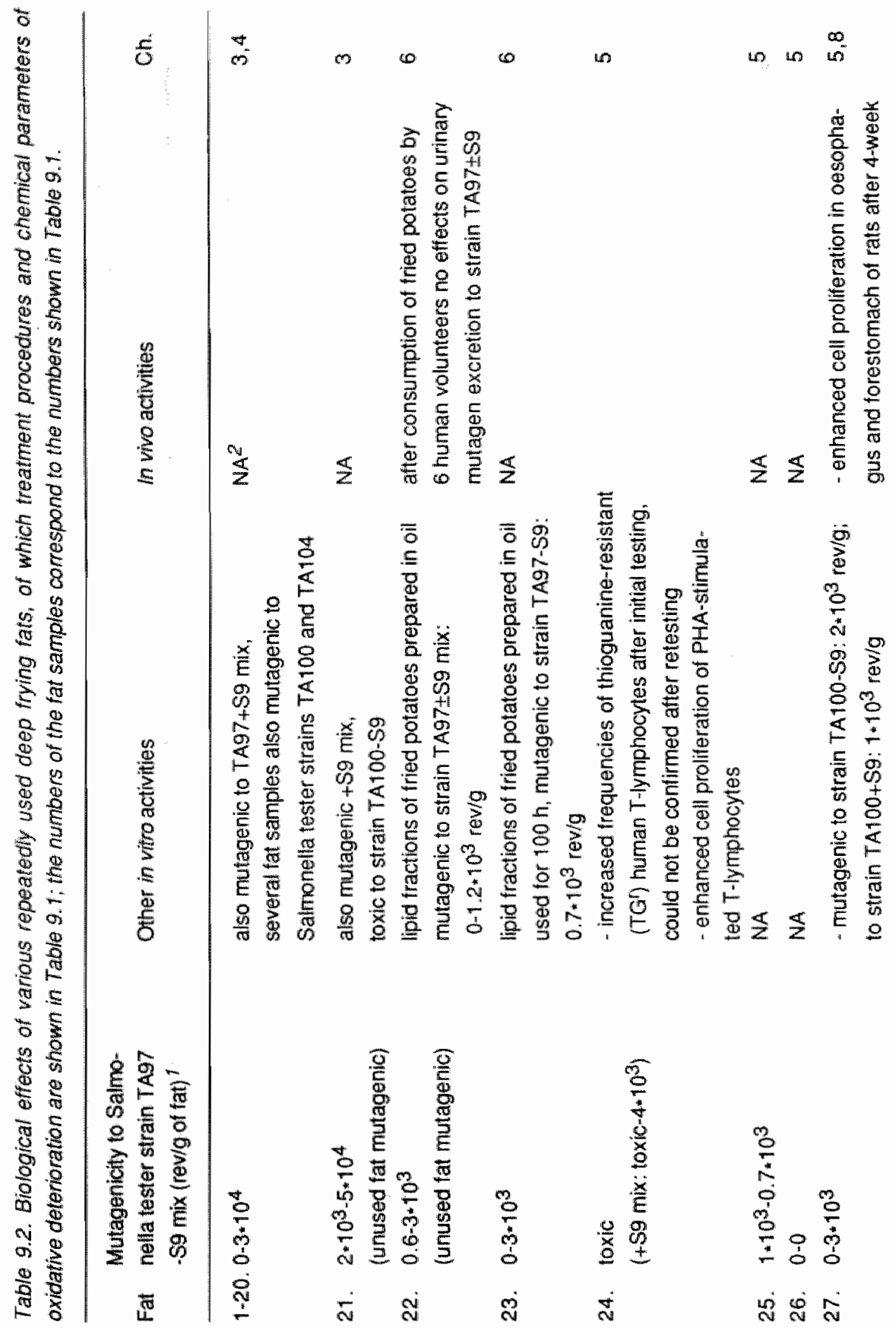




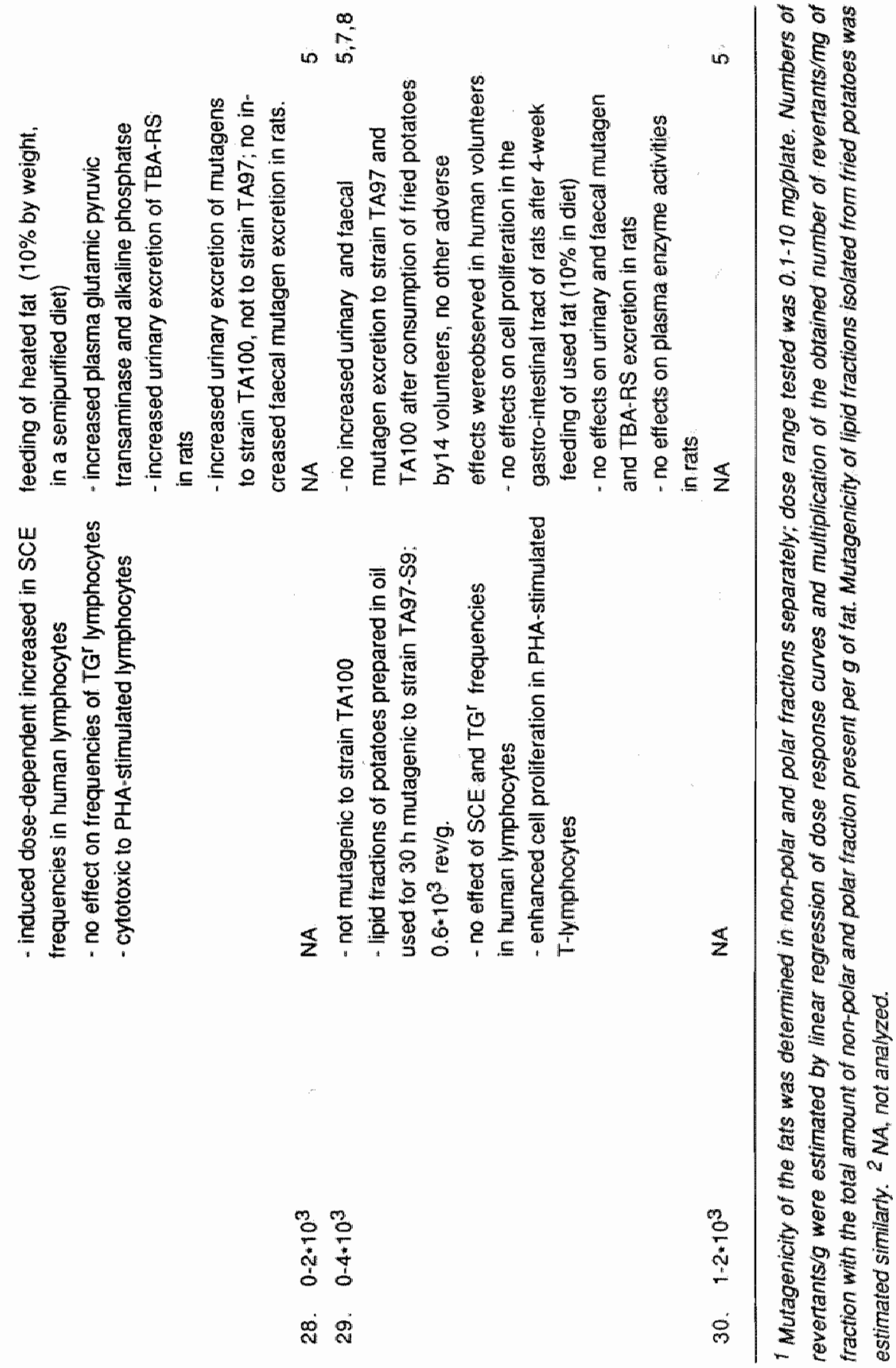


processed lipids in tumorigenesis. For this purpose, (i) deep-frying fats were tested for genotoxicity in vitro, (ii) biological fate of muttagenic compounds associated with deep-fat frying was assessed (iii) in rats and (iv) in man, and (v) the effects of heat-processed fats on cellular growth in the rat gastro intestinal tract were determined. Data obtained were applied to evaluate a possible involvement of heat-processed lipids in colon tumorigenesis. In Tables 9.1 and 9.2 results of the experiments described in Chapters 3 to 8 are briefly summarized, and serve as a reference to this Chapter.

\section{Mutagenicity testing of heated deep-frying fats in Salmonella typhimurium}

In Chapters 3 to 6 genotoxicity of repeatedly used deep-frying fats to Salmonella typhimurium, as well as to human lymphocytes was analyzed. In Chapter 3, repeatedly used deep-frying fats, sampled from local snackbars and restaurants by officers of the Maastricht Office for Food Quality Control after sensory indication of abuse and showing varying degrees of oxidative deterioration, were tested for mutagenicity in the Salmonella/microsome assay. Results of this study showed that several repeatedly used deep-frying fats do possess mutagenic activity to strains TA97, TA100 or TA104. Mutagenic compounds appeared to be present predominantly in the polar fraction of these fats, which was isolated using silicagel chromatography and which was reported to contain polar oxidation and degradation products (Billek et al., 1978). Non-polar fractions of some used fat samples also exhibited mutagenic acitivity, but numbers of revertants induced by this latter fraction were lower as compared to the polar fraction. Mutagenicity of polar and non-polar fractions which did not show toxic effects to the bacteria, was reduced when tested in presence of liver S9 mix obtained from Aroclor induced rats, indicating mutagenic compounds might be deactivated by liver microsomal metabolism or by free-radical scavenging systems present in S9 homogenate. Salmonella tester strain TA97 appeared to be most sensitive in detecting mutagenicity of repeatedlly used deep-frying fats; mutagenic activity of used fat samples to this strain in absence of S9 mix was estimated to range from $1 * 10^{3}$ to $3 * 10^{4}$ revertants per $\mathrm{g}$. In this study, it was also demonstrated that mutagens found in these used deep-frying fat samples were likely to be produced during deep-fat frying and not during storage; in a frying experiment carried out in the laboratory, in which a commercially obtained deep-frying fat was used for regular preparation of various fried foods, and which involved mutagenicity testing of fat samples within one week, increased mutagenicity was observed in the polar fraction of this fat after repeated use. 


\section{Mutagenicity of deep-frying fats in relation to oxidative deterioration}

Since mutagenic activity of heated deep-frying fats was found primarily in the lipid fraction containing oxidation products, it was suggested that lipid oxidation products might be involved in mutagenicity. Mutagenic activity of the used fat samples however, appeared not to be related to the extent of oxidative deterioration as determined by the amount of polar material or levels of di- and polymeric triglycerides (DPTG). Mutagenic activity of these fat samples to strain TA97, both detected in absence and in presence of S9 mix, did show a positive correlation with lipid oxidation products as determined by the colorimetric thiobarbituric acid assay. Since this assay non-specifically analyzes lipid hydroperoxides as well as several secondary oxidation products, such as MDA, alka-2,4-dienals and alk-2-enals (Kosugi and Kikugawa, 1989), the exact nature of lipid oxidation products involved remained unclear.

Hydroperoxides of linoleic and linolenic acid were reported to be mutagenic in the Salmonella/microsome assay (McGregor et al., 1985; Yamaguchi and Yamashita, 1979; 1980), and were therefore considered likely to contribute to mutagenicity of thermally oxidized fats. Consequently, the concentration of linoleic acid hydroperoxides (LAHPO) of repeatedly used deep-frying fat samples was determined using a high performance liquid chromatography (HPLC) method, which is described in Chapter 4. Mutagenic activity of the used deep-frying fat samples did show a weak positive correlation with concentrations of LAHPO, but this association was found for mutagenicity to strain TA97 in presence of S9 mix only. Concluding, these results indicate that secondary products of lipid oxidation may contribute to direct-acting mutagenicity of used deep-frying fat samples, whereas metabolites or non-enzymatic degradation products of LAHPO may be involved in mutagenicity detected in presence of liver $\mathrm{S9}$ mix. The absence of a relation between mutagenicity of repeatedly used deep-frying fats and concentrations of DPTG and polar material, which are chemical parameters used for quality control of deep-frying fats (Billek et al, 1978; Stevenson et al., 1984), indicates that quality control as currently applied does not determine compounds that are associated with genotoxic risk, and may therefore be considered inadequate.

Mutagenicity of repeatedly used deep-frying fats in relation to the foods prepared

In Chapters 5 and 6 , the influence of oxidative deterioration, lipid oxidation, type of frying fat and nature of the foods prepared on mutagen formation during deep-fat frying was investigated. Various types of frying fat, containing different concentrations of polyunsaturated fatty acids (PUFA), were used exclusively for frying of potatoes, or for preparation of various foods. Potatoes were initially used for frying, since these were considered to 
present the least complex food matrix. In Chapter 6 , it was demonstrated that prolonged and repeated use of the deep-frying fat for preparation of fried potatoes, resulted in increased mutagenicity of the fat to Salmonella strain TA97, which corresponded to increased concentrations of DPTG and of polar oxidation and degradation products. Levels of TBA-RS were below the detection level of 1.0 nmole of MDA/g, in the fat as well as in fried potatoes, indicating that mutagenicity of this used deep-frying fat was not related to autoxidation of PUFA, but that other compounds were involved. Mutagenicity of lipid fractions isolated from fried potatoes showed no clear tendency to increase with prolonged use of the deep-frying fat. In this frying experiment however, commercially obtained pre-fried, frozen potatoes were used, of which the polar lipid fraction was found to be mutagenic to Salmonella strain TA97. It was therefore suggested that either mutagens were produced during commercial preparation of pre-fried potatoes, or that naturally occurring components in potatoes contribute to mutagenicity of fried potatoes. Testing of mutagenicity of lipid fractions isolated from fresh, uncooked potatoes however, yielded negative results, thus providing no evidence for the latter possibility.

Mutagenic activity to Salmonella strain TA97 was also found in a fraction extracted with methanol from the fatt-free residue of fried potatoes and mashed potatoes, but not from fresh uncooked potatoes (Chapters 6 and 7 ). Since fat-free residues of fried as well as of cooked potatoes, as described in Chapter 7, were found to contain appreciable amounts of methanolextractable compounds, this extract is considered to contain very polar compounds produced during heating, which may be derived from lipids, carbohydrates or proteins, as well as from compounds naturally present in potatoes. Different frying experiments, in which various types of fat and potatoes were used, yielded varying mutagenic activity, showing the presence of pro-mutagenic compounds in methanol-extracts of fried potatoes in one experiment (Chapter 6), and direct-acting mutagenicity of mothanol-extracts in another (Chapter 7). These data illustrate the complexity of assessment of mutagenic activity of deep-fat fried foods, since various factors which include the nature of the fats and the fried foods, as well as frying conditions, influence mutagen formation and presence of mutagens in fried foods. Furthermore, isolation of mutagens from complex matrices like fried foods using standard extraction procedures for the isolation of lipids, may not result in detection of reaction products of lipids with proteins or carbohydrates.

Results obtained in frying experiments described in Chapter 5, in which freshly sliced potatoes were prepared, indicated that lipid oxidation or oxidative deterioration of fats per se does not cause mutagenicity of the frying fat, since frying of freshly sliced potatoes caused no or only marginal mutagenicity of deep-frying fats to Salmonella strain TA97, of which some 
showed severe oxidative deterioration and lipid oxidation after $30 \mathrm{~h}$ of use. Subsequently, both saturated and unsaturated fats were used for preparation of various products including proteinaceous foods, and heated for $30 \mathrm{~h}$. In these experiments, no evidence was found either for a causal relation between the degree of oxidative deterioration or lipid oxidation of the fats and mutagenicity to strain TA97. Chemical as well as mutagenicity results obtained for different unused batches of the same type of fat which were tested in frying experiments described in Chapters 3,5 and 6 , suggest that the quality and source of the fat may also be factors causing poor reproducibility of mutagenicity results and parameters of oxidative deterioration; the presence of anti-oxidants, the nature of foods prepared, volume and water content of foods prepared, and quality of the equipment used may be additional factors causing variation (Chang et al., 1978; Stevenson et al., 1984).

Data obtained in Chapters 3 to 6 suggest that frying of various foods enhances mutagen formation during deep-fat frying as compared to frying of potatoes. This may be related to the high protein content of meat products as compared to potatoes, since basic dichloromethane fractions of commercially deep-fried meat products were previously reported to show mutagenic activity in the Salmonella/microsome assay, whereas in dichloromethane extracts of starchy foods no clear indication for mutagenicity was observed (Taylor et al., 1982; 1983). At present, it is not clear which constituents of foods or meat are involved in mutagen formation. Further studies applying heating of model systems consisting of various triglycerides, proteins or amino acids, various carbohydrates, catalyzing metal ions and other minor food constituents including vitamins and antioxidants, may elucidate which compounds enhance or inhibit mutagen formation during deep-fat frying.

Genotoxic effects of heated deep-frying fats to human lymphocytes in vitro

Repeatedly used deep-frying fats, which showed mutagenic activity to strain TA97, were tested for genotoxicity to human lymphocytes. End points determined were induction of sister chromatid exchanges (SCE) and single gene mutations at the hypoxanthine phosphoribosyl transferase (HGPRT) locus. A modified procedure was developed for the HGPRT assay with human lymphocytes, which is described in detail in Chapter 2. Results of genotoxicity testing of 3 different heated fats are presented in Chapter 5 . In vitro exposure of human lymphocytes to heated deep-frying fats was observed to cause marginal efects. No dose-dependent induction of single gene mutations at the HGPRT-locus was found, although one heated fat significantly increased mutation frequencies at a single dose of $1.0 \mathrm{mg} / \mathrm{ml}$ when initially tested in two pillot experiments. Upon retesting one month later, no significantly increased mutation frequencies were observed over a 
dose range of 0.01 to $1.0 \mathrm{mg} / \mathrm{ml}$. Since this particular fat was found to contain appreciable amounts of LAHPO as compared to the other fats tested, it was suggested that mutagenicity to lymphocytes initially observed might have been due to instable lipid oxidation products, but this could not be confirmed by significant changes in the concentration of LAHPO after a twoweek storage period.

In addition, it was observed that phytohaemagglutinin- (PHA)-stimulated lymphocyte cultures exposed to non-toxic doses of heated fats, showed increased labeling indices as compared to unheated fats, which indicated that heated fats contained compounds that stimulate cell proliferation. Although intra-colonically installed hydroxy- and hydroperoxy-derivatives of linoleic acid were reported to stimulate mucosal DNA synthesis, ornithine decarboxylase activity and cell proliferation in rats (Bull et al., 1984; 1988), increased labeling indices in lymphocytes in vitro appeared not to be associated with presence of lipid oxidation products as determined by concentrations of TBA-RS, DPTG and LAHPO in the heated fats, indicating that other compounds are likely to be involved. Since free fatty acids were reported to enhance proliferation of PHA-stimulated lymphocytes in vitro (Spieker-Polet et al., 1981), and may be present in heated fats due to hydrolysis of triglycerides, these possibly also contributed to the observed enhancement of cell proliferation in human lymphocytes as described in Chapter 5. Marginally, but dose-related increased SCE frequencies were observed in human lymphocytes after in vitro incubation with another heated fat at doses ranging from 0.1 to $10.0 \mathrm{mg} / \mathrm{ml}$.

Genotoxicity of heated fats to human lymphocytes as assessed by in vitro induction of SCE's and mutations at the hgprt locus, appeared to be marginal, and was not observed for all samples showing mutagenic activity in the Salmonella/microsome assay. Various oxidation products of PUFA were reported to possess genotoxic properties to mammalian cells (Cajelli et al., 1987; Nakayama et al., 1986; Weitberg and Corvese, 1989). Genotoxicity to human lymphocytes however, was not found to be associated with parameters of oxidative deterioration or concentrations of lipid oxidation products as determined by analysis of DPTG, TBA-RS and LAHPO of the heated fats. Since some heated fat samples did show weak genotoxic effects, which appeared not to be related to the presently applied parameters of oxidative deterioration of the fats, it is concluded that further identification of active compounds is required for a reliable assessment of genotoxic risk associated with consumption of heat-processed fats. 
Effects of consumption of heated deep-frying fats on mutagen excretion in rats

In Chapter 8 , various biological effects of short-term feeding of two types of mutagenic heated deep-frying fats to rats were determined. Semi-purified diets containing $10 \%$ unheated or heated PUFA-rich frying oil and coconut oil, containing $<10 \%$ PUFA, were fed to groups of 7 rats for 4 weeks. Urine mutagenicity to Salmonella strains TA97 and TA100 was not significantly changed in rats fed heated coconut oll as compared to rats receiving unheated coconut oil. Consumption of PUFA-rich frying oil which showed mutagenicity to strains TA97 and TA100, did not show an effect on urinary mutagen excretion to strain TA97 in rats but was found to significantly increase urine mutagencity to strain TA100, which indicated different biological fate of mutagens detected by strain TA100 as compared to strain TA97. Faecal mutagenicity to strains TA97 and TA100 was not found to be significantly increased in rats after consumption of heated oils as compared to unheated oils, but appeared to be decreased in the group fed heated coconut oil as compared to the group receiving unheated oil. Mutagenicity of heated PUFA-rich frying oil to strain TA100 appeared to be detectable in urine and faeces of rats, and amounted to $7 \%$ of the ingested dose. This suggests that compounds present in heated frying oils and causing basepair mutations in strain TA100, may not be efficiently deactivated after absorption. Mutagenicity of frying oils to strain TA97 did not increase excretion in urine and faeces, suggesting frame-shift mutagens may either be efficiently deactivated in vivo, or are retained in the tissues.

In Chapter 8 , excretion of TBA-RS in urine and faeces of rats was found to be minimal as compared to TBA-RS present in diet, being maximally $0.1 \%$ of the dose consumed. These data indicate that $>99 \%$ of oxidation products were absorbed and metabolized or inactivated by in vivo acting antioxidative systems; these data do not suggest induction of in vivo lipid oxidation after short-term consumption of heated oxidized oils. In addition, plasma activities of glutamic pyruvic transaminase (GPT) and alkaline phosphatase (AP) were elevated in rats fed heated PUFA-rich frying oil as compared to the groups receiving unheated frying oil or heated coconut oil, which suggest that consumption of heated PUFA-rich frying oil may cause adverse effects to liver and kidneys. Heated PUFA-rich frying oil was found to contain detectable amounts of DPTG and LAMPO, whereas in heated coconut oil these lipid oxidation products were not detected. It should be noted however, that levels of TBA-RS and LAHPO in heated oils fed to the rats were low in comparison with concentrations reported in Chapters 3 and 4 for commercially used deep-frying oils. Since intake of high doses of lipid oxidation products was reported to cause tissue damage to liver and kidneys in rats (Alexander, 1981; Izaki et al., 1984; Kanazawa et al., 1985; 1986), and the present data showed that consumption of low amounts of oxidation products significantly increased urinary concentrations of TBA-RS in 
combination with increased plasma activities of GPT and AP in rats fed heated PUFA-rich frying oil as compared to unheated oil, chronic consumption of 5- to 10-fold higher doses of lipid oxidation products may be of concerm with respect to possible oxidative damage to tissues.

Although urinary excretion of TBA-AS was elevated in rats fed heated PUFA-rich frying oil no significant correlation was found on an individual level between urine mutagenicity and concentration of TBA-RS. Since no significant correlations were found either between individual intake of DPTG, LAHPO or mutagenic compounds, and effects on plasma clinical biochemical parameters and faecal mutagen excretion, no evidence is found for a causal relation. The nature of compounds responsible for the observed effects in rats after consumption of PUFA-rich heated frying oil remains to be determined.

Mutagen excretion in urine and faeces of man after consumption of deep-fat fried potatoes

Consumption of deep-fat fried foods is considered likely to include intake of compounds which are produced during heat-processing of fats and foods and which are mutagenic to Salmonella typhimurium. Therefore, effects on mutagen excretion in urine and faeces of consumption of deep-fat fried potatoes were determined in human volunteers to investigate the biological tate of mutagens present in fried potatoes, and to assess endogenous exposure to mutagens associated with deep-fat frying. Using Salmonella strain TA97 as indicator of mutagens produced during deep-fat frying, results obtained in diet studies described in Chapters 6 and 7 , showed that consumption of fried potatoes prepared in mutagenic deep-frying fats did not result in detectable increases in mutagen excretion in urine and faeces of human volunteers. These results were in agreement with the results observed for rats in Chapter 8 , although the daily dose of heated coconut oil consumed by the rats ranged from 5 to $7 \mathrm{~g} / \mathrm{kg}$ bodyweight, and was one order of magnitude higher as compared to the daily dose consumed by human volunteers with fried potatoes prepared in the same batch of oil (Chapter 7). which ranged from 0.40 to $0.45 \mathrm{~g} / \mathrm{kg}$ bodyweight. Patterns found for human faecal mutagen excretion determined with strain TA97 corresponded to data obtained for faecal mutagenicity of the rats fed coconut ail observed in Chapter 8 . These data implicate that in addition to mutagenic compounds, factors reducing faecal mutagenicity may also be present in heated coconut oil. Faecal mutagenicity to strain TA100 was not found to be increased in rats nor human volunteeers consuming heated coconut oil, a striking difference however, was observed in the degree of mutagenicity. Twenty-tive to $40 \%$ of faecal samples of human volunteers showed significant mutagenicity, whereas rat faecal samples did not show significantly increased mutagenicity to strain TA100. Obviously, this 
difference may be explained by the greater complexity of human diets as compared to the semi-purified rat diet. In addition, in the study described in Chapter 7, no adverse effects were indicated by changes in plasma clinical biochemical parameters. Since in Chapters 3 to 7 mutagenic activity of heated fats and fried potatoes to strain TA97 has been observed to be decreased in presence of liver $\$ 9 \mathrm{mix}$, as well as in presence of antioxidants, it is suggested that after absorption and metabolism directacting mutagens present in heated fats and fried potatoes, are likely to be inactivated in vivo.

Furthermore, it was observed in Chapter 7 that human faecal mutagen excretion as determined with Salmonella strain TA100, was influenced by diet. During the two diet intervention periods, either fried potatoes prepared in mutagenic coconut oil or mashed potatoes containing unheated coconut oil were included in the diet for 5 days using a cross-over design, while consumption of other food products was kept equal. Mutagenicity to tester strain TA100, both in absence and in presence of rat liver S9 mix, of dichloromethane extracts of faeces collected during both intervention periods was found to be increased as compared to faeces representing freechoice diets of the volunteers. It is however, not clear which dietary changes were responsible for the observed increase in faecal mutagenicity during the experimental periods; comparison of food consumption of the volunteers during the experimental diets with habitual dietary intake revealed a significant reduction of total fat consumption and a decrease of the P/S ratio of dietary fats during the experimental periods. Individual faecal mutagen excretion however, did not correlate with these or other diet-related parameters measured. Faecal mutagenicity to strain TA97 as well as to strain TA100, did show a positive correlation with faecal $\mathrm{pH}$, which implied that at higher $\mathrm{pH}$ faecal mutagen production may be enhanced, or inactivation inhibited. The nature of faecal mutagens detected by strain TA100 remains to be determined; fecapentaenes, bacterial products which have been isolated from human faeces and which are potent direct-acting mutagens to strain TA100 (Gupta et al., 1983; Schiffman, 1986), may be involved, but since dichloromethane extracts showed mutagenic activity to strain TA100 in absence and in presence of liver S9 mix, other mutagens are likely to be present in faeces as well.

Comparison of results obtained for human volunteers in Chapter 7 and results obtained for rats, showed that consumption of heated coconut oil did not cause adverse biological effects, neither in humans nor in rats, and although the daily dose received by rats was an order of magnitude higher as compared to human intake, no species differences appeared to exist with respect to the parameters measured. Since heated PUFA-rich frying oil did increase urine mutagenicity in rats, and possibly affected tissues of liver and kidneys, determination of biological effects in humans after consumption of 
PUFA-rich frying oils seems indicated.

Effects of heated deep-frying fats on cell proliferation in the gastro intestinal tract of rats

In rats, effects of short-term feeding of mutagenic heated deep-frying fats on cell proliferation of the gastrointestinal tract were determined; results are also presented in Chapter 8. Since enhanced cell proliferation was observed in PHA-stimulated human T-lymphoytes exposed to heated deepfrying fats (Chapter 5), and intra-rectal administration of hydroperoxides and hydroxides of linoleic acid was reported to stimulate DNA synthesis and increase colonic cell proliferation, it was postulated that enhancement of colonic cell proliferation by oxidized polyunsaturated fatty acids might facilitate tumorigenesis and most likely indicated tumor promoting activity of oxidized fats (Bull et al., 1984; 1987). Results obtained in our study, showed that after short-term oral administration of mutagenic deep-frying oil containing lipid oxidation products, cell proliferation of tissues of the upper gastro- intestinal tract was stimulated as compared to feeding of unheated oil. In contrast, colonic cell proliferation, was not found to be significantly enhanced.

In combination with faecal mutagenicity data, these data indicated that compounds present in heated fats which stimulated cell proliferation in the upper gastro intestinal tract are not likely to reach the colon after orall administration. Consumption of heated coconut oil did not affect celll proliferation in the gastro intestinal tract of rats. Although results suggested that stimulation of cell proliferation by the heated PUIFA-rich frying oil was related to the PUFA-content which resulted in formation of LAHPO and DPTG, no correlations were found between individual data of cell proliferation in the intestinal tissues in oesophagus and forestomach, and ingested or excreted mutagens and lipid oxidation products, thus not supporting a direct involvement of compounds determined by these parameters. Since differences between ingested doses of mutagenicity, DPTG and lipid oxidation products were marginal, determination of effects of heated frying fats containing higher doses of lipid oxidation and degradation products, will be required for a reliable assessment of the compounds and mechanisms involved.

The same batch of heated PUFA-rich frying oil (fat I B; Chapter 5) which was fed to the rats, was found to possess weak genotoxic properties, inducing a dose-dependent increase SCE frequencies in vitro in human lymphocytes when tested at concentrations ranging from $0.01-1.0 \%$ (w/v), which are 10-100 times lower than the concentration in the rat diets. This heated PUFA-rich frying oil also showed cytotoxic effects in human lymphocyte cultures in the HGPRT assay. The enhanced cell proliferation 
observed in the upper gastro intestinal tissues of rats consuming this oil, may therefore be explained either by compensatory cell proliferation due to increased necrosis of epithelial mucosal cells or by effects on genetic regulation of cellular growth. Heated coconut oil (fat $V_{i}$ Chapter 5) was observed to enhance cell proliferation of PHA-stimulated lymphocytes, but did not show genotoxic effects to human lymphocytes. Estimation of in vivo genotoxic potential and health risk based on the data obtained in vitro experiments however, is not possible. Unknown factors, such as the nature

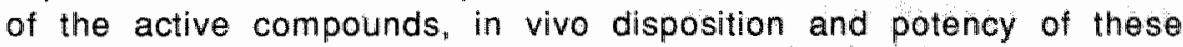
compounds at different dose-levels, and modulating effects of diet, which contains possible inhibitors of genotoxic and cellular injury such as alphatocopherol, calcium and fiber as well as possible enhancing components such as trace amounts of iron and copper (Caderni et al., 1988; 1989; Frankel, 1984; Hayatsu, 1988; Wargovich et al., 1984), will also have to be determined.

\section{Heat-processed lipids and colon cancer}

In various experiments described in this thesis, heated deep-frying fats were observed to exhibit genotoxic activity in Salmonella typhimurium as well as in human lymphocytes in vitro. Mutagenicity to Salmonella tester strains TA97 and TA100 of several heated commercially used deep-frying fats sampled after sensory indication of abuse, was found to reach levels which were an order of magnitude higher as compared to levels observed in fats tested in frying experiments in our laboratory, in which standard frying procedures and temperatures not exceeding $180^{\circ} \mathrm{C}$ were applied. Since a causal relation could not be demonstrated between the presence of autoxidation products of PUFA and mutagenicity of the heated fats, the nature of mutagenic compounds remains to be established. Lipid fractions of fried potatoes prepared under recommended frying conditions were also found to be mutagenic in the Salmonella/microsome assay. Consumption of fried potatoes prepared in mutagenic deep-frying fats and showing mutagenic activity to Salmonella strain TA97, was not observed to increase urinary and faecal mutagen excretion in human volunteers. These data do not indicate a genotoxic risk for colonic mucosa of TA97-mutagens consumed with deep-fried potatoes.

In rats, a differential effect of mutagens present in heated deep-frying oils to Salmonella strains TA97 and TA100 was found. Mutagenicity to strain TA97 of heated deep-frying oils was not found to cause increased mutagen excretion in urine and faeces, whereas mutagenicity of a heated PUFA-rich frying oil to strain TA100 appeared to enhance urinary mutagen excretion to strain TA100. Faecal mutagen excretion to Salmonella strains TA97 and TA100 was not found to be determined by mutagenic activity present in the ingested heated oils. Consumption of the PUFA-rich heated deep-frying oil, 
showing mutagenicity to strain TA100 and containing detectable amounts of LAHPO and DPTG, was found to enhance cell proliferation in upper gastro intestinal tissues of the rat. Since this oil was not found to affect colonic mucosal cell proliferation, results do not provide evidence for an involvement in colon tumorigenesis of biologically active compounds present in heated oils.

Finally, it is concluded that although heated deep-frying fats and fried potatoes have been found to possess genotoxic properties, the results presented in this thesis do not point to an involvement of these mutagens in colon tumorigenesis. In contrast, data indicate that active compounds may be retained in the upper gastro intestinal tissues, which may be possible target tissues for genotoxic or cellular damaging effects of heat-processed fats. Effects of consumption of heat-processed fats showing severe lipid oxidation, or exerting mutagenic activity equal to the "abused" fat samples from local snack-bars and restaurants, may be more pronounced and remain to be determined. Furthermore, in the frying experiments described in this thesis, mutagenicity to Salmonella typhimurium of fats used for preparation of various foods has been found to be moderate as compared to the initially tested "abused"' commercial deep-frying fats. Results of these experiments therefore indicate that application of normal, recommended frying practices, i.e. frying at temperatures of maximally $180^{\circ} \mathrm{C}$ and limited use of the fat, does not seem to result in high levels of mutagenicity.

\section{References}

Alexander J.C. (1981). Chemical and biological properties related to toxicity of heated fats. J. Toxic. Environ. Health 7, 125-138.

Archer V.E. (1988). Cooking methodis, carcinogens, and diet-cancer studies. Nutr Cancer $11,75.79$.

Armstrong B. and Doll R. (1975). Environmetnall factors and cancer incidence and mortality in different countries with special reference to dietary practices. Int. J. Cancer $15,617-631$.

Billek G. Guhr G. and Waibel J. (1978). Quality assessment of used frying lats: a comparison of four methods. J. Am. Oil Chem. Soc. 55, 728-733.

Bird R.P., Draper H.H. and Valli V.E.O. (1982). Toxicological evaluation of malonaldehyde: a 12-month study in mice. J. Toxical. Environ. Health 10, 897-905.

Bull A.W., Nigro N.D., Golembieski W.A., Crissman J.D. and Marnett L.J. (1984). in vivo stimulation of DNA synthesis and induction of ornithine decarboxylase in rat colon by fatty acid hydroperoxides, autoxidation products of unsaturated fatty acids. Cancer Res. 47 , 4237-4242.

Bull A.W. Nigro N.D. and Marnett L.」. (1988). Structural requirements for stimulation of colonic cell proliferation by oxidized fatty acilds. Cancer Res. $48,1771-1776$.

Byers T. (1988). Diet and cancer. Any progress in the interim? Cancer 62,1713-1724. 
Caderni G. Bianchini F., Dolara P. and Kriebel D. (1989). Proliferative activity in the colon of the mouse and its modulation by dietary starch, fat and cellulose. Cancer Res. 49,1655 1659.

Caderni G., Stuart E.W. and Bruce W.R. (1988). Dietary factors affecting the proliferation of epithelial cells in the mouse colon. Nutr. Cancer $11,147-150$.

Cajelli $E$. Ferraris A. and Brambilla G. (1987). Mutagenicity of 4-hydroxynonenal in V79 Chinese hamster cells. Mutation Res. 190, 169-171.

Carroll K.K. (1987). Summation: which tathow much fat - animals. Prev. Med. 16, 510-515.

Chang S. S., Peterson R. J. and Ho L.T. (1978). Chemical reactions involved in deep fat frying of foods. J. Am. Oil Chem. Soc. 55, 718-727.

Frankel E.N. (1984). Lipid oxidation: mechanisms, products and biological significance. J. Am, Oil Chem. Soc. 61, 1908-1916.

Gupta I., Baptista J., Bruce W.R. Che C.T., Gingerich J.S., Grey A.A., Marai L., Yates P. and Krepinsky J.d. (1983). Structures of fecapentaenes, the mutagens of bacterial origin isolated from human feces. Biochemistry 22, 241-245.

Hayatsu H. Arimoto S. and Negishi T. (1988). Dietary inhibitors of mutagenesis and carcinogenesis. Mutation Res. 202, 429-446.

Hill M.J. (1987). Dietary fat and thuman cancer (review). Anticancer Res. 7. 281-292.

Zzaki Y., Yoshikawa S. and Uchiyama M. (1984). Effect of ingestion of thermally oxidized frying oil on peroxidative criteria in rats. Lipids 19, 324-331.

Kanazawa K., Ashia H., Minamoto S. and Natake M. (1986). The effect of orally administered secondary products of linoleic acid and on the activity of detoxifying enzyme systems in the rat liver. Biochem. Biophys. Acta 879, 36-43.

Kanazawa K., Kanazawa $E$. and Natake M. ( 1985$)$. Uptake of secondary autoxidation products of linoleic acid by the rat. Lipids 20,412-419.

Kosugi $H$ and Kikugawa K. (1989). Potential thiobarbituric acid-reactive substances in peroxidized lipids. Free Radical Biol Med. 7, 205-207.

McGregor J.T., Wilson R.E., Neff W.E. and Frankel E.N. (1985). Mulagenicity tests of lipid oxidation products in Salmonella typhimurium monohydroperoxides and secondary oxidation products of methyl linoleate and methyl linolenate. Fd Chem. Toxic. 23, 10411047.

Nakayama T., Kaneko M. and kodama M. (1986). Detection of DNA damage in cultured human fibroblasts induced by methyl linoleate hydroperoxide. Agric. Bioll. Chem. 50, 261-262.

Phillips D.H. (1983). Fifty years of benzo(a)pyrene. Nature 303, 468-472.

Reddy B.S. (1987). Dietary fat and colon cancer. Animal models. Prev. Med. 16, 460-467.

Rogers A.E. and Longnecker M.P. (1988). Blology of disease. Dietary and nutritional influences on cancer. A review of epiderniologic and experimental data. Lab. Invest. 59 , $729-759$.

Rose D.P., Boyan A.P. and Wynder E.L. (1986). International comparisons of mortialily rates for cancer of the breast, ovary, prostate and colon, and per capita food consumption. Cancer $58,2363-2371$.

Schiftman M.H. (1986). Epidemiology of fecal mutagenicity. Epidemiol. Rev. 8, 92-105.

Siu G.M. Draper H.H. and Valli V.E.O. (1983). Oral toxicity of malondialdehyde: a 90-day study on mice. J. Toxical. Environ. Health 11, 105-109.

Spieker-Polet $H$. and Polet H. (1981). Requirements of a combination of a saturated and an 
unsaturated free fatty acid and a fatty acid carrier protein for in vitro growth of lymphocytes. J. Immunol/126, 949-954.

Stevenson S.G., Vaisey-Genser M. and Eskin N.A.M. (1984). Quality control in the use of deep irying olls. J. Am. Oil Chem. Soc. 61, 1102-1108.

Sugimura T., Sato S., Oghaki H. Takayama S., Nagao M. and Wakabayashi K. (1986). Overview: mutagens and carcinogens in cooked food. In: Knudsen I. (Ed.), Genetic toxicology of the diet, Alan R. Liss, New York, 81-87.

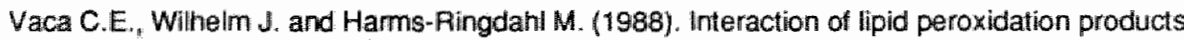
with DNA. A review. Mutation Res. 195, 137-149.

Wargovich M.J., Eng V.W.S. and Newmark H.L. (1984). Calcium inhibits the damaging and compensatory proliferative effect of fatty acids on mouse colon epithelium. Cancer Lett. $25,250-258$.

Willett W.C. (1989). The search for the causes of breast and colon cancer. Nature 338,389 394.

Yamaguchi T, and Yamashita $Y .(1979)$. Mutagenic activity of autoxidized linoleic and linolenic acid. Agric. Biol. Chem. 43, 1675-1678.

Yamaguchi $T$. and Yamashita $Y$. (1980). Mutagenicity of hydroperoxides of fatty acids and some hydrocarbons. Agric. Bioll Chem. 44, 3025-3027. 


\section{Summary}

The typical Western diet, characterized by its high fat and meat consumption, has repeatedly been reported to be associated with increased colon cancer incidence. Although several plausible mechanisms have been postulated, various epidemiologic as well as experimental studies have yielded conflicting evidence for a causal relation between high fat intake and tumorigenesis in the colon. This inconsistency may be due to the fact that in general epidemiological studies do not discriminate between heatprocessed and unheated dietary lipids. In the introduction of this thesis it has been hypothesized that heat-processing of lipids may give rise to the formation of oxidation and degradation products, which may possess tumorinitiating or -enhancing activity. Heat-processing of lipids has not yet been implicated in experimental studies investigating the role of dietary fat in colon tumarigenesis. The aim of this thesis was therefore to determine genotoxic and other adverse biologic efects of heat-processed fats, in order to investigate their possible role in colon tumorigenesis. For this purpose, used deep-frying fats which is heated for prolonged periods of time, subject to oxidative deterioration during preparation of food, have been tested for genotoxicity as well as for biological activity in the colon.

In first instance, repeatedly used deep-frying fat samples, which were collected from local snack-bars and restaurants by officers of the Maastricht Office for Food Quality Control after sensory indication of abuse, were analyzed for mutagenicity to Salmonella typhimurium, in order to obtain an indication of possible tumor-initiating activity. Seventeen out of twenty samples tested were found to possess mutagenic activity to tester strains TA97, TA100 or TA104. Highest mutagenicity was detected in the polar fraction of these used deep-frying fat samples, which was isolated using silicagel column chromatography and reported to contain oxidation and heat degradation products. Mutagenicity exerted by these polar fractions was detected most sensitively by strain TA97, and was generally reduced when tested in presence of rat liver $\$ 9$ mix. Numbers of revertants induced in this strain by repeatedly used deep-frying fat samples were estimated to range from $1 * 10^{3}$ to $3 * 10^{4}$ per $g$ of fat.

Mutagenic activity of these used deep-frying fat samples was found to correlate positively with concentrations of lipid oxidation products as determined by the colorimetric thiobarbituric acid assay, and with concentrations of linoleic acid hydroperoxides. The absence of an association between mutagenicity of repeatedly used deep-frying fats and levels of di- and polymeric triglycerides or polar material, which are chemical 
parameters used in the quality control of deep-frying fats, indicated that quality contral as currently applied does not determine compounds associated with genotoxic risk, and may therefore be considered inadequate. It has been shown that repeatedly used deep-irying fats do possess mutagenic activity in the Salmonella/microsome assay, which may be related to autoxidation of polyunsaturated fatty acids.

In a series of frying experiments, mutagen formation during deep-fat frying was investigated using various types of deep-frying fats. It was observed that frying of various foods, including proteinaceous products, appeared to enhance mutagen formation as compared to use of the fat for preparation of fried potatoes exclusively. In spite of substantial oxidative deterioration and lipid oxidation occurring in some used fats, it was found that after application of heating temperatures of maximally $180^{\circ} \mathrm{C}$ and limiting heating time of fats to 30 hours, mutagenicity to strain TA97 of these fats amounted to $1-3 * 10^{3}$ revertants per $g$ of fat, which was moderate as compared to the previously lested "abused" samples. The results of these frying experiments did not support the existence of a causal relation between lipid oxidation or oxidative deterioration, and mutagenicity of heated deep-frying fats. It was therefore concluded that other compounds are also involved in mutagen formation during deep-fai frying. These remain to be determined but are most likely to be related to the nature of the foods prepared and to the frying procedures employed.

Subsequently, in vitro genotoxicity to human lymphocytes was tested of three heated deep-frying fats showing moderate mutagenic activity to Salmonella strain TA97, inducing $2 \cdot 3 * 10^{3}$ revertants per $g$ of fat. Doserelated statistically significantly increased frequencies of sister chromatid exchanges were induced by one of the used deep-frying fats tested; the absolute increase observed however, was small indicating a relatively weak potency. Another fat increased mutation frequencies of 6-thioguanineresistant T-lymphocytes in a first series of tests, but since this effect could not be duplicated after retesting, it was therefore suggested that instable compounds might be involved. Heated fats were found to increase cell proliferation of phytohaemagglutinin stimulated human T-lymphocytes. Neither concentrations of lipid oxidation products, nor oxidative deterioration of heated deep-frying fats appeared to be associated with genotoxicity and stimulation of cell growth of PHA-stimulated human lymphocytes. These data indicate that heated deep-frying fats may possess genotoxic properties to human lymphocytes. Since no evidence has been found for a ciausal role of autoxidation products of lipids, the nature of the active compounds remains to be established.

Consumption by human volunteers of fried potatoes prepared in deepfrying fats, showing mutagenicity to Salmonella strain TA97, was not found 
to increase urinary nor faecal mutagen excretion to this strain, although lipid fractions isolated from deep-fat fried potatoes also showed mutagenic activity and the mutagenic load consumed with fried potatoes amounted approximately to $2-3+10^{5}$ revertants. These data indicated that mutagenic compounds present in the heated deep-irying fats, are not likely to affect the colon. No other adverse effects were observed in human volunteers after daily consumption of a portion of fried potatoes prepared in mutagenic deep-frying fat.

In rats, consumption of heated mutagenic coconut oil or pollyunsaturated fatty acid (PUFA)-rich deep-frying oil did not increase urinary and faecal mutagen excretion to Salmonella strain TA97 either. The heated PUFA-rich frying oil which showed mutagenic activity to strain TA100 however, was found to increase rat urinary mutagenicity to strain TA100. No effect was observed on rat faecal mutagen excretion to this strain. Urinary recovery of the dose consumed was $<1 \%$, suggesting that after absorption mutagenic compounds were inactivated in vivo, or retained in the lissues. In addition, consumption of heated PUFA-rich frying oil increased urinary excretion of thiobarbituric acid-reactive substances (TBA-RS) in rats. Excretion in urine and faeces was found to be $4 \%$ and $3 \%$ of the ingested dose respectively, indicating most TBA-RS present in this heated PUFA-rich frying oil were bioavailable. Short-term feeding of this PUFA-rich frying oil to rats also increased plasma activities of glutamic pyruvic transaminase and alkaline phosphatase as compared to feeding of unheated frying oill of heated coconut oil. which may indicate adverse effects on liver and kidneys.

After short-term feeding of heated PUFA-rich frying oil cell proliferation in the upper gastro intestinal tissues of rats was slightly, but statistically significantly enhanced as compared to feeding of unheated oil or heated coconut oil, indicating that heated PUFA-rich frying oil contained compounds that stimulate cell growth in wivo. This cell proliferation enhancing activity is considered to indicate tumor-promoting effects, but this may also reflect initiating properties since increased cell proliferation has been reported to be an early effect in tumorigenesis. No enhanced cell proliteration was found in the colon of rats fed PUFA-rich heat-processed fat, implicating the enhancing effects were limited to the upper gastro-intestinal tract. The degrees of oxidative deterioration and mutagenicity of heated frying oils fed to the rats however, were moderate as compared to levels of lipid oxidation products found in commercially used deep-frying fat samples. Elfects of consumption of high levels of specific oxidation products remain to be determined. Therefore, it can not be excluded that consumption of heated oils containing higher doses of lipid oxidation and mutagens may exert effects in the lower part of the gastro intestinal tract.

Finally, it is concluded that an involvement of heat-processed lipids in 
colon tumorigenesis is not supported by the data presented in this thesis, since consumption of mutagenic deep-frying fats did not increase faecal mutagenicity in both rats and humans, and was not found to affect colonic cell proliferation in rats. Heated deep-frying fats however, have been found to show genotoxic properties to human lymphocytes, causing some concern with respect to human genotoxic risk. Elucidation of the nature of active compounds present in heated deep-frying fats, as well as determination of their concentration in deep-fat fried and other lipid-containing heatprocessed foods is indicated before further testing of genotoxic, carcinogenic or tumor-enhancing activities is applied to evaluate health risk to man. 


\section{Samenvatting}

Een hoge consumptie van vet en vleesprodukten, hetgeen kenmerkend is voor het "Westerse" voedingspatroon, is in epidemiologische onderzoeken herhaaldelijk in verband gebracht met een verhoogd risiko voor colonkanker. Hoewel hiervoor verscheidene mechanistische verklaringen zijn gepostuleerd, hebben noch epidemiologische, noch experimentele onderzoeken consistente resultaten opgeleverd, die een causaal verband tussen een hoge vet inneming en het ontstaan van colonkanker ondersteunen. Deze tegenstrijdige onderzoeksresultaten kunnen onder meer worden toegeschreven aan het feit dat epidemiologische onderzoeken geen onderscheid maken tussen verhitte en onverhitte vetten in de voeding. In de inleiding van dit proefschrift is beschreven dat tijdens het verhitten van voedingsvetten oxydatie- en thermale degradatieprodukten ontstaan, die mogelijk tumor-initiërencie of bevorderende eigenschappen hebben. Experimentele onderzoeken naar de rol van voedingsvet in het ontstaan en ontwikkelen van colonkanker bestuderen hebben tot nu toe evenmin aandacht besteed aan een mogelijke rol voor componenten die aanwezig kunnen zijn in verhitte voedingsvetten. Het onderzoek beschreven in dit proefschrift had daarom tot doel de mogelijke rol van verhitte voedingsvetten in coloncarcinogenese te verkennen; hiertoe zijn verhitte voedingsvettten onderzocht op genotoxische en andere nadelige biologische effecten in het colon. Hierbij is gekozen voor herhaaldelijk gebruikte frituurvetten, omdat deze vetten langdurig verhit worden en zeer vatbaar zijn voor oxydatie tijdens het frituren van voedingsmiddelen.

In eerste instantie zijn herhaaldeijk gebruikte frituurvetmonsters getest op mutageniteit in de Salmonella mutageniteitstest om mogelijke tumorinitiërende aktiviteiten te bepalen. Deze frituurvetmonsters waren verzameld door de Maastrichtse Rijkskeuringsdienst van Waren op basis van sensorische indikatie van ondeugdelijkheid. Zeventien van de iwintig geteste frituurvetmonsters vertoonden mutagene aktiviteit in Salmonella stammen TA97, TA100 of TA104. De hoogste mutagene aktiviteit werd aangetroffen in de polaire fraktie van het vet. Deze was geïsoleerd met behulp van silicagel kolomchromatogratie en bevat voornamelijk polaire oxydatie- en degradatieprodukten. De mulagene aktiviteit van deze polaire frakties was het hoogst in Salmonella stam TA97, en was in het algemeen gereduceerd wanneer de frakties getest werden in aanwezigheid van rattelever 59 mix. Het aantal revertanten dat geïnduceerd werd door herhaaldelijk gebruikt frituurvet variëerde van $1 * 10^{3}$ tot $3 * 10^{4}$ per $g$ vet. 
De mutageniteit van deze frituurvetmonsters was positief geassociëerd met de colorimetrisch bepaalde gehalten aan lipid peroxydatieprodukten, en in mindere mate met de met behulp van HPLC gemeten concentratie linolzuur-hydroperoxyden. Er werden geen significante associaties gevonden tussen mutageniteit en gehalten aan di- en polymere triglyceriden of de hoeveelheid polair materiaal, hoewel dit chemische parameters zijn die worden gehanteerd bij de kwaliteitsbepaling van gebruikt friuurvet. Het ontbreken van een associatie tussen chemische kwaliteitsparameters en mutageniteit betekent dat deze parameters geen aanwijzing geven omtrent een eventueel genotoxisch risiko, en impliceert dat verbetering van de kwaliteitscontrole gewenst is. Op grond van de gevonden resultaten wordt geconcludeerd dat herhaaldeijk gebruikte frituurvetten componenten kunnen bevatten die mutageen zijn voor Salmonella typhimurium. De mutageniteit blijkt geassociëerd met de aanwezigheid van autooxydatieprodukten van meervoudig onverzadigde vetzuren.

In een serie frituuronderzoeken is vervolgens de vorming van mutagene componenten tijdens het frituren onderzocht. De bereiding van verschillende produkten, waaronder eiwitrijke produkten bleek aanleiding te geven tot een hogere produktie van mutagenen dan het frituren van uitsluitend patat frites. Hoewel in sommige van deze herhaaldelijk gebruikte vetten aanzienlijke oxydatie optrad na verhitten bij een temperatuur van maximaal $180^{\circ} \mathrm{C}$ gedurende 30 uur, bereikte de mutageniteit in stam TA97 waarden variërend van 1 tot $3 * 10^{3}$ revertanten per gram vet, wat in vergelijking met de eerder geteste "ondeugdelijke" monsters een relatief geringe mutageniteit genoemd kan worden. De resultaten van deze serie frituurexperimenten leverden geen aanwijzing op voor een causaal verband tussen lipid peroxydatie of oxydatieve degradatie, en mutageniteit van verhitte frituurvetten. Hieruit wordt geconcludeerd dat andere componenten eveneens een rol spelen bij de produktie van mutagenen tijdens het frituren. De aard van deze verbindingen dient nog nader bepaald te worden, maar gesteld wordt dat de vorming van deze componenten onder meer afhankelijk is van de aard en kwaliteit van de frituurvetten en de daarin bereide voedingsmiddelen, en van de omstandigheden waaronder wordt gefrituurd.

Drie verhitte frituurvetten, waarvoor in de Ames-test (stam TA97) een mutagene aktiviteit gevonden was van 2 tot $3 * 10^{3}$ revertanten per gram vet, werden met behulp van humane lymfocyten verder onderzocht op genotoxiciteit. Een dosis-afhankeilike statistisch significante toename in zuster chromatide uitwisselingen (sister chromatid exchanges, SCE's) werd geïnduceerd door één van de geteste gebruikte frituurvetten. De absolute toename was echter gering, wat duidt op een relatief lage genotoxische potentie. Een tweede vet veroorzaakte in een eerste serie van testen een verhoogde frequentie van 6-thioguanine-resistente T-lymfocyten. Echter, na 
hertesten van hetzelfde vetmonster werd geen verhoogde frequentie van mutante T-lymfocyten waargenomen, hetgeen mogelijk wijst op de aanwezigheid van onstabiele mutagenen. Verhitte vetten bleken in vitro de celproliferatie van met phytohaemagglutinine-gestimuleerde humane $T$ lymfocyten te bevorderen. Dit effect was noch geassociêerd met de concentratie van lipid oxydatieprodukten, noch met de mate van oxydatieve degradatie. Verhitte friuurvetten blijken dus componenten te kunnem bevatten die genotoxisch zijn voor humane lymfocyten Er is echter geen duidelijke aanwijzing gevonden voor een causale relatie tussen genotoxiciteit en de aanwezigheid van specifieke oxydatieprodukten van vetzuren.

Consumptie van patates frites gebakken in fritururvet dat mutagene aktiviteit in stam TA97 vertoonde, leidde niet tot verhoogde uitscheiding van mutagenen in urine en faeces van humane vrijwilligers, hoewel in de vetfrakties die waren geïsoleerd uit patates frites mutagene aktiviteit was gevonden en de inneming van mutagenen was berekend op 2 tot $3 \times 10^{5}$ revertanten. Dit impliceert dat de mutagene componenten in het verhitte frituurvet en de patat frites in het colon geen detekteerbare verhoogde mutagene aktiviteit veroorzaken. Evenmin werden andere nadelige gezondheidseffecten gevonden in humane vrijwilligers na dagelijkse consumptie van een portie in mutageen frituurvet bereide patates frites.

In ratten bleek dagellikse consumptie van verhitte, mutagene cocosnoot olie, noch van verhit mutageen meervoudig onverzadigde velzuren (MOV)rijk frituurvet in een verhoogde uitscheiding van TA97-mutagenen in urine en faeces te resulteren. In de groep ratten die verhit MOV-rijk frituurvet consumeerde werd een verhoogde uitscheiding van TAl00-mutagenen in de urine gevonden. De uitscheiding van TA100-mutagenen in de faeces was niet verhoogd in deze groep. Van de geconsumeerde dosis TA100. mutagenen werd in de urine minder dan $1 \%$ teruggevonden, wat erop wijst dat deze mutagene componenten na absorptie worden geinaktiveerd in vivo, of dat deze componenten achterblijven in de weefsels. De groep ratten die verhit MOV-rijk frituurvet consumeerde had eveneens een verhoogde urinaire uitscheiding van thiobarbituurzuur-reaktieve verbindingen (thiobarbituric acid-reactive substances: TBA-RS). De uitscheiding van TBA-RS in urine en faeces in deze groep was respektievelijk 4 en $3 \%$ van de ingenomen dosis, wat erop duidt dat de meeste TBA-RS biologisch beschikbaar zijn. In de groep ratten die verhit MOV-rijk frituurvet consumeerde werden een verhoogde activiteit van serum glutamic pyruvatic transaminase (SGPT) en alkalische fosfatase gevonden in vergelijking met de groepen die het onverhitte MOV-rijke frituurvet of de verhitte cocosnoot olie consumeerden, wat een aanwijzing is voor mogelijke celbeschadiging in lever en nieren. 
Consumptie van verhit MOV-rijk frituurvet bleek de celproliferatie in slokdarm en voormaag van ratten licht te verhogen in vergelijking met consumptie van onverhitte vetten of verhitte cocosnoot olie. Het verhitte MOV-rijke frituurvet bevatte blijkbaar verbindingen die in vivo de celproliferatie stimuleren. Een stimulatie van de celgroei word in het algemeen beschouwd als een tumorbevorderend effect, maar een verhoogde celproliferatie kan ook optreden als gevolg van bepaalde tumorinitiërende aktiviteiten. Er werd geen stimulatie van de celproliferatie in het colon gevonden na consumptie van verhit MOV-rijk frituurvet en het stimulerende effect op de celproliferatie beperkte zich tot het voorste deel van het maag-darm kanaal. De mate van oxydatieve degradatie en de mutageniteit van de verhitte frituurvetten die door de ratten werden geconsumeerd was relatief laag in vergelijking met gehalten aan lipid oxydatieprodukten die waren gevonden in een aantal commerciëel gebruikte "ondeugdelijke" frituurvetten. Niet bekend is of consumptie van verhitte vetten met hoge gehalten aan lipid oxydatieprodukten wel leidt tot nadelige effecten in het colon; hiervoor is nader onderzoek vereist.

Tenslotte wordt op basis van de resultaten beschreven in dit proefschrift geconcludeerd dat voor verhitte vetten geen rol van betekenis in coloncarcinogenese lijkt weggelegd. Consumptie van mutageen frituurvet bleek noch in de mens, noch in de rat aanleiding te geven tot een verhoogde faecale mutageniteit, en bleek in ratten de celproliferatie in het colon niet te stimuleren. Verhitte frituurvetten vertoonden echter wel genotoxische aktiviteit in humane lymfocyten in vitro, wat een mogelijk genotoxisch risiko voor de mens impliceert. Voor een evaluatie van het gezondheidsrisiko voor de mens is daarom eerst opheldering vereist van de aard van deze aktieve componenten, alsmede een bepaling van de gehalten hiervan in gefrituurde en andere vetrijke verhitte voedingsmiddelen. Vervolgens kan worden overgegaan tot een nadere analyse van specifieke genotoxische, carcinogene of tumorbevorderende eigenschappen van deze verbindingen. 


\section{Dankwoord}

Het tot stand komen van dit proefschrift is iets dat ik natuurlijk niet in m'n eentje heb klaargespeeld. Dankzij hulp, advies en belangstelling van velen in mijn directe omgeving is het uiteindelijk niet meer dan een logisch gevolg van enkele jaren samenwerken in het onderzoek. Het frituren, en tellen van kolonies en cellen waren bezigheden die door mij en enkele nijvere medeplichtigen meer dan eens verricht werden onder het motto: "oogkleppen op en stug doorgaan". Dat de resultaten van die inspanningen nu netjes bij elkaar in dit proefschrift staan, is te danken aan zowel wetenschappelijke als sociale interakties die mij hebben behoed voor al te veel "oogkleppenwerk".

Met het risiko dat ik toch nog enkele essentiële bijdragen aan het onderzoek en alles wat daarmee samenhangt vergeet, wil ik op deze plaats de volgende mensen met name bedanken:

Allereerst Piet, dit staat ook jou te wachten; ik hoop dat ik voor jou net zo'n vaste basis kan zijn.

Dan Dr. Jos Kleinjans, co-promotor en naaste begeleider van het onderzoek. Het is wat moeilijk om de juiste omschrijving te geven voor de fijne en speciale wijze waarop je het onderzoek en het schrijven van dit proefschrift hebt begeleid; je hebt mij geïnspireerd en gemotiveerd wanneer dat nodig was, en ik hoop van harte dat onze samenwerking in de toekomst nog tot één of meer "grote" publikaties zal leiden.

Mijn beide promotoren, Prof. Dr. Foppe ten Hoor en Prof. Dr. Pie Henderson, voor de goede adviezen en de prettige wijze waarop met name in de eindfase het commentaar werd geleverd op mijn manuscript.

Dr. Hans Verhagen, ex-kamergenoot, je hulp bij de rattenproef was onmisbaar. Maar vooral je constante goede humeur, je rustgevende aanwezigheid in de kamer die we bijna 5 jaar gedeeld hebben, en het geduldig aanhoren van mijn verhalen zal ik niet vergeten; je bent in mijn ogen de ideale kamergenoot.

Drs. IreneWelle, zonder jouw hulp bij de HGPRT-test was het onderzoek nooit op tijd af geweest. Het onderzoek beschreven in hoofdstukken 2 en 5 is mede dankzlj jouw doorzettingsvermogen succesvol afgerond.

René Kikken, dankzij het goede werk dat je als stagiaire geleverd hebt, niet 
alleen op chemisch analytisch gebied maar ook bij de Ames-test, zijn hoofdstukken 3 en 4 tot stand gekomen.

Drs. Rob Hermans en Drs. Trudi Volleberg, voor jullie onmiskenbare bijdragen aan hoofdstukken 5,6 en 7 , geleverd tijdens jullie onderzoekstages.

Dr. Rob Bos en Jaques Theuws, van de Vakgroep Toxicologie, Katholieke Universiteit Nijmegen, voor de goede adviezen en hulp bij het opzetten van de Ames-test in Maastricht.

Jaques Bex en Paul Koken van de Keuringsdienst van Waren te Maastricht, voor de analyse van di-en polymere triglyceriden.

Frans Weekers en alle andere mederwerkers van de Centrale Proefdiervoorziening, voor de hulp bij de rattenproef van Hoofdstuk 8

Drs. Ester Guinée, Drs. Cathy Rompelberg, Drs. Desirée Fliescher, Drs. Carla Martens, Ellis. Fransen en Suzie Otto, als BGK-studenten hebben jullie allemaal een steentje bijgedragen aan het "frituurvetonderzoek".

Marianne Simonis, voor het als stagiaire meehelpen aan mijn eerste serie Ames-testen bij een temperatuur van $35^{\circ} \mathrm{C}$, en voor het uitvoeren van de vetzuuranalyses.

Dr. Rian van Houwelingen, voor het snel en deskundig keuren van de proefpersonen.

Elly Brouwer en Trudi Mullers, voor de hulp in de diëetkeuken van Humane Biologie.

Mary Peters, Ine Poolen en Truus Dickhaut, voor de geweldige hulp op de tekstverwerker.

Dr. Bert Schutte, voor het leveren van de anti-BrdU antilichamen en het gebruik van de flow-cytometer.

Gerrit van Kranenburg, voor de klinisch-chemische bepalingen in bloedsera.

Alle proefpersonen, voor het nuttigen van de frites en het op tijd en zonder problemen leveren van de gevraagde monsters.

Ben, Theo, Els, Pauline en Jan, en alle collega's bij Humane Biologie, voor de diverse hand en span diensten en vooral voor de prettige werksfeer. 


\section{Curriculum vitae}

Gerrigje Johanna (Geja) Hageman werd geboren op 10 juni 1960 te Zwollerkerspel. In 1978 behaalde zij het gymnasium-B diploma aan het Carolus Clusius College te Zwolle. Daarna begon zij met de studie Humane Voeding aan de Landbouwuniversiteit te Wageningen. In 1983 behaalde zij het kandidaatsdiploma. De doctoraalfase werd in 1985 afgesloten en bestond uit de vakken Voedingsleer (Prof. dr. M.B. Katan, Prof. dr. J.G.A.J. Hautvast), Levensmiddelenchemie (Dr. ir. A.G.J. Voragen, Prof. W. Pilnik) en een buitenlandse stage Klinische Voeding (Prof. dr. V.R. Young, Massachusettes Institute of Technology, Cambridge, MA, USA). Sedert 1985 is zij als wetenschappelijk assistent werkzaam aan de Rijksuniversiteit Limburg bij de vakgroep Humane Biologie/Biologische Gezondheidkunde i.o. (Prof. dr. F. ten Hoor, Dr. J.C.S. Kleinjans) waar het onderzoek zoals beschreven in dit proefschrift werd uitgevoerd. Vanaf 1990 is zij als universitair docent verbonden aan dezelfde vakgroep. 



\section{Publications}

\section{Full papers}

- Leqlercq $E$. and Hageman G.J. (1985). Release of inulin by enzymatic liquefaction of chicory roots. Food Chem. 18, 131-138.

- Kleinjans J., Verhagen H., Hageman G: en Ten Hoor F. (1987). De carcinogeniteil van de voedingsmiddelen additieven butylhydroxytolueen en butylhydroxyanisol. Een literatuurstudie.Voeding (Neth. J. Nutr.) 48, 153-157.

- Hageman G., Kicken R., Ten Hoor F. and Kleinjans J.C.S. (1988). Assessment of mutagenic activity of repeatedly used deep-frying fats. Mutation Res. 204, 593-604.

- Hageman G.J., Verhagen H., Kleinjans J.C.S. (1988). Butylated hydroxyanisole, butylated hydroxytoluene and tert-butylhydroquinone are not mutagenic in the Salmonella. /microsome assay using new tester strains. Mutation Res. 208,207-211.

- Hageman G., IKikken R., Ten Hoor F. and Kleinjans J. (1989). Linoleic acid hydroperoxide concentration in relation to mutagenicity of repeatedly used deep-frying fats. Lipids 24 , 899-902.

- Kleinjans J.C.S., Janssen Y.N.W., Van Agen B., Hageman G.J. and Schreurs J. (1989) Genotoxicity of coal fly ash, assessed in vitro in Salmonella typhimurium and human lymphocytes, and in vivo in an occupationally exposed population. Mutation Res. 224. 127-134.

- Kleinjans J.C.S., Pluijmen M.H.M., Hageman G.J. and Verhagen H. (1989). Stabilization and quantitative analysis of fecapentaenes in human feces, using synthetic fecapentaene-12. Cancer Lett. 44, 33-37.

- Verhagen H., Van Agen B. "Hageman G.J., Beckers R.H.G. and Kleinjans J.C.S. (1989) Determination of alpha-tocopherol levels in rat microsomes by high-performance liquid chromatography. J. Liquid Chromatogr. 11/14, 2977-2982.

- Fukagawa N.K., Anderson J.W., Hageman G., Young V.F. and Minaker K.L. (1990). Highcarbohydrate, high-liber diets increase peripheral insulin sensitivity in healthy young and old adults. Am. J. Clin. Nutr., in press.

- Hageman G. Hermans R., Ten Hoor F. and Kleinjans J.C.S. (1990). Mulagenicily of deep frying fat, and evaluation of urine mutagenicity after consumption of fried potatoes. Food Chem Toxicol, in press.

- Hageman G., Verhagen H., Schutte B. and Kleinjans J. Effect of short-term feeding of mutagenic used deep-frying oils on cell proliferation in the gastro-intestinal tracl and the excretion of mutagens in urine and faeces of rats. Submitted for publication.

- Hageman G. Welle I. and Kleinjans J. 5-Bromodeoxyuridine labeling in combination with immunocylochemical staining for the detection of 6-thioguanine-resistant human peripheral blood lymphocytes. Submitted for publication.

\section{Abstracts}

- Hageman G., Hermans R. and Kleinjans J.C.S. (1987). Evaluation of mutagenic activity of deep fat fried foods. Pharmac. Whbl. Sc. Ed. 9, 353 
- Hageman G., Verhagen H. and Kleinjans J.C.S. (1987). Non-mutagenicity of butylated hydroxyanisole, butylated hydroxytoluene and tert-butylhydroquinone in the Salmonella/microsome assay using new tester strains. Pharmac. Wkbl. Sc. Ed. 9, 41.

- Hageman $G_{.}$Kicken R. and Kleinjans J. (1988). Mutagenic activity of deep frying fat fractions. Hum. Toxicol. 7, 79 .

- Hagernan G, Ten Hoor F. en Kleinjans J. (1988). Mutageniteit van trituurvet in relatie tot chemische en blologische parameters. Voeding (Neth. J. Nutr.) 49, 290.

- Kleinjans J., Van Agen B., Verhagen $\mathrm{H}_{\text {. }}$ Hageman G. and Ten Hoor F. (1988). Interaction of the food additive butylated hydroxyanisole with organ and whole body lipid peroxidation in the rat. Hum. Toxicol. $7,81$.

- Hageman G. Kikken R., Ten Hoor F. and Kleinjans J. (1989). Mutagenic activity of used deep-frying fats in relation to oxidation products of linoleic acid. Pharmac. Wkbl. Sci. Ed. $11, B 6$.

- Hageman G., Welle I. and Kleinjans J. (1989). Bromodeoxyuridine labeling and monoclonal antibody-peroxidase staining for the detection of 6-thioguanine resistant human lymphocytes. Pharmac. Wkbl. Sci. Ed. 11, B7.

- Janssen Y., Hageman G., Van Agen B., Schreurs J. and Kleïnjans J. (1989). Genotoxicity of Hly ash from powder coal combustion assessed in witro, and in wivo in man. Pharmac. Wikbl. Sci. Ed. 11, B7. 